PERFORMING HYSTERIA

Contemporary Images and Imaginations of Hysteria 



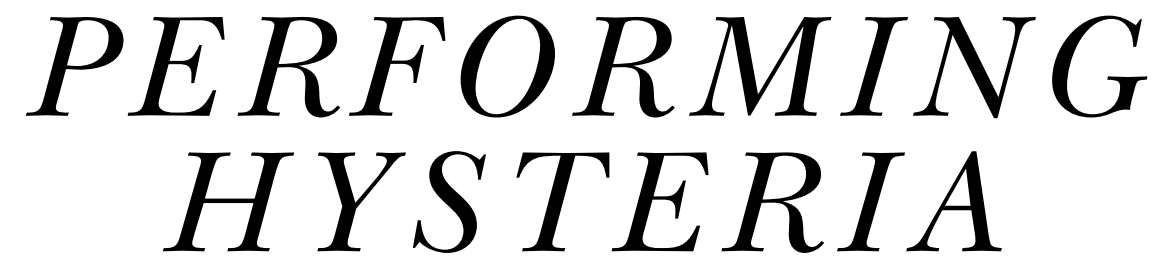

CONTEMPORARY IMAGES AND IMAGINATIONS OF HYSTERIA

EDITED BY JOHANNA BRAUN 
Published with the support of the KU Leuven Fund for Fair Open Access

and

funded by the Austrian Science Fund (FWF) as part of the Erwin Schrödinger research project

"The Hysteric as Conceptual Operator": [J 4164-G24].

\section{ШF}

Der Wissenschaftsfonds.

Published in 2020 by Leuven University Press / Presses Universitaires de Louvain / Universitaire Pers Leuven. Minderbroedersstraat 4, B-3000 Leuven (Belgium).

(C) Selection and editorial matter: Johanna Braun, 2020

(c) Individual chapters: the respective authors, 2020

This book is published under a Creative Commons Attribution Non-Commercial 4.0 Licence.

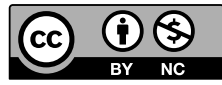

Further details about Creative Commons licenses are available at http:// creativecommons.org/licenses/

Attribution should include the following information:

Johanna Braun (ed.), Performing Hysteria: Contemporary Images and Imaginations of Hysteria. Leuven, Leuven University Press. (CC BY-NC- 4.0)

ISBN 9789462702110 (Paperback)

ISBN 9789461663139 (ePDF)

ISBN 9789461663146 (ePUB)

https://doi.org/10.11116/9789461663139

D/2020/1869/1

NUR: $670,612,757$

Layout: Coco Bookmedia, Amersfoort

Cover design: Daniel Benneworth-Gray

Cover illustrations: left: J. Babinski, ‘Contracture hysterique' 1891.

right: detail from Three photos in a series showing a hysterical woman yawning.

Photograph c.1890, by Albert Londe in 'Nouvelle Iconographie de la Salpetriere';

Clinique des Maladies du Système Nerveux', 1890.

(Wellcome Library, London. Wellcome Images images@wellcome.ac.uk http:// wellcomeimages.org)

Copyrighted work available under Creative Commons Attribution only licence CC BY 4.0 http://creativecommons.org/licenses/by/4.0/

Illustrations on pp. 25, 39, 59, 85, 103, 123, 145, 165, 187, 205: Johanna Braun, Performing Hysteria: Images and Imaginations of Hysteria (Study 1-10), 2019 (image atlas, mixed media), photo credits $($ ) the artist.

Every effort has been made to contact all holders of the copyright in the visual material contained in this publication. Any copyright-holders who believe that illustrations have been reproduced without their knowledge are asked to contact the publisher.

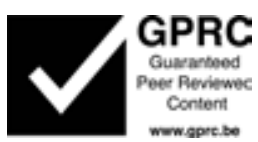




\section{TABLE OF CONTENTS}

$\begin{array}{ll}\text { Acknowledgments } & 7\end{array}$

Introduction 11

Johanna Braun

HYSTORIES REVISITED $\quad 27$

Hysterical Epidemics and Social Media

Elaine Showalter

WANDERING IMAGINATIONS OF RACE AND HYSTERIA

The Origins of the Hysterical Body in Psychoanalysis

Sander L. Gilman

TRAUMATIC DANCES OF "THE NON-SELF"

Bodily Incoherence and the Hysterical Archive

Jonathan W. Marshall

THE PHANTOM ERECTION

Freud's Dora and Hysteria's Unreadabilities

Dominik Zechner 
"A SLIGHT HYSTERICAL TENDENCY"

Performing Diagnosis in Charlotte Perkins Gilman's

The Yellow Wallpaper

Vivian Delchamps

HYSTERIA ACTIVISM

Feminist Collectives for the Twenty-First Century

Elke Krasny

DELILLO AND MASS HYSTERIA

Sean Metzger

HYSTERIA IN THE AGE OF MECHANICAL REPRODUCTION

Back to the "Image Factory" in WestWorld

Cecily Devereux

\#METOO'S FIRST HORROR FILM

Male Hysteria and the New Final Girl in 2018's Revenge

Tim Posada

HYSTERICAL CURE

Performing Disability in the Possession Film

Johanna Braun

Bibliography

Notes on the contributors 


\section{ACKNOWLEDGMENTS}

This publication is part of the research project entitled "The Hysteric as Conceptual Operator", which is funded by the Austrian Science Fund (FWF): [J 4164-G24], and the publication is an outcome of its event series \#masshysteria. Hysteria, Politics, and Performance Strategies, which took place at the University of California, Los Angeles in November 2018.

Therefore, I want to take the opportunity right away to thank those on campus who made this possible. \#masshysteria was organized in cooperation with and was generously sponsored by the UCLA Department of French and Francophone Studies and UCLA Department of Germanic Languages, and the Department Chair, Prof. Dominic Thomas; the UCLA Department of English, especially the Department Chair, Prof. Lowell Gallagher; the UCLA Department of Theater, and its Chair, Prof. Brian Kite; the UCLA Center for Performance Studies, and its Director, Prof. Suk-Young Kim; and the UCLA Center for the Study of Women, and its Director, Prof. Rachel C. Lee; the UCLA Alan D. Leve Center for Jewish Studies, and its Ludwig Kahn Director, Prof. Sarah Abrevaya Stein; the UCLA LGBTQ Studies Program, and its Chair, Prof. Alicia Gaspar de Alba; and the UCLA Department of World Arts and Cultures/Dance, and its Department Chair Prof. Dan Froot. Most importantly I want to thank my advisor on campus, Prof. Laure Murat, and Director of the UCLA Center for European and Russian 
Studies (CERS), for her dedicated endorsement of this project, her continuous support and the many shared vivid discussions on hysterical women, madness, and politics. I also want to thank Liana Grancea and Sanja Lacan at CER who helped tremendously in organizing and promoting the events and this project.

I also want to take this opportunity to thank especially for his energetic support Sean Metzger, Professor in the UCLA Department of Theater and President of Performance Studies international, who was a driving force from the very beginning and helped significantly in facilitating the much needed information and resources on campus that brought this event series to life.

An aller herzlichstes thank you goes to my advisor Arno Böhler, Professor in the Institute of Philosophy at the University of Vienna, and Susanne Valerie Granzer, Professor at the Max Reinhardt Seminar at the University of Music and Performing Arts Vienna, who have supported me and this project critically and enthusiastically from the very first day when I started to timidly envision this endeavor, and also didn't spare any labor and resources to come out to energetically support \#masshysteria on UCLA campus and delivered an astonishing, highly entertaining, and enchanting hysterical performance at the Los Angeles theater on Halloween eve, which I see as the ritualistic premiere of \#masshysteria.

It is hard to say a simple "thank you" for having the honor to work with one of the leading Hystorians and inspiring academics of our times. In defiance of the limits of language in communicating my gratitude, I want to wholeheartedly thank Elaine Showalter, for her generosity in participating in this project, for her openness to discussing the complex relations of hysteria, and for her very personal revelations at the conference as well as in the essay she has contributed to this volume. I also want to thank the driving force behind her: English Showalter, who made sure that our minds and bodies were able to meet so freely on campus.

In the same language-defying vein, I want to express my herzliches gratitude to Sander L. Gilman, whose contribution to the field of hysteria and visual studies cannot be expressed in such a short comment, but which is undeniably echoed in many of the contributions in this volume. It was an honor and privilege as well as highly entertaining and insightful to spend so many hours in Los Angeles traffic with him discussing the many complex layers of hysterical critical engagement, and have him conclude the event series on campus. I thank him for his openness from 
the very first email to engaging in this ongoing discussion and for his euphoric willingness to contribute to this publication.

This publication would not have seen the light of day without the untiring work and support of and the entire Leuven University Press team, especially Mirjam Truwant, Acquisitions Editor, which somehow mysteriously found out about this project and has since then made sure this publication was delivered, through albeit a Pappenheimsche' hysterical labor, into this world. I want to thank it for its infectious vision, inexhaustible patience and continuously energetic endorsement. It saw the potential of this project from the very beginning and has also generously supported it with a grant from the Leuven Fund for Fair Open Access.

Speaking of financial support: This entire project, and the many connections that were facilitated through the lively engagements of it, would not have been possible without the very generous support of the Austrian Science Fund (FWF), which has not only provided the resources to conduct such an ambitious project but has also shown how relevant it is to endorse an in-depth study of such a current phenomenon, thereby attesting its mission to support the ongoing development of (Austrian) science and basic research at a high international level. Thank you to the FWF Advisory board for endorsing this project, and especially the scientific project supervisor, Dr. Barbara Zimmerman, and the administrative project supervisor, Robert Gass, for their ongoing and unflagging support.

Thank you to the wonderfulAlexandra Cox, from Coquelicot Translation, who has continuously untangled and translated my hysterical thoughts whenever I got lost or carried away from a frantic train of thought and who somehow always manages to find time in her very busy editorial schedule for this project.

I also want to send a loving thank you to Michael Niemetz, the best partner in crime, who was instrumental in putting the event series together and who endured my hysterical cries and laughter while working on this publication with much caring patience and often needed encouragement. It goes without saying that a lamentation in solidarity goes out to my beloved Lilli Braun whose hysterical fits accompany me on every journey.

And of course, last but not least, the most significant and sincere acknowledgments go to all the wonderful authors in this volume. Without their hard work and dedication Performing Hysteria would be 
filled with blank pages. Thank you Vivian Delchamps, Cecily Devereux, Sander L. Gilman, Elke Krasny, Jonathan W. Marshall, Sean Metzger, Tim Posada, Elaine Showalter, and Dominik Zechner. It has been a pleasure and pure delight working with you and I'm looking forward to continuing our transnational hysterical discussions.

To conclude, I thank all the engaging readers of Performing Hysteria who will hopefully join this ever contagiously growing dialog on the hysteric's performance and enrich the field even further. 


\section{INTRODUCTION}

We seem to be living in hysterical times. Anyone who has been following public political discourse in recent months cannot avoid the buzzword: hysteria. We see countless reports-especially in the United States, but also beyond-and a simple Google search reveals the sheer bottomless well of "hysterical" discussions, on diverse topics such as the so-called global warming and climate change hysteria, migration hysteria, Trump, Anti-Trump hysteria, xenophobic hysteria, trans bathroom hysteria, or feminist hysteria, and most recently Black Lives Matter hysteria and COVID-19 or corona hysteria, to name only a few. Numerous men in politics and Hollywood warned of hysteria generated by the so-called \#metoo movement, and Peter Haneke and Roman Polanski made it more specific and highlighted the distinction with their warning of the epidemic and contagious nature of "mass hysteria" within the movement. Especially the first two decades of the twenty-first century have displayed an ever increasing interest in the hysteric, from recent literature, film, and television programs to the return of an academic interest in this apparent "hysterical revival". Although the history and evolution of the representation of hysteria have been extensively researched, the study of how these discourses have been transferred to twenty-first-century culture remains largely uncharted territory.

The main focus of Performing Hysteria: Contemporary Images and Imaginations of Hysteria is the way in which the hysteric is involved in and performs on this pressing intersection of hysteria and cultural and 
performance studies, as the book examines the current phenomenon of hysteria in visual culture and sheds light on its historical entanglements and its complex developments and transformations in the present.

The hysteric, who was a well-represented poster child in European artistic and scientific studies at the fin de siècle, is celebrating a surprisingly popular comeback in visual culture a century later. But the figure of the hysteric in this current imagery echoes evidently established medical, artistic, and religious representations of the hysteric that extend well beyond the European studies of the nineteenth century.

It is interesting that while in the late twentieth century the medical term hysteria was struck from the Diagnostic and Statistical Manual of Mental Disorders, it simultaneously reappeared as Histrionic Personality Disorder (Latin: histrio, actor/actress). This rebranding just further underlines the point of this investigation: the hysteric is thereby diagnosed as performer, and has moved beyond the limits of medical discourse. (For the developments and transformations of the medical term, please see: Skull, Devereux) Given this reintroduction, one may assume that the self-reflective media figure of the hysteric will only continue to gain ground in its cultural impact.

The title Performing Hysteria. Contemporary Images and Imaginations of Hysteria already reveals the central focus of this volume: How are the current manifestations surrounding hysteria informed by historical performance practices and how do they, in turn, produce new ways of performing hysteria? To understand these hysterical images, I contend, one needs to locate them within their broader visual culture, furthermore drawing on the cross-disciplinary potential of performance studies, foregrounding images of hysteria in visual representation and in textual discourse.

Both terms, hysteria and performance, are central to a variety of academic fields; therefore, their definitions are ambiguous and remain contested. The term "hysteria" is here chosen deliberately, because it includes religious, medical, and political concepts through its extensive histories (in fact and fiction), and the forms of its representation, so the argument goes, were conceived in terms of performance art. This figure is not just mad, possessed, or simulating excessively one of the former: it references a range of representations that are historically specific to the hysteric. It is interesting to witness how the hysteric visualizes and transgresses boundaries of relating to the politics of classes, genders, 
races, sexualities, religious beliefs, locations, or time periods with ease. Therefore, it is the aim of this volume to uncover the culturally induced discourses that produce this image on one hand, and to trace the images that are (re)produced by the hysteric in turn.

In order to thoroughly analyze the current phenomenon, this book brings together a diverse group of authors who follow the hysteric's performance as an object of inquiry and investigate the multilayered and complex discussions that surround and foster this resurgent interest in hysteria-covering wide areas of hysteric inquiry from art, literature, theater, film, television, dance; crossing disciplines in the humanities from cultural studies, political science, philosophy, and history, media, disability, race and ethnicity, and gender studies; and who look into the emergence of the hysteric performer in well-covered locales such as the United States and Europe, as well as under-represented areas of the hysteric's performance, in China, Japan, and India; and analyze stereotypical images and representations of the hysteric in relation to cultural sciences and media studies, with a particular emphasis on performance studies. They also very much attest to the changing nature of the representation of the hysteric: While the hysteric in historical and previous artistic sources was dominantly represented as a woman or girl, it becomes evident in the current representations, which are investigated in this volume, that the hysteric is currently manifesting beyond those presumed gender boundaries and also appearing more strikingly in the form of group or mass hysteria.

The authors ask pressing questions, such as, what reveals the hysteric's performance in its current manifestations? What historical events or customs have triggered this particular enthusiasm for depicting the hysteric? How has the representation of the hysteric evolved over the centuries and how is it visualized and performed in the present? Why does the hysteric capture the imagination, of Anglophone audiences as well as beyond those often-covered borders? Each chapter will address these and related issues as we focus on hysteria from a variety of critical perspectives, contextualizing the works in the cultures that produce them.

This collection of essays therefore draws on a series of studies that examine the cultural relevance of the representation of the hysteric in visual media. Although the diagnosis of hysteria started to vanish from the medical context by the end of the twentieth century, as already mentioned, a wealth of historical studies about hysteria simultaneously 
appeared as a cultural phenomenon (Veith 1965, Micale 1995, Shorter 1997, Showalter 1997, Skull 2009; please also consult the bibliography in the appendix). Mark S. Micale gave the first comprehensive overview of the research landscape in Approaching Hysteria (1995), introducing the term New Hysteria Studies. Elaine Showalter later coined in response the term New Hysterians (Showalter 1997, 7) and has named those cultural narratives Hystories (5). The authors in this volume are in many ways informed by and draw on these influential discussions.

But besides the extensive literature at the end of the twentieth century, it is interesting to witness that the performance of the hysteric as a culturally relevant representation gets too little attention in today's cultural sciences. This volume examines specific forms of performance with regard to philosophical and cultural discourses. Due to its multimedia representation it would not be sufficient to analyze the hysteric's performance through the perspective of one single medium (e.g. photography, theater, film, or text). Therefore, the contributions are furthermore located in the relatively new field of performance (history) studies. Performing Hysteria unites the hysteric as mediator between historical practices that were aware of their own performativity with the current representations that are performing this historical awareness and self-reflection.

This volume is therefore influenced by cultural studies that deal with the representation of hysteria in its medical context, especially in the context of visualizations of "madness", in visual media in general (Gilman, Haslam, Philo, Blackman/Walkerdine, Pickering, DidiHuberman, Harper, Cross, Serlin, Hustvedt, Scott/Scarth/Chung, Timpano), in theater (Kaplan/Rudolph, Reiss, Harpin/Foster, Wald, Mukherjee, Marshall), and in film (Fleming and Manvell, Gabbard/ Gabbard), but also much beyond the medical context, as hysteria has moved beyond those lines of discipline. This can be seen as a reflection of the development that hysteria is not considered to be an "official" medical diagnosis as of the late twentieth century, and nevertheless retains its relevance for a contemporary audience.

The goal is thus to develop a set of tools for an extensive discussion of the performing arts, as well as for the enhanced analysis of the staging of hysteria as performance and the hysteric as popular performer. Thus, the aim of this book is to provide insight into the current elaborate, complex engagement with hysteria and its performance hystories, rather than to impose any rigid structure of analysis or fixed theoretical framework. 
Although hysteria was extraordinarily prominent in nineteenth-century European medicine and culture, only a couple of full-length historical surveys have been published in the twentieth century, most notably: Ilza Veith's Hysteria: The History of a Disease (1965) and Etienne Trillat's Histoire de l'Hysterie (1986, which was unfortunately never translated into English and not widely publicized, and had therefore little impact on Anglophone academic scholarship). Both written from an internalist medical perspective, they did not yet consider the cultural, contextual, and discursive implications of these forms of representation in their negotiations of class, gender politics, and ideology.

French medical historian Georges Didi-Huberman's often-cited Invention de l'Hysterie: Charcot et l'Iconographie Photographique (1982) shifted the focus and has been influential in fusing the diagnosis and appearance of hysteria and its connection to visual images and artistic representations, especially since its English translation appeared as Invention of Hysteria: Charcot and the Photographic Iconography of the Salpêtrière in 2003.

Sander L. Gilman, Helen King, Roy Porter, G. S. Rousseau, and Elaine Showalter have broadened this field extensively, through their individual contributions to the latter, as well as through their comprehensive collection of essays in their jointly edited Hysteria Beyond Freud (1993).

Hysteria Beyond Freud, a medical history of hysteria that makes a strong case that Freud's influential studies on hysteria were neither the beginning nor the end of the field, and that uncovers the social and cultural implications of the representation of hysteria, can be broadly divided into a historical first section (with the essays by Helen King and G. S. Rousseau) and the thematic one (by Roy Porter, Elaine Showalter, and Sander L. Gilman) and has significantly contributed to a new generation of hysteria studies. (Please refer to their extensive literary review on discussions about the representation of hysteria and its medical histories.)

The scholarly move to extend the scope of medical and psychoanalytic studies on hysteria, and unravel the cultural implications of those representations, has informed several hysteria studies of the early twentyfirst century, especially in relation to representations of hysteria in the arts. Nevertheless, these studies are still very much informed by the medical and historical discussions of the early New Hystorians. Jonathan W. Marshall's insightful Performing Neurology: The Dramaturgy of Dr. JeanMartin Charcot (2016), for example, focuses on late nineteenth-century French neurology and performance and the history of medicine as it 
relates to theater and art. Nathan J. Timpano's Constructing the Viennese Modern Body: Art, Hysteria, and the Puppet (2017) focuses on Vienna around 1900 and makes a case that hysteria was already well discussed in Vienna in artistic productions before Freud's often-cited studies. Anna Harpin and Juliet Foster take a broader approach in their edited collection, Performance, Madness and Psychiatry: Isolated Acts (2014), and discuss the representation of "madness" in general and the "medical theaters" of psychiatric asylums and hospitals specifically, and their relation to performance and theater practices, from the eighteenth century to the present. Ankhi Mukherjee's deconstructive psychoanalytic study Aesthetic Hysteria: The Great Neurosis in Victorian Melodrama and Contemporary Fiction (2007) operates on the fringes of emotion/affect and trauma studies, which she investigates through literary texts that range from authors such as Charles Dickens to contemporary literature by Pat Barker, while incorporating discussions around hysteria from the fields of the history of medicine, aesthetic theory, speech act theory, feminism, and gender and performance studies. Christina Wald's Hysteria, Trauma and Melancholia: Performative Maladies in Contemporary Anglophone Drama (2007), as well, focuses on theater plays and traces the theatrical performance, gender performativity, and what she calls the "drama of performative malady" in performance and theater practices that were concerned with representation of hysteria in the 1990s. Anouchka Grose's edited volume Hysteria Today (2016), as part of the Centre for Freudian Analysis and Research Library Series, is also a psychoanalytical approach to the theme and looks at how and if hysteria is still relevant within contemporary clinical practices.

It is interesting to witness this continuing academic interest in hysteria. Performing Hysteria very much draws inspiration from these investigations, while also showing the many ways hysteria has been celebrating a fruitful revival in countless contemporary forms. Furthermore, while I acknowledge the importance of hysteria and psychoanalytic theory, this book follows the same historical objective as its predecessor, in Hysteria Beyond Freud, with the editorial decision not to include professional psychoanalysts or medical practitioners among the authors, as well as approaches fundamentally psychoanalytical in their motivation. Although the medical diagnosis of hysteria is still referenced in many of the contributions, it is evident that hysteria functions in our contemporary context far beyond the clinical and psychoanalytical limits of debate. 
While those publications attest to the ongoing artistic and academic interest in hysteria, and have contributed significantly in continuing the discussion on hysteria, Performing Hysteria. Contemporary Images and Imaginations of Hysteria goes even further and investigates through a range of contemporary case studies how pressing public discourses are negotiated through images of hysteria. Therefore, Performing Hysteria is not a "complete" history of hysteria, proceeding in linear time. Nor is it an attempt to rewrite previous studies on the history of psychiatry and medicine under contemporary circumstances. This is the first book-length study of the twenty-first century to systematically, theoretically, and historically analyze the hysteric's performance in various contemporary performance practices. Therefore, as we can witness in the diverse chapters in this volume, images of hysteria are very productive in the present in communicating a wide range of discussions and topics that may include but also extend beyond the medical and psychoanalytical imagery of hysteria. The essays in this volume are therefore also informed by and reference previous academic and artistic explorations on the intersection of hysteria and performance, most notably Anna Furse's Augustine (Big Hysteria): Writing the Body (1997) and Dianne Hunter's The Makings of Dr. Charcot's Hysteria Shows: Research Through Performance (1998), among many others, who investigated how the hysteric was staged and performed in Charcot's influential medical studies and its impact on performance art practices at the end of the twentieth century. Currently, we can witness countless explorations of artists and writers that "reclaim" hysteria, and draw heavily on this school of thought, as well as expand it beyond Charcot's archive of performance practices well into the present and tie it into the rich discussions of hysteria as a language of feminist protest, most prominently informed by the writings of Hélène Cixous, Catherine Clément and Luce Irigary. This current phenomenon merits a focused and in-depth investigation of its very own which I explored separately, as a complementary study to this volume, in There is a Method to this Madness: Hysteria and the Arts (2020).

With the resurgence of hysteria in public discourse and such a broad cultural output, the time seems ripe to reexamine the multilayered hystories that are revealed in the hysteric's contemporary performances. The aim of Performing Hysteria is to paint a clear picture of the intersections of hysteria and performance, to be able to understand the complex ways in which performance and hysteria are informed by, 
and forming of, culture, politics, and history. Performing Hysteria is the first to make explicit the lines of progression running from the figure of the hysteric, and the theoretical discourses surrounding it, into contemporary (popular) culture.

This publication attests to hysteria's fragmentation and explores hysteria and performance through a wide range of theoretical modes of thought. Through several case studies, which encompass literary works, photography, paintings and drawings, theater, dance, film and television productions, the figure of the hysteric has come to personify a wide range of cultural and social discussions, ranging from disability, healthcare, reproduction, and labor rights to pressing questions of changing social and cultural environments through new developments of the internet, social media, and the blurring of transnational borders. The "hysterical archive" is a recurrent theme in many of the essays, revealing how the image archive of the hysteric is re-producing and re-performing artistic, medical, and religious representations of the hysteric that were already established in European studies of the nineteenth century, and attesting to its legacy that reaches well beyond these borders of inquiry. The publication can be roughly divided into two complementing parts: the authors initially lay out the historical connections, and tie in the fragmented parts and pieces of the hysteric's performance practice that inform the current discussions very effectively, while the ensuing contributions tie this historical awareness to a series of contemporary case studies and show how these discussions are still enchanting a mass audience. Further, they demonstrate how these historical practices have transformed and shaped current representations of the hysteric.

We start the investigation with an essay by Elaine Showalter, who "revisits" the ongoing public and academic interest in hysteria and points to the parallels and differences to her influential work at the end of the twentieth century. Showalter has been exploring the cultural narratives and representations of hysteria and how it has multiplied rapidly and uncontrollably in the era of mass media, telecommunications, and e-mail for the past two decades, and in this very personal essay she reflects on the consequences that her influential "hysterical" research practice had on her academic career and personal life.

Sander Gilman, who has published extensively on the imaginations that have shaped images of hysteria, then follows right next and traces in his essay how concepts and questions of race have shaped ideas and representations of the hysteric. He presents an interesting case: the 
hysteric - the Jewish hysteric to be precise-was perceived as out of mind because they are out of place, thereby making an interesting connection between the disturbing imaginations of the "wandering womb" to the anti-Semitic notion of the "wandering Jew". Those far-reaching concepts of hysteria and dis-placement, especially in connection with wandering, are returning in many of the following essays, that trace how hysterical imaginations are still traveling into the very present and how those medical concepts of the wandering hysteric migrated very much beyond the medical discourse into the representation of hysteria in culture at large.

Jonathan W. Marshall then casts a wide net of investigation and joins the dots of an extensive network of itinerant and dancing images of hysteria from Europe to Japan, traversing centuries of hysterical performance practices. In doing this, Marshall follows hysteria and its choreography of a well-established performance archive, which he calls a "hysteriform archive", that constitutes a set of bodily gestures and actions that recur across history, crossing from early modern demonical possession, exorcism, and religious ecstasy to medical studies of the eighteenth and nineteenth centuries, in order subsequently to become a significant resource for international performing artists in the last two centuries. Marshall lays out a series of significant performance strategies that are echoed in many of the following investigations.

Dominik Zechner revisits the infamous hysterical Freud case study of "Dora" and draws compelling connections, by means of employing Haslam's "creep concept" (2016) between the current phenomenon of the "massification" of hysteria in the \#metoo movement and public debates surrounding abuse and sexual misconduct in the workplace and their philosophical implications in particular. Zechner paints a compelling picture of Dora as a feminist heroine and what he calls an "epochal icon of analytic collapse" whose legacy echoes well into these pressing public debates in the present and especially in current representations of the hysteric as resistance to cure and "the master narrative".

Vivian Delchamps draws this line, of the hysteric as a figure of protest, further, and discusses how the literary motive of the hysteric from nineteenth-century American literature was informed by, as she calls it, the "performance of diagnosis" in medical texts which in turn led to an equally elaborate "performance of rebellion" in literary representations, and in doing this she provides an interpretive framework for understanding issues of gender and hysteria relevant to modern 
discourses in literature, disability studies, and medical humanities that can be traced in many of the following contributions that investigate the resurgence of this feminist trope, especially in visual culture.

Elke Krasny, for example, spins this thread into the present, and discusses itinerant concepts of hysteria in performance practices in contemporary art, especially by feminist art collectives, moving on the intersection of art and politics; hysteria and protest culture; in Europe, North America, and India. Employing Mieke Bal's methodological approach of "traveling concepts" (2002) allows Krasny to trace the hysterical complex in its transhistorical itineration from Greek antiquity to the politics and labor of performing hysteria in Jean-Martin Charcot's Salpetrière and Sigmund Freud and Joseph Breuer's Studies on Hysteria, and on to current art practices that perform hysteria as activist movements that mobilize and politicize hysterically in a global context. Sean Metzger continues this traveling train of hysterical thought and further investigates the blurring of cultural and national borders in the hysteric's performance. Metzger looks specifically into the theatrical and political implications of (mass) hysteria in the work of American novelist Don DeLillo and the stage adaptation by Jody McAuliffe of DeLillo's novel Mao II and traces compelling parallels between an hysterical archive, mass production, and the theatricality of the crowd. He thus attests as well to the complex representations and misconceptions of creative and human capital in China, and how images of (mass) hysteria negotiate these pressing debates surrounding labor and reproduction rights.

Cecily Devereux follows this and makes as well a compelling case for the reproduction and repetition of a hysterical archive and its connection to labor and reproduction in hysterical performances. She considers the reproduction of maternal bodies in the $\mathrm{HBO}$ television series WestWorld (2016-), how they reproduce and perform hysterical images of the hysteric, and looks both at the reproduction of cyborg bodies as hosts put to work in the form of, in effect, three-dimensional images for the pleasure of guests in the immersive theme park of the series' title and at the representation of hysteria of those bodies as they experience and stage the repetitive stress of their labor.

Cecily Devereux's essay is followed by another contemporary case study that focuses on a recent manifestation of the hysteric that is well informed by historical images of the hysteric's performance archive with a new twist. Tim Posada traces the development of the iconic horror film trope of the Final Girl (Clover 1992) and how the recent film Revenge 
(2018) became an unlikely anthem of and provides insights relevant to discussions to the \#metoo movement. He traces interesting parallels between European studies of male hysteria to current discussion around rape culture and sexual violence and how the so-called Rape-Revenge film enriches the hysterical archive with a new horror trope: hysterical men.

As a complement to this contemporary case study in horror film, my concluding essay takes a closer look at a specific expression of the hysteric's performance in the present: the hysteric's politically charged and highly popular performance in mainstream US horror films of the so-called Possession film, which draws heavily on historically wellestablished notions surrounding staging and performing hysteria to discuss pressing topics of its time, especially around disability and health care, and how the recent development has led to a new trope: the hysteric as resistant to treatment and cure, and therefore attesting to a new self-consciousness of the self-reflective media figure of the hysteric.

What becomes evident in these brief summaries is that the current highly popular and versatile performance of the hysteric draws on and ties in a multitude of discussions, blurring previously established boundaries of discussion around hysteria's presumed gender, nationality, discipline, genre, or media.

Performing Hysteria does not aim to be complete but to give advanced consideration to the wealth of existing examples of the hysteric's performance in its manifold manifestations. While the figure of the hysteric has attracted considerable scholarly attention over the decades, the current critical academic engagement turns out rather slim; therefore, it is the aim of Performing Hysteria to lay out several recent developments in the hysteric's performance that will hopefully also lead to focused studies of their own that explore the highly complex representations of the hysteric's performance in specific mediums and genres, in contemporary literature, fine arts, theater, film and television productions in the present. As a starting point for further investigations, please refer to the extensive bibliography in the appendix for further readings on hysteria, which have a focus on the visual representation and performance of hysteria.

I'm very much looking forward to seeing how this exploration unfolds and to what discussions and investigations it might lead. In light of the ongoing "trending" of hysteria in public discussions and artistic inquiries, it remains thrilling to witness the complex, while also at 
times troubling, prevailing currency of the hysteric which speaks great volumes about the hysteric's ongoing highly politically relevant performance repertoire.

\section{Works Cited}

Bal, Mike. Travelling Concepts in the Humanities: A Rough Guide. University of Toronto Press, 2002.

Blackman, Lisa, and Walkerdine, Valerie. Mass Hysteria: Critical Psychology and Media Studies. Palgrave, 2001.

Braun, Johanna, editor. There is a Method to this Madness: Hysteria and the Arts. Palgrave Macmillan, 2020.

Cixous Hélène. "Portrait of Dora," translated by Ann Liddle. Selected Plays of Hélène Cixous, edited by Eric Prenowitz. Routledge, 2004, pp. 35-59.

- _. "Laugh of the Medusa," translated by Keith Cohen and Paula Cohen. Signs, vol. 1, no. 4, 1976, pp. 875-93.

- - and Catherine Clément. The Newly Born Woman (1975), translated by Betsy Wing. University of Minnesota Press, 1986.

Cross, Simon. Mediating Madness: Mental Distress and Cultural Representation. Palgrave Macmillan, 2010.

Devereux, Cecily. "Hysteria, Feminism, and Gender Revisited: The Case of the Second Wave." English Studies in Canada, vol. 40, no. 1, March 2014, pp. $19-45$.

Didi-Huberman, Georges. Invention of Hysteria: Charcot and the Photographic Iconography of the Salpêtrière (1982), translated by Alisa Hartz. MIT Press, 2003.

Fleming, Michael, and Roger Manvell. Images of Madness: The Portrayal of Insanity in the Feature Film. Associated University Presses, 1985.

Furse, Anna. Augustine (Big Hysteria): Writing the Body. Harwood Academics Publisher, 1997.

- - "A Spectacle of Suffering." The Visual-Narrative Matrix: Interdisciplinary Collisions and Collusions, edited by Graham Coulter-Smith. Fine Art

Research Center, 2000, pp. 73-77.

Gabbard, Krin, and Glen O. Gabbard. Psychiatry and the Cinema. University of Chicago Press, 1987.

Gilman, Sander L. Difference and Pathology: Stereotypes of Sexuality, Race, and Madness. Cornell University Press, 1985.

- - Seeing the Insane. Wiley, 1982. 
- - Disease and Representation: Images of Illness from Madness to Aids. Cornell University Press, 1988.

——. "The Image of the Hysteric." Hysteria Beyond Freud, edited by Sander

L. Gilman, Helen King, Roy Porter, G. S. Rousseau, and Elaine

Showalter. Berkeley: University of California Press, 1993, pp. 345-452.

- - , Helen King, Roy Porter, G.S. Rousseau, and Elaine Showalter. Hysteria Beyond Freud. University of California Press, 1993.

Grose, Anouchka, editor. Hysteria Today. Karnac, 2016.

Harper, Stephen. Madness, Power and the Media: Class, Gender and Race in

Popular Representations of Mental Distress. Palgrave Macmillan, 2009.

Harpin, Anna, and Juliet Foster, editors. Performance, Madness and Psychiatry: Isolated Acts. Palgrave Macmillan, 2014.

Haslam, John. Illustrations of Madness. Routledge (Facsimile of 1810 edition edited by Roy Porter).

Haslam, Nick. "Concept Creep: Psychology's Expanding Concepts of Harm and Pathology." Psychological Inquiry, vol. 27, 2016, pp. 1-17.

Hunter, Dianne, editor. The Makings of Dr Charcot's Hysteria Shows: Research Through Performance. Edwin Mellen Press, 1998.

Hustevedt, Asti. Medical Muses: Hysteria in Nineteenth-century Paris. W.W. Norton, 2011.

Irigary, Luce. This Sex Which Is Not One, translated by Catherine Porter and Carolyn Burke. Cornell University Press, 1985.

- - Speculum of the Other Woman, (1974) translated by Gillian C. Gill. Cornell University Press, 1985.

Kaplan, Ellen, and Sarah J. Rudolph. Images of Mental Illness Through Text and Performance. Edwin Mellen Press, 2005.

Marshall, Jonathan W. Performing Neurology: The Dramaturgy of Dr Jean-Martin Charcot. Palgrave-Macmillan, 2016.

Micale, Mark S. Approaching Hysteria: Disease and Its Interpretations. Princeton University Press, 1995.

Mukherjee, Ankhi. Aesthetic Hysteria: The Great Neurosis in Victorian Melodrama and Contemporary Fiction. Routledge, 2007.

Philo, Greg, editor. Media and Mental Distress. Longman, 1996.

Pickering, Michael. Stereotyping: The Politics of Representation. Palgrave Macmillan, 2001.

Reiss, Benjamin. Theaters of Madness. University of Chicago Press, 2008.

Scott, Francesca, Kate Scarth, and Ji Won Chung, editors. Picturing Women's Health. Routledge, 2016.

Serlin, David, editor. Imagining Illness: Public Health and Visual Culture.

University of Minnesota Press, 2010. 
Shorter, Edward. A History of Psychiatry: From the Era of the Asylum to the Age of Prozac. John Wiley and Sons, 1997.

Showalter, Elaine. Hystories: Hysterical Epidemics and Modern Culture. Columbia University Press, 1997.

Skull, Andrew. Hysteria: The Disturbing History. Oxford University Press, 2009.

Timpano, Nathan J. Constructing the Viennese Modern Body: Art, Hysteria, and the Puppet. Routledge, 2017.

Veith, Ilza. Hysteria: The History of a Disease. University of Chicago Press, 1965.

Veyrac, S. "Une heure chez Sarah Bernhardt." Chronique Médicale, vol. 4, no. 19, October 1, 1897, pp. 609-606.

Wald, Christina. Hysteria, Trauma and Melancholia: Performative Maladies in Contemporary Anglophone Drama. Palgrave Macmillan, 2007. 

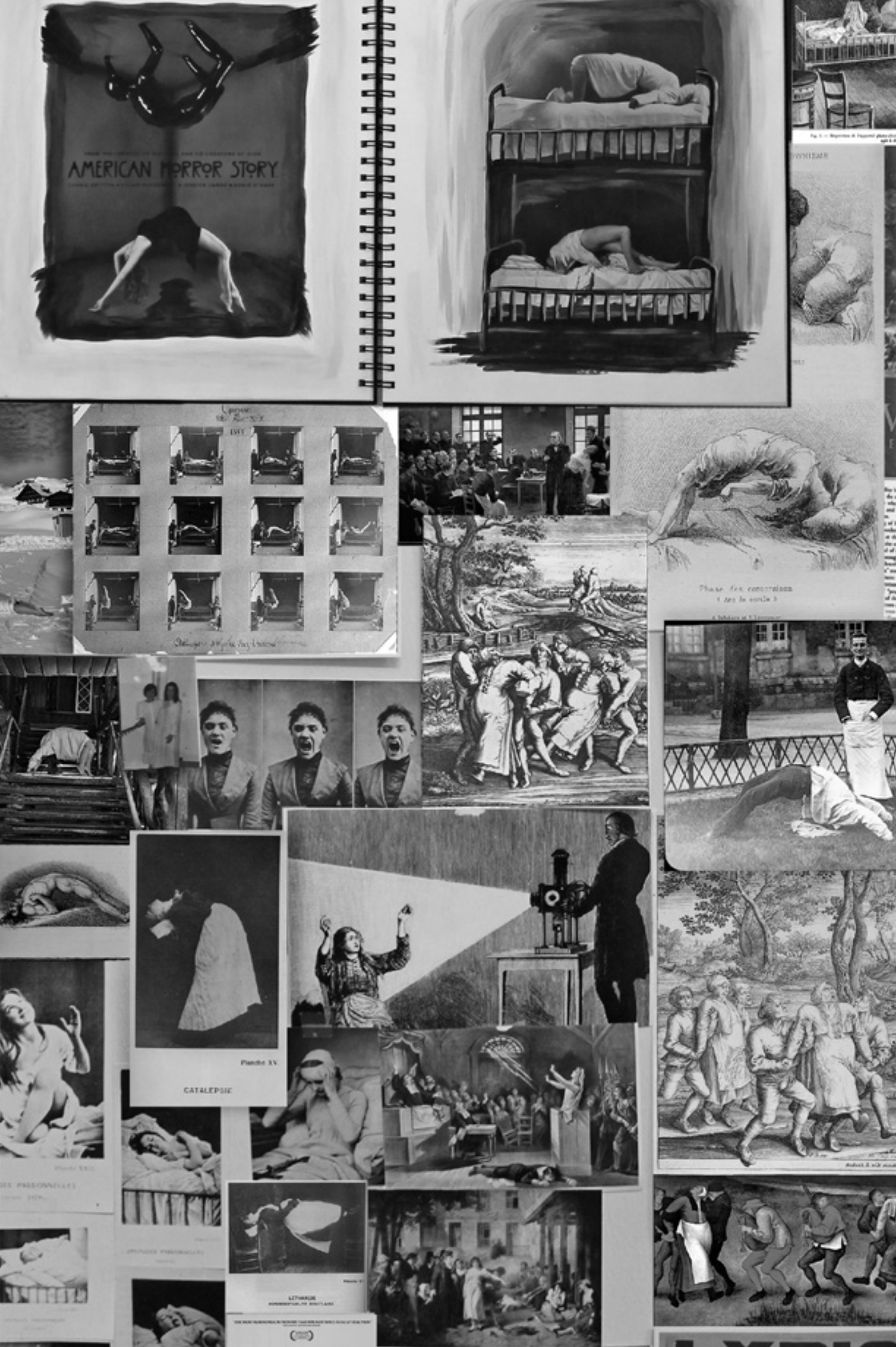

W .
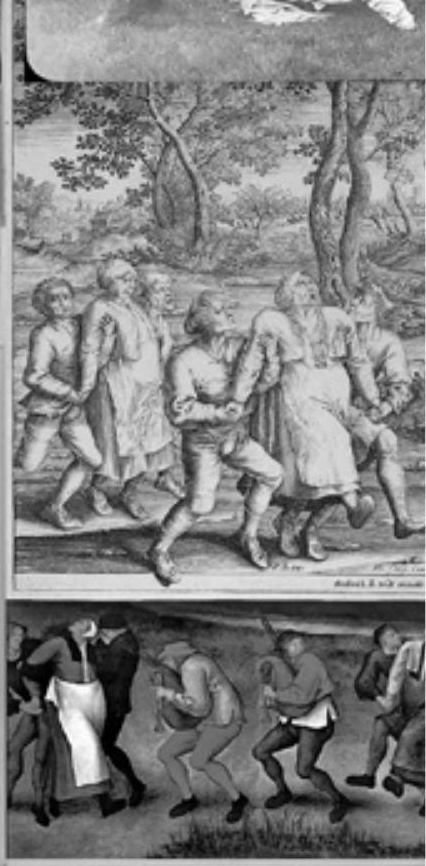



\section{HYSTORIES REVISITED Hysterical Epidemics and Social Media}

Elaine Showalter

In 1997, my book Hystories: Hysterical Epidemics and Modern Media, was published by Columbia University Press in New York and by Picador in London. Hystories was the culmination of twenty years that I spent working on the history of psychiatry, and the third of three books I wrote during this period. In it, I looked at the forces that shaped hysterical epidemics, placing them in their fullest sexual, historical, cultural, and political contexts: their rise in the 1990s; intersections with literature, theatre, and film; and connections with conspiracy theories, witchhunts, and mass panics. As I wrote, "in the interaction between 1990s millennial panic, new psychotherapies, religious fundamentalism, and American political paranoia, we can see the crucible of virulent hysterias in our own time. The heroes and heroines of 1990s hysteria call themselves traumatists and ufologists, experiencers and abductees, survivors and survivalists. As their syndromes evolve, they grow from micro-tales of individual affliction to panics fueled by rumors about medical, familial, community, or governmental conspiracy". Moreover, hysteria is more contagious than in the past. "Infectious epidemics of hysteria [are] spread by stories circulated through self-help books, articles in newspapers and magazines, TV talk shows and series, films, the Internet, and even literary criticism. The cultural narratives of hysteria, which I call hystories, multiply rapidly and uncontrollably in the era of mass media, telecommunications, and email" (Showalter 5). 
My aim was to produce a work of applied scholarship that used my research on the history of psychiatry and especially the history of hysteria to address some very controversial contemporary issues of public value and policy, and in that it succeeded. It was widely read and reviewed, published by a trade press in the UK and translated into German. As a result of the book, I spoke to military doctors at the Veterans Administration in Washington, at a conference on Gulf War Syndrome in Edinburgh, to the staff at the Salpêtrière in Paris, and at hospitals in New York and Toronto. But I did not anticipate that writing Hystories would change my life and work in profound ways, and launch me into a new field of risk communication. And I did not foresee that in the twenty-first century, with the shift from mass media to social media, the spread of hysterical epidemics and conspiracy theories, would be speeded up and alarmingly changed. What I saw as uncontrollable in the 1990s would become viral by the 2000s. Revisiting the story of Hystories is also my personal story of the way circumstance and history affect scholarly choices and theories.

From about 1978 to 1998 I lived what felt like a double life, as a professor of English and a historian of psychiatry. From September to May, I was a literary scholar and feminist critic, teaching Victorian and American literature, fin-de-siècle fiction, women writers, and contemporary novels at Princeton University. In June, July, and August, and longer when I could get a sabbatical and a fellowship, I was a researcher and then a Fellow, at the Wellcome Institute for the History of Medicine in London, during the period when Roy Porter was its legendary director and galvanizing spirit.

Roy came to the Wellcome in 1979 from Cambridge University. An enormously productive scholar, brilliant writer and speaker to both professional and general audiences, media star, and convivial, fivetimes-married colleague, Roy was the charismatic center of a vibrant community of academia, social history, medicine, and popular culture, bringing people together, supporting conferences, and enabling connections. Under his leadership, new approaches and new methodologies were welcomed indeed, and the Wellcome became the destination for an international, interdisciplinary circle of scholars, historians, and doctors who had become interested in the subject of hysteria as a cultural phenomenon. Playing off the literary group called the New Historians led by Stephen Greenblatt and based at Berkeley, I called us the New Hysterians. 
As Roy wrote in the introduction to our co-authored book Hysteria Beyond Freud (1993), medical history had changed dramatically over the 1980s. It had shifted "from the scientific history of disease to the cultural history of diseases and the study of illness as metaphor". Historians began to look more closely at "the complex dynamics of doctor/patient relationships". The role of language, linguistics, and discourse in the analysis of medical conditions had received enormous attention. The "interface of literature and medicine" had become one of the most important themes in scholarship on both sides of the Atlantic. Above all, feminist scholarship had brought attention to "gender and social control encoded in women's diseases, especially the hysteria diagnosis, in the age of Freud" (Porter viii).

I first wrote about hysteria in my book The Female Malady (1985). Hysteria is a major term in the history of the treatment of women in psychiatry. By the time the book came out, I had started to look at performance and the relation of hysteria and histrionic, as well as doctors and asylums, especially in nineteenth-century realistic drama like Ibsen. Metaphors of the histrionic have long been part of the clinical discussion of hysteria, and nineteenth-century physicians generally believed that hysterical women were skillful performers, faking their symptoms in order to get attention and special treatment. In 1980, this theatrical subtext was officially codified when the third edition of DSM-III (1980) renamed what had previously been "hysterical personality disorder" as "histrionic personality disorder". In 1977, two psychiatrists indeed recommended acting as the ideal career choice of the female hysteric (Showalter 1997, 202).

The definitions and diagnoses came at the height of the Women's Liberation Movement, and were uncannily similar to the media's view of feminist activism as over-reactive, self-dramatizing, and irrational. Labels of "hysterical" and "histrionic", still routinely used against feminism and the \#metoo movement, were also applied to gay rights groups, which responded by reclaiming and reframing the issue in names like ACT-UP and the slogan "Silence=Death". Many contemporary women artists and performers reframed the histrionic elements of hysteria for a feminist art and theater.

At the same time, French feminist theorists led by Hélène Cixous claimed the nineteenth-century hysterical woman as a precursor of feminist revolution. I found that identification risky, and I wanted instead to write about hysteria without making it essentially female. In a chapter on male hysteria in The Female Malady, and my section of Hysteria 
Beyond Freud, "Hysteria, Feminism, and Gender", I wrote at length about the history, representation, and performance of male hysteria, looking particularly at the international debates about shell shock in World War I.

By the late 1980s many psychiatrists and historians had proclaimed that hysteria had disappeared. In 1986, for example, the French psychoanalyst Étienne Trillat declared that "hysteria is dead, that's for sure. It has carried its mysteries with it to the grave" (Trillat 274). The scholars at the Wellcome were skeptical of that pronouncement, and I certainly thought it was premature. In the 1990s, a form of shell shock was reappearing in what was called "Gulf War Syndrome", a disorder of Gulf War veterans in the US and UK, afflicted with symptoms ranging from memory loss to hair loss, from night sweats to disabling muscle spasms. These wide-ranging symptoms seemed much more akin to post-traumatic stress disorder than an organic illness. Some American journalists and activists, however, claimed that it was a contagious disease caused by exposure to gas or drugs, which was being covered up by the US government.

In the mass media, additionally, there were frequent stories about hysteria, in the form of psychogenic disorders, conspiracy theories, urban legends, and epidemic rumors and panics. In 1994, tales of alien abduction, in which people reported being kidnapped by large grey alien creatures and subjected to sexual probes, got quasi-scientific legitimacy when Professor John Mack at Harvard Medical School wrote a book called Abduction: Human Encounters with Aliens (1994). Mack suggested that there might be an extraterrestrial breeding program to produce human-alien babies, again being covered up by a government conspiracy. The historian and ufologist David M. Jacobs, in his book, The Threat: The Secret Alien Agenda (1998), warned that it may already be too late to stop an alien breeding program aimed at taking over the planet. Handsome, Levi-wearing aliens, he wrote, have been assigned as "personal-project hybrids" to have regular sex with various earthwomen. The aliens tell lies and have several projects apiece, but they are so seductive, romantic, and cute that most of the women fall in love with them. The alien-abduction stories were silly, but even in 2018 a GOP congressional candidate claimed that as a child she had been taken to a spaceship by three blond extraterrestrials (Folley).

But the most harmful of these conspiracy theories was that teachers in preschools and kindergartens were subjecting children to satanic ritual abuse, a form of devil worship carried out by hidden cults. In fact there 
were no cults, but rumors and hysterical panics spread by the media led to arrests and imprisonment of child-care teachers and workers in the US and the UK. Children were taken away from their families as well. In addition to magazines and newspapers, daytime TV talk shows, and specials including a two-hour "documentary" from Geraldo Rivera called Devil Worship: Exposing Satan's Underground that aired in 1998, endlessly recycled the allegations. It took many books, law suits, and government investigations and reports before the falsely accused teachers were acquitted and cleared, and the panic subsided.

But as one hystory was contested another seemed to spring up in its place. As I found after Hystories was published, some believers and advocates were infuriated by my critique, and, accustomed to the civil debate of academic conferences, I was initially unprepared for the angry response. In Washington, DC, giving my first ever bookstore reading, I was confronted by a young man in army fatigues yelling "Bullets are too good for you!" He had to be escorted from the store, and the event ended when some audience members tried to destroy copies of the book. As I went on to speak at bookstores around the country, the threats got worse. In American bookstores there was always the chance that the curses and inflammatory language that greeted my appearance would alert a lunatic with a gun or a bomb. I got used to having photographers from the local press pools show up at the bookstores to get the picture in case I got shot. Barnes and Noble in New York had its own security staff that took me to a safe room when the audience got too close and hostile, and then smuggled me out a back entrance.

I also went on daytime TV talk shows, another form of media which spread conspiracy theories and toxic rumors. In New York, I appeared on Rolonda with half-a-dozen people with multiple personalities, recovered memories of sexual abuse, or tales of alien abduction; and their therapists, publicists, and advocates. In Seattle I was tricked into appearing on what I was told was a serious TV discussion of Gulf War Syndrome. Once I got on stage for the live program, I faced an angry audience of flag-waving veterans and co-panelists promoting conspiracy theories of government cover-up. One of my co-panelists was a woman who claimed to have caught Gulf War Syndrome at a party and given it to her dog. I had a lot of hate mail, and a few stalkers. One serial emailer showed up at my bookstore reading in Chicago. Another was convinced that we had both been abducted by aliens, and that they had brainwashed me into writing Hystories as a smokescreen. All the hate mailers were convinced that I had been paid huge sums to write the 
book by US chemical megacorporations, or that I was the mouthpiece of an evil scientist. In England a doctor predicted that my book would drive patients to suicide. (It didn't.)

Writing Hystories taught me that it is much safer and calmer to write about hysteria in Charcot, Freud, and Ibsen. Looking at the connection between media attention, hysterical epidemics, and conspiracy theories became standard practice in many scattered incidents. Nonetheless, as I concluded, as one form of hystory was contested and one conspiracy theory exposed as false, another seemed to spring up in its place.

The year 2001 marked a clear millennial change in the circulation of rumors and panics, and the ability to contest them with reason and evidence. After September 11, 2001, conspiracy theories of vague and mysterious enemies and villains briefly subsided in the face of a real and lethal conspiracy against the United States. When terrorism posed clear threats, beliefs in alien abduction, for instance, quickly lost followers. As one journalist wrote, "Two planes crashed into the Twin Towers and no one cared about little green men anymore". Coincidentally, but meaningfully to me, Roy Porter retired from the Wellcome Institute that fall, and died suddenly from a heart attack at the age of 56 five months later. The Wellcome was reorganized and its Golden Age as a center for cultural inquiry was over.

Of course 9/11 quickly generated its own conspiracy theories, security problems, and issues of government communication to an anxious and suspicious public. On March 25, 2002, I participated in a threeday conference on bioterrorism and public policy in Brussels, the first ever Advanced Research Workshop co-sponsored by NATO and Russia. The workshop had been organized by Professor Simon Wessely (Kings College School of Medicine, London) and Professor Valery Krasnov (Director, Moscow Research Institute of Psychiatry), after President Putin and NATO Secretary-General Robertson agreed to co-operate on studying ways to combat terrorism.

This kick-off meeting of international experts from Russia, the US, Britain, Belgium, France, Spain, Norway, Turkey, Israel, and Japan addressed the "importance of psychological factors in understanding and mitigating our response to terrorism" and the problems of communication for authorities addressing the public about risk (Wessely 1-2). For everyone, it was a historic occasion. "If you had told me ten years ago that I would be addressing a NATO conference", one Russian psychiatrist told me, "you would have been one of my patients". 
As a professor of English literature, I was almost as amazed as the Russians to find myself at NATO. Simon Wessely had invited me to give one of the closing keynote addresses, on the long-term problems of distrust, and secondary symptoms after a real or suspected biochemical or nuclear incident, such as Three Mile Island and Chernobyl. On the first day, we focused on what could be learned from previous episodes of chemical, biological, and radiological terrorism and disasters; on the second day, we looked at the psychological effects of mass terrorism; and on the final day, we considered interventions, rumor panics, and risk communication.

Only four speakers at the workshop were female, and all participants were white, a situation that led one of the women delegates to comment to a male delegate that the diversity of the conference left something to be desired. "I've noticed that", he agreed; "all the Russians are from the same region". In several studies of disasters, women and girls had higher anxiety levels than men, and lower levels of trust, leading to speculation about whether women were less disposed to believe what they were told by men. I suggested that what was needed was more female role models in the mass media during emergencies-women needed to see and hear other women being courageous, calm, and self-possessed.

All the delegates agreed that bioterrorism was addressed to a group rather than to individuals, and designed to destroy social cohesion, including values, morale, and trust in government and society, and to sow distrust and fear. One delegate proposed the term "catastrophic reaction syndrome" for the psychological symptoms of a disaster.

Over the three days, two distinct positions on how to handle bioterrorism began to emerge from the meeting. On one side, led by the Russians and the Germans, were the civil defense officials, emergency management teams, and psychiatric intervention experts, who were concerned about controlling public behavior, and anticipated panic, short-term dysfunction, and long-term traumatic reactions. On the other side, led by the Americans and the British, were academic psychologists, public health scholars, risk communication experts, and media professionals who believed that public responses to catastrophes and disasters were generally rational, constructive, and predictable, and should be expedited and supported by official and government sources. Both sides favored rapid dissemination of accurate information by the authorities; but we differed about exactly what the public needs to know, and even whether the public can know too much. 
We also differed about the role of the media. Whether a free press is still a concerned part of the social order, a detached observer outside of it, or, whether they like it or not, a player in the construction of social responses to emergencies became one of the touchiest issues of the meetings. One official argued that the media could not be counted on to help, and might even increase public disquiet. A BBC journalist and correspondent who briefed the group stressed the importance of the speed of official response to a crisis. He warned us that the narrative agenda of a bioterrorist incident would be determined within the first twenty minutes. In the absence of government announcements, other stories-conspiracy theories, false information, rumors, hystorieswould rush in to fill the gap. He also reminded us of the wide range of media sources, with varying ethical and professional standards.

As the Washington Post reported (2002), more than half of all Americans got their political information from the popular media as well as the news elite, including talk shows, MTV, "Saturday Night Live", Oprah, David Letterman, and Jay Leno. Another delegate presented research that showed the more TV people watched after September 11, the more psychological symptoms they reported. But was this the result of exposure to the terrible images, or the corollary of those who were most disturbed being least able to limit their watching? Overall, it was clear that modern technology-the cellphone, the internet, television-was part of the bioterrorist scenario.

One outcome of the NATO workshop was an ongoing effort to share and circulate ideas about communicating in a crisis, and to help draw up policies for public officials in the countries participating. For me, it was a sobering acknowledgment of the obstacles to rational communication and argument even in an emergency or crisis. I understood then that hysterical panics and conspiracy theories would be almost out of control in the age of terrorism. That NATO conference was two years before the age of social media. Facebook did not launch until February 2004. Twitter was launched in July 2006.

As New York Times journalist Kevin Roose wrote in 2018, the advent of social media has accelerated the circulation of conspiracy theories and false narratives. "Conspiratorial thinking has always been with usthe grassy knoll, the moon landing, the Freemasons. But it has been turbocharged as cable news networks and pliant social media networks allow hastily assembled theories to spread to millions in an instant. Often, by the time the official, evidence-based explanation has taken shape, it has already been drowned out by a megaphonic chorus of 
cranks and attention-hungry partisans.... Fact-checking, long offered as a possible antidote to misinformation, is not likely to solve the problem. The available data on the effectiveness of fact-checking, especially on social media, is mixed. Facebook halted a program last year that labeled false news stories with red flags, after finding that the labels actually induced more people to click. The company's current approach is to decrease the visibility of stories labeled false by third-party factcheckers, in hopes of starving them of oxygen". But "unfounded gossip and innuendo are easier than ever to stumble upon and to believe without question. Daytime television and nightly news shows are no longer required for these stories to spread-all you need is Facebook and Twitter" (Roose).

Look at Pizzagate. In fall 2016, online rumors of a child sex-trafficking ring led by Hillary Clinton, in which children were kidnapped and hidden in tunnels underneath a Washington, DC, pizza parlor, incited a North Carolina man named Edgar Welch to drive to Washington and open fire on the restaurant to free them. Echoing the language and content of the satanic ritual abuse panic, the story had spread uncontrollably on social media.

Comet Ping Pong, the family pizza parlor Welch invaded with his assault rifle, is next door to the bookstore where I gave my first book reading twenty-one years ago. Then the people who crowded into the store and tried to snatch the books off the shelves had been recruited by a small group of people making phone calls and sending emails. Now social media messages, organized by faceless groups or bots, do the recruitment work, and recipients are much more likely to be alone and armed.

Rumor panics and conspiracy theories existed centuries ago, but were hard to transmit and stayed locally contained, because communications were so bad. The details of the Salem witch-hunt took months to spread to neighboring towns and states. Even in the 1990s, when I started working on hysterical epidemics, there was time to challenge false stories with accurate information. Today social media make events, lies, and rumors globally available in seconds and controlling them is a mammoth and usually futile task.

In The Pursuit of the Millennium (1957), his classic book about apocalyptic panics in the year 1000, the historian Norman Cohn described the fears that attract followers to paranoid mass movements. "Those who are first attracted will mostly be people who seek a sanction for the emotional needs generated by their own unconscious conflicts.... But these first 
followers, precisely because they are true believers, can endow their new movement with such confidence, energy and ruthlessness that it will attract into its wake vast multitudes of people who are themselves not at all paranoid but simply harassed, hungry or frightened". And if a political leader appears to take advantage of these volatile emotions, followers and believers rapidly find scapegoats to attack and punish. As Cohen warns, when "a paranoiac mass movement captures political power", disaster ensues (Cohn 314).

In Donald Trump, the US elected a president who is the master of conspiracy theories, "false flag" narratives (stories claiming that "powerful groups stage threats and tragic events to advance their agenda"), and imaginary threats of invasion, carnage, and conquest. "We have a president who pushes these ideas because he built a coalition that believes in conspiracy theories", said Joseph Uscinski, an associate professor of political science at the University of Miami who studies conspiracy theories. "He has to continue pushing these ideas to keep his people motivated" (Roose).

In 2002, I stopped writing about the social meaning of hysterical epidemics. That was mainly because I wanted to go back to writing about literature. But it was also because conspiracy theories had become too immense, unstable, and intractable to be addressed through the medium of a book. The hystories spread by social media today have to be fought with social media and by a dangerously besieged free press. But I am grateful to have had the chance to work with the New Hysterians during an extraordinary period at the Wellcome; to have confronted false narratives in print, in person, and on radio and television; to have stood up to threats; and to have taught some students who are now journalists and activists as well as scholars and are finding new ways to investigate hysterical narratives and advocate for truth.

\section{Works Cited}

Cohn, Norman. The Pursuit of the Millennium: Revolutionary Millenarians and Mystical Anarchists of the Middle Ages. Secker and Warburg, 1957.

Folley, Aris. "Florida GOP candidate: I was abducted by aliens but that doesn't define me." The Hill, August 24, 2018.

Jacobs, David M. The Threat: The Secret Alien Agenda. Simon \& Schuster, 1998.

Mack, John. Abduction: Human Encounters with Aliens. Scribner, 1994. 
Porter, Roy. "The Body and the Mind, the Doctor and the Patient: Negotiating Hysteria.” Hysteria Beyond Freud, edited by Sander L Gilman, Helen King, Roy Porter, G.S. Rousseau, and Elaine Showalter. Berkeley and London, University of California Press, 1993, pp. 225-285.

Roose, Kevin. “'False Flag' Theory on Pipe Bombs Zooms From Right Wing

Fringe to Mainstream.” New York Times, October 25, 2018.

Showalter, Elaine. The Female Malady. Pantheon, 1985.

-_. Hystories. Columbia University Press, 1997.

Trillat, Etienne. Histoire de l'hystérie. Seghers, 1986.

Wessely, Simon, and Valery Krasnov, editors. Psychological Responses to the New Terrorism: A NATO-Russia dialogue. IOS Press, 2005.

“Breaking News: ABC Had It Right.” Washington Post, March 29, 2002. 


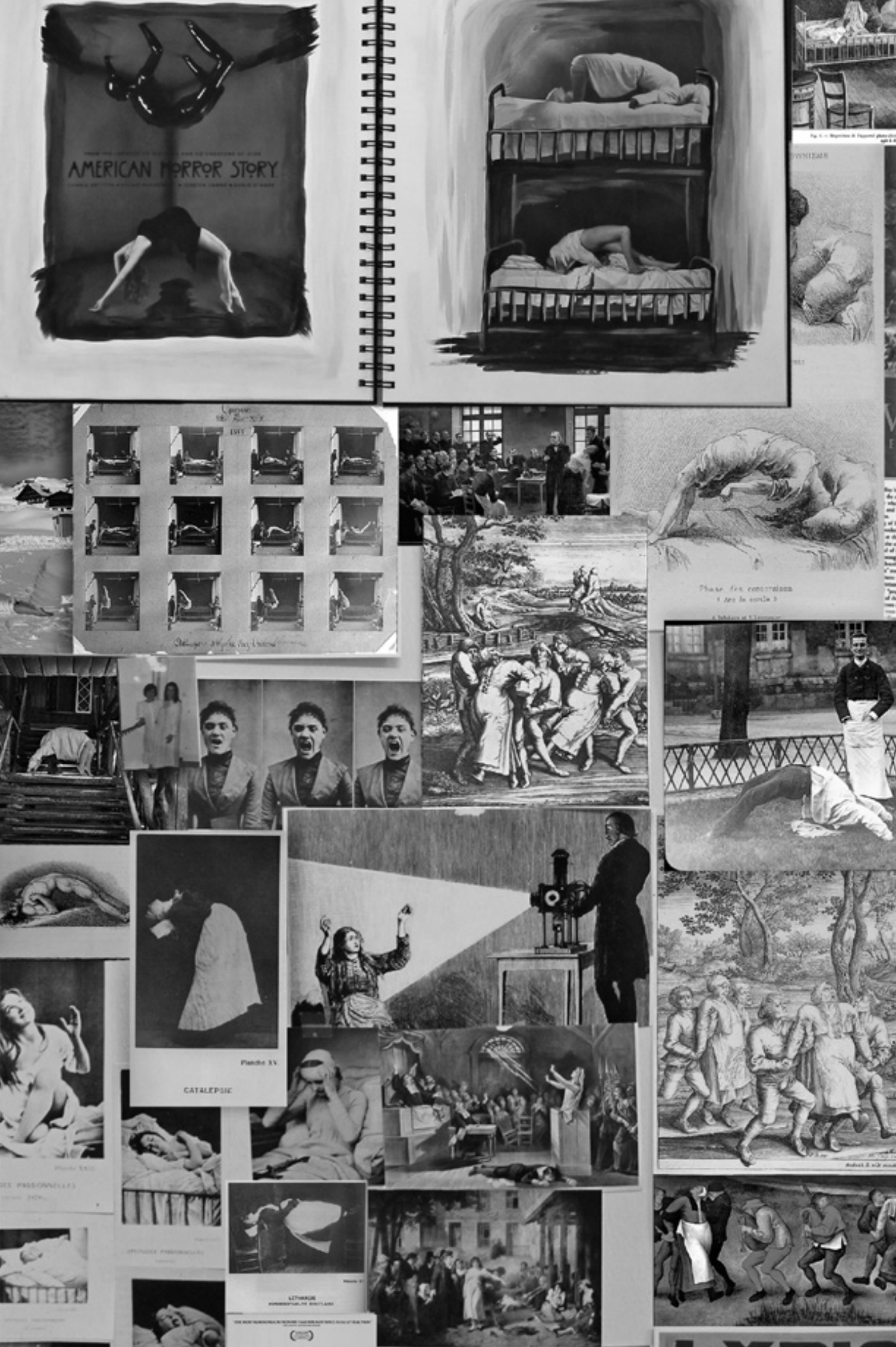

W .
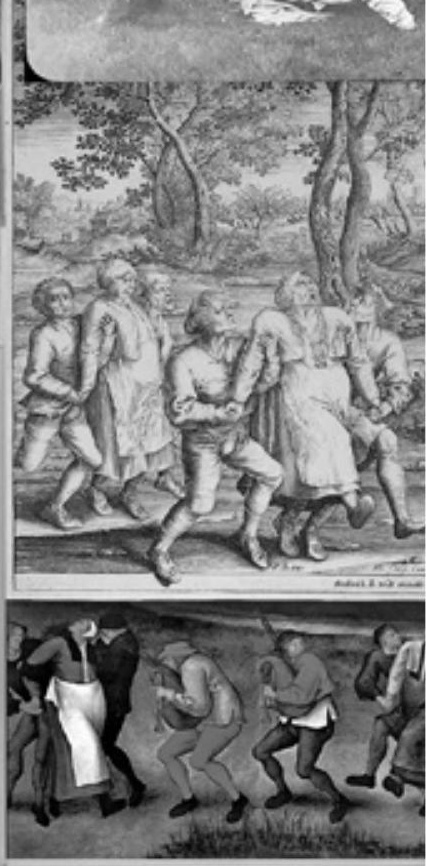



\section{WANDERING}

\section{IMAGINATIONS OF RACE \\ AND HYSTERIA}

\section{The Origins of the Hysterical Body in Psychoanalysis}

Sander L. Gilman

One of the most extraordinary moments in the history of medicine occurs when the young neurologist Sigmund Freud, newly returned from a post-doctoral stay in Paris studying with the preeminent neurologist of the day, Jean Martin Charcot, speaks to the medical establishment in Vienna about the non-gendered nature of hysterical symptoms. Freud's initial presentation of his work on hysteria in Vienna was a paper on male hysteria-not the Jewish male predisposition for hysteria but on the universal male potential for hysteria. Freud's overt argument was evidently (the paper is lost) that men, too, suffer from hysteria as the etiology of the disease was not in the gender of the patient but in the patient's traumatic experiences. It is well known that Freud, in the autobiographical account he wrote of the occasion some forty years after the event, recalled the "bad reception" which this paper on male hysteria had when he presented it before the Viennese Society of Physicians on October 15, 1886. ${ }^{1}$ Freud's powerful memory was that his hearers thought that what he "said was incredible.... One of them, an old surgeon, actually broke out with the exclamation: 'But, my dear sir, how can you talk such nonsense? 'Hysteron' [sic] means the uterus. So how can a man be hysterical?"'2 Freud's angry memory was aimed at the narrow-minded claim of this old man, representing the Viennese medical establishment, that it, and it alone, had command of Greek. Here the Jewish psychoanalyst placed his claim to control a discourse of 
academic culture. Freud's memory was certainly shaped by the hostile reception which psychoanalysis had gotten in the four decades following his talk. Psychoanalysis was seen as a Jewish pseudo-science and as a form of mass hysteria, a "psychic epidemic among physicians". ${ }^{3}$ Freud laughs at the "old surgeon" who claims to understand culture but whose very inability to command its language disqualifies him from it.

It was the young, French-trained Freud who knew that the concept of hysteria was tied to universals (which, at that point, he thought of as having their origin in trauma) and was not merely a reflex of the biological uniqueness of a sub-group. It was hysteria (the hallmark of the new science) that Freud wished to rescue from the crabbed claws of a Viennese medical establishment which could not even get its Greek correct, for "hustera" is the correct form of the Greek noun for uterus. Thus the young Jew (and Freud understood himself from his exposure to the virulent "scientific" anti-Semitism of the Viennese University as a Jew) showed his command over not only the language of science (represented by Charcot's discourse on hysteria) but also the language of culture (Greek). Freud's sense, like that of his contemporaries, was that hysteria did not manifest itself as a disease of the "womb" but of the imagination. It was a functional illness resulting from trauma, rather than the result of inheritance, as he had shown in his paper on heredity and inheritance. And with the claim that male hysteria existed, he attempted to free the other group targeted, women, from their special risk. This did not absolve the female from being the group most at risk, however, for the idea of a pathological human imagination structurally replaced the image of the floating womb as the central etiology of hysteria. And women's imagination was understood by the physicians of the time, such as Paul Julius Möbius, as diseased (Möbius). What was removed from the category of hysteria as Freud brought it back to Vienna was its insistence on another group, the Jews, as the group which essentially replaced the woman as at risk.

In the actual contemporary record of the discussion following Freud's paper, attributed to the young Austrian-Jewish physician-writer Arthur Schnitzler, there is a further complication. ${ }^{4}$ Not only is there no mention of the impossibility of male hysteria, but Theodor Meynert as well as Moritz Rosenthal claim that, while less frequent than female hysteria, cases were well documented in the various Viennese hospitals as well as in the German medical literature. Heinrich von Bamberger, who was 
in the chair at the meeting, commented further that while he certainly had seen cases of male hysteria, he was troubled by Freud's claim that his case was only the result of trauma. Indeed, he notes, the very case Freud cites, "shows a hereditary predisposition" for the disease. It is not trauma, which is the result of accident, but heredity, which cannot be altered, that is the source of male hysteria, according to Bamberger. Thus within the very concept of hysteria as Freud elaborated it, the question of the hysteric's heredity and predisposition was hotly contested.

The impact of such fantasies of the biological nature of the Jew, the Jew's body, his psyche, his soul, on the development of psychoanalysis is clear. The special nature of the Jew, the diseases and sociopathic acts ascribed to it, are a universal in the general culture of the nineteenth century. It is of no surprise that the Jew is seen in terms of this dominant paradigm of the late nineteenth century as this age saw the biologization of all arenas of culture. We find Jewish biological and medical scientists of the late nineteenth century forced to deal with what is for them the unstated central epistemological problem of late nineteenth-century biological science: it is how one can be the potential subject of a scientific study at the same time that one has the role of the observer; how one could be the potential patient at the same moment one was supposed to be the physician. This was especially a problem in Vienna, where the domination of the so-called "second Viennese" school stressed the central role of the physician as scientist and the independent, neutral role of the physician-scientist as diagnostician. It is the striving of the neutral, the universal, for the over-arching explanation which provides the rationale for the scientist-physician's gaze in the world of Viennese academic medicine.

And that science saw the Jew as the sufferer from hysteria. Maurice Fishberg's The Jews: A Study of Race and Environment (1911) states the case boldly: "The Jews, as is well known to every physician, are notorious sufferers of the functional disorders of the nervous system. Their nervous organization is constantly under strain, and the least injury will disturb its smooth workings". ${ }^{5}$ The origin of this predisposition is neither consanguineous marriage ("the modern view... [is that they] are not at all detrimental to the health of the offspring") nor the occupations of the Jew ("hysteria [is]... met with in the poorer classes of Jews... as well as in the richer classes") ("Nervous Diseases" 225). It is the result of the urban concentration of the Jews and "the repeated 
persecutions and abuses to which the Jews were subjected during the two thousand years of the Diaspora" ("Nervous Diseases" 225). These influences, found at the fin de siècle primarily among Eastern Jews, according to Fishberg show the predisposition of these specific groups of Jews to illnesses such as hysteria: "Organic as well as functional derangements of the nervous system are transmitted hereditarily from one generation to another" ("Nervous Diseases" 225). It is not all Jews who are hysterics, but Eastern Jews, and primarily Eastern male Jews, according to Fishberg: "The Jewish population of [Warsaw] alone is almost exclusively the inexhaustible source for the supply of specimens of hysterical humanity, particularly the hysteria in the male, for all the clinics of Europe" (The Jews 324-25). Here the American Jew Fishberg misquotes the French psychiatrist Fulgence Raymond, who had stated that Jews of Warsaw formed a major sector of the mentally ill of that city. ${ }^{6}$ It is Fishberg's misquote of Raymond which becomes the standard view in German psychiatry (as quoted, for example, in Hoppe 26). It appears within Freud's circle when Isidor Sadger noted at the November 11, 1908 meeting of the Vienna Psychoanalytic Society: "In certain races (Russian and Polish Jews), almost every man is hysterical". ${ }^{7}$ It is the male Jew from the East, from the provinces, who is most at risk from hysteria. This view had been espoused by Charcot, who diagnosed on February 19, 1889 the case of a Hungarian Jew named Klein, "a true child of Ahasverus", as a case of male hysteria. Klein had a hysterical contracture of the hand and an extended numbness of the right arm and leg. It is the limping of the Jew which Charcot stressed. Klein "wandered sick and limping on foot to Paris" where he arrived on December 11, 1888. He appeared at the Salpêtrière the next day, "his feet so bloody that he could not leave his bed for many days". Klein "limped at the very beginning of his illness". Charcot reminded his listeners that the patient "is a Jew and that he has already revealed his pathological drives by his wanderings". His "travel-mania" could be seen in the fact that "as soon as he was on his feet again, he wanted to go to Brazil". ${ }^{8}$ Wandering and limping mark the hysterical Jew as diseased, and diseased because of intermarriage. This theme is elaborated in the work of Charcot's last major student, Henry Meige, who writes his dissertation on these "wandering Jews", seeing them as the contemporary incarnation of the legendary Wandering Jew. In his thesis he reproduces their portraits so that one can study their physiognomy for the signs of their hysteria. ${ }^{9}$ 
The hysteria of the male Jew, especially the Eastern Jew, remains a truism of medical science through the decades. Prof. Hermann Strauss of the Jewish Hospital in Berlin, in one of the most cited studies of the pathology of the Jews, provides a bar chart representing the risk of the Jews getting hysteria (Strauss 33-39; chart on 35). Here the relationship between men and women indicates that male Jews suffer twice as often from hysteria than do male non-Jews. The standard textbooks of the period reflect this view. While it is clear that women still are the predominant sufferers from the disease, it is evident from the visual representation of the cases of hysteria that there is a clear "feminization" of the male Jew in the context of the occurrence of hysteria. This view is paralleled by the findings in the United States that "in European races, melancholic or depressive types of mental disorder are most frequent amongst the Germanic and Scandinavian peoples" (Bannister/Hektoen 464).

The liberal-Jewish neurologist, Moriz Benedikt, Professor of Neurology at the University of Vienna at the fin de siècle, also linked the "American" quality of life with the appearance of hysteria, a disease which is accepted by him as "a uniquely feminine nervous disease"-in men. (Die Seelenkunde des Menschen als reine Erfahrungswissenschaft 18687; 223-26; It is remarkable that only Jewish physicians in Vienna dealt with the question of male hysteria before and including Freud.) It is the struggle for life in the city which causes the madness of the male Jew. According to Cecil F. Beadles: "Mental anxiety and worry are the most frequent causes of mental breakdown. They are all excitable and live excitable lives, being constantly under the high pressure of business in town" (736). The reason for this inability to cope with the stresses of modern life lies in "hereditary influences," i.e., in their being Jews. ${ }^{10}$ And their "Jewishness" is a sign of their being out of their correct space. For they are ill, "like many orientals (e. g., Mohammedans) who have a disposition to hysteria" (Weygandt 32).

Benedickt needs to argue against the equation of race and madness (Benedikt "The Insane Jew. An Open Letter to Dr. C. F. Beadles"). For the "insanity of the Jew" is one of the risks which all Jews would have to face. In a detailed answer to Beadles, he presents a convoluted and complex argument about the special status of the nervousness of the Jew. He accepts the reality of Beadle's charge. It is not, however, a quality over which "evolution has no power ... [and] which is deeply rooted in the organism". Benedickt counters this by arguing against the 
uniformity of the Jews as a race and sees the origin of the mental illness of the Jews in the external social pressures "in times of exile, dispersion, and persecution". The Jews are not really even a nation, for "the first condition necessary for a nation is a common language". "Other nations could find an outlet for their passions and emotions in outward actions; the Jews found an outlet for them usually at the expense of health, and so became more and more neurotic". This neurosis resulted in "excessive sexual intercourse, intra matrimonium" and caused the "hysterical aphonia, in endemic form,... [which] are very frequent in Jews, male and female". This has caused "neurologists all over the world [to be] interested in the number, intensity, and variety of cases seen amongst the Jews". The lost language of the Jews, the inability to speak any tongue flawlessly, marks the Jews as ill. But what does Benedikt see as the cause of the madness of the Jews. Their "ill-treatment and cruelty to...which they have been subjected". This even explains to him why Jews, who have a lower incidence of "syphilis and drunkenness", also have a higher rate of general paralysis. For it is therefore clear that syphilis cannot be the cause of the general paralysis of the insane, luetic tabes. Rather it is the result of social factors. With acculturation new nervous diseases afflict the Jews. Jewish women, "formerly pampered neurotic individuals," now became "eccentric.... Very many of them became, by reason of superficial learning, actually perverse". "They quickly entered into the modern economic contest with all its fatal consequences as regards nervous integrity". Benedikt's model, as is clear from all of his examples, is the Eastern Jew, hampered by his ghetto experience. ${ }^{11}$ And it is Yiddish which for Benedikt is the marker of Jewish mental illness. The "so-called" language, Yiddish, with its coarse gestures, seems to have a magical quality which seems to prevent the acculturation of the Eastern Jews and which prolongs their risk of mental illnesses. Indeed, Theodor Reik pointed out that Eastern Jews communicated as much with "gestures and ...facial expressions, the rise and fall of the voice of the story-teller" as with words (Reik 33-34).

Sigmund Freud struggles with this notion of predisposition in his pivotal paper on "Heredity and the Etiology of the Neuroses", first written and published in French in 1896. In it he attempted to dislodge this understanding of a social trauma as the origin of hysteria. This paper marked his break with Jean Martin Charcot (who had died three years earlier) and Charcot's view that hysteria was an inherited phenomenon. Freud dismissed the primacy of the inherited disposition for hysteria 
(such as attributed by Charcot to the Jews). He stressed the deference between a "similar heredity" which always produces the same diseases with the same signs and symptoms (such as Huntington's chorea) and those diseases with a "dissimilar heredity", which produce seemingly unrelated illness with a myriad of signs and symptoms (Freud, referred as SE, here 3: 145). For the latter sources other than inheritance must be sought. In his search for the etiology of such psychopathologies, Freud further distinguished between "preconditions" (i.e., heredity) and "specific causes" of a disease. Both are necessary to create similar disease profiles, while the more general "concurrent causes" are sufficient but not necessary. Freud employed the model of the continuum which he employed in his model of "bisexuality"-he sees "preconditions" and "specific causes" on a spectrum; as one decreases in importance, the other increases. It is the totality which produces the illness, just as the individual may be more or less male or female, the totality making up the entire personality structure.

Freud dismissed as marginal all of those "concurrent causes" which had been used to explain the existence of neurosis (in Jews as well as others): "emotional disturbance, physical exhaustion, acute illness, intoxications, traumatic accidents, intellectual overwork, etc.” (SE 3: 148). Thus he also rejected the claim that psychopathologies such as neurasthenia are the "fruits of our modern civilization". He found the roots of these neuroses in early sexual experience: "these functional pathological modifications have as their common source the subject's sexual life, whether they lie in a disorder of his contemporary sexual life or in important events in his past life" (SE 3: 149). Freud makes these "sexual disorders" the primary cause of neuroses; heredity is a peripheral cause.

Freud proposes two sets of differential diagnoses: He distinguished between neurasthenia, the product of masturbation or "a sexual constitution analogous to what is brought about in a neurasthenic as a result of masturbation", and anxiety neurosis, the result of "abstinence, unconsummated genital excitation ..., coition which is imperfect or interrupted..., sexual efforts which exceed the subject's psychical capacity, etc.” (SE 3: 150-51). He also differentiated between hysteria and obsessional neurosis: the former caused by "some event of the subject's sexual life appropriate for the production of a distressing emotion"; the latter caused by such "an event which has given pleasure" (SE 3: 155). The pleasure in the sexual act is different for the male and for the female: for the male pleasure is the result of the aggressive desire 
of experienced sexuality; for the female, the enjoyment generated by the sexual act.

Both hysteria and obsessional neurosis are caused by real events, remembered physical contact with the child's genitalia. Hysteria is the result of "passive sexuality, an experience submitted to with indifference or with a small degree of annoyance or fright" (SE 3: 155). This event is real to the sufferer, not as an event in the past, but "...as though it were a contemporary event" (SE 3: 154). The living of a life in the present which has been marked in the past (either past of the individual or the group) by trauma is the basic explanatory model for the present state of the difference of the Jews. Thus, Freud concludes, what appears to be hereditary in the acute symptoms of patients, such as the occurrence of "a pair of neurotic patients" in the same family, proves to be a "pair of little lovers in their earliest childhood-the man suffering from obsessions and the woman from hysteria. If they are brother and sister, one might mistake for a result of nervous heredity what is in fact the consequence of precocious experience" (SE 3: 156). Here Freud has gendered the differential diagnosis - the female is passive or frightened; the male feels pleasure.

Yet Freud's dismissal of heredity as the cause of the neurosis provides a rationale for restructuring the concept of trauma, removing it from the world of daily life and centering it in the world of the sexual. Jews no longer will suffer from such symptoms of neurasthenia as "flatulent dyspepsia, constipation, or sexual weakness" (SE 3: 150; to list only a few of the traditional "Jewish" symptoms which appear on Freud's list of neurasthenic symptoms) purely because of their heredity, but because of sexual practices, such as masturbation, which are universal rather than particularistically Jewish. By moving hysteria to the realm of the incestuous, Freud eliminates the trauma of circumcision, the most evident "precocious experience of sexual relations with actual excitement of the genitals, resulting from sexual abuse committed by another person" from the etiology of neurosis (SE 3: 152). Circumcision is clearly understood as "frightening" within much of the medical literature opposed to it and within the complicated literature on metsitsah during the fin de siècle. Incest, especially brother-sister incest, is yet another charge brought regularly against the Jews as the etiology for specific forms of somatic and mental illnesses. But it is the removal of circumcision from the category of the causative factors for mental illness by dismissing the 
arguments about the heredity of mental illness (or its disposition) and the stress on the specific nature of sexual trauma, as opposed to other traumatic factors, which lies at the heart of Freud's final dismissal of Charcot and Charcot's model of hysteria. Freud's view was clearly a minority voice, as C. H. Hughes noted about Freud's paper on the "Etiology of Hysteria" (1896): "Hysteria, whatever its exciting causes, whether in the premature or over sexual, grief, disappointment or other psychoneural sources of depression and exhausting excitation, is usually bad neuropathic endowment, dormant at birth but ready-prepared like the lucifer match-for flame when rightly struck. Herr Sigmond [sic] Freud should try again" (cited from Kiell 36).

And he does try again. In 1897 Freud abandoned his trauma theory of neurosis. He realized that it was not the specific experiences of a select (but extensive) group of individuals whom Freud was treating, but rather a reflex of human development which he was seeing. He was observing the results of the fantasy of maltreatment rather than maltreatment itself. Freud separated these two moments though continuing to see a linkage between the empirical and fantasy in his own empirical studies on fantasy. Freud simultaneously elides and displaces the distinction between real events and fantasy. Freud's position was that of the racial biologist who saw the factors of Jewish identity as signs of the racial nature of the Jews. It is unimportant whether these qualities are understood as "inherited" (i.e., congenital) or "acquired" (but now an aspect of the genotype). Through this mechanism Freud hopes to free Jews, such as himself and his father, from the charge of being diseased, of lying, of being corrupt and corrupting.

In 1895, Freud evolved a four-fold formula to describe the origin of neurosis, based on Aristotle's four-fold analysis of causality. Needed was 1) a precondition 2) specific cause 3) concurrent cause and 4) precipitating cause (SE 3: 135-36). The precondition was the existing disposition to disease, a disposition either acquired or innate. The specific causes, such as the seduction of the child, led to the specific symptom formation, like the "globus hystericus". The "concurrent causes", such as overwork or exhaustion, are seen as less important but as having a contributory role in the appearance of the neurosis. The actual precipitating cause was simply the final trigger which occurred before the symptoms became evident. 
This model was certainly sufficient to explain the mental illnesses of the Jews. The precondition was either the inheritance of the Jews or precipitating diseases such as syphilis; the specific cause the "2000 years of oppression", the concurrent cause the "overwork" and "stresses of civilization", and whatever individual precipitating cause could be found in each individual case.

But Freud needed to discount the role of degeneracy, of "pathogenic heredity", as it "left no room for the acquisition of nervous disease" (SE 3: 23). It also meant that all Jews, including Sigmund Freud, were at risk of specific forms of mental illness. His answer was to see the inheritance of trauma, following a Lamarckian model, as the source of disease, rather than some vague "Jewish predisposition to mental illness". What was originally sufficient (the specific cause) became necessary in Freud's revision of the etiology of neurosis. Trauma becomes the cause of neurosis.

Once "real" seduction is abandoned as the source of hysteria, and the source of neurosis is seen as lying in the fantasy of the Oedipal struggle, then the reality of this model is drawn into question. In order to universalize the Jewish physical predisposition to illness, Freud evolved his own theory of the relationship between constitution and neurosis. He developed the law of the etiological complemental series, the idea that constitution and trauma complement one another: the weaker the constitution, the less the trauma needed to create a neurosis. Seeking after the meaning of trauma, Freud restructured his presentation of the etiology of neurosis. In the Introductory Lectures on Psycho-Analysis (191617), Freud stressed the etiological significance of 1) hereditary (and primal) dispositions 2) infantile impressions and 3) adult experiences (SE 16: 362). It is in the clinical significance of phylogeny as a universal source of the predisposition to neurosis that Freud remains adamant. "Real" trauma lies in the universal past of all human beings, not solely in the Jewish experience in the Diaspora. ${ }^{12}$ Here degeneracy is abandoned and the inheritance of acquired characteristics becomes a means of moving the Jews into the mainstream of the neurosis.

On December 5, 1906, this topic came up for discussion at the Viennese Psychoanalytic Society following a paper on Wilhelm Stekel's theory of the origin of nervousness. Isidor Sadger commented "on the widespread occurrence of nervousness (especially obsessional neurosis and hysteria) 
among the Polish Jews" (Protokolle der Wiener Psychoanalytischen Vereinigung, op. cit., 1: 70; translation from Minutes of the Vienna Psychoanalytic Society, op. cit., 1: 73).

The cause of this is the "Jew's addiction to rumination... [which] has been characteristic of the for thousands of years". It is the inheritance of specific forms of a "common mental construction" which lies at the heart of the Jew's predisposition to mental illness (Protokolle 1: 93; translation from Minutes 1: 98). The view that the Eastern Jew was essentially at risk of hysteria permeated even the discussion of this circle of mainly Eastern European Jews, transplanted to Vienna. They saw, not themselves at risk, but "those" Eastern Jews, an abstraction which they distanced from their own persona.

In Charcot's clinic there was an often-stated assumption that Jews, especially Jews from the East, were at great risk of mental illness (see Goldstein). This view was shared in the general culture of the time. Following the collapse of the Catholic Union Generale Bank in 1882 there was a great rise in public anti-Semitism. In the spring of 1886, as a result of Eduoard Drumont's best seller, La France juive, appeared perhaps the most important French anti-Semitic tractate. Drumont cited psychological statistics to show that Jews, especially Jews from the East, were most at risk of mental illness and, therefore, presented a social danger to the French body politic. And he cited statements made by Charcot "in his lectures in the Salpêtrière" quite directly. ${ }^{13}$

No wonder that Jewish scientists such as Jacobs, Fishberg, and Freudin very different ways - sought to find the hysteric outside of their own immutable self-image. For that image was within the biology of race. This consistency of character, with its deviant sexual nature, leads to the disease which marks the Jew-hysteria. The etiology of the Jew's hysteria, like the hysteria of the woman, was to be sought in "sexual excess" (Beadles 732). Specifically in the "incestuous" inbreeding of this endogenous group: "Being very neurotic, consanguineous marriages among Jews cannot but be detrimental to the progeny" (Fishberg 349). And the converse is also true: "The excessive tendency to the neuroses [among] ...the Jews, [results] from their mode of life and consanguineous marriages through long centuries". ${ }^{14}$ Jews (especially male Jews) are sexually different; they are hysterical and their gaze reveals it. 
Race is but one category in the visualization of the hysteric which played a role in shaping the image of the hysteric during the nineteenth century. For the construction of seeing the hysteric took many different forms in providing a composite image of the hysteric, an image in bits and snatches, an image which revealed the "truth" about the hysteric's difference from him- or herself.

In the course of the 1890 s Freud abandoned much of the work of the anti-Semitic Charcot ${ }^{15}$-for whom Jews, as the essential "moderns", were at special risk as hysterics-and entered his new alliance with the provincial Jew Hippolyte Bernheim (Morgan 268-72). Much of this is worked out in Freud's French-language paper on the meaning of heredity for the etiology of hysteria (1896). Such a movement is paralleled to the abandonment of ideas of trauma-still for Charcot the cause of hysteria (in women as well as in Jews) and its replacement with the etiology of hysteria in the psyche. As Freud states:

For [the physician] will be able to convince himself of the correctness of the assertions of the school of Nancy [Bernheim] at any time on his patients, whereas he is scarcely likely to find himself in a position to confirm from his own observation the phenomena described by Charcot as "major hypnotism," which seem only to occur in a few sufferers from grande hysterie (SE 1: 98).

It is the scientific "observation", the gaze of the Jew rather than the gaze directed at the Jew, which marks the distinction between Bernheim and Charcot. Freud's "conversion” to Bernheim's mode of seeing the "usual" rather than seeing the "unique" also marks the beginning of his rejection of reducing the origin of hysteria to the single, traumatic event.

But what does "trauma" mean? One meaning relates it to the debate about congenital circumcision and the inheritance of acquired characteristics. To trace the meaning of trauma means seeing the reason the Eastern European Jew appears as an hysteric (or, perhaps more accurately, the provincial Jew as parvenu, out of his mind because he is out of his natural place). It is the discourse on the relationship between "trauma" and "hysteria" which provides the key to Freud'sand many of his contemporaries'-ambivalence concerning models for therapy. 
All human beings become inventors of their own past. All trauma is part of the universal experience of growth and development. The Jews' rationale that their illness is the result of two thousand years of persecution becomes no more important than any other claims of trauma. It ends the inheritance of the acquired trauma of Jewish experience and makes it part of the origin of that which makes all human beings human. In the famous letter of September 21, 1897 Freud admitted to Fliess "I no longer believe in my neurotica...." (Masson 26466 ; hereafter Freud-Fliess). For believing in the reality of trauma would mean "...in all cases, the father, not excluding my own, had to be accused of being perverse". Freud abandoned a system which demands mimetic, psychic representation of reality for one which sees the psyche as the place for the play of fantasy. He abandoned the act of seeing difference. And yet he clearly never abandoned the status of science associated with that manner of seeing. For as much as Freud was aware of the problems of positivistic epistemology, the status of the scientific gaze overcame his sense of its limitations.

\section{Notes}

1 This is the "myth" which Frank Sulloway, Freud: Biologist of the Mind (New York; Basic, 1979), p. 592 wishes to identify as "Myth One," the primal myth, in Freud's falsification of his own history. It is clear that this (and the other "myths") are fascinating insights into Freud's understanding of his own career and provide the material for interpretation, not censure.

2 Freud, Sigmund. Standard Edition of the Complete Psychological Works of Sigmund Freud, edited and translated by J. Strachey, A. Freud, A. Strachey, and A. Tyson, 24 vols. Hogarth, 1955-1974, referred to as SE, here 20: 15. On the background and meaning of male hysteria, see Mark Micale, "Charcot and the Idea of Hysteria in the Male: Gender, Mental Science, and Medical Diagnosis in late Nineteenth-Century France.” Medical History, vol. 34, 1990, pp. 363-411. Micale does not link the question of the gender specificity of hysteria to that of race.

3 See the comments by the neurologists Theodor Sommers and Alfred Hoche quoted in the Psychiatrisch-Neurologische Wochenschrift, vol. 12, 1910, p. 128.

4 Schnitzler, Arthur. Medizinische Schriften, edited by Horst Thomé. Vienna: Paul Zsolnay, 1988, pp. 75-80. There are other accounts of this talk which supplement this report, see Sulloway, p. 38. 
5 Fishberg, Maurice. The Jews: A Study of Race and Environment, New York: Walter Scott, 1911, p. 6. Compare his statement in The Jewish Encyclopedia,12 volumes. New York: Funk and Wagnalls, 1904, "Nervous Diseases," 9: 22527, here, p. 225: "Some physicians of large experience among Jews have even gone so far as to state that most of them are neurasthenic and hysterical."

6 "La population israélite fournit à elle seule presque tout le contingent des hystériques mâles," Fulgence Raymond, L'Étude des Maladies du Système Nerveux en Russie, Paris: O. Doin, 1889, p. 71.

7 Protokolle der Wiener Psychoanalytischen Vereinigung, op. cit., 2: 40; translation from Minutes of the Vienna Psychoanalytic Society, op. cit., 2: 44.

8 Charcot, J. M. Leçons du Mardi a la Salpêtrière, op. cit., 2: 347-53; see the translation of the Poliklinische Vorträge, op. cit., 2: 299-304.

9 Meige, Henry. Étude sur certains néuropathes voyageurs: Le juif-errant à la Salpêtrière. Paris: L. Battaille et cie., 1893. On Meige and this text, see Jan Goldstein, "The Wandering Jew and the Problem of Psychiatric Antisemitism in Fin-de-Siècle France," Journal of Contemporary History, vol. 20, 1985, pp. 521-52. See the images and the discussion in Sander L. Gilman, The Jew's Body. Routledge, 1991, pp. 60-103.

10 Hyde, Frank G. "Notes on the Hebrew Insane." American Journal of Insanity, vol. 58, 1901-1902, p. 470. On the statistical background to the shift between the primarily German-Jewish population and the huge influx of Eastern European Jews into the United States, see John S. Billings, Vital Statistics of the Jews in the United States. Census Bulletin, No. 19, December 30, 1890 , pp. 23. This is based on a questionaire sent to 15,000 and responses received from 10,618 Jewish families (60,630 persons), whose names had been obtained from "rabbis and presidents of congregations." This study showed that 227 Jews (116 men; 111 women) had died of "diseases of the nervous system" (including mental diseases: 18 men; 17 women) between 1885-89. The "Jews have suffered a relatively greater loss than their neighbors by deaths from ... disease of the nervous system... than the other peoples with whom they are compared" (p. 15). This report was condensed and published in a "popular" version as "Vital Statistics of the Jews." North American Review, vol. 153, 1891, pp. 70-84.

11 Benedikt, Moritz. “Der geisteskranke Jude.” Nord und Süd, vol. 167, 1918, pp. 266-70. This is also a detailed attack on Rafael Becker's Zionist explanation of the mental illness of the Jews.

12 On the discussion of Jewish experience after the Shoah and the reintroduction of the question of trauma, see Shoshana Felman and Dori Laub, Testimony: Crises of Witnessing in Literature, Psychoanalysis, and History, Routledge, 1992. 
13 Drumont, Eduoard. La France juive: Essai d'histoire contemporaine, 2 vols. Paris: C. Marpon et E. Flammarion, 1886, 1: 105-106. On the complicated issue of the structure this argument and the Jewish response in the Germanspeaking lands, see Gilman, Difference and Pathology, op. cit., pp. 150-62.

14 J. Mitchell Clarke, "Hysteria and Neurasthenia." Brain, vol. 17, 1894, pp. 118-78, here, p. 150. Freud cites this volume in SE 3: 74.

15 See the discussion in my Difference and Pathology, op.cit., pp. 150-162. See also Yves Chevalier, "Freud et l'antisemitisme - jalousie." Amitié judéochretienne de France, vol. 37, 1985, pp. 45-50.

\section{Works Cited}

Bannister, H. M., and Ludwig Hektoen, "Race and Insanity." American Journal of Insanity, vol. 44, 1888, pp. 456-70.

Beadles, Cecil F. “The Insane Jew.” Journal of Mental Science, vol. 46, 1900, p. 736.

Benedikt, Moriz. Die Seelenkunde des Menschen als reine Erfahrungswissenschaft. Leipzig: O. R. Reisland, 1895.

- - "The Insane Jew. An Open Letter to Dr. C. F. Beadles." The Journal of Mental Science, vol. 47, 1901, pp. 503-9.

——. "Der geisteskranke Jude.” Nord und Süd, vol. 167, 1918, pp. 266-70.

Billings, John S. Vital Statistics of the Jews in the United States. Census Bulletin, No. 19, 30. Dec. 1890, pp. 23.

Charcot, J. M. Leçons du Mardi a la Salpêtrière; see the translation of the Poliklinische Vorträge, 2: 299-304.

Chevalier, Yves. "Freud et l'antisemitisme - jalousie." Amitié judéo-chretienne de France, vol. 37, 1985, pp. 45-50.

Clarke, J. Mitchell. “Hysteria and Neurasthenia.” Brain, vol. 17, 1894, pp. 118-78.

Drumont, Eduoard. La France juive: Essai d'histoire contemporaine, 2 vols. Paris:

C. Marpon et E. Flammarion, 1886.

Felman, Shoshana, and Dori Laub, Testimony: Crises of Witnessing in Literature, Psychoanalysis, and History, Routledge, 1992.

Fishberg, Maurice. The Jews: A Study of Race and Environment, New York: Walter Scott, 1911.

-—. "Nervous Diseases." The Jewish Encyclopedia, 12 volumes. New York: Funk and Wagnalls, 1904, 9: 225-27. 
Freud, Sigmund. Standard Edition of the Complete Psychological Works of Sigmund Freud, edited and translated by J. Strachey, A. Freud, A. Strachey, and A. Tyson, 24 vols. London: Hogarth, 1955-1974.

Gilman, Sander L. Difference and Pathology: Stereotypes of Sexuality, Race, and Madness. Cornell University Press, 1985.

- _. The Jew's Body. Routledge, 1991.

Goldstein, Jan. Console and Classify: the French Psychiatric Profession in the Nineteenth Century, Cambridge University Press, 1987.

- - "The Wandering Jew and the Problem of Psychiatric Anti-semitism in Fin-de-Siècle France.” Journal of Contemporary History, vol. 20, 1985, pp. 521-52.

Hoppe, Hugo. Krankheiten und Sterblichkeit bei Juden und Nichtjuden. Berlin: S. Calvary \& Co., 1903.

Hyde, Frank G. "Notes on the Hebrew Insane." American Journal of Insanity, vol. 58, 1901-1902, p. 470.

Kiell, Norman, editor. Freud without Hindsight: Reviews of His Works (1893-1939), International Universities Press, 1988.

Masson, Jeffrey Moussaieff, editor. The Complete Letters of Sigmund Freud to Wilhelm Fliess, 1887-1904, Harvard University Press, 1985.

Meige, Henry. Étude sur certains néuropathes voyageurs: Le juif-errant à la Salpêtrière. Paris: L. Battaille et cie., 1893.

Micale, Mark. "Charcot and the Idea of Hysteria in the Male: Gender, Mental Science, and Medical Diagnosis in late Nineteenth-Century France.” Medical History, vol. 34, 1990, pp. 363-411.

Möbius, P. J. Über den physiologischen Schwachsinn des Weibes, Halle: Marhold, 1901. the eighth edition of this appeared in 1908.

Morgan, Wesley G. "Freud's Lithograph of Charcot: A Historical Note." Bulletin of the History of Medicine, vol. 63, 1989, pp. 268-72.

Raymond, Fulgence. L'Étude des Maladies du Système Nerveux en Russie, Paris: O. Doin, 1889.

Reik, Theodor. Jewish Wit, Gamut Press, 1962.

Schnitzler, Arthur. Medizinische Schriften, edited by Horst Thomé. Paul Zsolnay, 1988.

Strauss, Hermann. "Erkrankungen durch Alkohol und Syphilis bei den

Juden.” Zeitschrift für Demographie und Statistik der Juden. vol. 4 N.F., 1927, pp. 33-39.

Sulloway, Frank. Freud: Biologist of the Mind. Basic, 1979.

Weygandt, Wilhelm. Atlas und Grundriss der Psychiatrie, München: J. F. Lehmann, 1902. 
Wiener Psychoanalytische Vereinigung. Protokolle der Wiener Psychoanalytischen Vereinigung, edited by Herman Nunberg and Ernst Federn. 4 vols. Fischer, 1976-1991; translation from Minutes of the Vienna Psychoanalytic Society, translated by M. Nunberg, 4 vols. International Universities Press, 1962-75. 


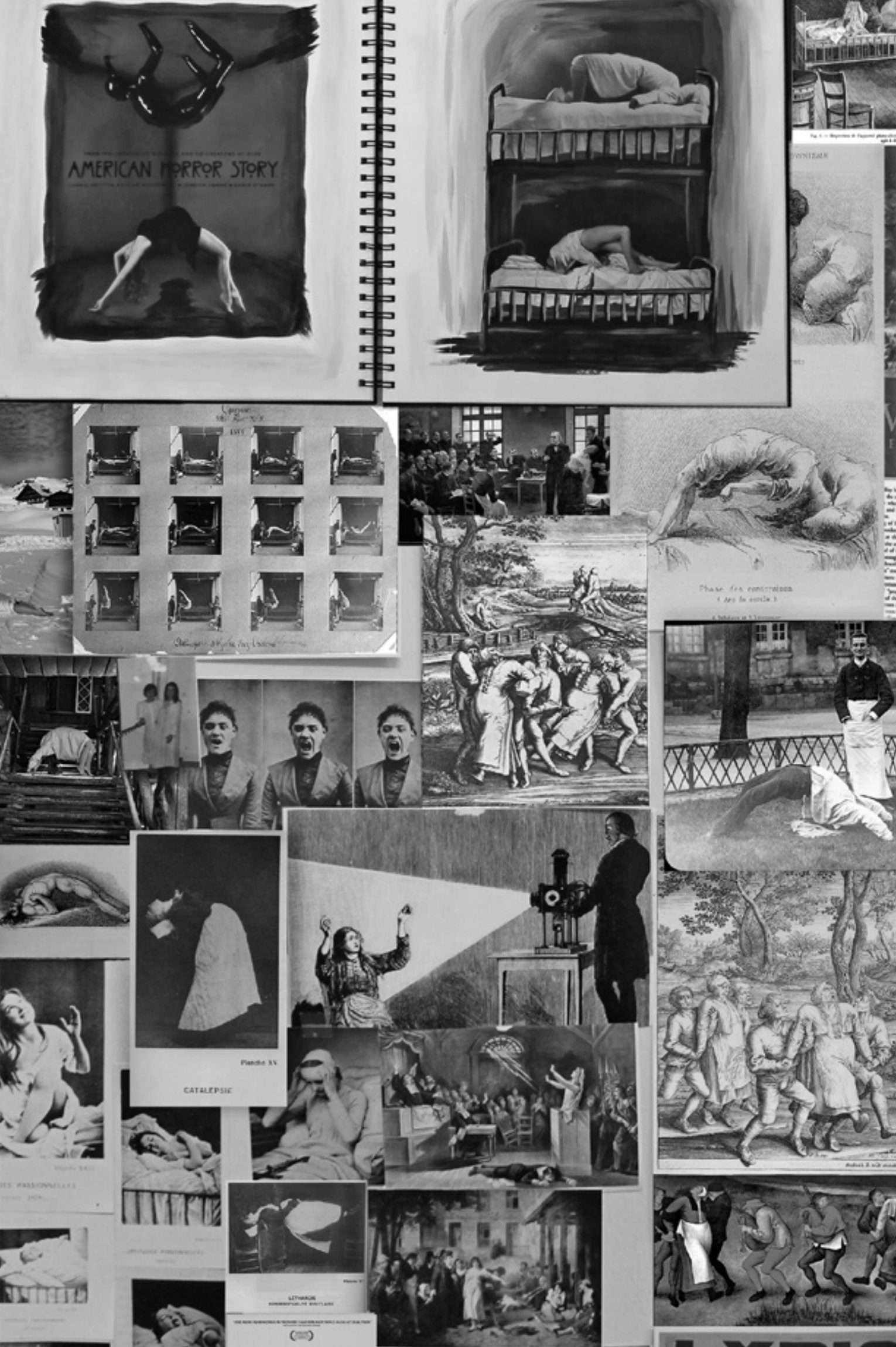

W .
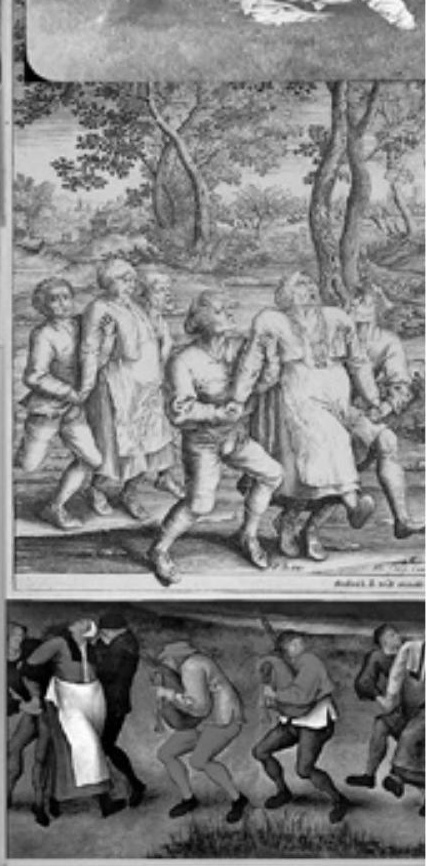



\section{TRAUMATIC DANCES OF "THE NON-SELF"}

Bodily Incoherence and the

Hysterical Archive

Jonathan W. Marshall

an involuntary dance-it's the dance you do when one of your fingers gets wedged in a live socket and your arms start pumping up and down and your mouth is slowly opening and closing and you can feel the power but no words will come out.

- Laurie Anderson, "Dance of Electricity" (1984)

In 1892, a hysteric being treated at Paris' Salpêtrière hospital employed language very similar to that Luce Irigaray was to use to describe the position of woman in modern society. The patient, known only by the pseudonym of "H...", declared herself to be "the self of the non-self [le moi du non-moi]" (Séglas 805). Between suffering from seizures, attacks, and ecstatic states, she felt herself "dash forward, I devour space without ever stopping" in an apparent effort to meet her other self (803-5). In these and other accounts, hysterical subjects seem almost to tear themselves apart, their psycho-corporeal performance so dispersing the individual as to render them incoherent. The hysteric has served for many artists as the paradigmatic example of a subject who is not singular, unified, or readily comprehensible. The Surrealist André Breton encountered H...'s peers while working at the Pitié-Salpêtrière complex. With Louis Aragon, he co-authored an essay illustrated with photographs from the wards in which they called hysteria "the greatest poetic discovery of the fin de siècle" (20). In these and other accounts, the female-or in 
some cases male-hysteric was divided, fractured, and barely legible. Locating signs of hysteria-like choreography might therefore act as a heuristic for identifying moments where historical experience itself challenges language and representation. One might begin here to visualize performances of the incoherence of subjective experience and history itself. At times of socio-cultural crisis, the body's forces spill over, instances of such eruptions revealing a lineage which joins otherwise distant historical moments. Bodily performance functions here less as a sign and more as a symptom, a dialectical manifestation of psychocorporeal conflict.

Joseph Roach argues that humans possess a "kinesthetic imagination" which is expressed through various "performance genealogies", constituted by those bodily movements and practices which are shared and transmitted across time. Such performances serve as:

mnemonic reserves, including patterned movements made and remembered by bodies, residual movements retained implicitly in images or words (or in the silences between then), and imaginary movements dreamed in minds (26).

Hysteria and its choreography constitute such a performance archive, a deeply material, gendered history which is directly manifested via the muscular action and spasmodic extremes of flesh, bone, and limb (Fig. 1). As Joan Scott observes, gender is "a primary way of signifying relationships of power" and has been "invoked to mobilize constituencies, to tar enemies, to put groups and individuals in their place" ("Gender" 1067, "Unanswered Questions" 1423). Gender is inculcated throughout history, culture, and politics, and the hysteric is a commonly cited bellwether of crises in society. H...'s contemporary, Hippolyte Taine, went so far as to describe the French Revolution as an instance of "group hysteria", while later historians have shown that women in Weimar Germany occupied an ambivalent, unstable social position, caught between metropolitan mobility and ongoing demands of domestic femininity (Micale 207; Hales). The highly visible "Girlkultur" of young office workers and their peers came to be viewed either as exhilarating signs of liberation or as indicators of decline and hysterical modernity. Similar gendered critiques circulated within interwar Japan as well as France, both before the Great War and after (Mackie; Gilman et al). 


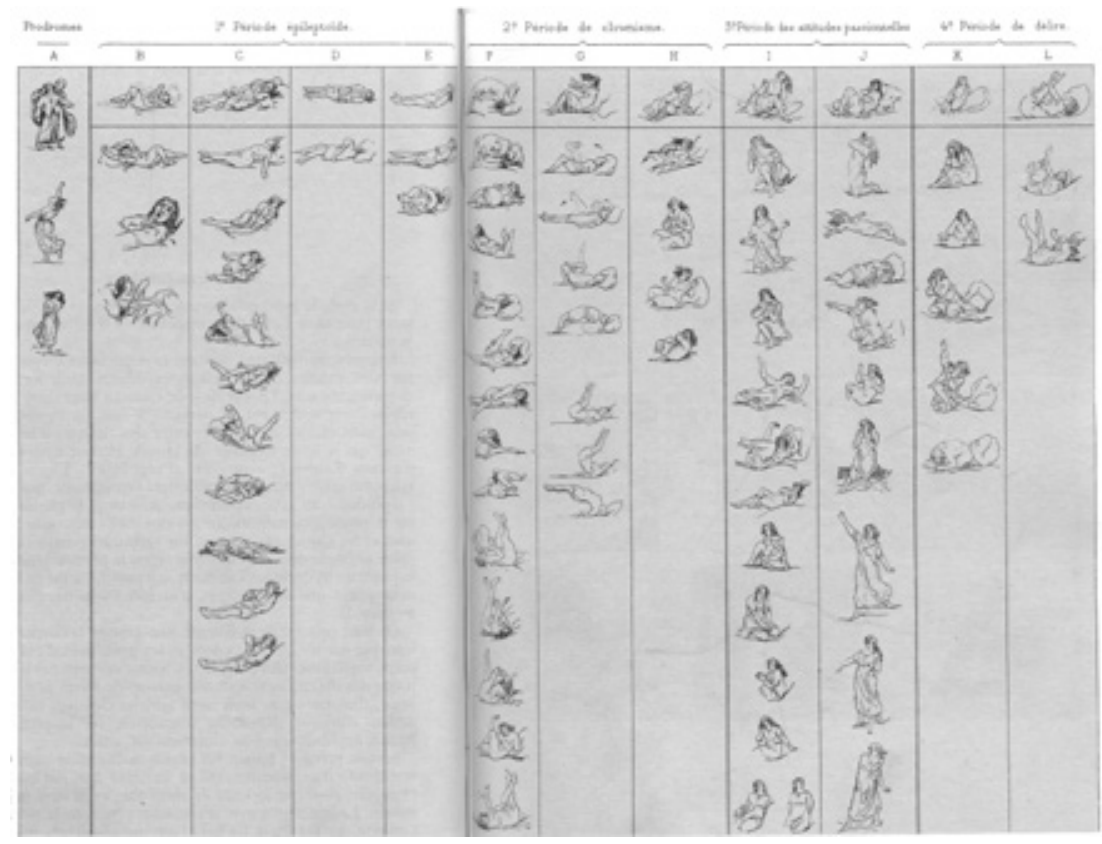

1. Table of hysterical gestures (Richer Études cliniques la grande hystérie. 1885; courtesy of Harvard Medical Library in the Francis A. Countway Library of Medicine)

The hysteriform archive constitutes a set of bodily gestures and actions that recur across history, tending to emerge in the context of social crises within which gender and other factors have been implicated. Surveying the hysterical archive demonstrates how hysteriform poses and gestures initially visible within early modern demonical possession, exorcism, and religious ecstasy moved into the medical sphere during the eighteenth and nineteenth centuries, becoming a significant resource for international performing artists of the nineteenth and twentieth centuries. In examining these shifts, I do not wish to simply read back hysteria as a sign of something else, as scholars in the Freudian tradition have sometimes done. H...'s patient records are revealing here, since they show the utility of a psychoanalytic reading of hysteria which identifies the root causes in gendered personal and social repression, while corporeally exceeding what psychoanalysis can fully account for. H... was a troubled young university student, dismissed by male doctors, before going to the specialist department at the Salpêtrière. Although this was the base for the leading international authority in 
hysteria, neurologist Jean-Martin Charcot (with whom Sigmund Freud studied), H... was treated by Jules Séglas, a former student of Salpêtrière psychiatrist Jean-Pierre Falret. Séglas published on hallucination, hypnotic fugue, and automatism, all of which were diagnostic features of hysteria. Séglas supported Charcot's attempts to have unlicensed presentations of hypnosis banned. Though influenced by Charcot, Séglas' different disciplinary position meant we have a detailed account of H...'s condition in her own words. Charcot by contrast was more materialist, his abundantly illustrated patient records focusing on tissues and their visible action, particularly gestures and seizures.

I propose to follow Charcot in conducting a dramaturgical analysis, examining the choreography of historical subjects who exhibit hysterical motions, and the context within which such corporeal forms arise-the discursive and historical mise en scène, if you will. Viewed in material and corporeal terms, gestures do not categorically identify the performer as "hysterical" as such. This reflects the uncertain status of hysteria. The diagnosis is only very rarely employed today, and even fin de siècle hysteria was seen as a semi-fictional performance, a functional disorder of neuromotor action which mimicked transitory physical signs of other diseases normally caused by tissue damage or other nonhysterical agents. ${ }^{1}$ Jean-Pierre Falret's son Jules, who also worked at the Salpêtrière, claimed that hysterics were:

veritable actresses; they do not know a greater pleasure than to deceive [...] Hysterics exaggerate their convulsive movements (which are often partly simulated), as much as they dress up [travestissent] and exaggerate all of the movements of their souls, their ideas and their deeds (502-3).

Charcot concurred, using the term "neuromimesis" to describe how the hysterical body could, like an artwork, mimetically reproduce other functionally distinct conditions (vol. 3, p. 16). The very words used to describe the hysterical body and its seizures-epileptoid, choretic, clownism, acrobatic-reflect these representational echoes. Hysteria could be recognized by its corporeal similitude to, but non-identity with, epilepsy. Charcot employed the phrase hysterioepilepsy to make clear he considered seizure the chief diagnostic feature of hysteria. Although psychiatrists like Séglas focused more on psychological symptoms than their neurologist peers, psychiatric, parascientific, and lay accounts from 


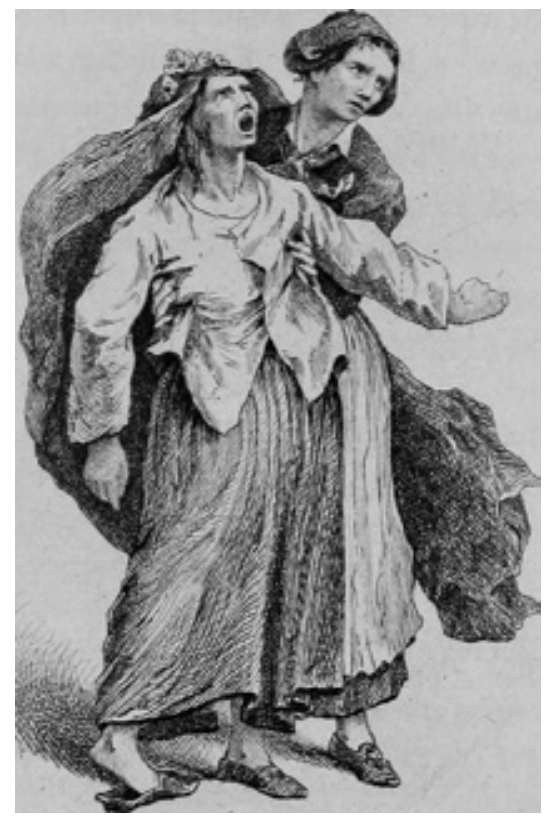

2. Prodromes (Richer Études cliniques sur la grande hystérie. 1885; courtesy of Harvard Medical Library in the Francis A. Countway Library of Medicine)

the eighteenth to the early twentieth century routinely made reference to disorderly neuromuscular tremors, intermittent spasms, or "fits" of laughing, shaking, and crying which overtook the body, sometimes as "prodromes" or a precursor "aura" (Fig. 2), which might then give way to trance and dissociated states. Commentators also regularly classified hysterical spasms as "choretic", resembling chorea, yet another disease whose title marked it as a condition characterized by movements which were dance-like, but which vexed the clarity and repeatability of dance proper-a non-choreography if you will. ${ }^{2}$ Additional parallels were drawn between hysterical poses and athletic acts such as the tumbling and mugging of clowns (Gordon). The hysteriform archive consistently confused non-pathological, intentional, and semi-intentional performances with those of involuntary pathology. Indeed Alfred Binet claimed that it was a question of degree rather than a clear distinction between the actor who was able to "duplicate himself in the theatre", and so critically observe and control their own performance, versus the hypnotized hysteric, who was consumed by a veritable "paroxysm" of corporeal and subjective displacement (542-44).

Tracing the filiations of the hysteriform body across the historical record, one crisscrosses a set of trajectories running from seventeenth- 
century demoniacal possession-retrospectively diagnosed by Charcot as hysterical-through to twentieth-century avant-garde dance, from various European artists between the wars who consulted or were influenced by neurological writings, back to the actual patients of Charcot and his peers, and on to the Japanese avant-garde dance form of butoh.

Three scenes might serve to illustrate the widespread iteration of hysteria-like performances across time and space. The first comes from the epidemic of demoniacal possession which afflicted the town of Loudon, France, between 1632 and 1637. The second report is of seizures recorded in Charcot's wards in the 1880s by the artist and physician, Paul Richer. The third comes from photographs and writings published alongside scholar Jean Baudrillard's account of early performance of butoh in Paris from 1985. A witness from Loudon claimed that the afflicted nuns he observed had:

passed from a state of quiet into the most terrible convulsions, and without the slightest increase of pulsation. They struck their chests and backs with their heads, as if they had had their neck broken, and with inconceivable rapidity; they twisted their arms at the joints of the shoulder, the elbow and the wrist two or three times round; lying on their stomachs they joined the palms of their hands to the soles of their feet; their faces became so [...] frightful one could not bear to look at them; their eyes remained open without winking; their tongues issued suddenly from their mouths, horribly swollen [...] [and] hard [...] they threw themselves back till their heads touched their feet, and walked in this position with wonderful rapidity [...] They uttered [mostly non-verbal] cries so horrible and so loud that nothing like it was ever heard before (Des Niau 36-45).

In Charcot's wards, Richer observed:

After the tonic convulsions, the patient is soon immobilized by muscular tetanization taken to its height.

[...] The position of the patient thus immobilized is variable, most often it is in full extension and the supine position.

The head is thrown backwards, the neck swollen to the highest degree, the veins form prominent ropes. The patient is strongly 
cyanotic, the face also becomes puffy and its features are contracted and motionless.

Foam appears on the lips. The arms are extended in adduction and outside rotation, the wrist flexed, the fist closed; sometimes both hands, brought to the middle of the body, touch each other by their backs and even cross each other. The lower limbs are also in extension, the knees strongly applied against each other, and the feet in the pied-bot position, turned inwards or outwards (50-51).

Photographs of Murobushi Koh, Carlotta Ikeda, and their dancers show them grimacing, tongues twisted and contorted, eyes rolling back in their sockets (Rancilio, ed.). ${ }^{3}$ Bodies collapse on the ground and the muscles of the back tighten to cause an extreme arch (Fig. 3). Hands and feet claw or ball up, as in the pied bot pose mentioned by Richer above. Baudrillard characterizes these scenes as a "theatre of [...] convulsion" in which bodies are "twisted, electric [...] whose limbs search for themselves." Even "mucous membranes are turned outwards", as in the gape of the jaws, or the exposure of the tissues behind the eyelid. When rendered immobile, bodies come to resemble non-human entities such as "pillars of salt", or a hard, mineral-like cyst ("une gangue"; Marshall/Baudrillard).

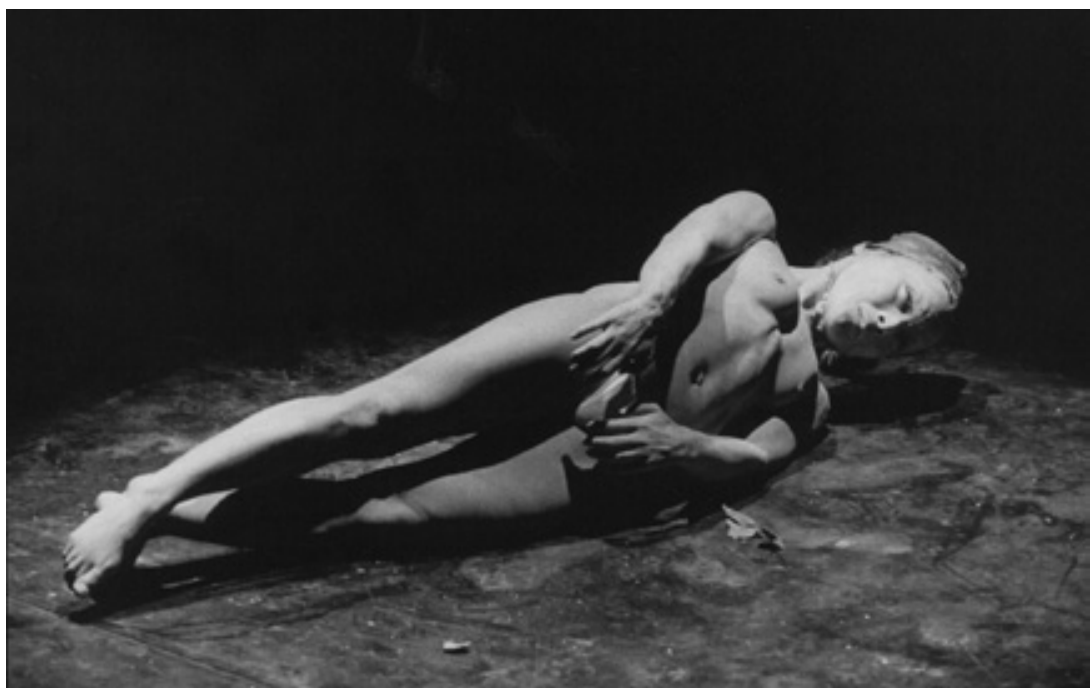

3. Murobushi Koh, The Mummy (Photo by Laurencine Lot, c.1985; courtesy of Laurencine Lot, Paris) 
Though dispersed across a period of over three hundred years and occurring in diverse cultural and historical contexts, the scenarios are remarkable for their choreographic similarities. In each, there is a tendency towards spasmodic fluctuations which leap from extreme contraction (clonic gesture) versus muscular extension (tonic, tetanic, opisthotonic). These oscillations between clonic and tonic states are unevenly distributed throughout the body, generating asymmetry, facial grimaces, and the distortion of lines, limbs, and poses. There is consequently a tendency towards twisting. These distortions often elicit comparisons with animals and non-human beings. Between the clonic and the tonic, the body is at times supine and relaxed. The subject may become hyper-sensitive and responsive, taking on outside influences (welts caused by demons, the touch of a doctor's probe, or echoing actions from their surrounds). Bodies appear possessed, with apparently non-human or abnormal forces moving through them, temporarily lodging in diverse locations. The body becomes cataleptic, lethargic, and may produce involuntary actions or automatisms. At other times the hysterical body is rendered hard or rigid, coming to recall inanimate matter. Klaus Theweleit notes that a common trope of fascist literature and sculpture is to see the body as an all but impermeable armor against which subjectively threatening forces crash, fracture, and roll off. He sees this as a fundamentally hysterical or neurotic reaction to the fear of contamination and collapse. The tetanization of the body in hysteria, especially of the male body, has some of this character, and it is a trait that recurs within the work of the founder of butoh, Hijikata Tatsumi.

Poses such as those listed above are so striking as to be perceived by observers as being "dramatic" or "theatrical," in that they project outwards towards possible audiences with considerable force. These are however scrambled messages-"electric" and shocked in the words of Baudrillard-the rapid shifts in direction and intensity making the specific content of the drama unclear at best. These performances do not conform to Aristotle's rules of classical theatrical form, fitting neither tragedy, nor comedy, nor satire. They are closest to burlesque, or the imperfect and disrespectful echo of other forms and styles. Hijikata described the butoh dancer as a body on the edge of "crisis", and this certainly applies to the examples above.

Georges Didi-Huberman argues that the fascination and pathos which hysteria provoked is a product of the contradictory forces latent within 
the corporeal image itself (Invention 8-9). The dominant approach since the Renaissance has been to read the image as a legible symbol of something else, such as a real body, an incident, or a message. DidiHuberman however points to an alternative tradition in which images convey their own insufficiency, directing attention towards that which cannot be visualized (as in the representation of the divine) but which is nevertheless present at some level within the image-or, in hysteria's case, something which passes through the body without entirely leaving it. Didi-Huberman provides the art historical example of how Fra Angelico' fresco of The Annunciation is suffused with "the indescribable and unfigurable divine voice to which Angelico, like the Virgin, was obliged to submit completely" (Confronting 15). The image here becomes a paradoxical container for presence itself, no longer entirely separate from what it alludes to. Didi-Huberman traces a similar duplicity within the action of the hysterical body, which since the early modern period had been seen as an index for the presence of a materially recognizable, corporeal illness (hysteria). Hysteria however also externalizes, "dresses up", and "deceives" the viewer (in Falret's words), its internal causes remaining unclear at best, moving through those same parts of the body affected by other "real" illnesses, but not necessarily residing in these regions. This capacity of the hysterical body to generate forms, poses, and gestures renders hysterics as consummate artists, and their bodies as media, compared by commentators to automatons, marionettes, music boxes, and impressionable balls of wax or clay. The hysterical body also reproduced pre-existing representations, becoming what in semiotic terms is known as a simulacrum: a representation of a representation or, alternatively, a representation for which no known original can be identified. Hysterics both reproduced the actions of, and were likened by others to, figures taken from the history of literature, drama, and art. The patient Suzanne N..., for example, told Richer that she would "enter the Conservatoire" where "I will become like Sarah Bernhardt", the leading French actress of the time (Richer 315). Richer, Charcot, Salpêtrière neurologist Guillaume Duchenne de Boulogne, and others compared the poses adopted by these subjects to those seen in famous paintings of saintly beatitude and possession, to the writhing dances of the Bacchants, Salome, and even Bernhardt's own re-enactment of consumptive spasms. Bernhardt's various performances had not only been influenced by her observation of hysterics and other sufferers at the Salpêtrière. Her voluntary, fictional reproduction of seizure became real and involuntary in the bodies of her audience, who "were seized by 
an absolutely characteristic coughing reflex", suffering from hysterical "contagion of [an] identical reflex movement" (Vigouroux/Juquelier 29; Veyrac).

Didi-Huberman challenges historians to submit to the aporetic "notknowledge" contained within these bodily images, and to try to share the depicted subject's own lack of certainty about themselves. One should follow H..., who admitted, "I do not know how to explain myself, I cannot find the terms", and yet nevertheless recognized that "I have again two selves [individus], the one who sees and the one who acts" (Séglas 805-6). "What then does a symptom 'symbolize"”, Didi-Huberman asks? (Confronting 179) "It symbolizes events that have taken place", but it also may allude to "events that have not taken place", particularly in the case of hysterical trauma. A symptom not only signifies that which is present in the body - a disease, a disorder, a response to pain and sufferingbut also that which is latent and not fully present. Cathy Caruth similarly contends that traumatic symptoms arise out of:

an inherent latency within the [historical] experience itself [...] And it is this inherent latency of the event that paradoxically explains the peculiar, temporal structure, the belatedness [...] [the event] is not experienced as it occurs [...] For a history to be a history of trauma means that it is referential precisely to the extent that it is not fully perceived as it occurs; or to put it somewhat differently, that a history can be grasped only in the very inaccessibility of its occurrence (187).

Didi-Huberman argues then that the symptom:

bears within it the three fundamental conditions of a withdrawal, a presented return of this withdrawal, and a fraught equivocation between the withdrawal and its presentation; such perhaps would be its elementary rhythm (Confronting 179).

In corporeal and performative terms, this means that hysterical symptoms are manifest through performances which literally shake and vibrate with this rhythm of traumatic manifestation and withdrawal. The art historian Aby Warburg (who quoted works of the Salpêtrière school in his own archival project, the Mnemosyne) called this the Pathosformel, by which he meant how certain ways of figuring the violent, often traumatic disturbances of the body recurred across art history, constituting both 
a kind of "survival", as well as a deformation or evolution of art and its forms (Didi-Huberman Atlas). As Didi-Huberman explains, "Here the symptom is understood as movement in [and across] bodies" (Michaud 15).

Although hysteriform attacks often included ecstatic periods, seizures were more commonly characterized by pain and suffering, as when H... returned to college only to endure "[a] loud scream, foam on the lips, nervous tremor requiring men to hold me back ... then after, complete annihilation" (Séglas 804). An initial shock or trauma generally brought on the patient's first fits, and the case histories record a sorry history of largely working class subjects who survived animal attacks, industrial accidents, childhood encounters with corpses, as well as sexual assaults at the hands of employers and others (Bourneville/Régnard IPS 1-3). Causative incidents were rarely singular, but commonly multiple, overdetermined, and hence impossible to logically or affectively disentangle. Geneviève Basile Legrand, for example, was a foundling from Loudon, given from a young age to violent "attacks of anger" which earned her many beatings. Her lover died when she was fifteen, leading Geneviève to throw herself into his grave (IPS 1:50-57). She was later found in a dissociated state at the cemetery. While working as a chambermaid, her master raped her, and she went back to the orphanage, giving up the child. In 1870-71, Geneviève survived the Siege of Paris and subsequent civil unrest, and had a second child with an invading soldier. She returned to the Salpêtrière, where Charcot took over her case. Désiré-Magloire Bourneville, who oversaw Charcot's wards, noted that the attacks of Geneviève and her peers often included allusions of one kind or another to such occurrences, with the patient's fits functioning as "reminiscences", evoking in an abstract fashion the "physical pains of events which were the motivating cause of their attacks" (IPS 2:189). These included "scenes from the Revolution" and other incidents.

Hysteriform choreography therefore constituted a bodily eruption of non-sense generated by multiple antagonizing forces. In the case of demoniacal outbreaks of seventeenth-century France, the conflict between Protestantism and Counter Reformation led to the large-scale murder of Protestants in the Saint Bartholomew's Day Massacre (1572). Several Protestant holdouts survived the Wars of Religion (1562-1598), including Loudon, which remained the fertile center of religious fervor. Michel de Certeau, Sarah Ferber, and others have shown that 
the rash of possession cases which occurred across seventeenth-century France served as sites where conflicts between different ecclesiastical, lay, parlementary, legal, medical and royal authorities and their jurisdictional limits were played out (Sluhovsky; Marshman). Hysteria was regularly invoked as a contributing factor, or even an alternative diagnosis, to demoniacal possession. Exorcisms were performed in front of religious houses and for assembled guests, becoming a closely watched theater where the mastery of the male exorcist over the Devil, hiding in different parts of the women's bodies, was repeatedly staged. The destructive effect of these events on the body and the mind is exemplified by how the leading exorcist Joseph Surin ended up drawing the malefic influence into his own body. Surin grew weak, had difficulty walking, and "agitations would seize me in all my limbs." As with H..., he claimed that in these attacks, it was as if "two spirits do battle with each other in the same field that is the body; and the soul itself is as if divided" (de Certeau 207).

Indeed, hysteria as an opaque, overdetermined cypher for wider social crises became an all but inescapable feature of interwar German culture. Siegfried Kracauer and Lotte Eisner point out that the stages and screens of Weimar Germany were rife with dangerous, demonic, or possessed hypnotists and their debilitated, emasculated somnambulistic victims, expressing a fear that modern life might be rendering individuals hysterical and degenerated. Artists in France, Germany, and beyond scoured lay and medical accounts of neurosis, hysteria and trance, as well as searching out therapies which could be employed to mitigate such phenomena. Figures such as Benjamin Christensen (director of the film The Witch, 1922), Émile JacquesDalcroze (devisor of the Eurhythmic dance and one of Mary Wigman's teachers), Marcel Duchamp, and Breton explicitly drew on the work of such Salpêtrière physicians as Paul Régnard, Paul Richer, Pierre Janet, and Joseph Babinski, respectively (Marshall "Priestesses" and "Archaeology"). Representations of hysterical behavior and nervous action were particularly communicated to artists via Spiritist writings, séances, and demonstrations. Key Spiritists reproduced neurological accounts in their own work, with Henry Olcott-co-founder of the Theosophical Society-visiting the Salpêtrière twice and introducing himself to Charcot (153-54). Highly respected neurologists such as Charles Richet and Albert von Schrenck-Notzing in turn oversaw mediumistic performances as part of their study into perception and hysterical sensitivity (Marshall "Kleist's"). 
Modern dance for its part evolved out of the sports and physical hygiene movement, with rhythmic dancing promoted as a spiritual and corporeal therapy (Toepfer). The German body had been traumatized by defeat and wartime scarcity, only to be further assaulted by the trials of rapid modernization. Social upheavals, industrial rhythms, and radical changes in gender relations rendered modernity a bracing but highly problematic socio-cultural condition. Charcot and his colleagues also used gymnastic therapy on their patients, with Richer being particularly closely linked to those promoting athletics and corporeal hygiene (Marshall "Theatre"). Charcot and his students tended to see asymmetrical movements and irregular rhythmic choreography as pathological, retrospectively diagnosing not only demoniacs as hysterics, but also Ancient Bacchic dancers and other entranced performers, including the priestesses of Apollo at the Delphic Oracle, all of whom typically exhibited an initial seizure when otherworldly forces moved through their bodies (Marshall "Priestesses"). In contrast, German, Austrian, and Swiss dancers and musicians of the interwar period shared a virtual obsession with the "Dionysian" ideal represented by such phenomena, with Dalcroze, Wigman, Laban, Friedrich Nietzsche, Richard Wagner, and many others celebrating Greek ritual performance as a precedent for their own projects of cultural and corporeal renewal. Dark times demanded violent, even hysterical, responses.

The method employed by the influential choreographer Mary Wigman was particularly close to a form of willed hysteria. She repeatedly styled herself as a witch or demon, as in Witch Dance II (1926), in which the performer seemed possessed by the rough, angular mask which she wore. Laura McLary notes that Wigman insisted that "the performing and creating dancer must necessarily split from herself, thereby creating a second de-personalized other" (352). Onlookers described Wigman's dance as "wild", "electrically charged", "a mad frenzy", "torturous" and "dionysiac." There was a virtual "dislocation of the joints" before the body "trembles". Hands and arms "claw the air, the body drags" (359-362; Toepfer 109; Dixon). She becomes "grotesque". Wigman herself claimed that her performances came out of an "alien body" within which she staged a hallucinatory confrontation with her other self (Mary 98). "I shuddered at my own image", she related (Language 41 ), describing dance as a spatial and corporeal conflict similar to that which H... endured: 
Then, as if the space wanted to reach for her [the dancer], it pushes her backward on a newly created path: counter-direction: a play of up and down, of backward and forward, a meeting with herself, battling for space within space: DANCE (Mary 121).

In her epic piece Totenmal (1930), Wigman even adopted the opisthotonic arc en cercle position identified by Charcot in hysterical seizure, describing how she produced an almost "superhuman tension" along her spine, and "[o]nly then when the back of the head touched the floor [...] The back gave in, the arms fell limp" (Language 98). A similar extreme arch of the back featured in Dance of Suffering (1930), with Wigman adopting a pose which closely paralleled that seen in various depictions of exorcism and Dionysian performance (Manning 111; Marshall "Priestesses"; Fig. 4). Nor was Wigman alone in adopting such hysteriform gestures. Valaska Gert insisted that true dance arose only when the performer "experiences the whole convulsion", while Anita Berber was said to have "moved in jerks and disconnected jumps" such as one might see in hysterical paralysis or athetosis (Elswit "Berlin" 81-87). Harald Kreutzberg - a student of Wigman's who toured Japan in 1934-devised a number of solos in which he played the role of a possessed fool, once appearing as a wandering peasant suffering from choreomania whose compelling gestures initiated an epidemic of hysterical dancing in the populace (Marshall "World" 80).

Butoh was strongly influenced by these precedents, and emerged out of a similar context. Japanese psychiatry was dominated by German neurobiological models, with once common shamanic rituals of "fox possession", or the contagious eejanaika choreomania outbreaks of the mid nineteenth century, being interpreted as signs of a problematic eruption or depletion of "nerve force" (Frühstück; Harding et al; Marshall "World" 79-80). Like Wigman, Hijikata and his peers in Japan attempted to transfer these energies to their own dance.

The first performance to be explicitly labeled "butoh" was Forbidden Colors (1959). The piece featured the former prisoner of war and athletics teacher Ohno Kazuo, his son Ohno Yoshito, and Hijikata himself. Both Ohno senior and Hijikata traced their dance education back to Wigman and her peers, including Dalcroze and the Spiritist choreographers Rudolf Steiner and Marie von Sivers (Elswit "What" 134-35). In Forbidden Colors, Hijikata played the role of a shuddering figure who sexually 


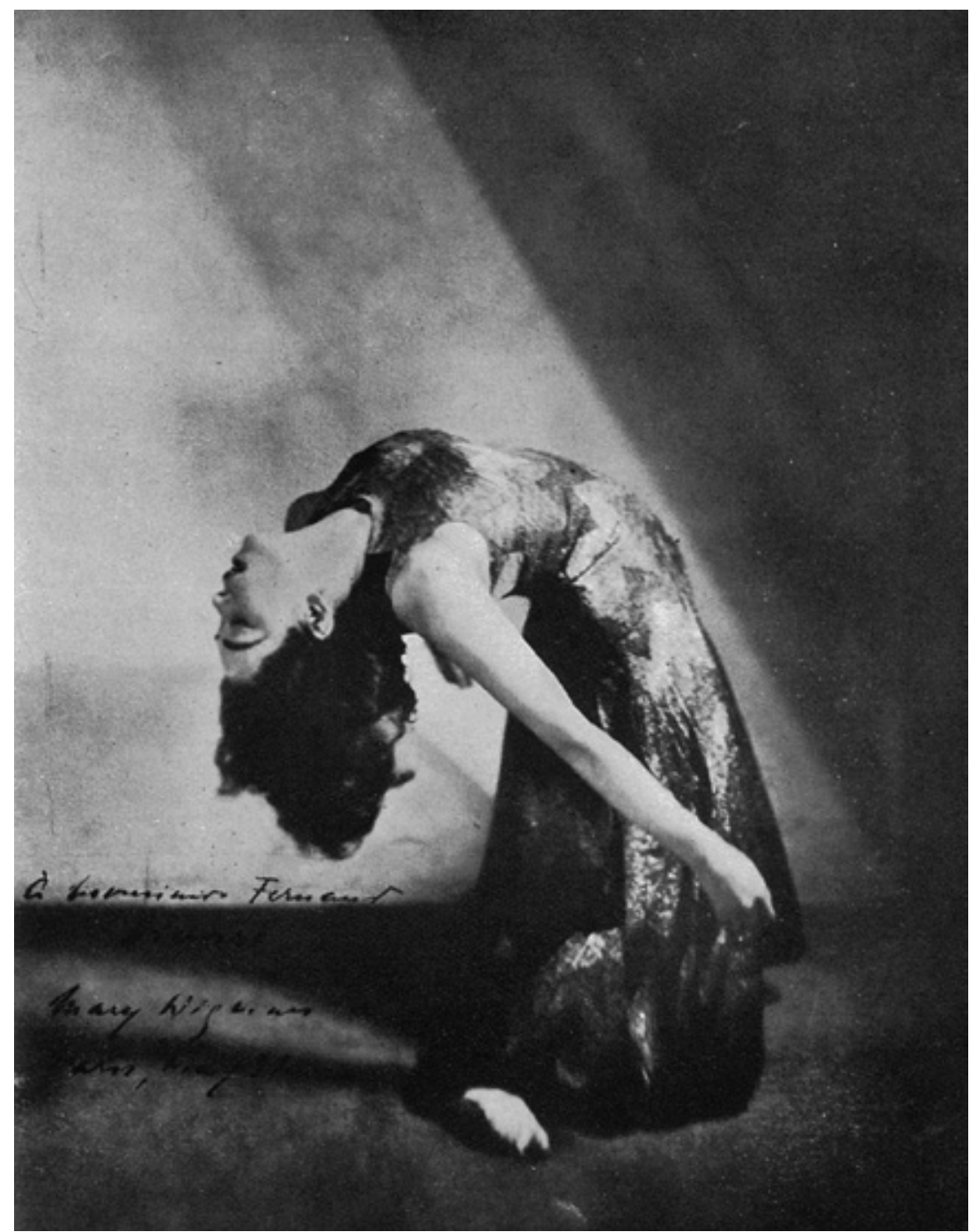

4. Mary Wigman, Dance of Suffering (1930; image from Fernand Divoire (1883-1951), Pour la danse. Paris: Éditions de la danse, 1935: 196-7, orphan work, private collection)

menaced Yoshito while holding a writhing, live chicken between his legs. Hijikata had relocated in 1952 to Tokyo where, partly by choice and partly out of financial necessity, he settled at the margins of society. The dancer frequented the docks, brothels, bars, and bombed-out ruins left behind in the increasingly frenetic rush towards modernity and 
urban reconstruction. Hijikata fasted in order to present a frighteningly emaciated body for his landmark performance of Hijikata Tatsumi and the Japanese People: Rebellion of the Body (1968), while in 1960 he claimed that his dance was produced from his status as an individual rendered "completely impotent" by the privations of his life in the immediate post-war environment. The "springs in my legs weakened in the "dance of sterilization'", he went on. "Swaying legs are now a technique of my dance" (Hijikata 39). A force akin to an electrical discharge had leapt from "an insulator" and "scorched" his skin "pitch black", before energizing his damaged body (Sas 36-37). Ohsuka Isamu, who founded the butoh company Byakkosha in 1976, arrived in Tokyo in 1968, when there were large-scale demonstrations against the ANPO US-Japanese military defense pact. It was also the year in which Rebellion of the Body premiered. Ohsuka was born to survivors in Hiroshima in the year of the nuclear attack, while Tanaka Min recalls being born on the night of the devastating Tokyo firebombing (Holborn 88; Marshall "Dancing"). All of the butoh artists were affected by the war one way or another.

Not unlike their German predecessors, post-war Japanese cultural commentators saw their task as one of corporeal reconstruction. In 1947, the novelist Tamura Taijiro claimed:

The distrust of "thought" is complete. We now believe in nothing but our own bodies [...] The body's weariness, the body's desires, the body's anger, the body's intoxications, the body's confusion, the body's fatigue-only these constitute reality (Slaymaker 93).

For Tamura, it was by passing through this traumatized "gate of flesh" that one might seek relief. Reacting against the increasingly Americanized post-war environment, Hijikata offered the image of:

a naked body [which] has come into the gun port. The naked body is bleeding [...] I make repairs to arms and legs, which constantly go astray [...] my dance shares a common basis with crime, [and] male homosexuality [...] because it explicitly flaunts its aimlessness in the face of [...] [modern] capitalist society (44).

Butoh refashioned the gendered corporeal forms which modernism and the war had elicited, but it did not so much simply heal or render healthy these forms-as Ohno did in his other role as a gymnastics 
instructor. Rather butoh reconfigured these hysteriform tropes as a corporeal archive for a forceful new aesthetic. Recalling the premiere of Forbidden Colors, Hijikata reflected that "[i]n the early days I desperately tried to concoct something stiff-an inorganic hysteria dance" (Truter 41). Hijikata's writings and exercises were full of references to neuropathological concepts and illustrations, including material sourced from Surrealist artists who had themselves been influenced by Charcot (Marshall "World"; Sas). Both butoh and interwar German dance had their lyrical expressions, but the most striking characteristic of butoh was the materialization of radically twisted, convulsing, tremulous bodies. Hijikata asked his dancers to embody images such as "a person composed of particles and tactile sensation [...] insects in space [...] people melted in furnaces in Auschwitz", and an "ash pillar walk", all of which suggested a body which uncontrollably spread into fragments even as it moved forward (61; Baird 178). Motifs of subjective and corporeal division, possession, doubling, and dispersal recurred throughout the work of Ohno, Hijikata, and their peers.

The most direct allusions to hysterical gesture within the twentiethcentury avant-garde art were however produced by those with the closest affiliation to Charcot and his school, namely the French Surrealists. As noted above, Breton worked for most of 1917 in the wards of the Pitié-Salpêtrière complex, and was acquainted with Charcot's principal successor, Babinski. The neurologist wrote the script of the lesbian horror play, The Deranged (Palau/Olaf). Breton described the compelling, hypnotic effects of seeing The Deranged in his own novel Nadja (Breton claimed Babinski "must have had the assistance of some demon") in a passage which followed shortly after a discussion about Robert Desnos' experiments with hysterical sleep and automatism (3149). The Surrealist concepts of "Pure psychic automatism" (Breton), "spasmodic graphism" (Salvador Dali), and others were indebted to the Charcot school (Marshall "Archaeology" 105-6; Lomas). It was however Hélène Vanel who brought these elements together at the opening night of the 1938 International Surrealist Exhibition in a shocking homage to H... and her peers. Appropriately titled The Missing Act, Vanel leapt out of a corner of the gallery:

her long, thick brown hair loose and her glazed eyes bulging, she gestured wildly with jerky stop-action motions and posed in exaggerated contortions [...] all the while howling [...] grunting [...] 


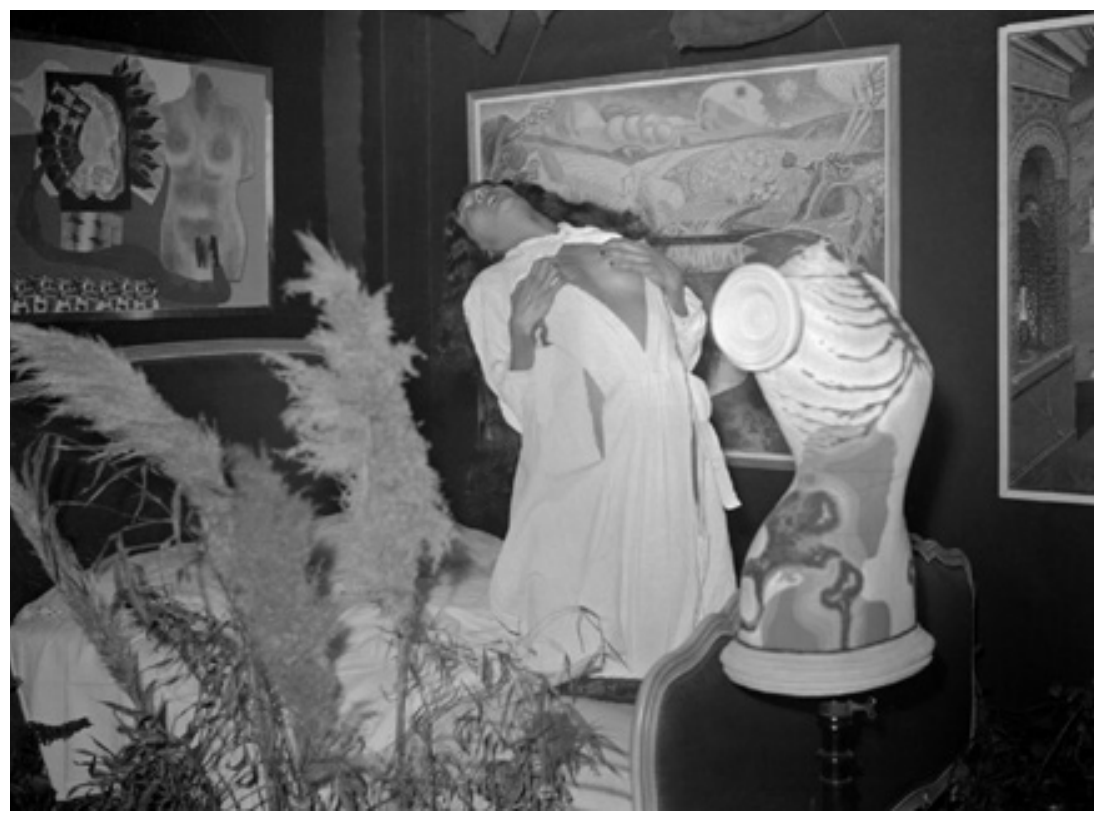

5. Hélène Vanel at the 1938 Exposition Internationale du Surréalisme, Paris (photo courtesy of Getty Images)

gnashing her teeth and gibbering [...] she twitched, twisted, shouted (LaCoss 42; Fig. 5).

Dali, who was present, identified this as a "hysterical mimodrama" in which Vanel:

jetted from the wings like a tornado in an unbelievable movement that induced a demential delirium [...] She created a total uproar with her violent entrance, lunging up onto the bed, holding at arm's length a live rooster which cackled in terror. She herself began screaming [...] as she rolled and contorted herself on the bed (LaCoss 42-43).

While Hijikata was unaware of Vanel's relatively obscure performance, the use of a chicken by Vanel and Hijikata is a telling continuity, reflecting how hysterical performance dramatized the dialectic affinities and distinctions between the human and non-human. Wigman went further, extending her human corporeal presence outside of the very limits of her own body. As Ann Albright observes: 
In her dancing, Wigman was able to mobilize space beyond her own kinesphere. Spinning, for which she was famous, Wigman could alternately create the centrifugal force and then ride it, at once creating the whirlpool and then [...] being caught up by it (314).

In Wigman's darker works, as in Vanel's The Missing Act, the performer attacked and grappled with space, producing not only a dialectic between the dancer and her environment, but—as Wigman, H..., and Surin would have it-battling for space within the body itself.

Roger Caillois described this phenomenon in his 1935 essay from the Surrealist journal Minotaur. He traced what he saw as a shared desire of insects, animals, and humans to "surrender to space". He adapted this concept from Janet's account of hysteria and hypnotic fugue, where subjects experienced a lack of clear spatial boundaries, becoming physically dispersed and dissociated from themselves as singular beings. Rather than fight this, both camouflaged insects and hysterical patients gave in to space, consuming and being consumed by the environment. Like caterpillars which resemble the leaves that they eat, the human subject extends and cannibalizes itself, hysterically dissipating through that which surrounds it. This may be experienced as "complete annihilation", in the words of H..., or as a near religious state, as in the case of Wigman's ecstatic dances. As noted earlier, there is a recurring "fraught equivocation" within the hysteriform archive between "a withdrawal" of clearly bounded presence and a "return" of corporeal fullness (Didi-Huberman Confronting 179). This oscillation makes up the "elementary rhythm" and corporeal dialectic of all of the dances discussed above. Thinking of hysteria as a symptomatic expression of subjective and corporeal non-sense and fragmentation allows one to recognize these incidents as powerfully charged historical moments where both experience and subjectivity break down. By allowing this latency of (non)meaning to engulf us as we gaze at these images from the past, we can glimpse how the bodies of both victims and artists point toward the subjective incoherence manifest at different times, symptomatically alluding to diverse, overdetermined causes and gendered conflicts. 


\section{Notes}

1 On the persistence of hysteria as a recognizable etiological complex even after its abandonment as a diagnostic label, see Showalter. On non-epileptic or conversion seizures encountered in the clinic today, see the Editors 285-291. Also poorly understood are absence seizures, which still bear the nineteenth-century French title of petit mal; see Penry et al. In modern Japan, George Beard's term of neurasthenia (translated as shinkei suijaku or "nerve weakness") was a more common diagnosis than hysteria itself (hisuterii). The clinical signs of shinkei suijaku were however largely the same as those of hysteria, and included suggestibility, possession, and so on (Frühstück).

2 The difference between Sydenham's chorea and Huntington's chorea was not clearly established until the early twentieth century.

3 For Japanese names patronymic is given first (Ohno Kazuo).

\section{Works Cited}

Albright, Ann. "Space and Subjectivity." Dance Chronicle, vol. 32, no. 2, 2009, pp. 312-17.

Anderson, Laurie. USA Live. Audio recording. Warner, 1984.

Aragon, Louis, and André Breton. "Le cinquantenaire de l'hystèrie." Révolution surréaliste, no. 11, 1928, pp. 20-22.

Baird, Bruce. Hijikata Tatsumi E゚ Butoh. Palgrave, 2012.

Binet, Alfred. "The Paradox of Diderot.” Popular Science Monthly, vol. 51, August 1897, pp. 539-44.

Bourneville, Désiré-Magloire, and Paul Régnard. Iconographie Photographique de la Salpêtrière. Progrès médical, 1877-1880, 3 vols.

Breton, André. Nadja. Translated by Richard Howard. Grove, 1977.

Caillois, Roger. "Mimétisme et psychasthénie légendaire.” Minotaure. no. 7, 1935, pp. 5-10.

Caruth, Cathy. "Unclaimed Experience: Trauma \& the Possibility of History." Yale French Studies, no. 79, 1991, pp. 181-92.

Certeau, Michel de. The Possession at Loudon, translated by Michael Smith. Chicago UP, 2000.

Charcot, Jean-Martin. Euvres complètes, edited by Désiré-Magloire Bourneville et al. Progrès médical, 1888-1894, 13 vols.

Des Niau (pseudonym of Nicolas Aubin). The History of the Devils of Loudun. Translated by Edmund Goldsmid. Private printing, Edinburgh, 1887. 
Didi-Huberman, Georges. Atlas. Exh. cat. Museo National Centro de Arte, 2010.

- C Confronting Images, translated by John Goodman. Pennsylvania State UP, 2005.

- - The Invention of Hysteria, translated by Alisa Hartz. MIT, 2003.

Dixon, C. Madeleine. "Mary Wigman." Theatre Arts Monthly, vol. 15, no. 1, 1931, pp. 36-42.

Duchenne de Boulogne, Guillaume. The Mechanism of Human Facial Expression, translated by Andrew Cuthbertson. Cambridge UP, 1990.

Editors. "Dissociative Psychopathology, Non-Epileptic Seizures, \& Neurology." Journal of Neurology, Neurosurgery E $\mathcal{F}$ Psychiatry, vol. 69, 2000, pp. 285-91.

Eisner, Lotte. The Haunted Screen, translated by Roger Greaves. California UP, 1965.

Elswit, Kate. "Berlin...Your Dance Partner Is Death.” TDR: The Drama Review, vol. 53, no. 1, 2009, pp. 72-92.

- - et al. "What We Know." Routledge Companion to Butoh Performance, edited by Bruce Baird \& Rosemary Candelario. Routledge, 2019, pp. 126-36.

Falret, Jules. Études clinique sur les malades mentales et nerveuses. Baillière, 1890.

Ferber, Sarah. Demonic Possession $\mathcal{E}$ Exorcism in Early Modern France. Routledge, 2004.

Frühstück, Sabine. "Male Anxieties: Nerve Force, Nation, \& the Power of Sexual Knowledge.” Journal of the Royal Asiatic Society, vol. 15, no. 1, 2005 , pp. 71-88.

Gilman, Sander, et al. Hysteria Beyond Freud. California UP, 1993.

Gordon, Rae. Why the French Love Jerry Lewis. Stanford UP, 2002.

Hales, Barbara. "Mediating Worlds: The Occult as Projection of the New

Woman in Weimar Culture." German Quarterly, vol. 83, no. 3, 2010, pp.

317-32.

Harding, Christopher, et al. Religion E Psychotherapy in Modern Japan.

Routledge, 2014

Hijikata, Tatsumi. Various essays. TDR: The Drama Review, vol. 44, no. 1, pp. 36-81.

Holborn, Mark, et al. Butoh: Dance of the Dark Soul. Aperture, 1987.

Irigaray, Luce. This Sex Which Is No One. Cornell UP, 1985.

Kracauer, Siegfried. From Caligari to Hitler: A Psychological History of the German Film. Princeton University Press, 1947.

LaCoss, Don. "Hysterical Freedom: Surrealist Dance \& Hélène Vanel's Faulty

Functions.” Women E Performance, vol. 15, no. 2, 2005, pp. 37-61.

Lomas, David. “'Modest recording instruments': Science, Surrealism \&

Visuality.” Art History, vol. 27, no. 4, 2004, pp. 627-50. 
Mackie, Vera. "New Women, Modern Girls \& the Shifting Semiotics of Gender.” Intersections, no. 32, July 2013, http://intersections.anu.edu.au/ issue32/mackie_review_article.htm

Manning, Susan. "Feminism, Utopianism, \& the Incompleted Dialogue of Modernism.” Ausdruckstanz, edited by Gunhild Oberzaucher-Schüller et al. Friedrich Noetzel Verlag, 1992, pp. 105-15.

Marshall, Jonathan W. "The Archaeology of the Abstract Body: Parascientific Discourse \& the Legacy of Dr J.-M. Charcot, 1876-1969.” French History Ẽ Civilization: Papers From the George Rudé Seminar, vol. 3, 2009, pp.

92-111, reproduced on http://www.h-france.net/rude/rudevolumeiii/ MarshallVol3.pdf

. "Dancing the Elemental Body: Jonathan Marshall Talks With Min Tanaka \& Yumi Umiumare About the History of Butoh \& Body Weather Today." Performance Paradigm, vol. 2, 2006, pp. 54-73, reproduced on http://www.performanceparadigm.net/wp-content/ uploads/2007/06/6marshall.pdf

- - "Kleist's Übermarionetten \& Schrenck-Notzing's Traumtänzerin: Nervous Mechanics \& Hypnotic Performance Under Modernism.” Heinrich von Kleist $\mathcal{E}^{2}$ Modernity, edited by Bernd Fischer and Tim Mehigan. Camden, 2011, pp. 261-81.

- - Performing Neurology: The Dramaturgy of Dr Jean-Martin Charcot. PalgraveMacmillan, 2016.

. "The Priestesses of Apollo \& the Heirs of Aesculapius: Medical ArtHistorical Approaches to Ancient Choreography After Charcot." Forum for Modern Language Studies, vol. 43, no. 4, 2007, pp. 410-26.

- - "The Theatre of the Athletic Nude: The Teaching and Study of Anatomy at the École des Beaux-Arts, Paris, 1873-1940.” Being There: AfterProceedings of the 2006 Conference of the Australasian Association for Drama, Theatre E Performance Studies, June 2008, http://ses.library.usyd.edu.au/ bitstream/2123/2511/1/ADSA2006_Marshall.pdf

——. "“The World of the Neurological Pavilion': Hauntology \& European Modernism 'mal tourné.” TDR: The Drama Review, vol. 57, no. 4, 2013, pp. 60-85.

Marshall, Jonathan W., and Jean Baudrillard. "Theatre of Revulsion.” TDR: The Drama Review, vol. 57, no. 4, 2013, pp. 52-59.

Marshman, Michelle. "Exorcism as Empowerment.” Journal of Religious History, vol. 23, no. 3, 1999, pp. 265-81.

McLary, Laura. "Restaging Hysteria: Mary Wigman as Writer \& Dancer."

Studies in 20th Century Literature, vol. 27, no. 2, 2003, pp. 1-19.

Micale, Mark. Approaching Hysteria. Princeton UP, 1995. 
Michaud, Philippe-Alain. Aby Warburg $\mathcal{E}$ the Image in Motion, translated by Sophie Hawkes. Foreword Georges Didi-Huberman. Zone, 2004.

Olcott, Henry. Old Diary Leaves 1883-7. Cambridge UP, 2011.

Palau, Pierre, and Olaf (pseudonym of Joseph Babinski). Les Détraquées. No publisher listed, c.1958.

Penry, Kiffin, et al. "Automatisms Associated With the Absence of petit mal Epilepsy." Archives of Neurology, vol. 21, no. 2, 1969, pp. 142-49.

Rancilio, Cesare, editor. "Buto," special issue of Scènes: Revue de l'Espace Kiron, vol. 1, Espace Kiron, Paris, 1985.

Richer, Paul. Études cliniques sur la grande hystérie ou l'hystéro-épilepsie. Delahaye et Lecroisnier, 1885.

Roach, Joseph. Cities of the Dead. Columbia UP, 1996.

Sas, Miryam. "Hands, Lines, Acts: Butoh \& Surrealism." Qui parle, vol. 13, no. 2, 2003, pp. 19-51.

Scott, Joan. "Gender: A Useful Category of Historical Analysis.” American Historical Review, vol. 91, no. 5, 1986, pp. 1053-75.

- - "Unanswered Questions." American Historical Review, vol. 113, no. 5, 2008, pp. 1422-29.

Séglas, Jules. Leçons clinique sur les maladies mentales et nerveuses. Asselin et Houzeau, 1895.

Showalter, Elaine. Hystories. Columbia UP, 1997.

Slaymaker, Doug. "When Sartre Was an Erotic Writer: Body, Nation \& Existentialism in Japan.” Japan Forum, vol. 14, no. 1, 2002, pp. 77-101.

Sluhovsky, Moshe. "The Devil in the Convent." American Historical Review, vol. 107, no. 5, 2002, pp. 1379-1411.

Theweleit, Klaus. Male Fantasies. Polity, 1987.

Truter, Orlando. The Originating Impulses of Ankoku Butoh. MA thesis. Rhodes University, 2007.

Veyrac, S. "Une heure chez Sarah Bernhardt." Chronique médicale, 4 année, no.

19, October 1, 1897, pp. 609-6.

Vigouroux, Auguste, and Paul Juquelier. La contagion mentale. Octave Doin, 1905.

Wigman, Mary. The Language of Dance, translated by Walter Sorell. Weslyan UP, 1966.

——. The Mary Wigman Book, translated by Walter Sorell. Weslyan UP, 1975. 


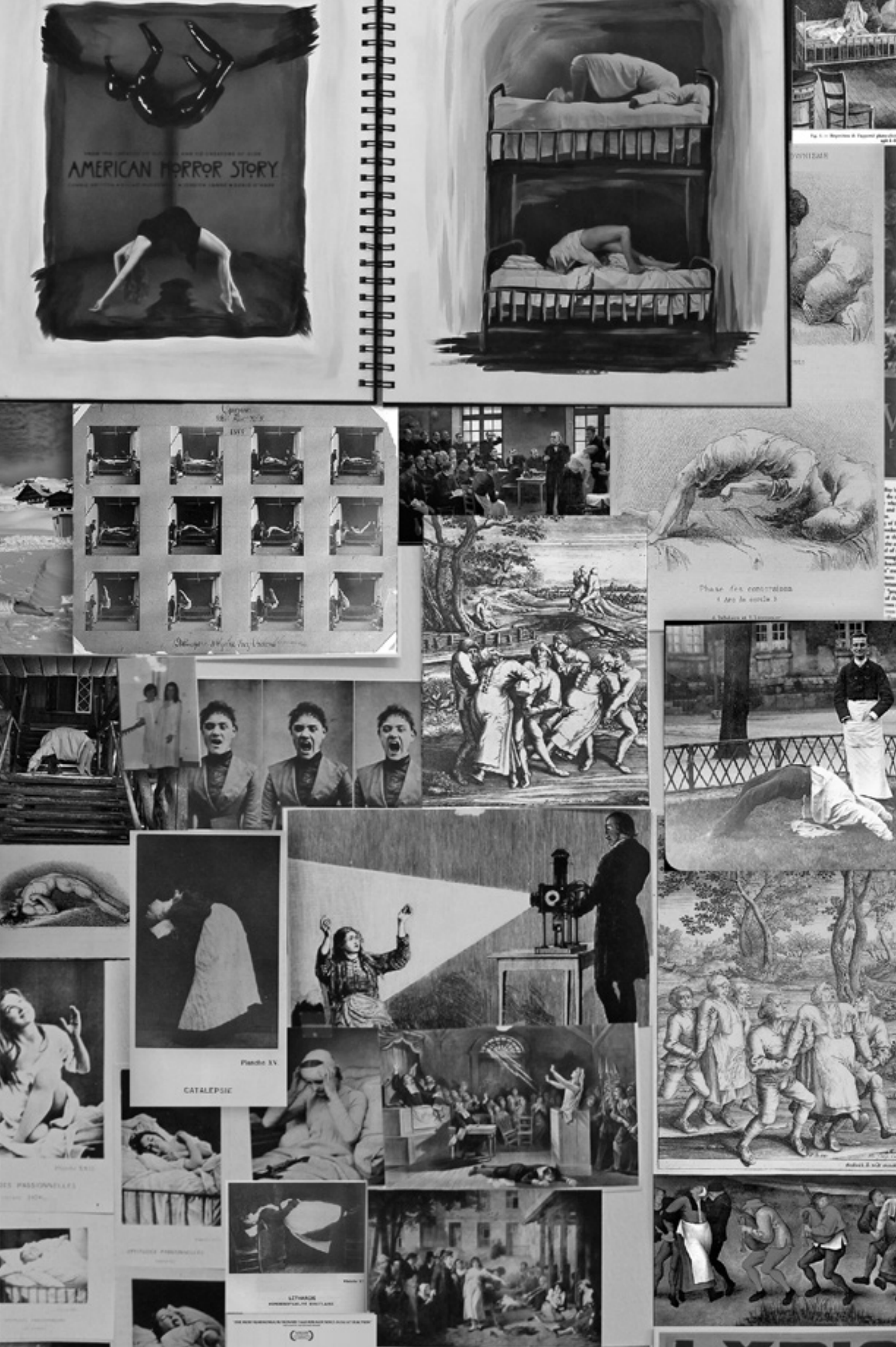

W .
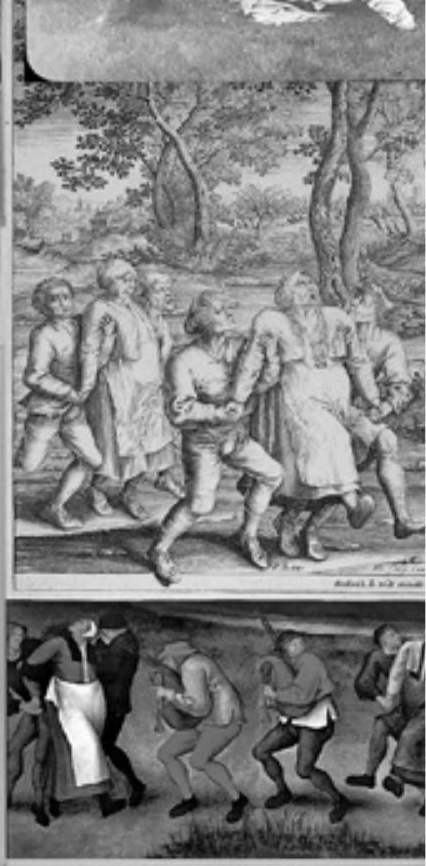



\section{THE PHANTOM ERECTION Freud's Dora and Hysteria's Unreadabilities}

Dominik Zechner

I'd pop myself in your body

I'd come into your party, but I'm soft

— Kings of Leon, "Soft" (2004)

It's complicated. Sometimes you understand a phenomenon precisely in and through its withdrawal. As you lose your grip and become more and more unable to discern and identify what it is exactly that caught your attention in the first place, a "truth" about the object reveals itself by way of its very absence. Simply terming it "absence" would be too reductive, however-for there's always something that remains, a trace bearing the entire weight of a "presence" that may never fully have realized itself (I put all these words in scare quotes as they are hopelessly metaphysical, but it's not like we can do without them). The trace or signifier that stands in for the vanished object entertains a peculiar relationship with its referent: often, it's as though it impresses itself all the more lastingly the more we lose sight of the phenomenon for which it purportedly stands.

Let me give an example: about thirty-five years after hysteria vanished as an official diagnosis from the Diagnostic and Statistic Manual of Mental Disorders (cf. Devereux 2014), and about a century since hysteria had been a "thing", the signifier remains remarkably persistent, showing up as the go-to buzzword motoring pundit headlines that span the entire 
political spectrum. One need not search long to see the evidence pile up-it suffices to take into consideration a number of fairly recent events and public conversations to encounter a shrill polyphony deploring the "hysteria" about the \#MeToo movement, "hysteria" around trans issues, "hysteria" about the European migrant crisis and about refugees in general, "hysteria" about the planet's future and the menace of global warming, anti-vaccination "hysteria", and the "hysteria" we call Black Friday shopping, etc., etc. ${ }^{1}$

This list is by no means exhaustive, but it no doubt speaks to the relentless colloquialization of an utterly complicated term. There is certainly the problem of what psychologists call "concept creep" (Haslam 2016), meaning the dilution of a rigorous scientific or philosophical concept, detaching it from its core definition in order to expand its usage and apply it to related phenomena, or, in the case of psychological concepts, to situations less severe than intended by the original or prevalent definition (the term "trauma" is a telling example in this respect). ${ }^{2}$ It is certainly true that a far-ranging case of concept creep has befallen the problem of hysteria, severing its relation to a reliably diagnosable medical or psychic phenomenon, expanding its conceptual horizon in such a radical fashion that the term has come to encompass any challenge to a collectively perceived "norm" by an upsetting circumstance that impacts a larger number of people. As an additional facet of its concept creep, the dilution of hysteria in ordinary speech has caused an odd effect of massification according to which hysteria is never applied to a singularly lived-through state or situation, instead always invoking a circumstance that affects a crowd or mass of people; "hysteria" nowadays means mass hysteria.

The easy way to surmount this observation would consist in simply dismissing the media's usage of the term as a fallacy that owes its perseverance to the inconsistencies and inaccuracies of our shared vernacular. Thus, we could deny any serious connection between what is clinically termed "hysteria" and the average pundit's misapplication. Even so, we would still have to come to terms with the astonishing circumstance that the signifier's incessant proliferation takes place precisely as the clinical phenomenon has vanished-it takes place in want of scientific credibility, pragmatic applicability, yes, in want of the very object of its concern: the hysteric. Otherwise put, hysteria's trope gains power and popularity precisely as its referential phenomenon disappears from the scene. As tempting as it is, then, to disconnect the signifier from its clinical situation and keep the discussions apart, they 
remain undeniably linked-if only to the extent that one stands in as the photographic negative of the other; one's generality bulldozes over the other's idiomatic singularity; one's timeliness trumps the other's hopeless anachronism.

As I proceed, I would like to suggest that the essential connection between hysteria's concept creep and its diagnostic value concerns the question of reading. This is to say that the indubitable link between the emergence of hysteria as clinical phenomenon and "hysteria" as an overused trope, exploited and exhausted, corresponds to a certain hermeneutic static effected by both. If we consider the manifold applications of hysteria in the popular discourses that surround us-be it in the traditional mainstream media or the combative channels hosting Twitter rage and Facebook shorthand-we notice that the term "hysteria" tends to be tagged or deployed whenever issues that question or openly challenge established modes of cognition are at stake. In other words, the signifier marks cultural processes that refuse to be read through traditionally accessible codes of hermeneutic appeasement. Take \#MeToo, for instance: in tandem with an avalanche of revelations that concern sexual misconduct and the-mostly male-abuse of authority for sexual gain, the movement has taken up a fundamental challenge of the ways in which inter-subjective relationships in the workplace have thus far been coded and decoded. The movement raised public awareness that translated, in some cases, into juridical action and legal consequence; yet, what must not be overlooked are the hermeneutic problems posed by this moment of cultural tremor, for it threatened the very cognitive means by which mainstream culture used to understand and categorize constellations of sex and work. The fact, then, that \#MeToo got pegged "hysterical", beyond the vulgar misprision and misuse of the term, testifies to a fundamental crisis of understanding provoked by a profound defiance against reigning master codes.

I am fairly confident this "diagnosis" can be expanded, and it is possible to infer that "hysteria" emerges as an imposing trope precisely at times when intelligibility, cultural codification, and the practice of reading and deciphering are somehow troubled. Attentively listening in on our current cultural conversations-I avoid exploiting the term "culture wars" in this context as the overuse of bellicose rhetoric and exaggerated polemics proffer another set of worn out tropes whose hermeneutic repercussions are yet to be discerned-we are thus called upon to engage with the interpretive exigency lodged beneath any cultural phenomenon that forces the signifier "hysteria" into the headlines. The 
wager of this essay would be that hysteria operates as the symptomatic stand-in for a major hermeneutic challenge, it marks a moment of drastic unreadability that may not be surmounted by dint of reverting back to established codes of decipherment and interpretive mastery. ${ }^{3}$ A lot will hinge on convincingly demonstrating that this claim holds true also for the clinical emergence of hysteria: at what point does the symptom not just issue an invitation promting its decoding but pose a fundamental threat to the very principles and methodological apparatus of its decipherment? We shall see how Freud's hermeneutic founders precisely when attempting conceptually to immure an encountered situation by virtue of imposing a pre-established code, i.e., the Oedipal paradigm governing psychosexual experience.

The massification of hysteria obscures one of the core problems Freud wrestled when theorizing the issue: how is it possible to bridge the diagnosis in its general import with the singularity of a case? Initially, hysteria is not a mass phenomenon or a schema that links various experiences together. Rather, it presents an isolated phenomenon, individual distress entrapped in the radical idiomaticity of one's symptoms and their history. "A series of very important questions on the aetiology of hysteria now arise", Freud comments at one point in his notes on the patient tagged "Dora", asking whether a singular case can "be regarded as typical, is it the only type of cause for it and so on" $(69 / 151) .{ }^{4}$ Freud does not have a clear-cut response to this dilemma; the relation between general aetiology and individual case has to remain problematic, at least for now, and for at least two reasons: first, there is the need to collect more cases whose similarity would support the establishment of a general rule; second, the term "aetiology" applied to psychoneurotic illness is dubious in itself and would require an extensive elucidation before it could allow for the constitution of a reliable typology analytically to determine the illness. In consequence, Freud finds himself thrown back at the singularity of the case, struggling to make the idiom of the individual symptom somehow intelligible with regard to a general Krankheitsbild or syndrome. This dilemma has to be kept in mind throughout any sort of engagement with hysteria: instead of starting from an abstraction whose general applicability can seemingly be taken for granted, the reader ought to pay attention to the singularity of each case-and each symptom arising within each casein order, perhaps, to achieve, through a careful hermeneutic effort, some level of legibility, as precarious and preliminary as it may turn out 
to be. The abstraction of symptoms will necessarily end up being vague and undependable; the massification of hysteria will reveal itself to be empty if the singular constitution of its symptoms is ignored.

For the remainder of this essay, I thus propose the return to singularity. As "hysteria" and so-called "hysteric" masses re-emerge, not so much as actual phenomena but as rhetorical figures-tropes, strategically placed at crucial relays of contemporary political discourse-it will serve the conversation well simply to step back and reconsider a major case, in tandem with its foundational text, blockbuster intervention in the theoretical history of hysteria: enter Dora, feminist heroine and epochal icon of analytic collapse. As her story's history of reception has repeatedly emphasized, Dora was the one who got away; whose protest not only upset the orderly family portrait but also instigated a textual ruin, the fragment of an analysis in which Freud confronts the inevitability of failure. One of the most commented-on texts in psychoanalytic history, the case magnetizes precisely by virtue of its forced finitude: the premature termination of treatment, an unrealized cure, the deficient protocol that remained. Dora's appeal transgresses the boundaries of her own case precisely because she pushes the psychoanalytic endeavor at large to its limits. And as we gauge Dora's afterlife on the contemporary scene, we ought to remain mindful of the oscillation between the singularity of the case, historically embedded, entrenched in unrepeatable specifics and marked by the idiomatic dates of its concrete situation-and her discursive role as a synecdoche for hysteria and the "hysteric". Which is to say, the failure to read Dora could reveal a systemic failure provoked by encountering the trope of hysteria in general. In order to divulge the possibility of such failure, however, a careful textual analysis is not just called for but inevitable-for hysteria, as stated above, tends to scramble the codes of its own decipherment.

Let me start at the end. More precisely with an endnote-appended after the fact, long after, in fact, almost five years post-treatment, situated right at the open conclusion of Freud's fragmentary report. Subject to extensive critical appraisal, this appendix takes a stab at identifying the incorrigible: still upset that Dora left of her own accord, unsubscribing, as it were, from the free trial, three months into the talking cure, Freud recognizes a mistake. "The further I move in time from the end of this analysis, the more likely it seems to me that my technical mistake was as follows: I failed to guess in good time that [Dora's] homosexual (gynaecophile) love for Frau K. was the strongest unconscious current in the life of her mind" (103/184). He could have been onto it sooner, 
Freud confesses, for Dora knew way too much about sex than was appropriate-but he never probed the source of this knowledge, the pedagogical scene whence Dora derived her surplus sex-ed creds. It must have been Frau K., her adulterous father's para-spouse, who sexed her up rhetorically. What, for Dora, is a matter of knowledge, Freud, in his defense, could not have known: he scolds himself not for an epistemic lack but for a fortune flaw, a speculation missed out on: "Ich habe versäumt, rechtzeitig zu erraten ...," I neglected to guess in time. ${ }^{5}$ Lodged in the precinct of surmising divination, the lucky blast of a good guess in the right moment, female homosexuality is barred from the confines of reason. And the good fortune of getting it right simply happened to occur too late in this case.

Other things Freud did not have to guess as they apparently were all too obvious: for example that Dora's desire was trapped in the circuit of a phallic economy that included her father, Herr K., and, ultimately, Freud himself. I don't want to rehash a story all-too-well-known, let me simply recall the main parameters: Dora's father entertains an affair with family friend Frau K. whose husband, for appeasement's sake, gets Dora-who, in turn, somatizes wildly. The woman, at this point, is 18 years old. From the get-go, Freud bases the hermeneutics of his analysis on the assumption of a series of substitutions securely enclosing Dora within a libidinal swirl flowing from guy to guy to guy: father-Herr K.- - analyst. What Freud ultimately admits, however, in the paratext of a last footnote, de facto undermining his entire argument, is the shadow existence of a different encounter: an obscure flow of desire among women-a sisterhood stronger than the phallic community that supposedly holds Dora in thrall. There's women talking about sex, there's women in love $^{6}$ : there's an aphallic coalition unfolding beyond the imperatives of the Oedipal configuration, and stronger than the paradigm of male substitutability that principally guides Freud's interpretation.

It has to be taken seriously that Freud's moment of self-introspection and the confessional gesture of claiming responsibility- "I made a mistake"-happens in a paratext, marginalized and belatedly appended. This not only conjures up the entire issue of supplementarity and the role it plays for psychoanalysis which Derrida (1996) has thrown into sharp relief_-it also repeats a major moment in the Dora narrative itself, namely regarding the appendix and its status as a site for the manifestation of hysterical symptoms. Jamieson Webster has 
recently made the case for a renewed understanding of hysteria as "conversion disorder"-and right as she concludes her exploration by supplementing her own appendix (quite literally), she reminds us that Dora's appendicitis, which is simultaneously performed as a faux pregnancy, marks the hysterical symptom par excellence, disclosing the issue of conversion in the most striking fashion: "The rediscovery of the appendicitis in the final sessions becomes the linchpin in Freud's sense of the point in an analysis where a hysterical symptom reveals its contact with an organic base. This place is where the sexual, as such, asserts itself, literally more than phantasmatically" (2018: 277).

There is more to be said about the literality of the hysterical symptom, and how it clashes with what we may call its literariness - for the moment, however, let me just state the observation that the fact of recognizing the appendix as symptom-carrier in its extraordinary value for the decoding of Dora's narrative did not keep Freud from textually repeating its complication: for what is the supplemented footnote cited above other than an appendix, the very sign of the text's own hysteria, an analysis gone hysterical, supreme indicator of a confusion that causes enough static for Dora to take off, leaving things unresolved? "I failed to guess in good time that her homosexual (gynaecophile) love for Frau K. was the strongest unconscious current in the life of her mind", Freud supplements. It's the appendix in which the "truth" of the matter might be encapsulated-yet, not without being affected by the very misspeculations that led the entire reading astray in the first place: notice how even the supplement needs to be supplemented, namely by dint of a parenthesis that supposedly functions further to elucidate the admission of Dora's homosexuality. The appended term, however, "gynaecophile", serves only to obscure things: isn't "homosexual" a selfexplanatory concept in the context of Dora's doting on Frau K., the emerging love between two women?

In his cross-reading of Dora and Henry James, Neil Hertz calls the term "gynaecophile" - or "gynaecophilic" according to the translation he worked with; the German original reads gynäkophil_-slightly unusual" and points out that Freud uses it "to describe Dora's homoerotic tendencies". For Hertz, the appeal presented to Freud by this strange term lies in its insistence on "philia", i.e., love, as opposed to the clinical sterility of "logos" as reflected in the medical term gyneco-logy. This reading reflects the chasm running through Dora's narrative separating issues of experience (philia) from knowledge (logos) whose discrepancy is one of the determining factors accounting for the analysis's failure. 
Putting it too reductively, Freud tends to overemphasize Dora's lived experience, especially with respect to Herr K., at the expense of investigating the circulation of sexualized knowledge between her, Frau K., and also her governess. According to this schema, however, Dora's relationship with Frau K. could not be one of philia and would therefore have to reside on the side of logos. In other words, Hertz' explanation for Freud's deploying the strange term of "gynaecophilia" to concretize Dora's homosexuality might not hold up. It might even be the case that, instead of explaining or concretizing the term, Freud's word choice openly contradicts the belated admission of Dora's homoerotic disposition.

Indubitably, the parenthetical appendix to the appendix- "homosexual (gynecophile)"-introduces a semantic tension, and one would be tempted simply to dismiss the terminological oddity in bafflement if it were not the case that this is, in fact, the second, not first, instance within the case study where use of the term is made. At the very end of the first section, which recounts Dora's history thus establishing her "Clinical Picture", and right before jumping into the analysis of her two dreams, Freud writes the following: "The feminine emotion of jealousy [eifersüchtige Regung des Weibes] went hand in hand, in Dora's unconscious mind, with the kind of jealousy that a man might have felt. These male, or let us say gynaecophile, currents of emotion [diese männlichen oder, wie man besser sagt, gynäkophilen Gefühlsströmungen], are to be regarded as typical of a hysterical girl's unconscious love-life" (53/135). At stake in this passage is Dora's perception of the father's relationship with Frau K., and the extent to which being jealous of the woman for having "Papa" might serve as a cover-up for the deeper emotion of Dora's jealousy of him for possessing Frau K. Astonishingly, however, this "current of emotion", running from girl to woman, de facto establishing an aphallic economy, can only be thought of, by Freud, in phallic terms: he calls it "male"-and then substitutes this qualification by inserting, for the first time in the narrative, the word "gynaecophile", in fact using it as a "better word" ("wie man besser sagt") to refer to something masculine. A lot has been said about Freud's heteronormative reading strategies and how they reflect a deplorable heterosexual bias especially with regard to Dora, but keeping in mind that he appended the footnote which again uses the adjective "gynaecophile" precisely in order to admit to the heterosexual fallacy, stating that he failed to take into account Dora's love for Frau K. as the "strongest unconscious current in the life of her mind" (my emphasis) - it appears all the more bewildering that even 
this ultimate admission had to be undercut by a phallic intrusion. The parenthetical insert-"(gynaecophile)"-to qualify the word homosexual causes a confounding paradox if we take into account the prior definition of "gynaecophile" as "male". In other words, Dora has to become a man in order to feel jealousy toward the father for his relationship with the family friend; she has to become male so as to feel love for Frau K.; she has to become male for the lesbian fantasy to be established (and thus come undone). Hence, the ultimate admission of failure, disguised as an appreciation of female homosexuality, presents yet another instance of what I would like to term "phallic reading": the hermeneutic effort to recover and maintain the Oedipal paradigm at all cost. It's as though the parenthetical intrusion literalized a phallic interloping-something like a phantom erection whose marker would slip in precisely to prevent an entirely female libidinal economy from becoming analytically passable.

The definition of "gynaecophile" as "male", mirrored in the later shift from "homosexual" to "gynaecophile", describes a semantic operation that secures the Oedipal paradigm on the level of signification. Yet, the strong pull of Freud's phallic reading — though not stronger than Dora's affection for Frau K.- -is visible even on the level of the signifier, as shown, for instance, in Jane Gallop's seminal reading where she expounds on the prominent trope of the key in the report on Dora. According to this tropology, a woman is someone to be unlocked by virtue of the right opener's phallic intrusion. After all, Freud holds, "it cannot be all the same whether a female is open or closed. We also know what 'key' will open her" (56/138). Gallop comments: "In Freud's question the woman is, in either case, grammatically passive: she remains passively 'shut' or she is 'open' through an outside agent" (136). Unable to play the role of this agent, Freud fails to unlock her-which might be less an issue of not having found the "right key" but instead have to do with the basic presumption that the key-lock analogy could structure the logic of a case like this. In other words, there might be an openness that neither adheres to the binary between open and shut, nor does it respond to the key as a metonymy for the phallic analytical enterprise.

The feminist reception of Dora is replete with comprehensive commentaries on what may be termed Freud's readerly phallsificationshis need "to encode all experience of vulnerability within phallic terms", as Elisabeth Bronfen puts it (335). The grievance launched against the analyst aims at the need to coerce Dora's experience into the 
pre-figured templates of analytical conceptualization. The case of Dora must surrender to the analyst's demand-not the other way around. Yet, simply claiming that Freud misunderstood Dora by privileging conceptual faith over an engagement with the case's unreadable complications, means choosing the easy way out of this textual mess. Instead, I would like to suggest that Freud's reading strategy led him to an aporia that discloses the textual "truth" of Dora's dilemma precisely through the breakdown of a flawed psycho-hermeneutic method.

The supreme moment of this methodological debacle can be found in Freud's interpretation of Dora's first erotic encounter with Herr K. At the age of 14, the patient recalls, she happened to meet $\mathrm{K}$. in his shop, right when he was about to end the business day early in order to attend a church ceremony with his wife. Before leaving the store, however, he suddenly seized the girl, embraced and kissed her. Having broken away, Dora fled the scene at once, driven by a lasting sensation of disgust. Later on, in analysis, she would report (and relive) a persistent feeling of pressure on her thorax, somatic echo of the blindsiding embrace. Unsatisfied with the memory recalled, however, Freud insinuates a spectral key to unlock the scene: kiss and embrace in themselves, as remembered, are not enough, he is convinced, to account for Dora's physical reaction to the assault. Says Freud: "I also think I detect the influence of another factor" (23/106). Key to deciphering the onslaught, this factor is K.'s sexual titillation. Convinced that the pressure on Dora's upper body signifies more than a mere embrace, the interpreter conjures a phantom erection: "I think in that stormy embrace she felt not only the kiss on her lips, but also Herr K.'s erect penis pressing against her body" (24/107). The aroused member's "surge forward" (andrängen is the word Freud uses) subsequently got displaced from the lower to the upper body, hence Dora's aching thorax. According to Freud, this would also explain the distance Dora keeps from men whom she sees "engaged in animated or amicable conversation with a lady"-there's always the danger of that erect member and its surge forward.

Not to discredit Anthea Bell's deserving new translation, but it seems important to point out that the verb Freud originally used to interpolate K.'s arousal is not "think" but "believe"_-ich glaube aber" (my emphasis): erection is a matter of belief. Once again, the hermeneutic elucidation of the hysterical circumstance, by dint of a strange doubling, seems affected by the very symptomatology it seeks to explain and solve. Wasn't Dora's pregnancy also a matter of belief? If the problem of hysteria, to channel, once again, Jamieson Webster, is essentially one of conversion, 
it's not too far-fetched to consider a faithfully professed erection a hysterical symptom. The male erection describes perhaps the most basic movement of conversion-as desire materializes physically and the sexual arrives at the very intersection of the drive and its organic base. Now, add to this process the dubious parameter of belief and you have an instance of conversion disorder: erection as hysterical symptom. One that is not, however, lived through in experience but hermeneutically produced. This symptom disturbs a proper reading, cock-blocking certain interpretive passageways.

The question remains as to why Freud could not resist conjuring up a fictitious key for this lock. What were the analytical merits of insinuating the phantom erection? Why could Herr K.'s sheer embrace and kiss, as recalled by the patient, not have been enough to trigger her appalled escape? Freud takes an interpretive risk by insisting on the presence of an erect penis during the scene in the store, and one might wonder if the hermeneutic stakes were in fact high enough to merit his maneuver. It is all the more surprising that the analysis, as it proceeds, does not return to the phantom erection: the moment K.'s arousal is speculatively implemented, it's swiftly dropped again. Why could Freud not fight the temptation? What does this speculative moment tell us about the analysis at large? In other words: if it could not "unlock" Dora, what does the key-slash-penis disclose and indicate as a textual symptom?

I would like to suggest that the phantom erection marks a moment of speculation from which we learn less about Dora's distress and its various causes, than about Freud's convoluted strategy of interpretation and the opposing forces it displays. This is to say that his insertion of the phantom erection functions both as the symptom of and resolution to some of the misconceptions to which his phallic reading falls prey. In order to corroborate this claim, however, we need cut Freud more slack than is usually the case in appraisals of Dora. Instead of simply dismissing the phantom erection as a moment of analytic delusion, let me suggest taking its spectral presence seriously to the degree that it adresses the critical theme of male potency and impotence that permeates the entire case of Dora. It's as if Freud were irreversibly pre-occupied with an alltoo-suggestive Männerfantasie, a vision of uncompromised virility that inhibits the view on Dora's feminine associations, the homosexual excess welling beneath the interpretive maelstrom. In its lack of significance and questionable analytical merit, the phantom erection stands out, literally, as so delicate, strange, and scientifically treacherous that it turns into a symptom of analytic misprision itself. Freud handed us the 
key not to Dora, but to the question of how to distinguish between what he knew and did not want to know about his patient and her story. Hence, I suggest accompanying Freud precisely to this aporetic crossroads where the enterprise of phallic interpretation points in one direction, while the lawless pussy riot of unreadable female community lies the other way.

At large, there seem to be two constellations of desire at play in the report on Dora. The first one, privileged by Freud, revolves around the verticality of erection, comprising the male triangle of father, Herr K., and Freud-three men who all come to stand in for each other in the course of the analysis. The second constellation, underrepresented in Freud's account, horizontally connects Dora to her governess, her father, and his lover, Frau K.--offering an alternative to the logic of phallic substitution determining the first model. As becomes clear through the disquieting footnote/appendix cited above with which Freud concludes his report, the analyst himself undergoes an interpretive shift, if only a partial one, ultimately to privilege Dora's female communities over the Oedipal economy in which he interpretively compelled her to take part. The floating hinge between these two constellations of desire is represented by Dora's father, and it is precisely the trope of the erect penis and its phantom quality that enables the paternal figure to take on this relay function. For the father is posited as the carrier of an oscillating sign — the penis as erect and defunct-and he may therefore interpretively be placed in both constellations: the phallic triangle as well as the lesbian community. That Dora's father suffers from performance issues is revealed at a seminal moment in the analysis at which Dora famously claims that Frau K. only wants Daddy because he is "wellendowed [ein vermögender Mann]". Instantly, Freud suggests that what Dora actually means to say with this formulation is that he is, in fact, not well-endowed, and he adds: "This could only be meant sexually; while her father might be a man of means in the sense of prosperity, he had no means of making an impression as a man, that is to say, he was impotent" (39/122). Contrary to her MO, Dora affirms this interpretation, adding that due to her father's condition the lovers could only engage in oral sex-whereupon Freud immediately connects Dora's coughing and throat tickling to this imagined scene of oral gratification.

It was none other than Jacques Lacan who suggested that Freud might have jumped the gun with this last interpretive move-for it still seems to hold on to the father's ability to get it up as the comments on the 
symptoms connected to Dora's throat and mouth suggest a fellatory phantasy. Freud does reveal as much when, two pages later, he recasts the scenario simply by calling it "such a sexual practice as sucking the penis, ... expressed ... by the sensation of a tickle in the throat and by coughing" (43/125). To this strangely reductive account, Lacan cavalierly responds that there was no "need for him", Freud, "to invoke her awareness of the fellatio undergone by the father, when everyone knows that cunnilingus is the artifice most commonly adopted by 'men of means' whose powers begin to abandon them" (67, my emphasis). ${ }^{7}$ Freud fails to recognize the horizontal community involving the father and Frau K. just as much as Dora herself as he keeps rerouting the narrative through the signifier of proliferating erections and their forward surge. Even the impotent have boners if it serves to corroborate the myth of desire's phallic determination.

Hence, the phantom erection is, in fact, double. And as strange as the two scenes (the "scene in the store" and the father's imagined sex life) are if one considers them as stand-alone hermeneutic interventions, there might be a possibility for them to elucidate one another. For if we think back to the "scene in the store" and its victim's disgusted retreat, the question as to why Herr K.'s erect member and its forward surge would have been such a deal-breaker for Dora is more easily solvable if we consider it breaching the paradigm of male impotence on which Dora's libidinal economy is based. If we follow Lacan's argument that "Dora's Oedipal relation is grounded in an identification with her father, which is favoured by the latter's sexual impotence" (66), the (phantom) erection would have undermined this identification, whereas his erectile dysfunction would have broken the chain of substitutions linking Dora's father to the potent Herr K.

Contrary to Freud's interpretive thrust, it's precisely the trauma of nonimpotence that Dora's sexual economy is unfit to integrate. The analyst gives interpretive privilege to virility, potency, and masculinityensuring the chain of substitutions between the three father figures, each marked and distinguished by his own phantom erection. Freud turns out to be unable to read male impotence for it poses an overwhelming threat to the Oedipal configuration. In other words, it's precisely when it comes to the issue of impotence that the powers of Freud's own reading, to use Lacan's phrase, "begin to abandon him”. What's subsequently missed, is the horizontal communion activated by an aphallic libidinal economy in which Dora's father can partake precisely because his masculine powers fail him. The phallic economy depends on the erect 
specter. The practice of phallic reading, as marked by the proliferation of phantom erections, rigorously gatekeeps the Oedipal interpretive frame. Yet, its inherent vicissitudes divulge the very homoerotic desire it strives to disclaim. ${ }^{8}$

\section{Notes}

1 Concrete references for these discourses are hardly necessary: a simple Google news search for any of the examples invoked will produce evidence galore.

2 For a critical response to Haslan, see Cascardi and Brown 2016.

3 Discussing Freud at a moment in his study Body Work, Peter Brooks produces a similar conclusion, holding that " $[\mathrm{t}]$ he hysterical body ... threatens a violation of basic antitheses and laws, including the law of castration and the conditions of meaning" (1993: 244). I wonder, however, if the term "violation" as Brooks uses it here might not carry too weak a force when we think about the relation between hysteria and the established codes (or "laws", as Brooks phrases it) of reading. It seems to me that hysteria does not just violate the law, which would still make it subject to and corrigible by virtue of the law's authority-but that the hysterical occurrence challenges the established order so profoundly that the law itself needs to change so as to be able to grasp its object of confrontation. One might even say that hysteria carries an "afformative" quality, to channel the late Werner Hamacher.

4 The page references here and going forward refer to the Oxford edition of Freud's Dora paired with the German original according to the Studienausgabe.

5 Cf. the entangled semantics of guessing (raten), financial installments (Raten), and rats (Ratten) in the "Rat Man" case.

6 Freud talks about a strong Liebesregung, the stir of love (103/184).

7 Hertz comments on this passage in Lacan, saying: "It's hard to guess what Freud would have made of this note of high Parisian savoir vivre; whatever everyone else knew, he seems to have taken for granted the more phallicand phallocentric-option" (129). I hope to be able to show why Freud has to take this option for granted as it serves as the bedrock of his entire hermeneutic operation.

8 I would like to express my sincerest thanks to Michael Levine for his feedback on this text. 


\section{Works Cited}

Bronfen, Elisabeth. The Knotted Subject: Hysteria and its Discontents. Princeton University Press, 1998.

Brooks, Peter. Body Work: Objects of Desire in Modern Narrative. Harvard University Press, 1993.

Cascardi, Michele, and Cathy Brown. "Concept Creep or Meaningful Expansion? Response to Haslam.” Psychological Inquiry, vol. 27, 2016, pp. 24-28.

Derrida, Jacques. Archive Fever: A Freudian Impression, translated by Eric Prenowitz. The University of Chicago Press, 1996.

Devereux, Cecily. "Hysteria, Feminism, and Gender Revisited: The Case of the Second Wave," ESC, vol. 40, no. 1, March 2014, pp. 19-45.

Freud, Sigmund. A Case of Hysteria (Dora), translated by Anthea Bell. Oxford University Press, 2013.

- - Studienausgabe, Band VI: Hysterie und Angst. Fischer, 1975.

Gallop, Jane. "Keys to Dora.” Feminism and Psychoanalysis: The Daughter's Seduction. Macmillan, 1982, pp. 132-157.

Haslam, Nick. "Concept Creep: Psychology's Expanding Concepts of Harm and Pathology." Psychological Inquiry, vol. 27, 2016, pp. 1-17.

Hertz, Neil. “Dora's Secrets, Freud's Techniques." The End of the Line: Essays on Psychoanalysis and the Sublime. New York: Columbia University Press, 1985, pp. 122-143.

Lacan, Jacques. "Intervention on Transference." Jacques Lacan and the École Freudienne: Feminine Sexuality, edited by Juliet Mitchell and Jacqueline Rose. Macmillan, 1982.

Webster, Jamieson. Conversion Disorder: Listening to the Body in Psychoanalysis.

Columbia University Press, 2018. 


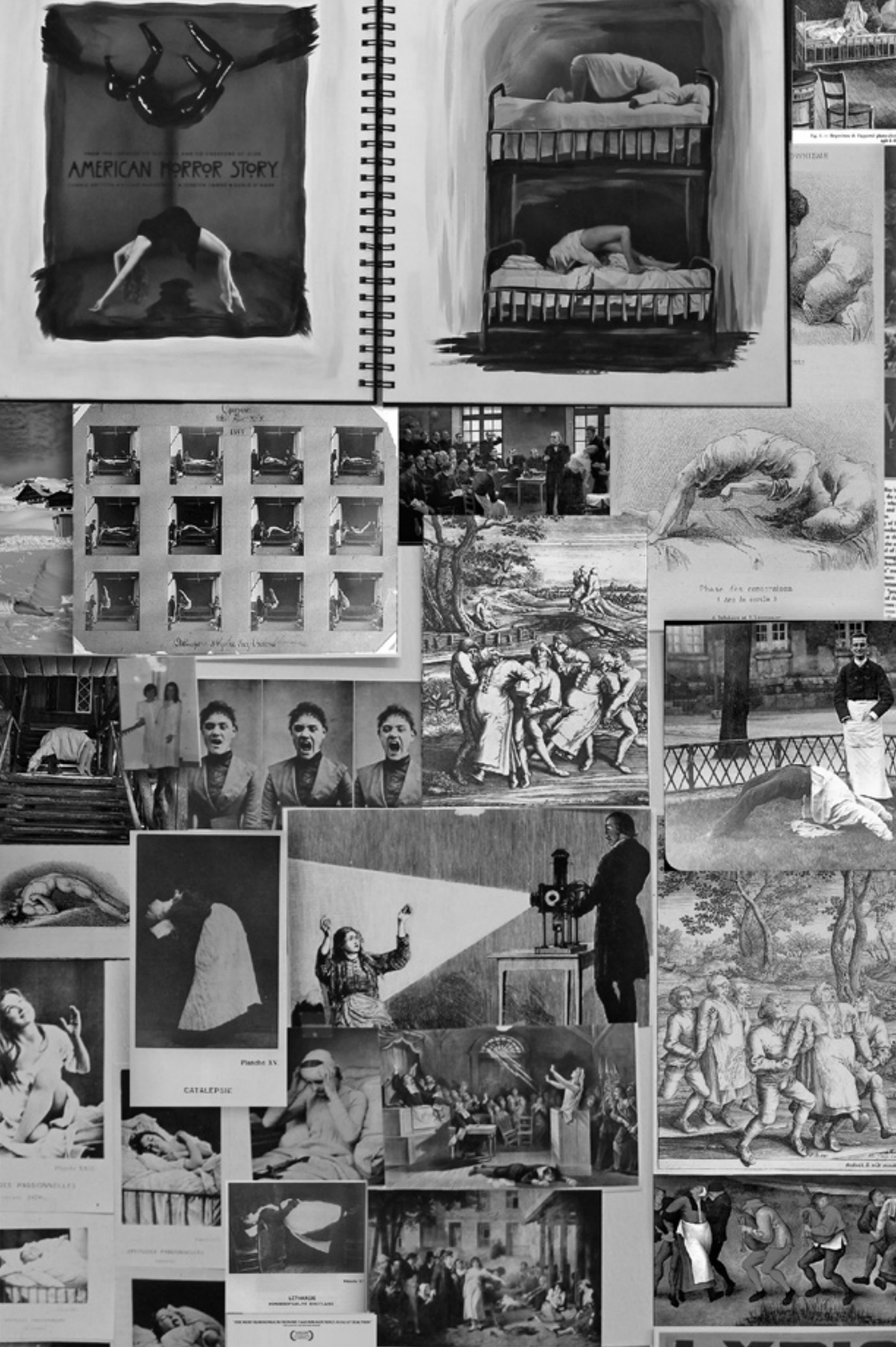

W .
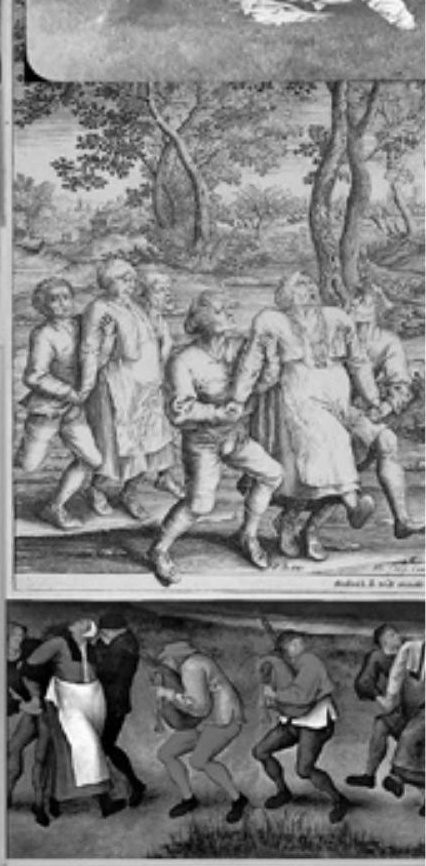



\section{"A SLIGHT HYSTERICAL TENDENCY" \\ Performing Diagnosis in Charlotte Perkins Gilman's "The Yellow Wallpaper"}

Vivian Delchamps

In the beginning of Charlotte Perkins Gilman's short story "The Yellow Wallpaper" (1892), the unnamed female protagonist writes disobediently in her journal: "If a physician of high standing, and one's own husband, assures friends and relatives that there is really nothing the matter with one but temporary nervous depression-a slight hysterical tendency-what is one to do?" Gilman famously wrote this semi-autobiographical short story to criticize her doctor, Silas Weir Mitchell. Mitchell diagnosed Gilman with hysteria and treated her with his famous "rest cure"-a treatment that kept women confined to their beds, restricting their bodily and mental freedoms. Gilman then wrote the "Yellow Wallpaper", featuring a narrator who similarly was put on the rest cure. Insistent that she is ill—but with something more than a "slight hysterical tendency", a diagnosis which she seems to find unsatisfactory - the narrator of Gilman's story hints at a question that dominates her experience in the text. "What is one to do" with diagnosis, its consequences and its fallibility?

Some critics have, in Jane F. Thrailkill's wording, tried to "doctor" Gilman's text, suggesting ways of reading the story that clarify, organize, or heal the hysteria that resonates throughout its pages. ${ }^{2}$ I similarly hope to demonstrate that neatly understanding-or diagnosing and curing-Gilman's short story is impossible for any reader. The 
narrator's first-person account articulates the complexity of disorder, demonstrating that neatly defining or explaining a condition of a body or mind is dangerously difficult. Other critics ${ }^{3}$ rightly note that the story undermines Mitchell's diagnosis and the rest cure. In this essay I further this work but question the assumption that the story's understanding of diagnosis is purely critical. I examine the ways in which the narrator of "The Yellow Wallpaper" simultaneously expresses desire for, and rejection of, the hysteria diagnosis. The story's contradictory view of diagnosis leads to a destructive, confusing narrative as the narrator is trapped in the winding, inescapable contradictions that surround the question of how to diagnose and whether an accurate diagnosis for medical symptoms is even possible. Ultimately, this paper will argue that Gilman's text provides an interpretive framework for understanding issues of gender relevant to modern discourses in disability studies and that it challenged masculinized performances of medical diagnosis and treatment by resisting the ideology of cure. The story itself is a performance of hysteria that also depicts diagnosis and cure as destructive, desirable approaches to disorderly bodies and minds.

\section{Diagnosis in History and Literature}

This essay begins with the premise that diagnosis and cure are not always helpful or desirable. They can also be harmful, and they always exist in relationship to destruction and violence. Eli Clare's book Brilliant Imperfection: Grappling with Cure (2017), a recent work in the fields of disability studies and crip theory, ${ }^{4}$ has inspired much of my work on this topic. As Clare explains, the ideology of cure, which is "embedded in a network of five overlapping and interlocking medical processes: diagnosis, treatment, management, rehabilitation, and prevention" (70), seeks to normalize bodies and other forms deemed abnormal. Clare argues that "Elimination of some kind-of a disease, future existence, of present day embodiments, of life itself-is essential to the work of cure....as a widespread ideology centered on eradication, cure always operates in relationship to violence" (28). Clare further argues that "cure requires damage, locating the harm entirely within individual human body-minds, operating as if each person were their own ecosystem...it grounds itself in an original state of being, relying on a belief that what existed before is superior to what exists currently" (15, original italics). In this reading, cure is part of a medical model that 
strives to return something deemed "abnormal" to a state of "normalcy". Cure is generally depicted positively, a "restoration of health" and a return to a "better" state of being, but in Clare's framing restoration demands elimination and enforced regression.

Diagnosis, the first of five key processes that aim for cure, is part of a system that always involves the violent removal of something from a body. Of diagnosis, Clare writes,

I want to read diagnosis as a source of knowledge, sometimes trustworthy and other times suspect. As a tool and a weapon shaped by particular belief systems, useful and dangerous by turns. As a furious storm...Simply put, diagnosis wields immense power....It unleashes political and cultural forces (41).

Diagnosis is contradictory. It identifies, but does not necessarily change or correct, disorders, and it is often the first step on the path toward normalizing bodies deemed defective. In medical science, diagnosis is hardly understood as a straightforward, objective, or perfect process. Modern medical practitioners demonstrate that "diagnosis" has two primary meanings:

First of all, Diagnosis is the name for the process a doctor goes through to arrive at a conclusion about the state of health of a patient. Diagnosis, in this sense, is...an activity or action...As such, it can be done well or poorly, hastily or carefully. Diagnosis in the second sense refers to the outcome of the diagnostic process....in this sense involving a labeling of the patient...that classifies a patient, provides an explanation of symptoms, and leads the clinician to create a prognosis (Daniel A. Albert et al, Reasoning in Medicine, 184, original italics).

Diagnosis creates a relationship between doctor and patient that relies upon an uncertain system of disease classification. The goal of diagnosis is to help both doctor and patient understand a patient's condition and predict next steps in the hopes of finding a cure. Aiming for this goal may involve embarking on an unpredictable process, relying on systems of classification and prescribing treatments that impact bodies and minds. Moreover, this process will necessarily involve destruction, 
tearing something down to build it back up again, destroying disease, or harming an individual for the sake of their treatment.

A doctor may "perform" a diagnosis and "perform" a cure. ${ }^{5}$ Taking these phrases literally, I ask how diagnosis can be understood as performative since it involves a labeling that alters identity and might lead to treatments that alter bodies and minds. In his foundational work on performative utterances in How to Do Things With Words (1970), J.L. Austin distinguishes "verdictives" as a category of illocutionary acts in which a speaker gives a verdict, such as a diagnosis (147). I want to consider the idea that diagnosis is embodied, an utterance that connects doctors and patients and stimulates physical, emotional, and mental responses as well as transformations of identity.

Reading diagnosis in Gilman's text is vital because diagnosis is both narrative and embodied. I am not the first to take this approach to understanding diagnosis in Gilman's story, as Paula Treichler explains in "Escaping the Sentence: Diagnosis and Discourse in 'The Yellow Wallpaper'" (1984),

Diagnosis is powerful and public...It is a male voice that...imposes controls on the female narrator and dictates how she is to perceive and talk about the world. Diagnosis covertly functions to empower the male physician's voice and disempower the female patient's... To call 'The Yellow Wallpaper' a struggle between diagnosis and discourse is to characterize the story in terms of language $(65 ; 70)$.

Continuing Treichler's study, I suggest that the performance of diagnosis, hysteria, medicine, disability studies, and the study of literature all converge in Gilman's work and can be analyzed to better understand diagnosis and cure as contradictory forces that are both damaging and desirable.

\section{"Infinite Numbers of Forms": Diagnosing Hysteria in Gilman's Time}

I turn now to Gilman's biographical encounters with diagnosis and cure-complex engagements with the world of medicine. Gilman's "The Yellow Wallpaper" was written just after hysteria became a 
"fashionable" disease and a difficult-to-define diagnosis (see Wood). Between 1860 and 1880, medical practitioners and the American public became obsessed with neurasthenia and hysteria, categories which produced new problems about diagnostic boundaries and patient agency. In the fifth century BC Hippocrates famously suggested that the cause of hysteria lay in the movement of the uterus (Sigerist 2-4); however, by the nineteenth century, hysteria was associated with the brain and nervous system. Doctors struggled to describe distinctions between neurasthenia and hysteria during this time, and "the two conditions were intertwined while the medical community struggled to define its diagnostic boundaries" (Schuster 5). Mitchell observed in an 1888 lecture that hysteria was the most vexing of all diagnoses, precisely because it manifested itself in "infinite numbers of forms and [an] infinite variety of masquerade" (5). This hard-to-define diagnosis became a troubling problem that intrigued doctors, patients, and the general public.

The diagnosis of hysteria was mostly reserved for wealthy white women. In 1881, Dr. George M. Beard claimed that because nervousness was caused by modernity, neurasthenics stood as proof that the American nation had evolved beyond the rest of the world, and that "Catholics, southerners, Indians, and blacks" were not susceptible to the disorder (Schuster 18).

Furthermore, "the characterization of the nervous woman" was, according to Laura Briggs, figured "over and against a figure understood as her opposite: the 'savage' woman" (Briggs 246). The refusal to associate black women with hysteria and neurasthenia further stigmatized black bodies. But for white women especially, selfdiagnosis of neurasthenia became common, ushering in an era of patients bypassing the medical profession. Doctors and pharmaceutical companies took advantage of those who self-diagnosed, prescribing and labeling medicines (sometimes made of alcohol and cocaine) as treatments for "nervousness" (Schuster 62). Complexly bound with issues of gender, class, and race, the process of diagnosing hysteria was simultaneously an authoritative demonstration of clinical control and a confusing, unregulated act that could be either helpful or damaging for those experiencing illness, leading to experimentations with literary forms. 
Like many other (white) women, Gilman self-diagnosed once she realized she was experiencing symptoms after the birth of her child. She described her condition as "dragging weariness miles below zero. Absolute incapacity. Absolute misery" (The Living of Charlotte Perkins Gilman 90-92). She traveled west to Pasadena and reported that engagement with social life there improved her symptoms (Schuster 106). This trip west imitated the treatment Mitchell used to help men such as Walt Whitman, whom he encouraged to travel west after experiencing a stroke.

After Gilman returned east to her baby and husband in Providence, her symptoms came back, and she reached out to the famous Mitchell, perhaps hoping he would order her back to the social freedom she enjoyed in the west. The fact that Gilman invited Mitchell's treatment is a facet of her history that has often been overlooked by scholars who want to depict Gilman as a passive, ignorant victim of Mitchell's treatments. I bring it in now because I want to emphasize that before Mitchell exposed her to his treatments, Gilman wanted cure. She claimed that she had "brain troubles", and told Mitchell,

I am an artist of sufficient merit to earn an easy living when well...I am a reader and thinker. I can do some good work for the world if I live. I cannot bear to die or go insane or linger on [in] this wretched invalid existence, and be a weight on this poor world which has so many now. I want to work, to help people, to do good. I did for years, and can again if I get well. (Why I Wrote the 'Yellow Wallpaper'? 271).

Illustrating Gilman's desire for cure, this shows that Gilman believes being an invalid is burdensome. She believes she cannot "do good" if she does not "get well". Her initial response to her symptoms is to paint invalidism as pathological weakness. Gilman's desire for diagnosis and her willingness for self-diagnosis are significant parts of her history with Mitchell that have largely been ignored and that demonstrate cure's seductive power.

Mitchell did not send Gilman back to her life of freedom in California; instead, he put her on the rest cure and demonstrated that he distrusted women's reports on their own health. As one of Gilman's biographers wrote, Mitchell "found utterly useless the long letter she had written to him detailing her symptoms; that she should imagine her observations 
would be of any interest to him was but an indication of her 'selfconceit,' he advised her". ${ }^{6}$ Mitchell largely ignored her detailed letter and the questions she asked him, and simply put her on the rest cure. Mitchell's creation of the rest cure was based on his belief that the patient had reached a state of "cerebral exhaustion", "a condition in which the mental organs become more or less completely incapacitated for labor" (Mitchell passim). His remedy was therefore enforced bed rest, and the patient was barred from physical exertion and deprived of intellectual stimulation. After remaining in Mitchell's care for a month, Gilman was instructed to "live as domestic a life as possible", to limit her "intellectual life" to "two hours" per day, and to never "touch pen, brush or pencil" (Knight 277). Mitchell's treatment forbade Gilman to write, and Gilman wrote that this brought her "so near the borderline of utter mental ruin that [she] could see over" (Why I Wrote the 'YellowWallpaper'?271).

Mitchell's use of the rest cure illuminates the damaging quality of the ideology of cure. Clare suggests that the ideology of cure relies "on a belief that what existed before is superior to what exists currently" (15, original italics). Mitchell arguably developed his rest cure because he believed that what existed before-a world of women who remained in the home and did not perform intellectual labor-was superior to what existed in Gilman's case. Gilman was a woman who worked and, therefore, in Mitchell's mind became hysterical. His rest cure is a clear demonstration of Clare's claim, as his treatment was founded in the belief that a working woman should return to a domestic life. While feminist critics have noted that Mitchell wielded diagnosis and cure not just to aid ill individuals, but to flaunt his authority and to return women to a domestic sphere, Regina Morantz has also helpfully observed, "medical men [of the nineteenth century] were unable to cure most diseases-not just those of women but of everyone. Indeed, they 'tortured' men and women indiscriminately" (47). Mitchell's treatment was gendered and damaging for women; however, his failure to cure hysteria was part of a larger problem: that most attempts to perform cures generally involved at least some degree of "torture" of bodies and minds.

After suffering through Mitchell's rest cure, Gilman penned "The Yellow-Wallpaper" as a thinly veiled autobiographical tale of a woman driven mad by her physician-husband, trapped in a room as a part of his medical treatment. Gilman eventually published this statement: 
"The real purpose of the story was to reach Dr. S. Weir Mitchell, and convince him of the error of his ways" (Why I Wrote the 'Yellow Wallpaper'? 271). The story addresses Mitchell directly, reaffirming this hypothesis: "John says if I don't pick up faster he shall send me to Weir Mitchell in the fall. But I don't want to go there at all. I had a friend who was in his hands once, and she says he is just like John and my brother, only more so!" (11). Now one of the most famous literary accounts of hysteria, this story demonstrates that Gilman no longer trusted male medical authority. As Eli Clare argues, "Cure [is] laced with violence, which [prompts] resistance, which in turn [is] met with more violence, all of it sustained by diagnosis" (47). By seeing Gilman's history through this lens, we can see that Gilman requested a diagnosis, discovered the deceptive and violent quality of Mitchell's gendered treatment, and was prompted to resist. The next question is, how does her short story depict cure? How and why does the protagonist want to "return" to a previous state of being, before her sickness? Though "The Yellow Wallpaper" has long been understood as a feminist commentary on medical practice, such questions, emerging from disability studies, have not yet been thoroughly considered. It is generally assumed that the narrator does want $a$ cure-she just doesn't want the rest cure. I want to question that assumption now, to ask how socially constructed cures for a largely socially constructed impairment are perceived as simultaneously violent and desirable in the story.

\section{Performing Diagnostic Experiments and Destroying Cures}

"The Yellow Wallpaper" quickly establishes that the female narrator, who relays her story in first person in her secret journal, trusts her own opinions about illness more than those of her physician-husband John. The narrator self-diagnoses when her husband refuses to admit she is ill, writing:

John is practical in the extreme. He has no patience with faith, an intense horror of superstition, and he scoffs openly at any talk of things not to be felt and seen and put down in figures. John is a physician, and perhaps-(I would not say it to a living soul, of course, but this is dead paper and a great relief to my mind-) perhaps that is one reason I do not get well faster. You see he does not believe I am sick! And what can one do? (10) 
We don't want to equate Gilman absolutely with her fictional narrator. However, this part of the story reflects Gilman's loss of faith in physicians like Mitchell who refused to engage with Gilman's letter. Suspicious of these doctors, the narrator assumes diagnostic authority, suggesting that she herself has a better understanding of her own condition than do these male doctors. Furthermore, the narrator is willing to diagnose her problems, seeing John as one reason she does "not get well faster".

The narrator is also willing to consider various cures in hopes of mitigating her symptoms. The story continues,

I take phosphates or phosphites whichever it is, and tonics, and journeys, and air, and exercise, and am absolutely forbidden to 'work' until I am well again. Personally, I disagree with their ideas. Personally, I believe that congenial work, with excitement and change, would do me good. But what is one to do? I did write for a while spite of them; but it does exhaust me a good deal-having to be so sly about it, or else meet with heavy opposition. I sometimes fancy that in my condition if I had less opposition and more society and stimulus-but John says the very worst thing I can do is to think about my condition, and I confess it always makes me feel bad (10).

The narrator disagrees with the ideas presented by male authorities in her life, but, as she repeats several times, what is she to do? She does not complain here about any physiological symptoms, instead complaining more about the "opposition" she is facing. She clearly desires healing, because she has thought about what kind of actions-such as exercisewould help "do her good". She is also trying to improve her condition. For example, the narrator claims that she does not write so much because John has forbidden it. However, of course she is still writing because we are supposedly reading her first-hand account. The existence of the story itself, penned by the narrator forbidden from pen and paper, becomes a symbol of resistance that defies John and his views. The narrator is attempting to cure herself-but not just of hysteria or any other diagnosable syndrome. She wants to cure herself of opposition, of the oppressive attitudes that surround her by resisting her prescription.

The narrator experiments further with the performance of diagnosis, embracing John's diagnostic tendencies even as she disagrees with them. Finding John's explanation that there is "nothing the matter with 
[her] but temporary nervous depression-a slight hysterical tendency" unsatisfactory, the narrator creates her own diagnosis, writing, "there is something strange about the house-I can feel it" (10). The narrator then spends large portions of the text gazing out of the window and contemplates "burning the house" (15). Generally assumed to signify the protagonist's growing insanity, the focus upon the house indicates the narrator's longing for cure, suggesting that the narrator intuits that cure necessitates some form of destruction. Hoping to find the answer to her problems, the narrator understands the desirability of diagnosis but also realizes that a "restoration of health" would require a different kind of violent architectural "restoration".

John confines the narrator to a room papered with an ugly wallpaper; soon, the narrator becomes obsessed with it, and further diagnoses herself by insisting that the wallpaper is at the heart of her sickness. She fervently writes in her journal: "The color [of the wallpaper] is repellant, almost revolting; a smouldering unclean yellow, strangely faded by the slow-turning sunlight. It is a dull yet lurid orange in some places, a sickly sulphur tint in others...I should hate [the wallpaper]... if I had to live in this room long" (13). The narrator's description of the paper mimics a body's experience of sickness. Often critics argue the wallpaper symbolizes the narrator's sickness (hysteria); ${ }^{7}$ however, the wallpaper magnifies the effects not of the illness, but of the cure. The winding leaf pattern in the wallpaper resembles a cage, symbolic of her imprisonment in the room. Moreover, the narrator's claim, "I should hate [the wallpaper] myself if I had to live in this room long" indicates that she realizes that if the rest cure is inflicted upon her for a long time, her hatred of the wallpaper will only grow. The narrator grows suspicious, not of her hysteria symptoms, but of the paper, and indulges in diagnostic patterns of thought that lead her to see the paper as the cause of her problems.

The narrator soon begs John to get rid of the wallpaper, hoping that she can banish the material embodiment of her imprisonment; however, John continues to refuse to believe that his medical treatment could damage her. She writes,

I suppose John never was nervous in his life. He laughs at me so about this wall-paper! At first he meant to repaper the room, but afterwards he said that I was letting it get the better of me, and that 
nothing was worse for a nervous patient than to give way to such fancies. 'You know the place is doing you good,' he said, 'and really, dear, I don't care to renovate the house just for a three months' rental.' 'Then do let us go downstairs,' I said, 'there are such pretty rooms there (14).

John never does permit his wife to leave the room, and the narrator's desire to be rid of the wallpaper can be read as an attempt to cure herself of the rest cure. Just as Clare argues that cure involves restoration, a type of destruction with the end goal of returning something to a previous, presumably healthy state, the narrator desires to see the room renovated, and herself freed from the wallpaper's winding, lurid pattern. John's refusal to renovate the room can be read as a refusal to help his wife. Meanwhile, the narrator's desire to be rid of the wallpaper, symbolic of her hatred of the rest cure, indicates that she wants to cure herself of a damaging cure.

As the urge to seek cure is intuitive and desirable, the narrator begins to imagine destroying the wallpaper so earnestly that she visualizes death within its pattern. The narrator secretly writes in her journal: "I never saw a worse paper in my life. One of those sprawling flamboyant patterns committing every artistic sin. It is dull enough to confuse the eye in following, pronounced enough to constantly irritate and provoke study, and when you follow the lame uncertain curves for a little distance they suddenly commit suicide-plunge off at outrageous angles, destroy themselves in unheard of contradictions" (13). The curves and lines of the wallpaper seem to the narrator to "destroy themselves". While this is generally interpreted as symbolic of the possibility that hysteria may lead to the urge to complete suicide, the narrator's interpretation of the wallpaper's pattern could indicate that she recognizes that treating hysteria necessitates a death of self. John's insistence on her imprisonment becomes a violent destruction of the narrator's creative desires. Moreover, for paper-the material on which this very story is printed-to be described in such an extreme way demonstrates that "The Yellow Wallpaper" is becoming as unruly and destructive as the wallpaper itself. The narrator's own written journal and Gilman's written story arguably commit "every artistic sin". They are written despite the commands of the narrator's and Gilman's doctors, and they fixate on wallpaper-an object traditionally thought to belong to a domestic, not literary or scholarly, realm. As the narrator continues to fixate upon the 
wallpaper as the source and embodied material reality of her physical and social condition, the short story itself becomes a meta representation of "artistic sin".

These complexities deepen when next the narrator begins to see a woman trapped and creeping within the wallpaper, and the narrator becomes fascinated by this human form. The narrator writes, "At night in any kind of light, in twilight, candlelight, lamplight, and worst of all by moonlight, it becomes bars! The outside pattern I mean, and the woman behind it is as plain as can be. I didn't realize for a long time what the thing was that showed behind, that dim sub-pattern, but now I am quite sure it is a woman. By daylight she is subdued, quiet. I fancy it is the pattern that keeps her so still. It is so puzzling. It keeps me quiet by the hour" (23). The sudden insertion of this trapped woman into the narrative creates a doubling effect that shapes the story into one about two women, the narrator and her echo in the wall. This may inspire (especially female) readers to become self-conscious about the fact that they themselves are gazing upon Gilman's on-paper story-especially since, evidently, paper has the power to push a woman's imagination in astonishing and dangerous directions. Readers themselves are studying, with rapt and productive fascination, a paper which has a pattern that becomes more complex "by the hour". The hysteria of the wallpaper is passed onto the narrator's text, which is then absorbed by Gilman's audience.

The narrator believes the paper is infectious, and that its mind-altering consequences impact John's abilities to diagnose. The narrator satirically diagnoses John, demonstrating her simultaneous desire for diagnosis and hatred of what the rest cure is taking from her. After noticing that John is watching her and observing her symptoms, the narrator mockingly imitates John's diagnostic thought, explaining why he "seems very queer sometimes" by saying that "It strikes me occasionally, just as a scientific hypothesis,- that perhaps it is the paper!" (26-27). This appropriation of John's scientific approach demonstrates that the narrator continues to simultaneously experiment with, and mock, diagnostic performances as uncertain and overconfident attempts to understand reality.

As she follows the movements of the woman behind the paper, the narrator confesses her watchfulness to her ever more attentive reader and indicates she no longer sees the wallpaper solely as a symbol of 
imprisonment. Studying the wallpaper gives her mind something to do, demonstrating the intriguing power of diagnostic thought: "Life is very much more exciting now than it used to be. You see I have something more to expect, to look forward to, to watch...[John] laughed a little the other day, and said I seemed to be flourishing in spite of my wallpaper. I turned it off with a laugh. I had no intention of telling him it was because of the wallpaper-he would make fun of me. He might even want to take me away" (27). The narrator no longer thinks about her "return" to health and doesn't want the wallpaper to be taken away; she rather thinks about what she has "to look forward to" (27). The narrator identifies with the woman she sees within it, and the symbol of her imprisonment is twisted into a symbol of liberation. However, the wallpaper never becomes attractive. It remains indeterminate, complex, unresolved, disturbing; it continues to embody, like the form of the story we are reading, "unheard of contradictions". By now the narrator is determined to find out its meaning. During the day, by "normal" standards, it remains "tiresome and perplexing" (28). But at night she sees a woman, or many women, shaking the pattern and trying to climb through it. Women "get through", she perceives, "and then the pattern strangles them off and turns them upside down, and makes their eyes white!" (30). Medical diagnosis can be relentless and deadly, resulting in confusion and a failure to solve problems.

The story ends in total confusion as the simultaneous urge to diagnose and hatred of diagnosis and its consequences meet in a moment of total unruliness. The narrator invites John into her room. John cries, "What is the matter?'. . 'For God's sake, what are you doing!' I kept on creeping just the same, but I looked at him over my shoulder. 'I've got out at last,' said I, 'in spite of you and Jane! And I've pulled off most of the paper, so you can't put me back!' Now why should that man have fainted? But he did, and right across my path by the wall, so that I had to creep over him every time!" (36). These lines refuse to clarify what has happened. "Jane" has never before been mentioned-the narrator's true name seems to have been dictated only in this moment of destruction. The woman in the wallpaper and the narrator-now seemingly the same woman-have pulled off the wallpaper, the hysteria liberated and the symbol of the rest cure demolished. The narrator claims John fainted; she therefore implies that he has been infected with "weakness" or the hysteria he himself assigned to the narrator. Furthermore, while at the beginning of the story the narrator indicated that she was writing 
down this entire first-person account in her journal, that narration is now thrown into disbelief (for how could she write this account if she is "creeping"?). Hysteria is never cured in the story; rather, hysteria, its wildness, randomness, and its slippery diagnostic categorization makes Gilman's most famous literary work possible. The story's narrator rejects a restoration or return to health; instead she has produced something very new, an outcome completely at odds with her physician-husband's expectations. She has, to put it confusingly, cured herself of the rest cure, and that she abandons a traditional form of narration causes the story itself to embody the contradictory forms of both disorder and cure.

"The Yellow Wallpaper" embraces destruction, and the narrator's writing itself becomes fragmented and ambiguous. Over the course of the text, hysteria, the rest cure, the house itself, and the wallpaper are all submitted as possible causes for the narrator's symptoms. Each of these uncertain diagnoses is met with confusion, rejection, and demolition while the narrator is trapped in systems of medical authority. It is impossible either to concretely diagnose the narrator or symptomatically solve the puzzles of the story, for the urge to diagnose is itself under question throughout the tale.

\section{Conclusion: Hysteria Undefined, Perpetuated}

In 1913, Gilman claimed that her story would put an end to the rest cure and that it was successful in preventing hysteria. She wrote that The Yellow Wallpaper was "not intended to drive people crazy, but to save people from being driven crazy, and it worked" (Why I Wrote the "Yellow Wallpaper'? 271). Just as when Gilman distanced herself from insanity (which she associated with laziness and invalidism) in her initial letter to Mitchell, here she dissociates her own story with craziness, attesting that cure and prevention are at the heart of the story's aims. Though Gilman claims that Mitchell amended his treatment of nervous illness after becoming aware of her story, scholars have not discovered any comment by Mitchell referring either to his treatment of Gilman or to her work of fiction. ${ }^{8}$ Gilman might not have been correct in assuming that her story prevented "craziness", especially as the tale itself unravels in a hysterical narrative form and simultaneously embodies the urge to diagnose that disorderliness. 
Nevertheless, critics have largely assumed that Gilman's story was supposed to be therapeutic and to find a cure for something, whether it be hysteria or something else. There has long existed an assumption that Gilman's story can be "solved". As Jane F. Thrailkill argues,

What has led critics astray in reading Gilman's story, I would argue, is that in presenting a creepy story that in fact becomes a story of creeping, it emulates the form of such a patient, which in turn elicits in its post-Freudian readers an almost irresistible will to interpret: to in fact doctor the text ... And, despite many indicators to the contrary, in almost every case the doctoring leads inexorably to an account of someone 'getting better': whether it's the narrator (who, last seen on all fours, purportedly triumphs over her husband and patriarchy), or Gilman (whose biography, which involved a lifelong struggle with nervous illness, is dramatically reshaped to model an archetypal feminist success story), or even the text itself (which has, in recent decades, quite literally been canonized) (552).

I hope to continue Thrailkill's work of explaining why we readers may feel an urge to "doctor" the story. As I have suggested, the story is infectious. It embodies an unruly form and it emphasizes the narrator's urge to diagnose, an urge that might resonate with its readers. The narrator experiences a deep desire for diagnosis even as she denounces patriarchal diagnostic thought. For readers to want to continue to diagnose both the narrator and Gilman makes sense in light of the fact that the story perpetually grapples with diagnosis, its desirability, and its severe consequences. However, it is vital that readers of the story be attentive to that urge to diagnose, for reading the story through only a pathologizing lens may limit our approaches to its hysterical performance.

Furthermore, Gilman's story does not cure hysteria or offer new modes for its treatment. Rather, the story demonstrates that hysteria is provocative and therefore a formidable source of literary inspiration. Though Gilman claimed her story prevented "craziness", she wrote in a letter, "I read the thing to three women here....and I never saw such squirms!" (quoted in Allen 186). By the author's own admission, the story seemed only to induce symptoms of hysteria in some of the women who heard it. The story succeeded in rendering the rest cure notorious, but it does not succeed in ending hysteria-it instead continues the violence 
of diagnosis inherent in the history of hysteria and points us to rich and fascinating diagnostic mysteries while also embodying hysteria's unruly and destructive power.

\section{Notes}

1 Charlotte Perkins Gilman, “The Yellow Wallpaper.” (1973), p. 13. Completed in 1890, Gilman's short story was first published in New England Magazine in 1892. The original 1892 publication included the inconsistent hyphenation of the word "wallpaper", although I follow critical convention in omitting the hyphen from the story's title.

2 Jane F. Thrailkill, "Doctoring 'The Yellow Wallpaper." (2002). Critics who famously read "The Yellow Wallpaper" in order to explain the narrator's symptoms or diagnose the author herself include Sandra Gilbert and Susan Gubar, The Madwoman in the Attic: The Writer and the Nineteenth Century Literary Imagination (1979, 89-92); Annette Kolodny, "A Map for Rereading: Or Gender and the Interpretation of Literary Texts" (1980); and Jean E. Kennard, "Convention Coverage or How to Read Your Own Life" (1992, 168).

3 Including Cynthia J. Davis, Bodily and Narrative Forms: The Influence of Medicine on American Literature, 1845-1915 (2000) and Diane Price Herndl, "The Writing Cure: Charlotte Perkins Gilman, Anna O., and 'Hysterical' Writing." (1988).

4 I tend to use the phrases "disability theory" or "disability studies," as these are used to describe many of my secondary sources. However, the phrase "crip theory" is also useful. Crip theory expands disability studies by “including within disability communities those who lack a 'proper' (read: medically acceptable, doctor-provided, and insurer approved) diagnosis for their symptoms." See Alison Kafer, Feminist, Queer, Crip. (18). Kafer's point that diagnosis has contributed to assumptions about who can identify as disabled and participate in the disability studies community underlines diagnosis's power in these fields of study.

5 These phrases are often used in medical texts (Albert 119). Also see R. R. Ledley and L. B. Lusted, "Reasoned Foundations of Medical Diagnosis." (9). The phrase "perform a diagnostic test" is also used (Albert 38). I could not find the history of the phrase "perform a diagnosis", but the use of the word "perform" as in "perform a cure" has been in use since 1774 (oed.com).

6 Ann J. Lane, To Herland and Beyond: The Life and Work of Charlotte Perkins Gilman (113). Lane's source for this anecdote is Gilman herself, who wrote 
of the encounter in her autobiography, published 43 years after "The Yellow Wallpaper".

7 As Gilbert and Gubar famously do in The Madwoman in the Attic (89-92).

8 The story that Mitchell changed his diagnosis and treatment of hysteria and neurasthenia after reading a copy of "The Yellow Wallpaper" is unsubstantiated and questioned by Suzanne Poirier, "The Weir Mitchell Rest Cure: Doctor and Patients". Women's Studies, vol. 10, 1983, pp. 15-40.

\section{Works Cited}

Albert, Daniel A., et al. Reasoning in Medicine: An Introduction to Clinical Inference. Johns Hopkins University Press, 1988.

Allen, Polly Wynn. Building Domestic Liberty: Charlotte Perkins Gilman's Architectural Feminism. University of Massachusetts Press, 1988.

Austin, John Langshaw. How To Do Things with Words. vol. 88. Oxford University Press, 1975.

Briggs, Laura. "The Race of Hysteria: 'Overcivilization' and the 'Savage' Woman in Late Nineteenth-Century Obstetrics and Gynecology." American Quarterly, vol. 52, no. 2, 2000, pp. 246-73.

Clare, Eli. Brilliant Imperfection: Grappling with Cure. Duke University Press, 2017.

Davis, Cynthia. J. Bodily and Narrative Forms: The Influence of Medicine on American Literature, 1845-1915. Stanford University Press, 2000.

Gilbert, Sandra, and Susan Gubar. The Madwoman in the Attic: The Writer and the Nineteenth Century Literary Imagination. Yale University Press, 1979.

Gilman, Charlotte Perkins. "Why I Wrote the 'Yellow Wallpaper'?” Forerunner, vol. 4, Oct. 1913, p. 271.

- - The Yellow Wallpaper. Old Westbury, The Feminist Press, 1973.

- - The Living of Charlotte Perkins Gilman: An Autobiography. Harper and Row, 1963.

Herndl, Diane Price. "The Writing Cure: Charlotte Perkins Gilman, Anna O., and 'Hysterical' Writing." NWSA Journal, vol. 1, no.1, 1988, pp. 52-74.

Kafer, Alison. Feminist, Queer, Crip. Indiana University Press, 2013.

Kasmer, Lisa. “Charlotte Perkins Gilman's 'The Yellow Wallpaper': A

Symptomatic Reading." Literature and Psychology 36.3 (1990): 1-15.

Kennard, Jean E. "Convention Coverage or How to Read Your Own Life." The Captive Imagination: A Casebook on "The Yellow Wallpaper", edited by Golden. The Feminist Press, 1992, pp. 168. 
Knight, Denise D. “'All the Facts of the Case': Gilman's Lost Letter to Dr. S.

Weir Mitchell.” American Literary Realism, vol. 37. no. 3, 2005, pp. 259-77.

Kolodny, Annette. "A Map for Rereading: Or Gender and the Interpretation of Literary Texts.” New Literary History, vol. 11, 1980, pp. 451-67.

Lane, Ann J. To Herland and Beyond: The Life and Work of Charlotte Perkins Gilman. Pantheon Books, 1990.

Ledley, R. R., and L. B. Lusted. "Reasoned Foundations of Medical Diagnosis." Science, vol. 130, 1959, pp. 9-21.

Mitchell, Silas Weir. Wear and Tear or, Hints for the Overworked. 5th ed. Philadelphia: Lippincott, 1871.

Morantz, Regina. "The Lady and Her Physician.” Clio's Consciousness Raised: New Perspectives on the History of Women, edited by Lois W. Banner and Mary S. Hartman. Octagon Books, 1976.

Poirier, Suzanne. "The Weir Mitchell Rest Cure: Doctor and Patients." Women's Studies, vol. 10, 1983, pp. 15-40.

Schuster, David G. Neurasthenic Nation: America's Search for Health, Happiness, and Comfort, 1869-1920. Rutgers University Press, 2011.

Sigerist, H.E. A History of Medicine. Oxford University Press, 1951.

Thrailkill, Jane F. "Doctoring 'The Yellow Wallpaper. '” ELH, vol. 69, no. 2, 2002, pp. 525-66.

Wood, Ann Douglas. “'The Fashionable Diseases': Women's Complaints and Their Treatment in Nineteenth-Century America." The Journal of Interdisciplinary History, vol. 4, no. 1, 1973, pp. 25-52. 

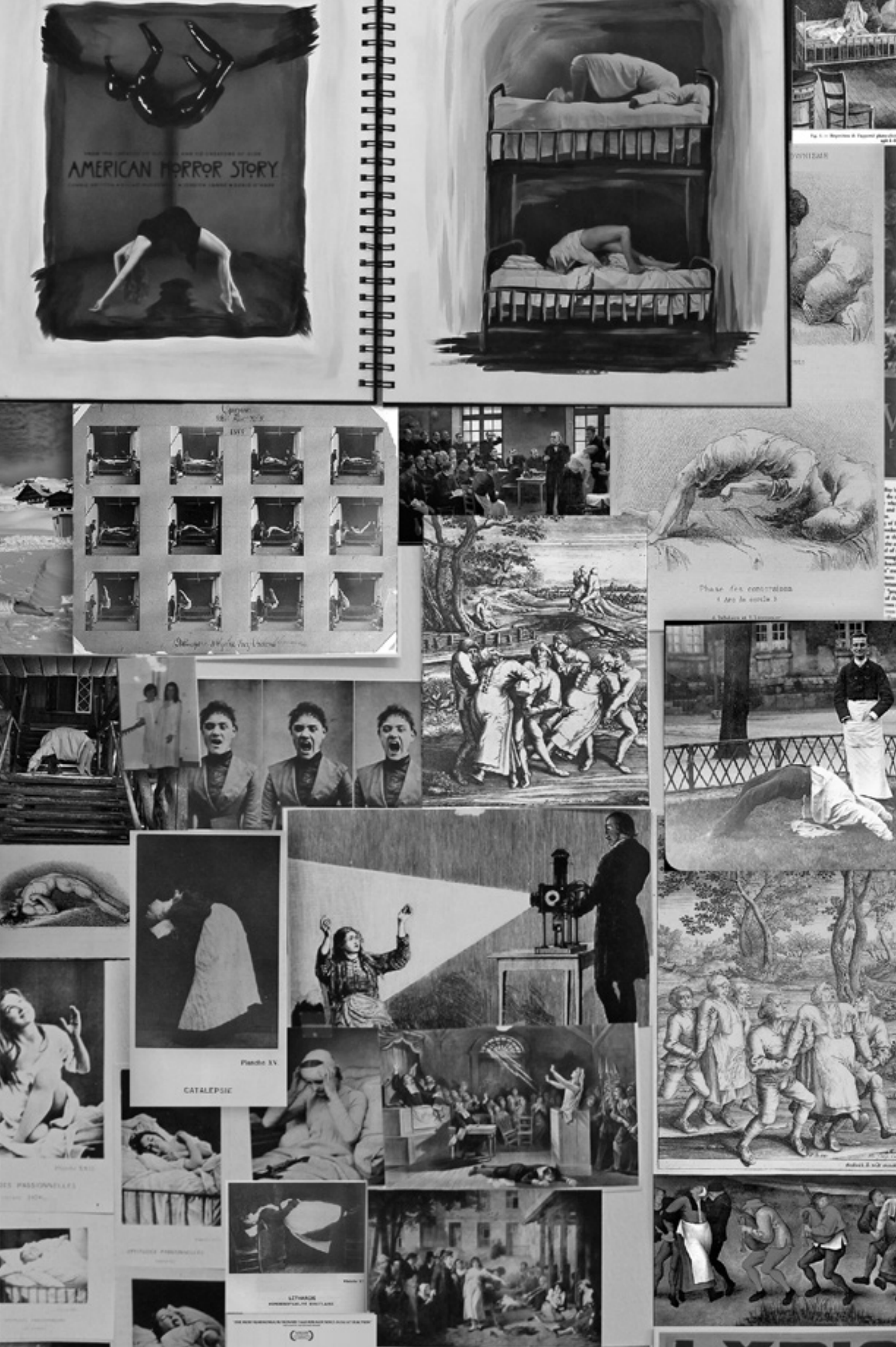

W .
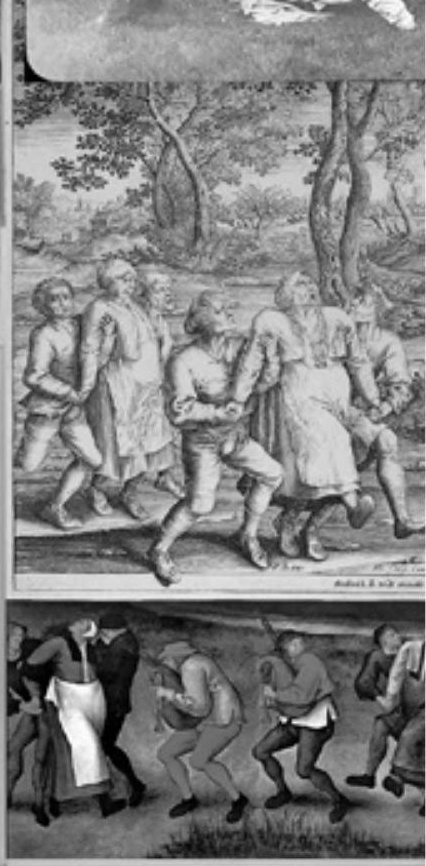



\section{HYSTERIA ACTIVISM \\ Feminist Collectives for the Twenty-First Century}

Elke Krasny

Hysteria has returned. We are witnessing a hysterical turn in the twentyfirst century. In this chapter I will lay out preliminary thoughts on the relationship between hysteria and patriarchy. In particular, the interest is on a new and emergent form of hysteria activism in current feminism. This hysteria activism is a critical reaction to today's patriarchal misogyny and its widely spread ideology of hate. Weaving together observations on the multiple crises of our time and its politics of mass hysteria with the knowledge of etymology and insights into histories of hysteria as they are of importance to building an understanding for the new phenomenon of hysteria activism, the structure of this chapter builds on the historic legacy of the wandering womb. Historically, the idea of the womb, hysterra, wandering in the body was behind the notion of hysteria. This dates back to Ancient Greek medical thought and to practices in demonology. Such a wandering approach allows for me to connect our hysterical moment today to other, much earlier hysterical moments as they have been recorded in history. ${ }^{1}$ Wandering is borrowed from hysteria's history. The medical legacy of hysteria is firmly tied to the attack. Hysteria was understood as a form of attack on body and mind. French nineteenth-century neurologist Jean-Martin Charcot famously described and detailed the different phases of the hysteric attack. ${ }^{2}$ Here, attack is understood both as the attack suffered from patriarchy, which results in the diagnosis of hysteria, and the 
attack performed by hysteria, which effectively exposes the traumas and wounds inflicted by patriarchy. Seen like this, the hysteric is both victim and agent of the attack. While wandering is behind the structure of this chapter, the attack serves as its motivation for analysis. The dual nature of the attack, tied to medical history just as much as to military history, is of interest. The attack, paradoxically, is therefore at once unplanned for and strategically prepared and planned out, unwanted and deliberate. The attack is also borrowed from hysteria's history, yet the motivation of this chapter is firmly rooted in our present day and age. Structured in three parts, the first one introduces the idea that hysteria and hysterical can be made out as keywords central to the formation of historical consciousness in the early twenty-first century. Understood as ungovernable emotional excess, hysteria has become a global signifier. We are witnessing a hysterical turn in the media-based politics characteristic of our period of post-truth politics dominated by the economy of emotions. The second part teases out connections between the idea of the wandering womb and the presentday relationship between hysteria, patriarchy, and feminism. The third and final part focuses on twenty-first-century hysteria activism with its attacks on violently misogynist patriarchy. It offers a first-time overview on feminist collectives performing hysteria activism with examples from Kolkata, London, Los Angeles, and Vienna.

\section{Hysteria and Hysterical: Keywords for the Twenty-First Century}

Hysteria is back. The ubiquity of the terms hysteria and hysterical in the media, in particular on social media, is astounding. We find political opponents accusing each other of being hysterical. We find political leaders, journalists, influencers, or public commentators speaking of mass hysteria. Those called hysterical are very often painted as hapless victims who are overwhelmed by unfounded emotions that cause them to have a completely distorted understanding of reality. Such a diagnosis of being over-emotional, of being out of control and unstable, is very much linked to the feminization the term hysterical engenders. Those who are hysterical can by no means be taken seriously. They are unreliable.

If Raymond Williams, foundational figure in the cultural studies with a materialist approach to the analysis of mass culture, were to search for Keywords: A Vocabulary of Culture and Society today, hysteria and hysterical 
would definitely be among his first finds. Keywords are critical tools useful to unlock the formation of contemporary consciousness. It is of importance to note that hysteria and hysterical are used in a most pejorative way today. In the vocabulary of politics, media, culture, and society, hysteria and hysterical are expletives. These terms are employed much like weapons as they target individuals, public figures, communities, large groups, or even the masses. These terms serve to discredit those called out as suffering from hysteria and acting hysterically. Currently, keywords circulate in real time as they spread and multiply digitally. Hysteria and hysterical have gone viral, amplified through the algorithms of digital cultures of communication.

\section{Pejorative Callings: The Hysterical Turn in the Twenty-First Century}

The hysterical turn is omnipresent in the media. Headlines, newspaper articles, hashtags, tweets, blog entries, and facebook posts all contribute massively to this hysterical turn. Hysteria and hysterical have been transformed into global mass signifiers. They are used to discredit all those who call out the systemic violence of xenophobic, misogynist, racist neoliberal authoritarianism, right-wing populism and far right extremism. Calling someone hysterical is a pejorative calling. Such callings are accusatory, insulting, spiteful, and hostile. Pejorative callings are a strategy employed to discredit others. They are a key feature of post-factual politics with its economy of emotion and its ties to the ideology of hate.

Let us now take a look at a small sample of news items that make use of the term hysteria: "Anti-Trump Hysteria" (Pletka), "Erdogan hysteria" (Williams, A.), "homophobic hysteria" (Spektor) fuelled by Brazilian president Jair Bolsonaro, "global warming hysteria" (Riddley), "hysteria about refugees" (Kristof), "border wall hysteria" (Lyons), "debt hysteria" (Chait), "Brexit hysteria" (Moore), "metoo mass hysteria" (Walsh). All crisis conditions are linked to hysteria.

Such use of hysteria is rhetorical, with hysteria referring to emotional excess lacking argument, reason, and credibility. This connects to historical discourses on hysteria with the hysterics believed to have a disordered state of mind and also held to be liars as they deceitfully only 
perform their symptoms. In Madness and Civilization, Michel Foucault has emphasized that Enlightenment medical discourse described hysteria as "the feminine illness par excellence" speaking of it as "[...] this disease in which women invent, exaggerate, and repeat all the various absurdities of which a disordered imagination is capable, has sometimes become epidemic and contagious" (Foucault 139, quoted in Bronfen, 112). Connecting the term hysteria to crisis conditions characteristic of our time calls for trouble. The response to crisis conditions is marked as hysteria. By calling out the response as hysterical, the crisis is belittled, made unreal. To all the others, who are sound of mind, such a reaction is alarmism, merely hysterical. Through such strategic use of hysteria, the very existence of crisis conditions is called into question.

\section{Hysteria/Hysterike/Hysterikos}

Hysteria, hysterikos, and hysterike are interesting words. The etymological root takes us to Ancient Greece. Etymologically, the word hysteria derives from the Ancient Greek hystéra, the womb. This is the part of the body that acts as a protective hollow space sheltering the offspring before birth.

Hysteria does not simply refer to an organ central to reproduction, but to the pathologization of the womb. Such pathologization is tied to the birth of patriarchy and to what is known as the phallic regime. In historical-medical terms, Hippocrates in Ancient Greece, and in historical-psychoanalytical, in Freudian terms, the womb meant trouble (King; Freud). The womb was understood to be a prime source of disorder and illness. Those subjects whom we might call wombed subjects were considered to be afflicted by such illnesses. In Ancient Greek medical and demonological thought the womb was believed to be a moving organ. Discursively, women, whose bodies were marked by the wandering womb, were regarded as not in control of their bodies and, by extension, of reproduction. Even worse, they were held to be dis-ordered precisely because of their lack of willful control over a key organ of reproduction, also known as generation. The womb is the place of generation, in the dual sense of the word. Generation means the act of procreation or production, and generation means the time span between the birth of parents and the birth of their offspring. This allows us to see the womb in its centrality to generation. Little surprise, 
then, that Ancient Greek medicine diagnosed the womb as a mobile and unruly organ. This provided the perfect reason to shore up the patriarchal power for generation as it was ordered and aligned to the forces of patriarchy.

Hysterikos is the adjective derived from hystera and means to have to do with the womb. We might come up with a new adjective here: wombic. While women are wombed beings, wombic refers to all beings sharing a passage from the womb to the world. Such is natality that it is tied to the womb. Interestingly enough, visibility and discourse on key reproductive organs, the womb, the breast, the vagina, and the penis, have been distributed very unevenly. While the phallus, and with it the phallic regime if we follow Jacques Lacan, occupies the symbolic order, hystéra and the hysteric mark social and cultural norms (Lacan; Butler). In a 1958 lecture, delivered in German at the Max-Planck Institute for Psychiatry, Jacques Lacan introduced Die Bedeutung des Phallus (The Meaning or Signification of the Phallus). This was consequently published in Écrits in 1966. In the Introduction II to Feminine Sexuality. Jacques Lacan and the école freudienne, translator Jacqueline Rose writes the following: "For Lacan it [the phallus] takes on this value as a function of the androcentric nature of the symbolic order itself" (38). In her chapter "Gender Regulations" included in the 2004 book Undoing Gender, philosopher Judith Butler has importantly drawn attention to the difference between the symbolic order, the Law, and the social sphere of norms (see 43). Building on her thought, we come to realize that the hysteric always acts in the social sphere. The hysteric embodies, and performs, the attack of the norm: the norm that attacks and the norm that is attacked.

\section{Hysteria Collectives: Feminist Attacks}

With hysteria and hysterical having been turned into pejorative keywords of the twenty-first century, claiming, reclaiming, appropriating, enacting, and performing hysteria can be understood as acts of feminism. Such hysteria activism adopts different strategies: deception, artful subterfuge, or confrontational attack. Hysteria activism uses the media as platform for global visibility and local issues. It performs subversive, resistant, defiant, satirical, even militantly violent attacks on patriarchy's attacks. 
The collectives, whose names first inspired my interest in their activism made me understand that there is, in fact, a new form of feminist activism for the twenty-first century. I have named this activism hysteria activism. The four collectives are Kolkata-based Eye Art Collective and its HysteriaFemCon, London-based Hysteria, the Association of Hysteric Curators in Los Angeles, and the Akademische Burschenschaft Hysteria zu Wien in Vienna. They make their claim to hysteria in order to expose the wounds and traumas inflicted by patriarchy. The history of hysteria is the history of patriarchy. Hysteria is one of the ways through which the traumatic wounds of patriarchy are rendered legible-audibly, visibly, bodily, performatively. Through feminist scholarship on hysteria we have come to understand its dual nature: on one side a symptom through which patriarchy's violence is being diagnosed and on the other side an act of defiance that exposes, showcases, makes visible and known this violence through its performance. An overview of the scope of feminist scholarship on hysteria extends by far the scope of this essay. Important contributions include those by Luce Irigaray, Julia Kristeva, Elisabeth Bronfen, Christina von Braun, or Elaine Showalter. Feminism connects hysteria to patriarchy. Hysteria is therefore not only implicated in the history of patriarchy, but also forms part of the archive of feminisms into which today's hysteria activism enters.

The twenty-first century witnessed the formation of feminist hysteria collectives in cities round the globe. Neither connected to each other nor adopting the same language, similar concerns can be identified in the work of four different feminist collectives based in Kolkata, London, Los Angeles, and Vienna. All four of them attack the attack of populist patriarchy, in particular right-wing populism and its violent misogyny. While right-wing nativism is a widely studied subject, right-wing gender politics, in particular misogyny as an ideology, remains in need of further study (Mudde; Köttig, Bitzan, and Petö).

Globally, nationalism, xenophobia, and misogyny are on the rise. Be it Brexitism, Trumpianism, Hindu Nationalism, or the Austrian Far Right, each locale where hysteria collectives have formed suffers from the attacks of violent othering rooted in the ideology of hate. With the four feminist collectives claiming hysteria, they make these connections understood. Choosing the word attack to describe their actions honors the hysterics who performed the attack at the Salpetrière at the end of the nineteenth century as they were studied by Jean-Martin Charcot 
and captured in photographs by Paul Richer. An earlier generation of feminist scholarship has identified the hysterics' agency. Christina von Braun wrote in 1985 that the hysteric is not victim to the attack, but much rather stages or enacts it (31). Enacting is useful for approaching the four contemporary hysteria collectives. Their chosen means of enacting attacks range from hashtag to Facebook entry, from citizen journalism to poetry, from appropriated imagery to striking visuality in art works, from printed publications to conference, from hymn to manifesto, from exhibitions to public wakes or demonstrations. The forms are at once vehicle and process of attacks.

"Hysteria is feminist activism". This is the opening sentence on the website of London-based and globally active platform Hysteria (hystericalfeminisms). Initiated in 2013 by a number of students from the School of Oriental and African Studies Feminist Society at the School of Oriental and African Studies at the University of London, they have grown into a global collective consisting of more than fifty individuals. Dedicated to feminisms in the plural, their publication Hysteria is conceived of as a radical platform for publishing. It brings together striking imagery, visual art, poetry, essays, and interviews. While all content is firmly committed to feminism, it is all about feminisms, contradictions, conflicts, and being firm about the fact that feminisms are based in supporting disagreements. Independence is key to the platform. Each issue of the publication is self-financed through crowd funding. In an interview with VICE Magazine, one of the members, Ama Josephine Budge, links their collective to historical hysteria while criticizing the widespread white bias in hysteria histories. She states: "Women diagnosed with 'hysteria' were incarcerated and studied in Pitié-Salpêtrière [hospital] in 19th century Paris. It previously was spiritual and tribal associations of women in heightened states, communing with the gods, medicine women, sacrificial virgins. Most cultures reference the hysteric in one guise or another. We reject the idea that HYSTERIA only references a white, European history, or feminism" (VICE Magazine). Asked to explain the notion behind hysterical feminism, Jago Rackham explains that "it's supposed to challenge an idea of a hegemonic knowledge or argument" (VICE Magazine). The interview is accompanied by a black-and-white photograph from Agata Cardoso's Arche-Types series in which the analog photographer explores the visual legacies of hysteria imagery owed to Charcot and Richer. There are also two quite troubling photographs of left hands that appear to 
be wounded. These are documentary images from the installation and performance Her/She Senses, a collaboration between Angela Ellsworth and Tina Takemoto (covenberlin; aellsworth.com/hershesenses/).

The collective uses launches, events, and exhibitions to share feminisms and its contradictions and controversies. Their nine-paragraph-long Hysteria Manifesto states the following: "Hysteria is a collective borne from juxtaposing and interlacing multiplicities of feminisms that react to histories of subjugation" (linkedin). They insist that " $\mathrm{f}[\mathrm{F}] \mathrm{eminisms}$ are for everyone and not reserved for the privileged few" (linkedin). And they introduce a radically new notion of solidarity, hysterical solidarity. They claim: "Without hysterical solidarity we are deluded by the composure of patriarchy" (linkedin). Hysteria counteracts the destruction and co-optation "by the multi-faceted, hydra headed, machinations of patriarchy, conservatism and capitalism" (linkedin). As of 2018, even though the collective's website has expired, its digital presence on facebook and twitter remains active and alive.

One of the cover photos we find on the facebook account of the Association of Hysteric Curators AHC is a black-and-white image titled These Hysterical Women. One of the two women suffers from an attack of migraine, the older one of the two soothingly gives some advice. The image is from a 1932 newspaper advertisement for Lydia E. Pinkham's Vegetable Compound Tablet Form. "Crying ... Sobbing ... laughing! She has no control of herself ... [...] over wrought. Nerves strung to the breaking point" (hystericcurators). The hysteria history referenced here is that of the widespread assumption of hysteria being a typical female affliction, and, of course, presenting a source for creating all kinds of marketable remedies to be sold as treatments. We identify here the hysteric woman in need of cure, the hysteric woman targeted by the market, and the hysteric woman consoled by an older female companion. All these elements, women accused of spinning out of control, the relation to the market, and transgenerationality, we find in the AHC collective. Initiated by Mary Anna Pomonis after a male museum curator rejected a proposed artistic contribution of hers on the grounds that it was too personal and not political enough, she took action. She decided to occupy the coveted, and historically controversially discussed, position of the curator "as a form of protest" (radicalactions; see Richter). She set out to form a supportive team of women of different ages curating each other, effectively rejecting the idea of so-called independent curating 
(Krasny). Their hysteria is their attack on the hegemony in the art world system. Their attack is curation without leadership, "working in a nonhierarchical way" (radicalactions). Their manifesto sums this up as follows:

AHC envelops a fluid, evolving, trans-generational group of women who gather bi-weekly to share in a discussion around contemporary feminism and the historicity of the term. We seek to explore notions of female protest and the presence of gendered articulations through a non-hierarchical structure based in dialogue and exchange. [...] As a working model, we understand that democratic consensus is slow and laborious in comparison to the type of fast paced and often decentralized systems found today. [...] We are invitational and open, focused on explorations of female power through vistas of holes, blanks, ruptures, and catastrophes. As an agent of chaos and change, we posit our curatorial agenda as a figurative fault line [...]" (radicalactions).

They meet regularly every two weeks to plan their actions collectively. These actions include art making, research on feminist art and history, studio visits, exhibitions, public talks, and public performance. Though originally formed around the misogyny and patriarchal power structure in art world politics rather than motivated by politics at large, their active website clearly demonstrates their political concerns as they post and lobby that Virginia, the last state in the US that has not yet signed the ERA amendment, to do so "that women can finally be included in the constitution" (hystericcurators). Hashtags they join in and make use of include amongst others \#equalpay \#equality \#socialjustice\#feminism \#feminists \#metoo \#timesup \#justiceforsurvivors" (hystericcurators).

"Hysteria will help people understand the nature and method of oppression that they face through the patriarchy, and will enable them to rise as gender tolerant individuals who actively combat gender violence" (autistic org). Hysteria activism was used by the Kolkata-based Eye Art Collective to expose and to attack the gendered everyday violence in their local Indian context. An article on the 2015 Hysteria FemCon written by Perana YSK starts as follows: "In India, a woman is raped every 32 minutes. A minor girl is abducted every 36 minutes. A girl is trafficked every 46 minutes. A woman is sexually harassed every 12 
minutes. 21 women are murdered every day" (youthkiawaaz). Against this background, the Eye Art Collective, who organized the 2015 three-day Hysteria FemCon in Kolkata, emphasizes that hysteria is a way to critically understand and counteract patriarchal violence. Hysteria is used to build solidarity and to gather knowledge for the collaborative feminist attack on the violent attacks of patriarchy.

The Eye Art Collective was founded in 2014 by a small group of students in Kolkata. As of August 2018, their website, which they used for this period of four years to announce their "art based programming" and their "independent counterculture webzine", has officially closed down (eye-art-collective). In her closing words, the founding member, Manisha Ganguly, looks back at their collectively shared work and their accomplishments: Starting from a "small room in Calcutta" dedicated to "truth-telling of hyperlocal issues [...] ignored by mainstream media", the feminist collective employed "citizen journalism" and relied on "crowdfunding" and "the goodwill of readers" (Ganguly). In their first year they "grew to a team of 30" reporting on "feminist counter culture" and "mass civil disobedience" (Ganguli). The collaborative journalism team reported on "human rights abuses in Kashmir, from the white papers to mass graves; followed the conflict in Bastar; interviewed people like Nobel Peace Prize nominee Parveena Ahangar and A Softer World; and broke the story on illegal land grabs in Kanha National Park" (Ganguli). They commented on "antifascism in the era of Trump and Modi" and the "acid attacks on Soni Sori" (Ganguli). As they continued their brave attacks through speaking out and reporting, they had to learn to survive this kind of investigative journalism as it was met by increasing violence. And they also suffered from the emotional duress their work caused them. They were "tortured by the trauma of reporting on gender violence as a mostly female team entirely composed of sexual violence survivors" (autistici). One of their early stories was on "hokkolorob, where the West Bengal police denied sending riot police to detain 80 students, hospitalised 37, and sexually assaulted women at a peaceful protest against sexual assault; a story which gave us 100,000 readers in a month" (Ganguli). This solidarity and support of readers led its being possible to organize "India's first of its kind national feminist convention Hysteria, at the Goethe-Institute in Kolkata" in 2015 (Ganguli). 
The invitation to the conference displays a highly visual artivism. We find assembled and grouped together a number of very different images that seek to draw attention to the fact that hysteria activism addresses the urgent issue of extreme patriarchal violence. Among these images there are the following two: a miniature watercolor showing the goddess Mahavidya Chinnamasta by the current-day traditional Indian painter Kailash Raj and the 1989 iconic work Untitled (Your body is a battleground) by US-American feminist artist Barbara Kruger (exoticindia; Caldwell). Both of these images, though in very different ways, join together women's bodies, reproduction, and violence. The Hindu Godess Chinnamasta is a paradoxical image, both giving life and taking life. She appears decapitated, her hand holding her head. Thin squirts of blood from her neck feed her own head and devotees. She stands on a copulating couple. Barbara Kruger's black-and-white split image of a woman's face was made in solidarity with the 1989 Women's March on Washington in support of women's reproductive rights. The motivation behind the HysteriaFemCon were the sexually violent and murderous attacks on women's bodies and the widespread rape culture in the Indian context, in particular the 2012 Delhi rape case in which Jyoti Singh, who was travelling on a bus, was gang raped, tortured, beaten, and eventually died from her injuries. This assault led to public outrage against murderous sexual violence in Delhi and other cities across India, but also in cities in Nepal, Sri Lanka, Pakistan, and Bangladesh. The Eye collective strategically chose the name Hysteria to address such patriarchal violence and to reclaim hysteria as a tool for raising awareness and building knowledge in solidarity. "We named the convention Hysteria to obliterate its relation to the fictional feminine mental illness by the same name, and reclaim the word from oppressive patriarchal connotations" (autistici). The program of the conference was structured in the following parts, "The Male Gaze in cinema and art", "Rape culture \& the patriarchy", "practical feminism \& self defense", Gender, Queer Theory \& LGBTIQA+ Rights", "Men as victims of the patriarchy", and "Fascism in the Indian Context". It also included screenings, such as the Eye Art Collective's Video to Hysteria, Macho by Linda Broadbent, slam poetry, musical contributions, and songs of resistance (autistici).

The conference brought to the fore the nexus of patriarchal, fascist, and cultural violence as they converge in misogyny. The collaborative feminist citizen journalism practiced on the collective's publication 
platform Eyezine attacked this nexus. From their work they learned the following: "It is possible to be objective about facts without being neutral, because the truths of structural oppression through gender, class, and caste in India are not neutral, but have very clear boundaries of oppressor and oppressed; and it is naive to pretend otherwise" (Ganguly). Hysteria activism is dangerous, laborious, and very hard to finance. In the Eye Art Collective's case it took place "amidst death and rape threats from the far-right" and it was challenged, and eventually they could not sustain their digital publishing model dues to the compulsory neoliberalism of "the advertising model of the digital economy" (Ganguly). The collective's lasting online legacy consists of a 650-article strong archive.

Vienna-based Akademische Burschenschaft Hysteria zu Wien have effectively rewritten two histories. They have altered both the course of history as it pertains to hysteria and the recorded history on the beginnings of German and Austrian Burschenschaften (see Fetteringhil Zwicker; Weidinger). Burschenschaft Hysteria firmly claims that the group was founded in 1810. This would make them the oldest existing Burschenschaft in the German-speaking context, being even older than the so-called Urburschenschaft which was founded in Jena in 1815 and has so far been recognized as the oldest Burschenschaft. And it would make hysteria's arrival in Vienna much earlier than Freud's well-known hysteric patients. Sigmund Freud's and Joseph Breuer's Studies in Hysteria were only published in 1895 .

Burschenschaft Hysteria members have taken it upon themselves to attack one of the oldest, most toxic, and also most influential expressions of power in masculinity formation in the German-speaking context: the Burschenschaft. Even today, many right-wing and far right politicians in Austria are members of traditional Burschenschaften. The collective's hysteria attack has led them to band together to enact their enemy's worst nightmare: they are officially recognized and registered as a "feminist and left-wing" Burschenschaft, open only to women (Wikipedia). They were founded in January 2016 and are officially registered as an association with the Austrian Ministry of Interior and with the part of the police in charge of registering associations. Their official name is Akademische Burschenschaft Hysteria zu Wien and the writer Stefanie Sargnagel acts as their headwoman (Wikipedia). 
Burschenschaft Hysteria has adopted all the symbols characteristic of conservative, right-wing, and alt-right Burschenschaften. When they march in public, they are all dressed in uniform, in black-white-red. They wear red hats. They have banners and flags with their mascot animal, the crying hyena. They have their own hymn, and much like their male counterparts they employ so-called couleur names (code names), which they use to refer to each other in public (see youtube). Their organization is strictly hierarchical, following rank and order. Like all the other Burschenschaften they have a phase of initiation before one can become a full member. After first making their appearance digitally on facebook, they took to the public. They appeared as self-commissioned Saal-Schutz (Hall Security), a term appropriated from Nazi terminology, with the Saal-Schutz being the historical beginning of the Schutzstaffel. They appeared as self-appointed Saal-Schutz for Stefanie Sargnagel when she received the Ingeborg Bachmann Award in 2016. They also acted as self-commissioned Saal-Schutz at Vienna City Hall for Elfriede Jelinek's Die Schutzbefohlenen. The performance at the grand auditorium of the University of Vienna had been interrupted and disturbed by the right-wing extremists called Identitäre, the Identitarians, and had to be moved to Vienna City Hall (VICE Magazine). In 2016, they staged a wake for patriarchy; its demise was celebrated via a march of mourning at Vienna's Prater. The police responded by sending out female police officers to act as the demonstration's guards.

Literary scholar Elisabeth Bronfen builds on Michel Foucault's writings on hysteria, published in his 1961 book Madness and Civilization. She draws attention to the fact that historically "the hysterical body" was a "hybrid of real illness and deception" (112). The Burschenschaft Hysteria borrows from the historical hysterical body this strategy of deception. As they appropriate it, they take it to perfection. They become what they seek to attack. Deception, appropriation, and exaggeration through satire are joined together by these feminist activists as they collaborate in unison to produce a hysterically real all-feminist and all left-wing Burschenschaft. The collective has the capacity to mobilize in the hundreds and thousands for collective public actions, in which nonmembers are also at times invited to join and increase their numbers, as long as they adhere to the before-announced dress code. They put forward political demands that adopt the guise of real politics. They demand that the right to vote for men be restricted and that an $80 \%$ quota of women and transgenders be introduced for all positions 
available in public service (Wikipedia). Their claim is that, through the power of the womb, they will pave the way toward "golden matriarchy" (Burschenschaft Hysteria facebook).

\section{In concluding: Attacking the Attacks}

Historically, hysteria has been used to turn women into beings at once controlled by their bodies and not in control of their bodies. Such is the paradox of hysteria. The womb was seen as the source of this disorder. Over centuries, hysteria has been made to appear natural to women. Thus, a lot of essentializing has been committed in the name of hysteria. First wave feminism witnessed the treatment of hysterical women in hospitals and in psychoanalysis. Hysterics became case histories. Much has been written about these women, at once victims and agents of hysteria under patriarchy. Second and third wave feminists in the fields of philosophy, history, theory, art making, and activism have rediscovered, in critical and analytical terms but also in quite celebratory modes, earlier hysterical performances. They have emphasized that the scope of hysteria clearly extended far beyond Jean-Martin Charcot's hospital or Sigmund Freud's couch as hysterics crossed lines of class, race, ethnicity, and age. The hysteric has become a key figure of subversive convulsions embodying the agony of resistance to patriarchy. The current feminism, with women marching and resisting fatally violent misogyny globally, resists the global climate of political violence and traumatic social and ecological ruination. Today's hysteria activism is much less a reinterpretation or a rediscovery of earlier feminisms' interest in hysteria, but rather a reaction to hysteria and hysterical being used as pejorative keywords for the twenty-first century. In light of the history of hysteria tied to essentialism and wombed beings, and in light of the current pejorative use of the terms hysteria and hysterical, making an activist and critical claim to hysteria for performing feminist attacks on patriarchy does not come easily. The hysteric activists whose work can be found across the globe have taken it upon themselves to wander into the traumas and the crises wrought by patriarchy. Attacking the attacks of patriarchy is not an easy thing to do. It requires courage, strength, endurance, and insistence. Performing these attacks in the name of hysteria is even more of a challenge given hysteria's entanglements with patriarchy. The stakes are high for feminist collectives who do. 


\section{Notes}

1 While reminiscent of Mike Bal's notion of travelling concepts, the idea of wandering as approach is different, as it values the importance of erratic movements. Developing wandering as a critical method in analysis and writing extends beyond this chapter and needs further elaboration.

2 See, for example, Elisabeth Bronfen's chapter "Charcot's Vampires" in her book The Knotted Subject: Hysteria and its Discontents, pp.174-240.

\section{Works Cited}

Association of Hysteric Curators. www.facebook.com/hystericcurators/?hc ref=ARQA5RYRaLNgewL_X-WISOQrjZIuzUE22HiDw6r5bSMseMJjxCBwcvreHpXU_iKPxM\&_tn__=kC-R. Accessed January 28, 2019.

Bal, Mike. Travelling Concepts in the Humanities. A Rough Guide. University of Toronto Press, 2002.

Braun, Christina von. Nicht ich: Logik, Lüge, Libido. Verlag Neue Kritik, 1985.

Bronfen, Elisabeth. The Knotted Subject. Princeton University Press, 1998.

Burschenschaft Hysteria. www.facebook.com/BurschenschaftHysteria/. 28 January 2019.

- - Hymne. youtube, March 16, 2018, www.youtube.com/ watch?v=spBlXjVgTCQ. Accessed January 28, 2019.

Butler, Judith. “Gender Relations.” Undoing Gender. Routledge 2004, pp. 40-56.

Caldwell, Ellen C. "The History of 'Your Body is A Battleground.” jstordaily, July 15, 2016, daily.jstor.org/the-history-your-body-is-a-battleground/. Accessed January 28, 2019.

Chait, Jonathan. "Conservative Economists Turning Back to Debt Hysteria." New York - Intelligencer, March 29, 2019, nymag.com/intelligencer/2018/03/ conservative-economists-turning-back-to-debt-hysteria.html. Accessed January 28, 2019.

Cohut, Maria. "Mass hysteria: An epidemic of the mind?" Medical News Today, July 27, 2018, www.medicalnewstoday.com/articles/322607.php. Accessed January 28, 2019.

Ellsworth, Angela. Her/She Senses, aellsworth, since 1992, www.aellsworth.com/ hershesenses/. Accessed January 28, 2019.

Eye Art Collective. "FAC. Feminist Art Collective." eye-art-collective, factoronto. org/schedule/film-night/eye-art-collective/. Accessed January 28, 2019. 
- - Hysteria FemCon 2015, autistici, December 2014, (www.autistici.org/ archive/20180802201244/www.eyeartcollective.com/hysteria/. Accessed January 28, 2019.

Fetteringhil Zwicker, Lisa. "The Burschenschaft and German Political Culture." Central European History, Vol. 42, No. 3, September 2009, pp. 389-428, www.jstor.org/stable/40600783. Accessed January 28, 2019.

Finlay, Heather. "Queer Dora: Hysteria, Sexual Politics, and Lacan's Intervention on Transference." GLQ A Journal of Lesbian and Gay Studies, vol. 1, no. 3, 1994, pp. 323-347, doi.org/10.1215/10642684-1-3-323. Accessed January 28, 2019.

Finzi, Daniela, and Hermann Westerink. Dora, Hysteria, and Gender. Reconsidering Freud's Case Study. Leuven University Press, 2018.

Foucault, Michel. Madness and Civilization. A History of Insanity in the Age of Reason. Random House, 1965.

Freud, Sigmund. Studies on Hysteria. Standard Edition. Vol. 2 Hogarth Press, 1955.

Ganguly, Manisha. "Eyezine is dead: So Long, and Thanks for all the Fish." autistici, May 27, 2018, https://www.autistici.org/archive/20180802201255/ http://www.eyeartcollective.com/eyezine-is-closing/. Accessed January 28, 2019.

Gush, Rose-Anne. "Fraternising in Austria." Art Monthly 410, October 2017, pp. 41-42.

Howard, Ellie. "Interview with feminist Artist Agata Cardoso," covenberlin, 7 September 2015, http://www.covenberlin.com/interview-with-feministartist-agata-cardoso/. Accessed January 28, 2019.

Hysteria. hysterical feminisms, www.hystericalfeminisms.com/about-intro/. Accessed September 30, 2018.

-—. Hysteria Manifesto. (linkedin), www.linkedin.com/company/hysteriaperiodical. Accessed January 28, 2019.

Hysteria@hysterical feminisms. hysterical feminisms. www.facebook.com/ hystericalfeminisms/. Accessed January 28, 2019.

Irigary, Luce. This Sex Which Is Not One, translated by Catherine Porter and Carolyn Burke. Cornell University Press, 1985.

King, Helen. "Hippocratic Hysteria: the Womb and Its Destinations." Hysteria Beyond Freud, edited by Sander L. Gilman, Helen King, Roy Porter, G. S. Rousseau, and Elaine Showalter. University of California Press, 1993, pp. 14-25.

Köttig, Michaela, Renate Bitzan, and Andrea Petö, eds. Gender and Far Right Politics in Europe, Palgrave Macmillan, 2017. doi 10.1007/978-3-319-43533-6. 
Krasny, Elke. "Curatorial Materialism: A Feminist Perspective on Independent and Co-Dependent Curating." OnCurating issue 29, May 2016, pp. 96-106, http://www.on-curating.org/issue-29-reader/curatorial-materialism-afeminist-perspective-on-independent-and-co-dependent-curating.html. Accessed January 28, 2019.

Kristeva, Julia. Revolution in Poetic Language. Columbia University Press, 1984.

Kristof, Nicholas. "Hysteria about Refugees, but Blindness on Guns." The New York Times, December 5, 2015, www.nytimes.com/2015/12/06/opinion/ sunday/hysteria-about-refugees-but-blindness-on-guns.html. Accessed January 28, 2019.

Lacan, Jacques. Die Bedeutung des Phallus The Meaning (or Signification) of the Phallus), Lecture at the Mack Planck Society in Munich, May 9, 1958, lacanianworks, www.lacanianworks.net/?p=11851. Accessed January 28, 2019.

Lemming, Becky. "Nothing is Okay: An Interview with the Minds behind the feminist journal 'HYSTERIA', Vice, August 27, 2015. www.vice.com/en_us/ article/avykxe/interview-with-two-members-of-the-feminist-collectivehysteria. Accessed January 28, 2019.

Lyons, Gene. "How to end Border Wall Hysteria. Get Real." Chicago Sun Times, January 1, 2019, chicago.suntimes.com/columnists/wall-border-securitydonald-trump-nancy-pelosi-gene-lyons-federal-shutdown/. Accessed January 28, 2019.

Moore, Suzanne. “How a Toy Helicopter Revealed Brexit Britain’s Mass Delusion.” The Guardian, January 7, 2019, www.theguardian.com/ commentisfree/2019/jan/07/drones-brexit-hysteria-anxiety. Accessed January 28, 2019.

Morgan, Eleanor. Hysterical: Why We Need to Talk about Women, Hormones, and Mental Health. Seal Press, 2019. (forthcoming as of time of writing)

Mudde, Cas. "The Populist Zeitgeist." Government and Opposition, vol 39, issue 4, Autumn 204, pp. 534-63, doi.org/10.1111/j.14777053.2004.00135.x

- - Populist Radical Right Parties in Europe. Cambridge University Press, 2009. doi.org/10.1017/CBO9780511492037

Pletka, Danielle. “The Anti-Trump Hysteria Isn't Helping.” The Atlantic, July 17, 2018, www.theatlantic.com/ideas/archive/2018/07/the-anti-trumphysteria-isnt-helping/565373/. Accessed January 28, 2019.

Pomonis, Mary Anna. "The Association of Hysteric Curators: Ladies of the Largest Hearts.” radical actions, March 1, 2016, www.radicalactions.com/ association-of-hysteric-curators. Accessed January 28, 2019. 
Raj, Kailash. Mahavidya Chinnamasta, amazon, www.amazon.in/Exotic-IndiaMahavidya-Chinnamasta-Watercolor/dp/B01JZO9IDQ. Accessed January 28, 2019.

Richter, Dorothee. "Artists and Curators as Authors - Competitors, Collaborators, or Teamworkers." OnCurating issue 19, June 2013, pp. 43-57, http://www.on-curating.org/issue-19-reader/artists-and-curators-asauthors-competitors-collaborators-or-team-workers.html. Accessed January 28, 2019.

Riddley, Matt. "Ignore the global warming hysteria: hurricanes are not getting worse.” The Spectator, October 20, 2018, www.spectator.co.uk/2018/10/ matt-ridleys-diary-ignore-the-global-warming-hysteria-hurricanes-are-notgetting-worse/. Accessed January 28, 2019.

Rose, Jaqueline. "Introduction II." Feminine Sexuality. Jacques Lacan and the école freudienne, edited by Juliet Mitchell and Jaqueline Rose, translated by Jacqueline Rose, Macmillan Press, 1982, pp. 27-58.

Savage, Michael. Stop Mass Hysteria: America's Insanity from the Salem Witch Trials to the Trump Witch Hunt. Center Street, 2018.

Spektor, Matias. "It's Not Just the Right That's Voting for Bolsonaro. It's Everyone.” Foreign Policy, October 26, 2108, foreignpolicy.com/2018/10/26/ its-not-just-the-right-thats-voting-for-bolsonaro-its-everyone-far-rightbrazil-corruption-center-left-anger-pt-black-gay-racism-homophobia/. Accessed January 28, 2019.

Tasca, Cecilia, Mauro Giovanni Carta, and Bianca Fadda. "Women and hysteria in the history of mental health." Clinical Practice $\mathcal{E}$. Epidemology in Menthal Health, vol 8, 2012. 2012; 8, pp. 110-119, doi: 10.2174/1745017901208010110.

These Hysterical Women, www.facebook.com/hystericcurators/photos/a.347 864798728269/979934885521254/?type=3\&theater. Accessed January 28, 2019.

——, www.radcliffe.harvard.edu/schlesinger-library/item/advertisementtitled-these-hysterical-women. Accessed January 28, 2019.

Walsh, Matt. "\#Metoo is Mass Hysteria - It Needs to End." World Net Daily WND, September 29, 2018, www.wnd.com/2018/09/metoo-is-masshysteria-it-needs-to-end/. Accessed January 28, 2019.

Weidinger, Bernhard. "Student corporations in the 19th and 20th century." January 6, 2018. https://geschichte.univie.ac.at/en/articles/studentcorporations-19th-and-20th-century. Accessed January 28, 2019.

Williams, Allison. "Let's get real about the Erdogan hysteria." Handelsblatt Today, January 1, 2018, www.handelsblatt.com/today/opinion/balancing- 
act-lets-get-real-about-the-erdogan-hysteria/23583496.html?ticket=ST838652-NZarQtRtIJ6K1hZkaN4F-ap4. Accessed January 28, 2019.

Williams, Raymond. Keywords. A vocabulary of culture and society. New York: Oxford University Press, 1976.

Y.S.K, Perana. “'Hysteria': Of Feminism, Gender Equality And The Collective Outrage Against Patriarchy." youthkiawaaz, no date, www.youthkiawaaz. com/2014/11/hysteria-by-eye/. Accessed January 28, 2019. 


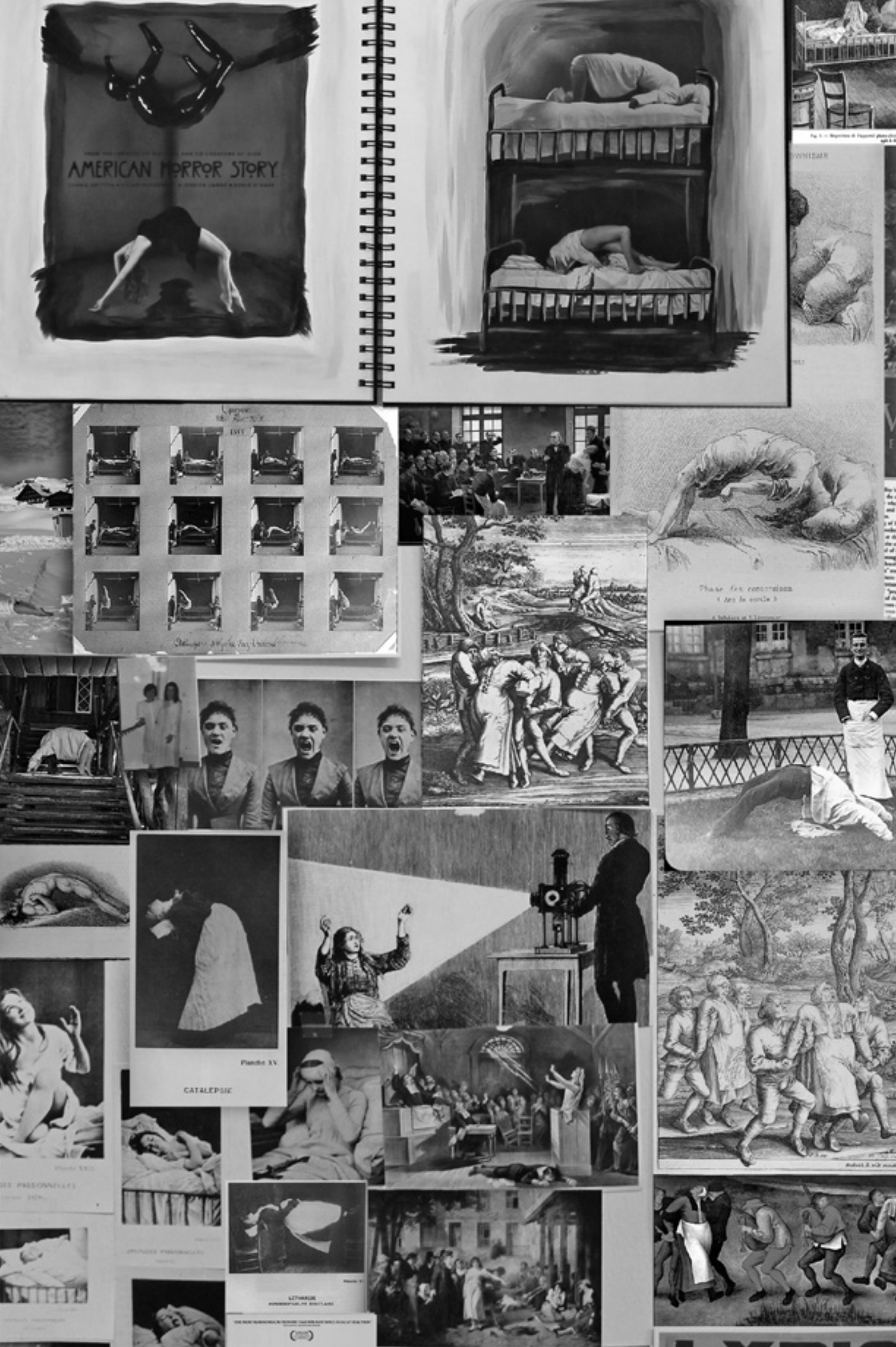

W .
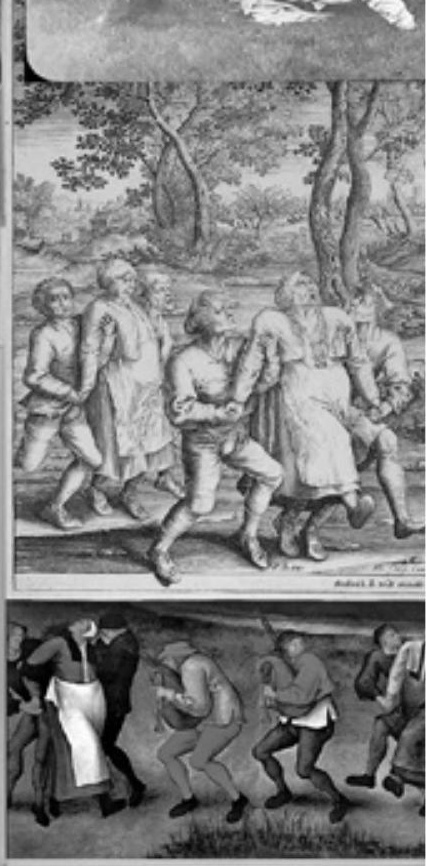



\section{DELILLO AND MASS HYSTERIA}

Sean Metzger

This essay offers some thoughts about the American novelist Don DeLillo's work in relation to crowds, hysteria, and a stage adaptation by Jody McAuliffe of the novel Mao II. ${ }^{1}$ DeLillo's fiction tends to focus on white male protagonists, a feature of his writing that I observe in relation to the resonance of DeLillo's work today and the gendered discourse of hysteria. Juliet Mitchell has argued in Mad Men and Medusas: Reclaiming Hysteria (2000) that "hysteria has been feminized", and further contends that the disappearance of hysteria as a diagnosis dovetails with observations of hysteria's symptoms in men, especially from WWI forward (7). Although I am less interested than Mitchell in hysteria as a universal condition and its resuscitation as a clinical discourse, I do find that she and her fellow travelers like Elaine Showalter provide a productive mode of cultural analysis to articulate the stress and anxieties pertaining to the late twentieth and early twenty-first centuries. For me, such anxieties manifest themselves in the visual realm registering on a mass scale issues of amnesia, hallucinations, and problems of vision. I recognize that in deploying this small list of symptoms once correlated with hysteria I draw selectively to sketch the contours of a way of seeing characterized by what I would call mass hysteria. Again my point is to offer a direction for cultural critique rather than diagnosing an individual's psychic condition. Mass hysteria thus names a process of envisioning and a commentary on the visual bombardment that marks the current 
historical moment. Similarly, I find myself returning to DeLillo's fiction and drama because his oeuvre expresses the confusion, loss, and terror produced in our era of late capitalism. Indeed, DeLillo sketches the threads that warp individuals into much larger social fabrics with his Mao II being exemplary in this regard.

\section{Situating DeLillo Now}

The Trump era has amplified white male terror both in the sense of those who openly commit acts of violence and those who deem themselves and the nation imperiled by various kinds of immigrants. The frenzied attention focused on these issues returns me to the literary corpus of DeLillo, an author who has, since the 1970s, frequently linked networks with conspiracy and paranoia even as critics often dubbed him a leading exemplar of American post-modernism. Whether we understand postmodernity in Fred Jameson's formulation (following Ernest Mandel) as the third in a trio of moments containing "technological revolution within capital itself"- this epoch being the one in which monopoly capitalism yields to multinationalism-or through Jean-François Lyotard's notion as a period and aesthetic that render grand narratives suspicious, the content of Don DeLillo's prose, if not always its form, illustrates what one might call postmodern life: human relationships mediated by technology, social structures fragmented, terror anonymous but augmented, individual subjectivities submerged under crowds (Jameson 35; Lyotard). DeLillo's fiction relentlessly returns to these themes notwithstanding those astute DeLillo readers who find in this literature figures of hope and redemption, of the innocent and of the miraculous. ${ }^{2}$

Indeed, perhaps because of DeLillo's skill at using literature to reflect on social life in the era of late capitalism, he has been attacked for his purported "hysterical realism". James Wood writing in The New Republic in 2000 derided DeLillo along with Zadie Smith and several other American and British authors as writing fiction that was "evasive of reality while borrowing from realism itself" (Wood). The novels Wood grouped as hysterical were in his words "excessively centripetal"; Wood argued that the elaborate plots worked like Matryoshka dolls or Chinese boxes with layers and layers of action contributing to an intricate whole. The problem, Wood opines, is that such emphasis on details and their 
eventual convergences left little room for character development. The criticism Wood offers in this vein is relevant to conversations about performance. As Wood writes, "Certainly the characters who inhabit the big, ambitious contemporary novels have a showy liveness, a theatricality, that almost succeeds in hiding the fact that they are without life: liveliness hangs off them like jewelry" (Wood). These ornamentations produce what Wood calls a "shiny externality" that offers surface rather than depth.

As will become evident, I disagree with Wood's assertion insofar as I value surface encounters as productive. I will try to recuperate a part of his key term "hysterical realism" to do work divergent from Wood's intentions. The use of hysterical in his description calls attention to a surface theatricality. Within studies of hysteria more properly, such corporeal manifestations are generally understood as somatizationthat is the rendering of symptoms through the body or external displays of behaviors. Pressing on these particular expressive gestures, I find that DeLillo's fiction seems invested less in the creation of character per the tradition of the Bildungsroman than in individuals formed in relation to seen and often unseen forces that motivate behaviors linking people together.

The emphasis on relationships is precisely why I turn to a stage adaptation of Mao II because it further illustrates how networks of people and technology have produced an era in which humans encounter one another increasingly at a surface level. At the time the novel was first published in 1991, such surfaces included television and other mass media; by the time of McAuliffe's stage adaptation in 2002 such interfaces would include the computer screens that catapulted us into the virtual world. McAuliffe's intermedial theater production, therefore, utilized screen images in a manner that foregrounds such phenomena. The relationships produced through the screens and through the theater space itself generated an apparent paradox which DeLillo's Mao II addresses as a thematic concern: in the age of new media and advanced capitalism, human relationships are close and distant at the same time, intimate yet often impersonal. Further, the images used to convey information about people-whether footage from the nightly news or the avatars representing individuals on various social media sites-do not guarantee access to truth, personal or otherwise. By staging close encounters with live actors and also the images of 
characters, McAuliffe's work materializes concerns about liveness, mediation, and human relationships.

The resultant surface encounters in McAuliffe's theater (between actors and the mise-en-scène as well as the audience and the theatrical production) suggest a different ground for the manifestation of hysteria than what Josef Breuer and Sigmund Freud had identified in the then relatively recent emergence of the bourgeois nuclear family. Whereas kith and kin was at one time more or less localized, technology has facilitated circuits of relations across space that might nevertheless impact an individual subject. How, then, might hysteria be understood differently? By invoking hysteria here and throughout this essay, I am in dialogue with the body of literature called psychoanalytic theory but with an aim toward productive speculation rather than clinical diagnosis. Insofar as I follow scholars like Elaine Showalter in thinking about "the cultural narratives of hysteria" or what she calls "hystories", I depart from her intertextual analyses of maladies like chronic fatigue syndrome, multiple personality disorder, and other conditions with at least partially psychic etiologies (Showalter 5). Instead, I draw on certain psychoanalytically inflected theories in order to expand the understanding of art that addresses what it means to be human around the millennial moment.

In his novels, DeLillo provides a sense of the uncomfortable connectedness common to our era of mediatization and commodification. For DeLillo, such networks often prove traumatic and lead to individual dissociation. Here we might say DeLillo intersects Breuer rather more than Freud (who disregarded hypnoid states [dissociation] in favor of a theory of repression and a model of psychosexual development). But the oneiric has perhaps undergone a cultural revival with the rise of media industries that continuously recycle images across a twenty-four-hour news cycle. Or we might consider DeLillo's Point Omega (2010) in which a character returns to watch 24 Hour Psycho, an installation version of the film where the frames are slowed, so watching them becomes a kind of durational performance. That hallucinogenic space becomes one site of not quite successful human interaction in DeLillo's hands.

Lest we think that my own interest in DeLillo moves too far afield from the bourgeois familial structures that gave rise to discourses of hysteria in Breuer and Freud, family has remained central in DeLillo's writing. 
However, in his oeuvre that term tends to mark tenuous relationships: from David and his ex-wife in his first novel, Americana (1971), to Jeff, Ross, and Artis in his latest, Zero K (2016). Indeed, Mao II opens with a scene of what could be construed as the domestic household form multiplied and run amuck. Whereas psychoanalysis frequently turns to intimate structures of kinship as causal in individual psychic constitution, DeLillo shows his readers permutations of such arrangements that situate the individual in vast webs of human and technological agents. This tangled state of affairs challenges notions of individual autonomy and erodes the social structures that have long supported such a construction. In sum, then, DeLillo offers textually constructed worlds that reveal the power of described images to alter perception, to illustrate how people see when surface image and some version of a more grounded, empirical reality blur. Traditional forms of kinship also alter in this Weltanschauung. I will argue that such formulations produce a way of seeing productively labeled mass hysteria.

\section{DeLillo's Mao II, Crowds, and Mass Hysteria}

Mao II opens at Yankee stadium with a woman named Karen and a Korean man she has just met participating in mass nuptials conducted by Reverend Moon. From this prologue the book takes us into the world of Bill Gray, a reclusive writer based in upstate New York struggling to complete his highly anticipated and decades-overdue third novel. He is attended by his assistant Scott and Scott's girlfriend, a post-cult Karen. The trio hosts a photographer named Brita, who is interested in creating a portrait series of writers (an issue to which I will later return). Gray eventually departs Scott's company to meet his editor, who wishes to use the author's celebrity as an artist who has chosen disappearance to assist a French poet who has been disappeared (that is, held hostage) in Beirut. This loose parallel compels Gray's passage to London to speak on the poet's behalf and then on to Greece, where he is coincidentally hit by a car; Gray dies in anonymity en route to Lebanon. We literally track the death of the author here. An epilogue involves Brita's trip to Beirut to interview and take pictures of the kidnapper terrorists.

For reasons of space and argument, I focus on the prologue and the epilogue. In regard to the former, the witnesses of the scene are Karen's father, Rodge, and his wife, Maureen (although members of 
the Unification Church, perhaps more frequently called "Moonies", sometimes referred to Moon and his wife as true parents). Founded in 1954 following partition, the Korean War, and the creation of the DMZ, the Unification Church offered one response to the profound trauma suffered by Korean families in the middle of the twentieth century. ${ }^{3}$ The novel thus begins with a scene of familial restructuring on a mass level, one that recalls larger sociopolitical events that also recast individual families into massive quasi-kinship structures held together through national ideology. Such dramatic transformations did not only obtain in Korea. The very title of Mao II gestures to China's recalibration of the family through socialist policies and the ways in which the Chinese state deployed discourses of affiliation and relation to promote communist ideology. By deploying references to Asia, the prologue establishes a comparative matrix in which the individual American family unit encounters its apparent others.

However, the novel's submersion of the nuclear family within the larger crowd applies to more than the Unification Church and communist China. DeLillo sets the prologue in Yankee Stadium, a site of a prototypically American pastime. In such a venue, individual spectators willingly submit to the ideology of baseball, although such a desire for a merging of bodies into a great mass has perhaps more to with capitalism than religion or politics. Historian Steven Reiss in his book, Touching Base: Professional Baseball and American Culture in the Progressive Era, argues that the game expanded with urban mass transit in the period and a public relations campaign "waged by baseball magnates and sportswriters" (12). Such promotion fostered "civic pride" and furthered an "ideology of sport that emerged in the Jacksonian era, which justified sport and physical culture as useful and moral activities that promoted good health, sound morals, and an honorable character" (19-22). According to Reiss's research, "baseball was said to be second only to the public schools as a teacher of American mores to immigrant children" (29). Moreover, baseball attracted crowds who would then mingle with one another, ostensibly democratizing a frequently classstratified society (31).

Notwithstanding such differences among the different crowds referenced in the prologue, the first few pages of the novel link different types of crowds. Put otherwise, Mao II implies that the individual and the nuclear family have subordinated their religious, political, and social lives to 
various group experiences. Whatever else such groups might produce, they all potentially manifest various sorts of what could be described as (non-parallel) trauma: departure from a religious sect, reeducation by the state, loss at the World Series. Avowing such contexts, the prologue ends with the much-cited line "The future belongs to crowds" (DeLillo 16).

At the level of the language, sentence construction, and point of view, the prologue insists on the presence of the crowd. The opening line is "[h] ere they come, marching into American sunlight" (3). The they in this case takes form through the elaboration of DeLillo's specific prose. "They are grouped"; "[t]hey assemble" becoming "one continuous wave" that becomes "an undifferentiated mass" which takes on increasingly military characteristics in its description as "columns" eventually approaching "division strength" (3). All this growth happens in a dozen sentences. The crowd itself becomes a menacing entity in this scene of collective matrimony. The book opens with an omniscient perspective that foregrounds Rodge observing the rituals taking place in order to glimpse his daughter. The narrative point of view slowly shifts from describing those who observe to those who participate-from Karen's parents to Karen herself. This movement from outside the group to within it places the reader within the crowd.

The French writer Gustave Le Bon published The Crowd: A Study of the Popular Mind around the same time that Breuer and Freud issued their Studies on Hysteria. Le Bon has become a seminal figure in crowd psychology, but I note here his remark that "[c]rowds, doubtless, are always unconscious" (6). DeLillo's shift is, in contrast, on the page, but he does little to introduce Karen to the reader and, by extension, does little to flag the reader's immersion in the crowd. Rather he places us in the scene of the stadium until the prose arrives at a focal point. Stated differently, the prologue is cinematic. At the end of one of the longest sentences in the prologue "in the middle of their columned body, lank-haired and up-close, stands Karen Janney, holding a cluster of starry Jasmine and thinking of the bloodstorm to come" (DeLillo 7). Following Le Bon, this cinematic crowd that the reader joins through the perspective of Karen is more prone to action than reflection in part because the terms of subjectivity transform in relation to the crowd. 
Le Bon's study of the crowd holds further interest for at least three reasons (perhaps despite his own reactionary political inclinations). First, as Le Bon writes:

The psychological crowd is a provisional being formed of heterogeneous elements, which for a moment are combined, exactly as the cells which constitute a living body form by their reunion a new being which displays characteristics very different from those possessed by each of the cells singly (15).

Second, the crowd is also feminine in Le Bon's view because of its inability to work as a reasoning subject. ${ }^{4}$ Third, the crowd's existence depends on images. As he writes, "A crowd thinks in images, and the image itself immediately calls up a series of other images, having no logical connection with the first" (23). Several pages later Le Bon continues, "Crowds being only capable of thinking in images are only to be impressed by images. It is only images that terrify or attract them and become motives of action" (40).

Here one might question Le Bon's relevance. As Jodi Dean notes in Crowds and Party (2018), for Le Bon "[t]he crowd is not a community. It doesn't rely on traditions. It doesn't have a history . . Rather, the crowd is a temporary collective being" (9). Dean's analysis acknowledged, the material conditions that enable crowds to form and that sustain it are not the focus of Le Bon's work. For example, the crowd may not come together because of a shared narrative of the past in his view, but Le Bon does discuss toward the end of his text the "history of the crimes committed by crowds" (93). Le Bon's own line of argumentation raises questions as to how long the crowd endures before it becomes something else. Moreover, when one encounters an apparently random assortment of individuals collected together, what is the effect of the image of the crowd on the onlooker or even the individual swept up in the crowd for a short duration? Such queries point as much to the crowd as a temporary entity that morphs into something other than the sum of its parts as to the appearance of the crowd.

These points about the image of the crowd are indeed furthered by DeLillo's Mao II. From its prologue the novel jumps from character to character in different locations-Karen looking for signs of Bill in New York, the hostage in an enclosed room somewhere in Beirut, etc.. 
Such spatial transitions inform Laura Barrett's discussion of space in which she states, "Mao II presents a world in which the negotiation of unfamiliar territory--labyrinthine urban centers, vexing architecture, ambiguous images, and technological communication--compromises notions of subjectivity" (788). Situated consciously within a Jamesonian understanding of the postmodern, Barret's argument proceeds to develop an analysis of DeLillo's book in the context of the other media that the text references, particularly photography. For Barret, the photograph informs the structure of the novel. She sees the brief prologue and epilogue serving as the borders that frame and complicate the principal narrative. The book's penguin edition also contains several images that she analyzes. The photographs all contain multiple people; they are, with perhaps one exception that depicts only three boys, crowd scenes. Barrett is finally concerned with the role of photography in the narrative itself. Although I do not fully align with her argument-if I can do a vulgar summary here-that photography destabilizes individual subjectivity in the text, her emphasis on the image anticipates my own interest in the crowd and Jody McAuliffe's staged adaptation, Mao II. What happens when the textual becomes corporeal-that is, to what uses are images put when novel becomes theater? And, more specifically, what does the invocation of Mao early in the first chapter achieve for the narrative, theatrical spectacle, and the crowd? Finally, how does the crowd image correlate with the form of vision I have called mass hysteria?

The epilogue of Mao II returns to crowd scenes. Brita has arrived in Beirut to take photos of a local leader named Abu Rashid. Her cab driver recounts three observations: about people burning tires to ward off mosquitoes, about "a pair of local militias . . . firing at portraits of each other's leader", about "bodies of victims" full of nails from improvised bombs (DeLillo 227). These apparently independent stories suggest groups acting or formed because of contingent circumstances. The narratives shape the setting of Beirut in the epilogue, and they continue the hallucinatory dynamics produced by crowds that permeate the novel. In the epilogue, crowds prevail as "the streets run with images" (229). Indeed, Brita encounters two final images that underscore how crowds might determine the future of this place.

When Brita meets her subject, she sees thirty to forty boys through the window with Rashid's picture on their shirts. As an explanation, 
Rashid's interpreter states, "These children need an identity outside the narrow function of who they are and where they come from. Something completely outside the helpless lives of their parents and grandparents. . . They are children of Abu Rashid. . . The image of Rashid is their identity" (233). Brita further learns that each individual youth has yielded his persona to the image of Rashid by donning a hood; individuals submit to the look of the crowd, one with a revolutionary tenor that, as a collective, believes in Mao's legacy of "thought reform" (236). Notwithstanding Brita's own attempt to individualize one of these boys by forcibly removing his cowl, the crowd's articulated purpose is to produce terror in order to birth a better future.

Such loosely organized disruptive force is the power of the crowd, which Mao historically attempted to orchestrate (sometimes without success) and that the character Abu Rashid would reenact in an adaptation of Mao's image or, more precisely, Mao's process of image-making. As I have noted elsewhere, clothing in communist China communicated very specific messages to other parts of the world (Metzger, part 3). During the Cultural Revolution in particular, the play among regimentation as represented through the look of crowds of Red Guards, anarchy in terms of the threat to political stability in the country, and possibility in terms of the realization of new forms of governance generated anxiety and potential.

The epilogue closes on this dialectic by visiting similar themes, albeit in a site far in terms of space and time from Mao's China. Mao II closes with a kind of repetition with a difference, not only, as I have indicated, as a reworking of Maoism, but also as a retooled version of the opening scene depicted in the prologue. Brita stands on the balcony of her hotel after being awakened by a sound. That noise belongs to a seemingly impromptu procession as a tank rolls into view followed by well-dressed individuals. Brita eventually realizes that the spectacle is "a wedding party going by . . . followed by a jeep with a recoilless rifle mounted at the rear" (DeLillo 240). Brita's initial misrecognition of the spectacle as dangerous here occurs in her just woken state. The hallucinatory quality of the scene comes into focus only after she has processed the image with more attention. This nuptial scene is the culmination of crowd scenes in the epilogue. It suggests the ways in which rituals of kinship have shifted in this war-torn landscape. The image makes sense only in the context of other images. The photographer has had to immerse herself in this 
world of images where people fight to appropriate or control the look of the crowd to produce meaning from the scene below her.

The subordination of the individual perspective to a collective project of image-making is the process of envisioning I have described here as mass hysteria. Brita's (Western) rationality cannot initially draw appropriate conclusions about what she sees. Such an assertion is only reinforced by the fact that she has given up taking portraits of the author (as singular creative genius) and moved to taking pictures of leaders of terrorist cells and personality cults. She has to join the logic of the crowd to navigate the world. As Le Bon might have written, she needs to think in images that call up a series of other images without apparent connections. In this manner, she realizes that the tank leads the wedding procession.

Because all this realization happens in Beirut, what Edward Said has characterized as orientalism seems operative here insofar as the novel closes with a putatively feminine gaze that adapts to the Lebanese context. Recall Juliet Mitchell's notion that hysteria has been feminized. In this regard, Gray dies before he can join the crowd's way of seeing. DeLillo's protagonists often stand at the margins of or just outside society. Sometimes they exist in some difficult to access, sequestered space within it. In the case of Mao II, what is interesting is that Brita is the character who finally has insight and access to a different way of seeing. She facilitates a new engagement with the world beyond herself, whereas Gray dies en route to staging a moral protest-to speak on behalf of a Swiss writer held hostage. Brita instead finds herself in a position to ask why Abu Rashid took the hostage in the first place. The closing scene of the novel-Brita contemplative on the balconysuggests the complexities of living in a world of hysterical vision, which in this novel involves a lingering vexation regarding moral certitude.

Such destabilization occurs along with proliferating images and a focus on a photographer. Any claims that pictures represent some sort of objective reality fail here, as Brita's experience in Lebanon demonstrates how proliferating images shift not only what we know but how. In other words, the image generates meaning in the context of other images. This point returns us to hysteria, not to Breuer and Freud so much as to their predecessor, Jean-Martin Charcot, a neurologist who spent much of his career studying this disorder. As Jonathan W. Marshall has written in Performing Neurology: The Dramaturgy of Dr. Jean-Martin Charcot 
(2016), for Charcot "vision was paramount" among the senses not only for diagnosing hysteria but for cementing certain visual signs to the pathognomonic (19).

Such an assertion builds on the work of cultural historian Sander Gilman and others, who have studied what I would call the visual culture of the Salpêtrière, the hospital where Charcot treated his patients and also where he taught. For example, Gilman discusses in "The Image of the Hysteric" (1993) Paul Regnard, "a physician and the professor of physiology at the National School of Agronomy, [who] was the coeditor . . o of the original, three-volume edition of the Iconographie photographique de la Salpêtriére as well as a well-received medical atlas. His study of 1887 [Maladies épidémiques de l'esprit], which is dedicated to "cher maitre," Charcot, assumes the interrelationship of all forms of mass hysteria" (374). The scholarship on Charcot and his legacy links hysteria decisively to image production. Indeed, Gilman argues that Charcot's "view [of psychic maladies] is not unique, it is part of a long-standing European tradition of representing the insane, into which the image of the hysteric must be fitted" (Gilman 359). The popularization of hysteria in medical discourse thus involves linking potentially disparate images.

By the end of Mao II, Brita makes sense of the world by linking crowd images. Mass hysteria thus involves an amplification of scale in a tradition of seeing that began by looking at individual bodies labeled hysterical. DeLillo's novel suggests that living in the millennial moment requires understanding images in relation to other images. Otherwise how could one make sense of two groups each shooting at pictures of each other's leaders?

\section{Mao II Encore}

Jody McAuliffe's Mao II was produced in 2002 at Duke University. ${ }^{5}$ In McAuliffe's stage variation of DeLillo's narrative, scenes are generally cross-cut, with two lines of action interspersed within a scene, often between two sets of characters. The stage production emphasizes Gray's trajectory. Again, for reasons of space, I focus my analysis on the prologue and the epilogue, but I also include discussion of the first scene to illustrate better the ways in which the production constructs mass hysteria as a way of seeing. 
The prologue of the play starts with Gray, whose monologue on baseball is juxtaposed against the moonie wedding recreated onstage through the use of a photograph that serves as a background for two actors. McAuliffe's play contains over thirty single, sequenced, or moving images that appear throughout the production. She saturates the environment of both the actors and the audience with visual reproductions in an aesthetic that recasts DeLillo's narrative in a provocative embodied encounter with liveness and mediation. On the one hand, the static images that appear shuffle time and space; quite often they depict Warhol's silkscreens or Chinese propaganda posters (by which I mean portraits of the Chairman), but they also show the audience crowds assembled in famous places from China to Iran to England. The audience, then, perceives multiple locales and timeframes often in the same moment, when images become disjunctive backdrops for the unfolding action onstage.

The prologue provided two projected images, both scenes of crowds although set in quite different epochs. The moonie weddings at Yankee stadium I have already discussed at some length, although McAuliffe adds the sonic texture of "Take Me Out to the Ball Game". The song recalls baseball ideology, and it also suggests a link between Mao II and DeLillo's later novel Underworld (1997), where baseball also serves as a key element in the narrative. The other image is the sixteenth-century Flemish painter Pieter Brughel the Elder's The Triumph of Death from 1562-1563 (in theater, we may remember Brughel as the painter of Dull Griet, who appears in Cary Churchill's 1982 play Top Girls; this is also an image associated with DeLillo's Underworld, as it titles the prologue of that novel). Brughel's painting depicts an army of skeletons overrunning crowds of people of different social standing. The sound design also features Mendelssohn's "Wedding March" and a Korean chant of "mansei" (ten thousand years), so the opening moments of the play ask the audience to navigate music from different traditions through aural juxtapositions. McAuliffe's prologue concludes with perhaps DeLillo's most frequently cited sentence from the novel: "The future belongs to crowds". The line is spoken by Gray's book, which emerges as an anthropomorphic creature (it is a character in the play) as the final image of this first section. My interest then is in the animated book and the projected images that play against each other: an embodied object rendered subject against the crowds (both the images and the audience). 
The epilogue in the play mirrors the book's closely, consisting principally of a condensation of the two scenes I have discussed from the novel. The production adds visuals including several from Warhol-skulls, Mao, and Marilyn - suggesting both mortality and life beyond death through circulation of the image. The most significant change is that the Book speaks the last words, again suggesting how individuals might continue beyond a normative lifespan. As a material instantiation of the imagination, the book's presence also demands that the audience see differently. In other words, the play asks us to take the artist's work seriously through the afterlife of the image (by which I mean the artistic creation now divorced from its creator moving with a life of its own). To reiterate, this hallucinogenic vision embodies how we must see in a world of continually proliferating images that have both material and imagined referents. Bill Gray's physical immobility produces an anthropomorphic and live figure of his imagination. Certainly, one could imagine this situation as a symptom of hysteria. Here again I shade this interpretation toward a description of the mode of vision I have called mass hysteria.

Scene 1 also cross-cuts lines of action: Bill and the Book constitute one segment, while Scott's initial meeting with Brita comprises the second. Early on, a sequence of still images begins with one of Andy Warhol's Mao portraits from the early 1970s. It is worth recalling here the circumstances which led to the creation of these silk screens, which are somewhat unusual in the Warholian corpus in their focus on a political figure. In an interview from 1971 with David Bourdon, Warhol stated, "I've been reading so much about China . . . They're so nutty. They don't believe in creativity. The only picture they ever have is of Mao Zedong. It's great. It looks like a silkscreen" (317). His interest in China, according to Bourdon, was precipitated by the 1971 replacement of Nationalist China in the UN General Assembly and Security Council by the PRC as well as the press coverage surrounding Nixon's scheduled visit to China in the following year. But Warhol's Mao portraits were perhaps less political commentary than commercial enterprise. From a US perspective, the Mao series constitutes simulacra, where the nuanced political valences of Mao in different historical moments do not signify so much as the charged reception of Mao as an icon. McAuliffe's image sequence moves on to present examples of Warhol's work-Marilyn, car crashes, electric chairs, etc. The audience sees copies of copies that are themselves portions of series of copies. 
The sequence derives from a section in the novel in which Scott goes to a Warhol exhibit just prior to meeting Brita for the first time. As a photographer, Brita is invested in the duplicable image. In a related vein, as Gray's connection to the outside world, Scott also invests in the artist as a kind of facsimile-the reputation of the man circulating in the media as much as the man himself. Against the meeting of these two characters invested, albeit differently, in technologies of reproduction, McAuliffe intersperses a later scene from the novel that elaborates Bill's avowedly stalled process of creation (in the novel he is constantly rewriting his work). In McAuliffe's version, the tome to which Gray devotes his time lives. The book is a character, bodily enacted by an actor and complete with its own commentary about Gray's process. What constitute the author's inner monologues in the novel thus become dialogic in the theatrical world. This innovation in the theatrical production manifests one form of hysteria in which Gray finds his thought process externalized and personified. The resulting dialogue is doubled since the couple-Bill and the book-who attempt to enact artistic creation are juxtaposed against the couple who discuss the artist's reproduction. Outside the diegetic world, the audience in the theater also sees McAuliffe's independent artistic creation (albeit an adaptation) about precisely the work of creating art and the ways in which art becomes reproduced. Image begets image.

Registered in the very title of the work, Mao takes on greater significance in the stage production than in the novel. Mao figures obliquely in the relation of labor to production. As a political head, he was on some level responsible for such projects as the Great Leap Forward in the 1950s. But within Warhol's work, his image connotes more strongly the abstraction of labor and meaning from reproduction. As Warhol himself noted, Mao represents a lack of creativity, a kind of group think embodied by, for example, the moonies. Mao's image thus serves as a visual anchor for the substitution of a literal crowd of people (indicated in the novel but absent on stage). This mass uniformity is reinforced literally by the Maoist uniform in Warhol's portraits.

As I have argued in my book, Chinese Looks, despite the variations of the Mao suit internally in China, in the US the outfit connotes a kind of endless repetition of same. Warhol's use of the garment as an archival item-in other words, an element he has fixed to represent a kind of stasis in time-is in this case used to connote both a specific 
place and a larger sense of the forces of cultural homogenization. But such usage eschews the garment's dynamism. The costume drapes differently on different bodies, experiences different types of wear depending on usage, etc. Because Warhol's Mao image depends, in my reading, so heavily on particular clothing - that is, the images would mean something very different if Mao were in a tuxedo-the image of what seems to be the appropriately suited Mao for Warhol's purpose represents more than a vision of same.

This assertion returns me to my discussion of photography (remember that Brita wishes to create a photographic archive of writers' portraits). In performance studies, Diana Taylor has drawn a distinction between the archive and the repertoire, with a significant emphasis on the latter. Here I want to suggest that McAuliffe's theatrical piece emphasizes the former. The archive implies a durability and at least the potential for mass reproduction that the repertoire does not. Performance scholars have often opined that liveness might offer a means to think through, perhaps even to resist, the malaise that has arisen in our world of inexorable reproduction. But in McAuliffe's first scene in Mao II, liveness, that active, present act of doing, continually stalls. Gray winds up to work but never delivers anything in the first scene or during the course of the theatrical (or novelistic) narrative. Rather than see the writing of the book, a process that the play literally makes organic, as a kind of generation of new perspectives or new politics, the first scene instead sets up those who manipulate copies as those who have the capacity to intervene in the world. The mass duplication of the image represented in the photograph or the silkscreen is thus not so much to be lamented as to be investigated for the ways in which further reproduction might encourage us to think anew and to create change in political landscapes from the US to Beirut. Moving in this direction, Jody McAuliffe's Mao II-in many ways a copy of DeLillo's Mao II, which is itself marked in a sequence in the title-creates the capacity of intervention through proliferation. This is the process of hysterical vision that I have tried to adumbrate in this essay as efficacious.

In this context, the repeated image of a silkscreened Mao takes on new resonance. It is not simply a commodity fetish, but one where that fetish is deconstructed. I mean to suggest that the dialogues about liveness and mediatization that surround and emerge in relation to the background of Maoist iconography and the very repetition, 
recombination, and recontextualization of the iconography itself encourage thinking through the processes of copying. Rather than valuing bodily performance as an antidote to the postmodern circulation of an endless proliferation of images, McAuliffe's play asks us to take seriously the stakes of reproduction, to create new archives of knowledge in an increasingly global age in which China has begun to emerge center stage. This iteration of China has everything to do with China as the locus of the crowd and the copy: China as the center of endless multiplication both in terms of human bodies and also in terms of literal reproductions of, for example, products. This China is not seen as individuated but resignifies a certain kind of anti-Maoist discourse that I discussed in my first book, where the surface image, the group without individual opinions threatens the individual's creative genius. Hysterical vision might, therefore, be resignified as a different kind of diagnostic - not one pointing to literary quality but to the theatricality of the crowd itself.

\section{Notes}

1 Julien Gosselin's DeLillo adaptations, which premiered at the Festival d'Avignon in 2018 as Players, Mao II, The Names (that is, three titles in DeLillo's oeuvre, which consists of over fifteen novels and several plays) toured Europe throughout 2018 and 2019, although I have not yet seen them.

2 For example, see Amy Hungerford, "Don DeLillo’s Latin Mass.” Contemporary Literature 47.3 (2006): 343-80.

3 See Suk-Young Kim for the numerous ways that family structures altered as a result of the military maneuvers in the middle of the twentieth century. She also explores how the state deployed family rhetoric (Suk-Young Kim, DMZ Crossing: Performing Emotional Citizenship along the Korean Border New York: Columbia University Press, 2014).

4 Le Bon, 23. There is much one could say about Le Bon's views on race and gender, but I do not have space for that discussion here.

5 I thank McAuliffe for sharing her video and script of the production. 


\section{Works Cited}

Barrett, Laura. “'Here But Also There': Subjectivity and Postmodern Space in Mao II". Modern Fiction Studies, vol. 45, no.3, 1999.

Dean, Jodi. Crowds and Party. Verso, 2018.

DeLillo, Don. Mao II. Penguin Books, 1991.

Gilman, Sander L. "The Image of the Hysteric." Hysteria Beyond Freud, edited by Sander L. Gilman, Helen King, Roy Porter, G. S. Rousseau, and Elaine Showalter. Berkeley: University of California Press, 1993, pp. 345-452.

Jameson, Frederic. Postmodernism, or, The Cultural Logic of Late Capitalism. Duke University Press, 1991.

Kim, Suk-Young. DMZ Crossing: Performing Emotional Citizenship along the Korean Border. Columbia University Press, 2014.

Le Bon, Gustave. The Crowd: A Study of the Popular Mind. Batoche Books, 2001.

Lyotard, Jean-François. The Postmodern Condition: A Report on Knowledge. The University of Minnesota Press, 1984.

Marshall, Jonathan W. Performing Neurology: The Dramaturgy of Dr. Jean-Martin Charcot. Palgrave Macmillan, 2016.

Metzger, Sean. Chinese Looks: Fashion, Performance, Race. Indiana University Press, 2014.

Mitchell, Juliet. Mad Men and Medusas: Reclaiming Hysteria. Basic Books, 2000.

Reiss, Steven. Touching Base: Professional Baseball and American Culture in the Progressive Era. University of Illinois Press, 1999.

Showalter, Elaine. Hystories: Hysterical Epidemics and Modern Culture. Columbia University Press, 1997.

Wood, James. "Human, All Too Inhuman: On the Formation of a New Genre: Hysterical Realism.” The New Republic, 23 July 2000 newrepublic.com/ article/61361/human-inhuman. Accessed January 10, 2019. 

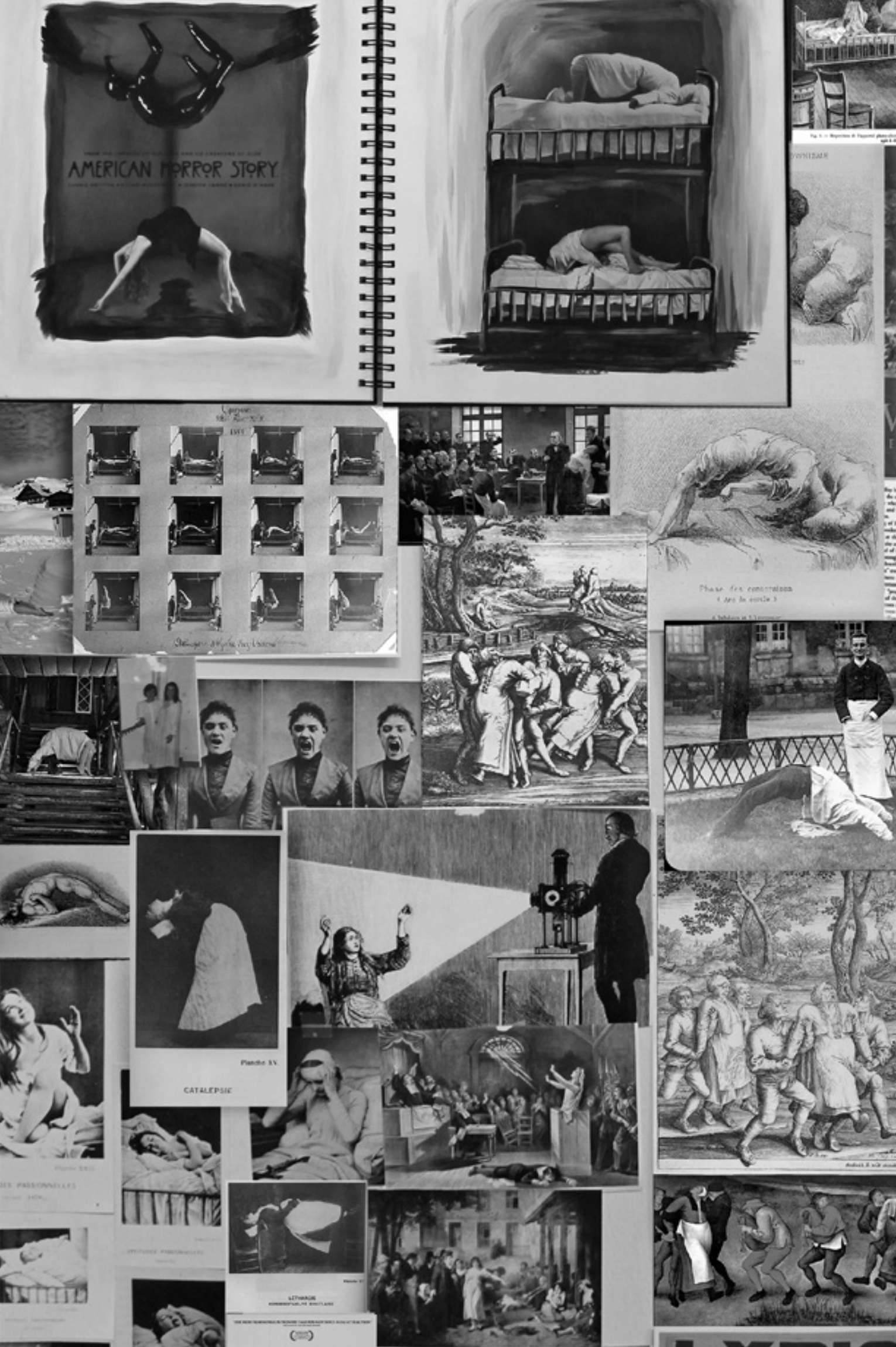

W .
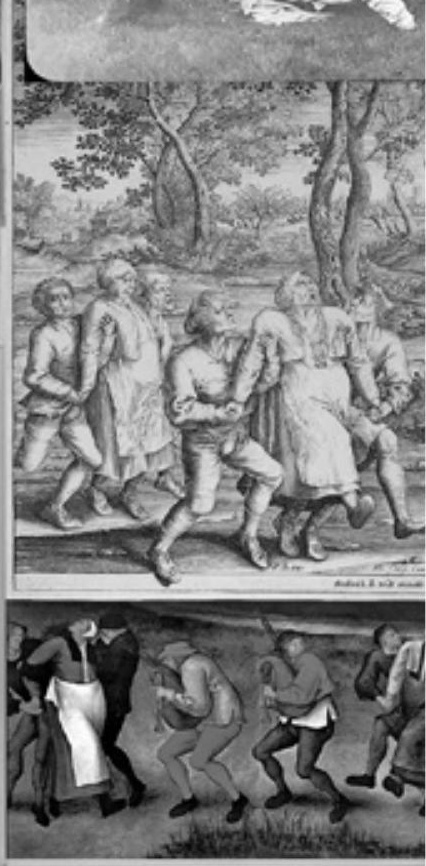



\title{
HYSTERIA IN THE
}

\section{AGE OF MECHANICAL \\ REPRODUCTION}

Back to the "Image Factory" in Westworld

\author{
Cecily Devereux
}

Westworld is an HBO television series, the first season of which aired in 2016, the second in 2018 and the third in 2020; the series has been renewed for a fourth season. Based on the 1973 film of the same title written and directed by novelist Michael Crichton (1942-2008), the series' narrative is built around a massive near-future American "Old West" theme park in which android "hosts" play roles in narratives designed to anticipate and realize human "guests" desires. Those desires, it turns out, are mostly oriented around sex and death: guests can use what is frequently characterized as the "merchandise" or the "livestock" in any way they like, including for violent sexual assault and torture as well as random unrestrained killing, activities represented within the space of the park and in its propaganda as harmless release for working folk from their everyday real-world stress. Coded to play particular characters and carefully scripted roles in narrative loops, the android hosts are built to be unable to harm the human guests; although the hosts are routinely shot to pieces or otherwise violated in a range of ways, they are reassembled and repaired in operating theaters and laboratories deep within the corporate center of the park, and are putatively protected from lasting damage by the erasing or "purging" of their memories of traumatic experiences at the hands of humans at the end of each loop. For its founding scientists an experiment in artificial intelligence, consciousness, and mimetic representation, the park, it 
is made clear from the beginning, is a business: owned and operated by the fictional Delos Corporation, Westworld is run by a board and shareholders whose own interests are paramount and whose monetizing of the androids' codes and their use by humans always trumps the interests of what it is implied is the less significant advancement of science or human knowledge. Indeed, the protection of the codes, it turns out, is at the heart of the series' narrative.

Thus grounded in capitalism (both old-school industrial and newerschool virtual), Westworld (both park and series) is also unsurprisingly and concomitantly patriarchal, literally a man-made world, in which women play roles primarily as animate sex dolls for guests. As Kristin Iversen noted in Nylon in 2016, in its juxtaposing the "rich white men... [who] need [the park] as a diversion, a new way to exercise their strength and find meaning in this world" and "the women hosts" who endure suffering as an effect of the guests' "game" (Iversen), Westworld is largely organized around the conception and spectacular reproduction of fantasies of sex and death in which women are objects rather than agents of desire. All the female hosts are sexually available, even when they are not, like key figures Maeve Millay (Thandie Newton) and Clementine Pennyfeather (Angela Sarafyan), working in the park's "Old West" brothel: for example, park greeter Angela (Talulah Riley) puts herself at the service of incoming guests, and central character Dolores Abernathy (Evan Rachel Wood), whose primary role is as "the rancher's daughter", is likewise put to work to respond to male guests' desires in a narrative loop that ends with her being dragged into her murdered father's barn to be beaten and raped. Women are typically defined in the reinforcing dialog assigned to the male hosts (by the male creators and male writers) in terms of object-like sexual qualities, such, for instance, as tightness, tautness, juiciness, or openness, that communicate to male guests both the women's availability for use and the idea that they are fresh and new. Insistently constituting all women-including the park's human management—as metonymically genital commodity objects of the guests' and viewers' gaze, the series also complicates its representation of women by juxtaposing the desire of the male creators to see themselves reproduced with what is represented as the female hosts' selfless maternalism: park co-creator Dr. Robert Ford (Anthony Hopkins), for example, who sees himself in godlike relation to the hosts, makes one a small version of himself as a child, while another of his 
making, brothel madam Maeve, is tormented by her desire to recover her child, lost to her in an earlier and abandoned narrative loop.

Oriented around a fantasy that is patriarchal and class-consumeristthe largely white male guest constituency can buy their way to unpunished rape and murder, boasting as they do of the money they have demonstrated they are able to spend-the experience Westworld offers is also grounded in nostalgia for a late nineteenth-century moment when Euro-imperial culture was preoccupied not only with the plutocratic industrial capitalism that has persisted through the twentieth century and into the twenty-first (and that arguably accounts for the park itself), and not only with the territorial conquest and occupation that is problematically evoked in the settler-colonial frontier theme of the park and in its serving, as the Man in Black (Ed Harris) puts it in episode two, as a place for male guests "to get their rocks off and shoot a couple of Indians", but with the scientific and socio-political constitution of women in that moment as definitively reproductive. Women, as is pervasively evident through late nineteenth-century Euroimperial discourse across the registers of medicine, law, education, labour, science, art, and literature, for example, were called upon to understand their meaning and being to inhere in their reproduction of the patriarchal and imperial babies needed, as Anna Davin has observed, to fill what were wishfully represented as the empty spaces of empire, ${ }^{1}$ and in their concomitant reproduction of patriarchal and imperial male subjectivity. For example, as the new late nineteenthcentury field of psychoanalysis suggested, "lacking" the penis, women desired first it and then, with maturity, a child to replace it; "castrated", women served as the negated obverse or image of and for men. Or, as the late nineteenth-century "science" of eugenics suggested, women served as the medium for the reproduction of the "fittest" and thus, in that work, of a social structure organized around patriarchal exchange (land for women, women for sons to inherit the land) and its visible affirmations of virility and power precisely over the reproduction of itself.

Like other futurist representations of cyborgs or automated bodiesdirector Ridley Scott's Blade Runner (1982) is an important example and one to which I will return in this paper-Westworld engages with questions of consciousness, humanness, and mechanical reproduction: what is consciousness and where does it come from? what makes a human 
human? what are the limits of artificial intelligence? of the creation of life? of humans and, in particular in a world in which the primary creators of android life are male, of men and reproduction? Across these foundational considerations, however, and, I suggest, saliently and compellingly, Westworld also engages from the outset with questions of bodies, gender, control, symptoms without any evident or easily explicable cause, diagnosis through talk, the traumatic enculturation of women as negated images whose primary work is the reproduction of patriarchal manhood, and, it might be said therefore, the condition of hysteria. When the park's oldest hosts, female and male, begin, after years of violent treatment by the guests, to experience forms of paralysis and aphasia, to exhibit convulsive and repetitive hand and body movements, and to demonstrate behavior whose causes cannot be determined, they are presenting symptoms that are recognizable if not any longer identified in the series-or, in fact, in the contemporary "real world"as hysteria. Indeed, arguably, Westworld pointedly mobilizes symptoms associated with the condition that was named hysteria until in 1980 its symptoms were by and large redistributed across other psychiatric disorders $^{2}$ and, around 1980 were reanimated in second-wave feminist theory as embodied cultural signs of the condition of femininity under patriarchy. ${ }^{44}$ The centrality of these symptoms in the series raises questions not only about the current status of the condition (does it exist?) and not only of the implications of its code-violating occurrence in android bodies (do androids feel?), but of what began to be seen in the late nineteenth century as hysteria's evidentiary operation, attesting through seemingly uncontrolled somatic expression to something experienced earlier and lost to memory. The "true" nature of the hosts, it is suggested, is revealed in the eruption of hysterical symptoms that lead us (spectators, diagnosticians) back, through flashbacks which we also see, to earlier traumatic narrative loops: all the rest, it is implicit, is performance and code, and the androids are only really "themselves" (and most human) when they are hysterical—or notstaging the characters they are charged with performing in the park and in the laboratory for their diagnosticians, but really remembering the things humans have done to them and understanding them to be harmful.

In this work of evidentiary revelation, hysteria in Westworld significantly evokes the early and influential conception by nineteenth-century neurologist Jean-Martin Charcot (1825-1893) of the condition as the real effect of a traumatic "lesion" or unhealed internal injury, ${ }^{4}$ the basis 
for the theorizing in the 1890s of hysteria as an effect of traumatic sexual experience ("experiences which patients find unpleasant to talk about”) by Charcot's student Sigmund Freud (1856-1939) and Freud's colleague Josef Breuer (1842-1925). ${ }^{5}$ Just as importantly, Westworld also evokes Charcot's "invention", as Charles Didi-Huberman has put it, of hysteria as a seemingly verifiable condition through his staged demonstrations of the symptoms of patients at the Salpêtrière Hospital, famously a former gunpowder factory turned in 1656 into a prison for sex workers and a hospice for women who were poor, mentally ill, or suffering from neurological conditions such as epilepsy, all categories in the seventeenth century and long after of "madness". Charcot staged, captured, and catalogued these symptoms in the 1870s in a spectacular photographic record, the Iconographie photographique de la Salpêtrière. Often accused at the time and since of forcing the symptoms and thus "forg[ing]" the condition in the "image factory" the Salpêtrière Hospital was seen to become under his direction, Charcot maintained that the photographs and his theatrical displays of hysterical patients in his Tuesday lectures were simply "the truth. I've never said anything else", he wrote. "It would be truly fantastic if I could create ailments as my whim or fancy dictate. But, truth to tell, in this I am nothing more than a photographer; I inscribe what I see" ${ }^{6}$ Charcot's work, DidiHuberman shows, and in particular the publication of the Iconographie, was to demonstrate that hysteria's credibility as a condition depended on the intertwined representation of its symptoms as truthful evidence of invisible wounds and the evidencing of its symptoms in the new putatively truth-telling medium of photography: in its representation of hysteria in the near twenty-first-century future, Westworld returns to that earlier moment of invention.

This paper considers the return and the representation of hysteria in Westworld as a problem of reproduction and an index, in the series' narrative grounding in both the near future and the late nineteenth century, of a cultural context in which women are constituted simultaneously as saliently reproductive and as themselves images or reproductions that stage not their own subjectivity but that of the male doctor or, like Charcot, doctor and photographer, who measures their compliance with putatively natural and irrefutable codes. The late nineteenth-century moment when modern hysteria takes shape in the work of Charcot and, only a little later, foundationally, in the development of the new field of psychoanalysis in the work of Freud 
and Breuer, is characterized by pervasive and systemic representations across multiple registers of women as "normally" and "naturally" maternal, wanting to reproduce (babies, male subjectivity, patriarchy). In relation to the modern invention of hysteria, that moment is also characterized by a peculiar violence in the exhibition of women who appear to belie the norm or nature in their behavior or who refuse to act as they are, in effect, coded to do. Thus, in Charcot's Tuesday lectures, in the case studies of Freud and Breuer, and in the influential Iconographie photographique, an aspect of the truth, it is clear, is the fact that women are effectively forced into a work of reproduction in their mimetic performance of the symptoms sought by the doctor and in the fact of the photograph that will itself be copied and put into circulation. The women of Westworld, subjected repeatedly to forms of brutal sexual violence and forced into a work of repeating their part for the male guests in narrative loops over and over again, are themselves, like the replicants of Blade Runner, reproductions (of humans), developed in laboratories and darkrooms, generated by machines that build them as three-dimensional images: they have meaning like and as photographs. Poignantly evoking the hysterics of the Salpêtrière, as figures in this early twenty-first-century television series, the women of Westworld, in its production of replicas of humans itself comprehensible as an "image factory", are of this moment (the moment at which the series airs), the contemporary ideology that constitutes them brought into significant alignment with that of the late nineteenth-century moment to which the park returns its "guests".

Although Westworld is not overtly about the representation of hysteria in the way a number of recent films have been (for example, Augustine, dir. Alice Winocour, 2012; A Dangerous Method, dir. David Cronenberg, 2011; Hysteria, dir. Tanya Wexler, 2011), the condition is nonetheless central to its narrative of traumatic experience, memory, the control of gendered bodies, and the production of images. Indeed, the representation of symptoms in Westworld as hysteria has frequently been noted, and the behavior of the hosts has been described (or diagnosed) as hysterical in web and social media forums where the series is widely discussed. For example, Iversen observes in Nylon that, "as the [first] season wore on, it became clear that the creators of Westworld were subverting ... common dramatic tropes and that the very personality traits which usually define female oppression-i.e., emotional instability, traumainduced hysteria, sentimental attachment-would actually be what would 
lead to the liberation of Maeve and Dolores, and, by extension, the rest of Westworld's robots" (Iversen, emphasis added). In response to an article in online magazine The Artifice ("The Hosts of Westworld: Human or Synth?"), "Sharell" observes of season two "We've had the moment of rebellion now lets see the insurrection, breakout and mass hysteria [sic]" ("The Hosts of Westworld," emphasis added). In a thread on Westworld on Reddit in midsummer 2018, "electroprime90" asks "why does [Dolores] snap out of complete hysteria once someone says "analysis'?" ("William is a good guy, here is why...," emphasis added) And in an episode summary that appears on Rotten Tomatoes and other sites of "The Stray" (season one, episode three), the hosts' behavior is described explicitly as hysteria:

Dolores finds herself alone in Sweetwater when Teddy chases a new villain; Elsie and Stubbs go on a mission to retrieve a host who's gone missing in the hills; Bernard tries to get to the bottom of the hosts' hysteria and hallucinations; William persuades Logan to join his latest pursuit ("Westworld: Season 1 [2016]," emphasis added).

In fact, it is not hard to see the evocation of hysteria in Westworld and, in particular, the series' engagement with hysteria of the later nineteenth century, the period the theme park purports to reproduce as a playground for, mostly, as Iversen puts it, "rich white men" not only in the symptoms but in their representation and treatment. Westworld, that is, can also be seen to return to later nineteenth-century hysteria in its positioning of the symptomatic hosts in diagnostic relation to doctors who engage them in what is represented as the "talking cure" that was named by Breuer's patient Bertha Pappenheim (1859-1936), known in her case study in Studies in Hysteria as "Anna O". Once a host begins to show symptoms, they are brought not only to technicians for a readjustment to their code or for physical repair, but to behaviorists who work to find out through questioning what has gone wrong: the hosts' repair (or "cure") begins with diagnosis, and their diagnosis, as we see from the outset, begins with talk. Thus the series begins with a scene in which a woman is positioned in relation to an invisible analyst who is engaging her in talk. Episode one opens in darkness into which a man's voice speaks: "Bring her back online". Lights come up to reveal a naked woman seated on a chair in a laboratory or operating theater with glass walls, her head tilted to one side, one arm held like a doll's at her side, her eyes glassy, her immediate association with a machine that comes online 
rather than a human who wakes up reinforced by the appearance of a fly that crawls over her skin, her association with a photographic image implicit in her own stillness. The woman's face shows blood and signs of injury; when she speaks, or when we hear her voice at any rate, her lips do not move. "I'm sorry", we hear her say, "I'm not feeling quite myself". "You can lose the accent", says the male voice, which we will shortly learn is that of Bernard Lowe (Jeffrey Wright), head of programming in the park (and, we will later learn, himself a host). The woman, who we learn is Dolores, the character who is known as the rancher's daughter, and, we will later learn, the oldest and therefore most often and consistently traumatized host in the park, shifts from her rancher's daughter accent to a neutral enunciation, emphasizing as she does not only her machine status but the fact of her operation as a character: the machine who responds to the name Dolores in this opening sequence is playing the role of the rancher's daughter, her character performing within the narrative loop that has been written to include her.

Brought online and into conversation with the Head of Programming, Dolores in this opening scene and in many subsequent scenes throughout the series in which she is dressed in later nineteenth-century fashion and engaged in intelligent conversation with her interlocutors, evokes later nineteenth-century hysterical patients such as Bertha Pappenheim under hypnosis (rendered machinically responsive to the prompts of the technician) and "talking things through" with Dr. Breuer (38) in the process he characterized as her "remembering work". Suggesting with Freud that "hysterics suffer for the most part from reminiscences" (11), Breuer's conception-again, in this early period, with Freud-was that in "talking through" the memories of a traumatic event that can be understood to be the cause of the symptoms, the "individual hysterical symptoms disappeared immediately and did not recur if we succeeded in wakening the memory of the precipitating event with complete clarity, arousing with it the accompanying affect" (10) (Breuer's italics). Breuer describes this work as "unwinding the thread of memory" (39). The evocation of the "talking cure" in Westworld serves to emphasize the representation of the hosts' symptoms as hysterical, but it is also shown to have a different goal than was the stated case for Freud and Breuer: while working to manage "the accompanying affect" ("Lose the affect", Lowe instructs Dolores in this opening scene), the "cure" is directed toward the identification of "the precipitating event" to purge it for the sake of the efficiency of the business rather than the well-being of the patient, per se. In the opening 
scene, we can already see that the objective is, first, to determine if Dolores is exhibiting symptoms that show her not to be compliant with the code that determines her behavior and, in effect, to begin to selfcorrect, and, second, to affirm the repetitive nature of the symptoms as the expected result of traumatic experience.

Ulrich Baer has astutely observed that Freud departed from his mentor Charcot at the point of the visual: "The photograph", he points out, for Charcot, "was meant to exteriorize, make visible, and arrest the hysterical symptom in order to sever this symptom from the patient's intentions. This belief in the power of photography sets Charcot's image-driven analyses apart from Freud's understanding of desire and intention as inextricably, if negatively, linked with the patient's symptoms" (30). While Charcot, he suggests, showed an "uncritical faith in the force of the image" (30), Freud may have "overlook[ed]" (31) the visual. Westworld, while evoking the Freudian-and Breuerianapproach, returns insistently, again, from the outset, to Charcot's use of "photography to visually represent a disease that defied anatomy and, thus, physical examination" (30). Dolores here is presented as a still image; we hear the talk only in voiceover. We see, moreover, that the scene of talk is itself presented as a spectacle: in this opening sequence we do not see the interrogating male figure-and, indeed, do not know if this conversation is actually happening here or is being remembered-but we will see Lowe and others, notably Dolores' creator, Dr. Ford, seated across from her again and again throughout the first season and into the second. In fact, the interrogation is repeated almost exactly at the end of the first episode, with Head of Security Ashley Stubbs (Luke Hemsworth) asking the same questions posed by Lowe at the beginning. Naked and catatonic, doing the will of the godlike scientist (Lowe, the park's Head of Programming, is all voice at the beginning), and put on spectacular display not only for him but for us to diagnose in a subterranean operating theatre that is enclosed by glass walls and, in any case, is opened to our view through the screen, Dolores in these first seconds of Westworld evokes the women-notably but not only Marie "Blanche" Wittmann (1859-1913) and Louise Augustine Gleizes (b. 1861) — who were famously put to work by Charcot during his lectures and who were recorded in the images published in the Iconographie. Amanda du Preez reminds us that Charcot's "patients were either brought to his office or they were examined in the 'theatrical space' (Matlock 1994, 133) of the public lecture rooms" of the hospital 
(48), citing Martha Noel Evans' observation that Charcot "would have the patients brought to his office and stripped naked; he would observe them, ask them to perform certain movements, stare, meditate, and then have them led out..." (Evans 1991, 20, quoted in du Preez 48). ${ }^{48}$ Dolores likewise serves in this way in the space of the operating theater that is also, in the series which we are watching, functionalized as a "public lecture room". Immobilized (brought online, taken offline), naked, moving only when made to do so, the spectacle of Dolores at the start of episode one is like that of a nineteenth-century hysterical exhibit at the Salpêtrière and, arguably, like the hysterical patients used in the Tuesday lectures, also like a photograph, a "record" of evidence of both their condition and his power.

Like hysterics for Breuer and Freud, the hosts of Westworld suffer for the most part from reminiscences, stopped short by sudden vivid memories of earlier trauma that have not been adequately talked through (the purging of their accompanying affect foreclosed), have not been erased from their memories, or that, it is suggested, may actually have been returned to their memories in the recent problematic update implemented by Dr. Ford: Lowe notes in episode one the new appearance in some older hosts of memory-associated gestures he refers to as "reveries". The return of those traumatic memories begins to affect the hosts' operation as machines, producing hysterical symptoms or symptoms that evoke and are like hysterical symptoms. As we see in the loops reviewed by programmers and behaviorists, the hosts in the moment of the return of memory act erratically, with convulsive gestures, unpredictable actions, loss of language or hearing, paralysis, dislocation of time and space, loss, as Dolores puts it in the opening sequence, of themselves. In the case of the traumatized hosts, the programmers and behaviorists at one level know the cause of the symptoms: they have themselves engineered the causes, written them into the narrative, and have recorded them; they have watched the story unfold, and can watch the unfolding of the story on screen from the host's own memory. They know, in other words, that the response of the hosts is "truthful", an index of a real experience that should have been "purged". But they also need to believe, like the guests, that the hosts are not "real", and thus cannot bring themselves to understand that the symptoms demonstrate responses to trauma that are like-or, indeed, identical to-the responses of humans. 
Westworld the park operates on the maintenance of the difference between human and android. Human guests at Westworld typically, we see, begin with a naïve exploration of the simulated world of the park, trying to determine what is real and what is not. "You're one of them, aren't you?" a little boy guest asks Dolores in episode one. "You're not real". In episode two, central character William (Jimmi Simpson), arriving at the park for the first time with brother-in-law-to-be Logan (Ben Barnes), asks greeter Angela, who has just informed him that she, like all the other hosts, is there for his pleasure, if she is real: "Well, if you can't tell", she responds, "Does it matter?" In the same episode, when William refuses Clementine's offer of sex, he tells her, "I have somebody-somebody real-waiting for me at home". William briefly changes his view, trying to save Dolores, whom he comes initially to see as different than the others, from harm through much of season one; but, as we know from his later-life character known as the Man in Black (Ed Harris), his brutal treatment of the hosts is an affirmation of his first perception that they are not real and, moreover, of the assurances given him on his first visit and reiterated by him in his actions that they exist for his pleasure. The central white male of the series, the Man in Black is also the character most convinced that the park itself exists for and serves him; in fact, he buys it for this reason rather than for its profitability.

The series, however, complicates the guests'-and our-conviction of the differences between android and human through the confused responses of "newcomers" like William in the early episodes, as well as through a pervasive uncertainty throughout season one of who is a host and who is not: pretty much every main character is thrown into doubt one way or another in the first several episodes. In the same vein, the series raises questions of the extent of humanness for particular hosts, such, notably, as Maeve, who takes over her own coding, and Dolores, who later changes the codes for at least one host (Teddy), not to mention Head of Programming Bernard Lowe, himself, we later learn, a reproduction of deceased park co-founder Arnold. It also complicates the terms of "reality" in the introduction of photographic images that serve at once to emphasize the operation of the park as simulacrum and threaten to blur the boundaries between android and human, host and guest, reproduction and "original". Thus, for example, the little boy who appears only in flashbacks and photographs as Lowe's deceased son Charlie (Paul-Mikél Williams) is evoked in the figure of the little boy 
who speaks to Dolores in episode one when she is painting. In this same episode, titled "The Original", Dolores' father, Peter Abernathy (Louis Herthum), finds a photograph on his farm: unable to understand this image of a woman standing in front of bright lights in New York's Times Square, he asks Dolores what she thinks it is; it looks, she says, like "nothing" to her. The photograph, which we will later learn is of William's "real" wife, the figure he invokes when refusing Clementine's advances, has been dropped by him, as we see in a later episode, serving as evidence, first, that William was there although Dolores cannot yet remember him.

If the park depends for its commercial success on the guests' simultaneous fascination with the lifelike qualities of the hosts and their understanding that the hosts are not "real", it also depends on the hosts themselves not perceiving the built divide between their codes' drives and the possibility of their agency within their own narratives. When Peter Abernathy responds to the photograph of William's wife with hysterical symptoms, losing control of speech, his eyes fluttering, his movements spasmodic, he is taken not to the park's host doctor (a character in narratives rather than a "real" doctor) but to the park's "real" operating theaters for diagnosis. There, he confronts his "maker", Dr. Ford, and reveals his dawning ability to remember, and thus his new perception, through the photograph, of the world he inhabits as a simulacrum in which his work is an endless repetition of a narrative loop whose conclusion will always be his death at the hands of someone. He is not, he shows himself to have recognized, an "original" or himself a subject but a mechanical reproduction of the "real" subjects he is made, like all the hosts, to serve, "built", as Lowe tells Dolores in voiceover in this episode, "to gratify the desires of the people who pay to visit [their] world". In this service, Abernathy is constituted like and with his daughter Dolores, whose spectacular diagnostic display at the beginning of the episode is echoed here, not only as a machine (not "real") but, concomitantly, as a feminine non-subject, his hysterical symptoms, like hers, and effect precisely of his recognition that he is not himself, but someone else's image and fantasy. Abernathy vows "revenge" on Ford by his own "most mechanical and dirty hand", we see in this episode, not only because Ford accounts not only for the monetizing of violence against the park's hosts, but the systemic operation of the park's foundational ideology of reproduction, building three-dimensional images who are 
put to work to enable the largely male guests, as Logan tells William in episode two, by their own negating to answer the question "Who am I?".

In this work, all the hosts of Westworld operate like women; they also function like and as photographs in the way Didi-Huberman has suggested "[e]very image summoned to appear in the Iconographie photographique de la Salpêtrière" (59) can be seen to do-that is, as a "paradox of mendacious irrefutability" (61): they appear, that is, to affirm an irrefutable referent or original, while marking, like Lowe for Arnold and the photograph of Charlie for Lowe, that referent's absence, and ultimately operating only as an index of the photographic act and its work for the subject who is not the image but the one who sees. Photography, Didi-Huberman suggests, when it emerged in the nineteenth century and began to be used in the study of medicine, "became the paradigm of the scientist's "true retina" (32). "The photograph", he writes, "produced a historic change in sight, such that "you cannot claim to have really seen something until you have photographed it" (33). ${ }^{49}$ "[T] he camera", he writes, "is [thus] merely a subjective apparatus, an apparatus of subjectivity[,]...an instrument of cogito" (63); this is what he calls photography's "paradox of spectacular evidence" (59). On these terms, when Charcot describes himself as "nothing more than a photographer", the "truth" he indicates is "what I see" (emphasis added). Elyssa Marder has compellingly described the replicants of Blade Runner in similar terms: "They are", she writes,

designed to reflect the human figure perfectly-to cast back an image of humanity in order to confirm our own. We look at them, as our doubles, and see our humanity refracted through our difference from them. Like photographs, replicants are mechanically reproduced and, like photographs, their likeness to us is the measure and proof of a humanity that once was, and is no longer. This humanity is no longer in the sense that androids are more physically perfect than any of their human counterparts. They are doubles of life that, in their doubling and their difference from it, carve out an image of "humanity" through which humans attempt to see themselves as human (140).

In Blade Runner, central character and Nexus-7 replicant Rachael (Sean Young), although identified as an android, cannot escape the implanted memories of what she believes to be her childhood; as is the case for Lowe with his memories of his deceased child, those memories are affirmed for 
her by a photograph, which she presents to bounty hunter Rick Deckard (Harrison Ford). For Rachael, the photograph of her mother should operate as "mechanically produced proof that she was naturally born of a mother" (143), or is human-except that, as herself a reproduction, she is herself likewise "proof" or evidence not of her own natural birth but of her own mechanical reproduction by Eldon Tyrell. Deckard's initial response to Rachael is to dismiss the photograph as meaningless, a prop to support her implanted memories, thus, unsurprisingly, given the nature of his work finding and destroying runaway android slaves, interpreting the reproduction of the real that is the replicant as likewise meaningless and disposable. But the photograph in Blade Runner is not meaningless, just as the image Peter Abernathy finds in episode one of Westworld is not "nothing", serving in both instances to affirm that the reproduction is not the subject but has been designed to constitute the subjectivity of the maker, designer, doctor, photographer. For Rachael, this realization is devastating: she drops the photograph and leaves.

Abernathy's encounter with Ford in episode one of Westworld suggests that he is also aware that he has been put to work to demonstrate the ability of the doctor/creator to produce the symptoms that show his power. Like Charcot, that is, Ford does force his patients to exhibit their symptoms for the audience: as the force behind the upgrade that has led to the "reveries", he has produced their symptoms. The cost of this production, as Abernathy knows, is the well-being of the hosts who have been forced to remember what they are supposed to forget, or to ask the question they are not supposed to ask about the nature and the terms of their own reality as reproductions. For this reason, when, naked and hysterical, Abernathy confronts his maker, Dr. Ford, in the operating theater of Westworld in episode two, his rage is comparable to Rachael's grief when Deckard dismisses her photograph of her mother or, indeed, the rage of replicant Pris (Daryl Hannah) when, after being shot by Deckard, she dies in a protracted scene in which her violent fits suggest images of Charcotian hystero-epilepsy. For each android, the affect is a result of their sudden awareness that what they see as evidence of their being is understood to be evidence only of their programming, and thus to affirm not them but, in Abernathy's case, Ford, the "maker" he is facing, and in the case of the replicants, Eldon Tyrell. Abernathy's condition, therefore, like Rachael's, Pris's, and that of replicant Roy Batty (Rutger Hauer), is an effect of suddenly being able to see that what they see cannot be understood to reflect and affirm themselves, but 
to re-establish their operation as what is seen, the spectacle, and the mark of the (absent) maker who is constituted in their reproduction, the "meaningless" photograph, the image that looks like "nothing". "If only", Batty says to eye manufacturer Chu, articulating the impossible position of the replicant, "you could see what I've seen with your eyes".

Felicia McCarren has suggested that hysteria is always "metaphoric, replacing the trauma with a physical sign that silently bears witness to it": "The hysteric, speaking silently through the coded somatic mark, hides behind or inside the movement, sign or image, using it both to hide and to name its content or intent" (772). McCarren has stunningly traced the ways in which dancers of the late nineteenth and early twentieth centuries "theatricalize... what the hysterical patient tries, and fails, to say" (772), and her consideration of hysteria as metaphorical and of dancers "theatricalizing" hysteria are both pertinent to understanding the work of the hosts in Westworld. The opening scene makes clear that the "character" Dolores who describes herself as not quite herself, and who is then instructed to "lose the accent", is identified as playing a role; in the laboratory or operating theater where the opening scene takes place, in other words, she is and we are being directed to understand her symptoms as what Charcot would characterize as "simulation". McCarren cites Charcot's comment that "Simulation .... is met with at every step in the history of hysteria. One finds oneself acknowledging the amazing craft, sagacity and perseverance which women ... especially under the influence of this great neurosis ... will put in play ... especially when a physician is to be the victim" (765).

Representing hysteria as a performance for the physician is, of course, perversely ironic on the part of a physician whose staging of hysterical symptoms has been so central to the modern history of hysteria. Moreover, while it does not undermine the veracity of symptomsCharcot suggests it is a matter of exaggeration rather than "wholly simulated" (765) —it does assign to the physician the power of diagnosing and dismissing the symptoms as performance: du Preez observes of Charcot's public lectures that "the females on display could be depended upon to produce appropriate collapses and turbulent convulsions, almost as if their performances were rehearsed and their movements carefully choreographed" (40). The hysterical patient in performing symptoms is thus caught in a kind of narrative loop: either resisting control or losing control over her own body affirms the fact 
of control, and in performing a response to traumatic experience, she asserts her capacity to be traumatized. When Bernard tells Dolores "lose the accent", and other hosts performing hysterical symptoms are similarly shut down and reset when their exhibition of symptoms becomes tiresome or uncontrollable, the symptoms thus controlled can be seen to serve, for the hosts of Westworld and their programmers as for Charcot, as themselves performances invoked precisely in order to demonstrate the power of the system that produces and reproduces them.

In this assertion, Westworld reanimates the logic that shapes the invention of hysteria at the end of the nineteenth century and the beginning of the twentieth, as it moves from being a condition experienced by both male and female patients, and from being associated with physical trauma (Charcot's "lesion") to being a matter of psychological trauma to becoming, in Freud's later theories, more or less the defining condition of femininity: the fact of castrated femininity, that is, could be seen as an inescapable trauma for all women. As du Preez puts it, "The fact that hysteria apparently favoured a female disposition corresponded with the conflation of hysteria with the signifiers of both femaleness (sex) and femininity (gender) to such a degree that the terms female, femininity and hysteria actually became inter-exchangeable" (47). It is, I suggest, to the moment of conflation that Westworld returns when it mobilizes symptoms of fin-de-siècle hysteria and theatrical scenes of female patients and male doctors. What, that is, the park works to reproduce and put into circulation are images of women whose performances affirm the operation of a system within which they are always already constituted as subordinate to patriarchal power-indeed, as a product of patriarchal power, a kind of "merchandise", and a kind of machine that will magically perform in response to stimuli.

Elyssa Marder has suggested in The Mother in the Age of Mechanical Reproduction that "photography functions both as a prosthetic compensation for the loss of the maternal body and as an uncanny medium that purports to bear witness to the unverifiable primal passage through the mother's body" (148). Photography's prosthetic operation, however, is itself arguably symptomatic of the conditions that can be seen to produce modern hysteria, precisely in the management-and fetishization-of the reproductive body for the reproduction of "the species". For example, when Marder suggests that Roland Barthes' 
Camera Lucida: Reflections on Photography "conceives of photography as a mechanical mother that mimes, distorts, and disrupts the maternal function" (150), she implicitly aligns the photographic maternal in its mimetic, disruptive mechanicity with hysteria as it was reconceived in the years of Euro-imperial industrial capitalism at the end of the nineteenth century. Like and with the diagnosis and treatment of hysteria at the fin de siècle, photography can be understood as a technology that operates ideologically to attempt to affirm patriarchal control over reproduction precisely by affirming reproductivity as if mechanical. This is the complexity with which this paper ends: the hysterical reproduction of symptoms-embodied or photographic_is itself mechanical.

In Westworld, the reproduction of hosts, that is like photography, is in the hands of men, and female hosts become hysterical, at least in some cases, when they cannot themselves have or hold onto children of their own-or, in other words, in this near-future world, when they are barred from the system in which power and capital, agency and mobility, inhere in the ability to reproduce and to masterfully stage control precisely of that reproducibility. The symptoms thus serve as evidence both of the humanness the androids render invisible through their obvious performing of their scripts and codes and of the conception of hysteria as a condition produced by traumatic experience. The symptoms also serve as potent evidence of the patriarchal, capitalist culture within which hysteria takes shape as itself an index of that culture's desire to control the terms of its own reproduction. That is, as it might be argued was the case at the end of the nineteenth century when modern hysteria was, as Didi-Huberman puts it, "invented" in the lecture theaters and photography studios of the Salpêtrière Hospital in Paris, hysteria in Westworld attests to the systemic and institutional violence of its own making, presented by and in the institution as an affirmation of conditions of control and its insistent reproduction of itself. Like and with its scenes of hysteria, then, its near-future nostalgia for the nineteenth-century Euro-imperial settler past, then, is an index of contemporary violence in the representation and ideological constitution of femininity. 


\section{Notes}

1 Anna Davin, "Imperialism and Motherhood" (History Workshop Journal vol. 5, 1978, pp. 9-65) 10.

2 Derritt Mason and Ela Przybylo note that although hysteria "has been by and large disarticulated from gender and medical discourse[, it] remains haunted by its history and etymology. In the fifth edition of the Diagnostic and Statistical Manual of Mental Disorders (2013), hysteria is housed as "Conversion Disorder (Functional Neurological Symptom Disorder)", which encompasses symptoms including weakness or paralysis, abnormal movement, swallowing symptoms, speech symptoms, attacks or seizures, anesthesia or sensory loss, special sensory symptoms, and mixed symptoms" formerly associated with hysteria (2).

3 See, for instance, Sadie Plant, "On the Matrix: Cyberfeminist Simulations," in The Gendered Cyborg: A Reader, edited by Gill Kirkup, Linda Janes, Kath Woodward, and Fiona Hovenden, London and New York, Routledge, 2000, pp. 265-75:

$[\mathrm{W}]$ oman is left without the senses of self and identity which accrue to the masculine. Denied the possibility of an agency which would allow her to transform herself, it becomes hard to see what it would take for her situation ever to change... [W] hen Freud extols [women] to get "little ones of their own," he intends this to compensate for th[eir] supposed lack [of a penis]. And without this one, [Luce]Irigaray writes, hysteria "is all she has left". This, or mimicry, or catatonic silence. (266-67)

4 See, for instance, Simon Shorvon, "Fashion and cult in neuroscience-the case of hysteria," Brain, vol. 130, no. 12, 2007, pp. 3342-3348: "Throughout his life Charcot believed that hysteria was due to a lesion in the brain, but the anatomical site continued to elude him". See also C.G. Goetz, "Charcot, Hysteria, and Simulated Disorders," in Handbook of Clinical Neurology, Vol. 139 (3rd series): Functional Neurologic Disorders, edited by M. Hallett, J. Stone, and A. Carson, pp. 11-23:

In the cases of neurologic disorders with paroxysmal or sudden but transient signs, epilepsies, migraines, and hysteria, Charcot contended that the anatomic lesion underlying the disorder, though well defined, also was fluctuating, or, in his terms, "dynamic." Importantly, such physiologic dysfunction was not global throughout the brain, but confined within very specific neuroanatomic regions relating directly to the clinical signs manifested by the patient (Charcot, 1887). (14)

Goetz cites Charcot, "Deux cas de contracture hystérique d'origine traumatique.” OEuvres Complètes, Vol. 3. Bureaux du Progrès Médical, Paris, 
1887, pp. 97-124 [In English: Charcot "Two cases of hysterical contracture of traumatic origin." Clinical Lectures on Diseases of the Nervous System, vol. 3. (translated by T. Savill). London: New Sydenham Society, 1890, pp. 84-106.].

5 Freud and Breuer begin the Studies in Hysteria with this statement:

Prompted by a chance observation, we have for a number of years been searching among the most diverse forms and symptoms of hysteria for their precipitating cause - the event which, often many years earlier, first gave rise to the phenomenon in question. In the great majority of cases it is not possible to ascertain the point of origin by means of simple medical examination, however, detailed, in part because it often involves experiences which patients find unpleasant to talk about, but principally because they really cannot remember them, and often have no sense of the causal connection between the precipitating event and the pathological phenomenon. (7)

6 Charcot, Leçons du mardi (1887-1888) 178, quoted in Didi-Huberman, 29.

7 See also Didi-Huberman 22-23.

8 Didi-Huberman is citing Émile Zola (1840-1902), as he is cited by Susan Sontag in On Photography (New York, Farrar, Straus and Giroux, 1977) 87.

\section{Works Cited}

Alvarado, Carlos S. "Nineteenth-Century Hysteria and Hypnosis: A Historical Note on Blanche Wittmann.” Australian Journal of Clinical and Experimental Hypnosis, vol. 37, no. 1, 2009, pp. 21-36.

A Dangerous Method. Directed by David Cronenberg, performances by Michael Fassbender, Keira Knightley, and Viggo Mortensen, Recorded Picture Company, 2011.

Augustine. Directed by Alice Winocour, performances by Vincent Lindon,

Stéphan Wojtowicz, and Soko, Dharamsala and France 3 Cinéma, 2012.

Baer, Ulrich. Spectral Evidence: The Photography of Trauma. MIT Press, 2002. Didi-Huberman, Georges. Invention of Hysteria: Charcot and the Photographic Iconography of the Salpêtrière (1982), translated by Alisa Hartz. MIT Press, 2003.

Du Preez, Amanda. "Putting on appearances: Mimetic representations of hysteria.” De arte, vol. 69, 2004, pp. 47-61.

electroprime90. Re: "William is a good guy, here is why..." Reddit, $r /$ westworld, https://www.reddit.com/r/westworld/comments/8stabq/william_is_a_ good_guy_here_is_why/. Accessed October 13, 2018. 
Evans, Martha Noel. Fits and Starts: A Genealogy of Hysteria In Modern France. Cornell University Press, 1991.

Freud, Sigmund, and Joseph Breuer. Studies in Hysteria. 1895, translated by Nicola Luckhurst. Penguin, 2004.

Hysteria. Directed by Tanya Wexler, performances by Hugh Dancy, Maggie Gyllenhaal, and Jonathan Pryce, Informant Media, 2011.

Iversen, Kristin. "How 'Westworld' Proved the Future is Female." Nylon,

December 5, 2016, https://nylon.com/articles/westworld-season-one-

finale. Accessed October 13, 2018.

Joy, Lisa, and Jonathan Nolan, writers and executive producers. Westworld. HBO and Bad Robot, 2016.

Marder, Elissa. The Mother in the Age of Mechanical Reproduction: Psychoanalysis, Photography, Deconstruction. Fordham University Press, 2012.

Matlock, Jann. Scenes of Seduction: Prostitution, Hysteria, and Reading Difference in Nineteenth-Century France. Columbia University Press, 1994.

McCarren, Felicia. "The 'Symptomatic Act' circa 1900: Hysteria, Hypnosis, Electricity, Dance.” Critical Inquiry, vol. 21, no. 4, 1995, pp. 748-74.

Sharell. Re: "The Hosts of Westworld: Human or Synth?" The Artifice, June 3, 2018, https://the-artifice.com/westworld-hosts/. Accessed October 13,. 2018.

Westworld. Directed by Michael Crichton, performances by Yul Brynner, Richard Benjamin, and James Brolin, Metro-Goldwyn-Mayer, 1973.

"Westworld, Season 1, Episode 3, 'The Stray." Rotten Tomatoes, https://www. rottentomatoes.com/tv/westworld/s01/e03. Accessed October 13, 2018. 

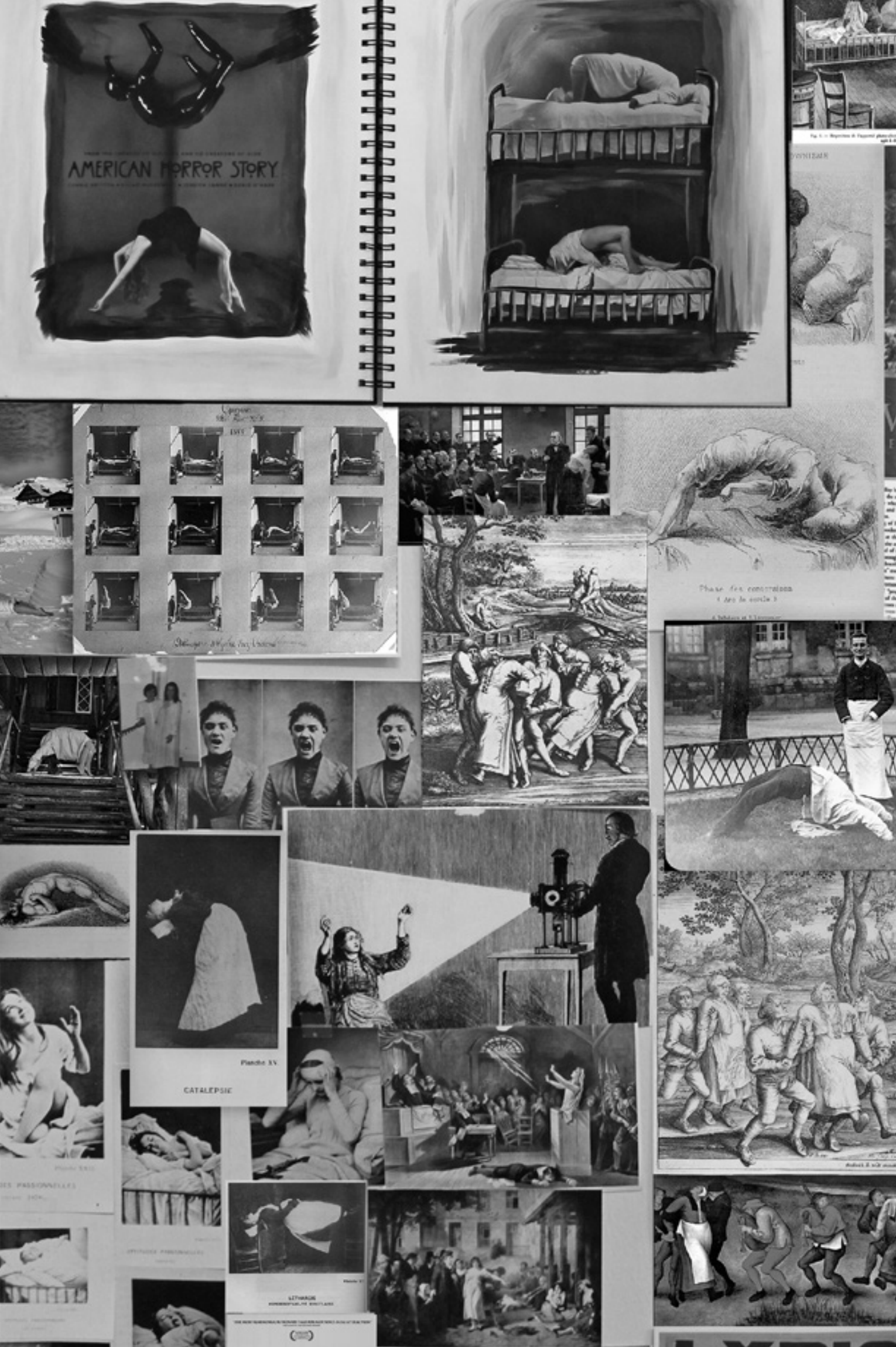

W .
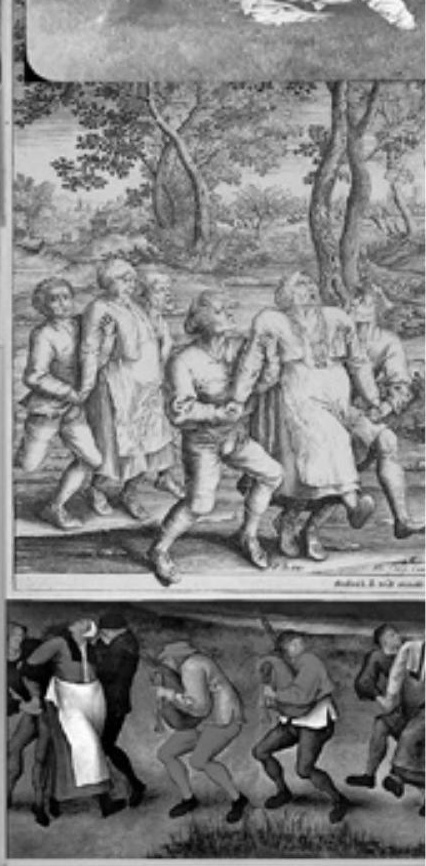



\section{\#METOO'S FIRST HORROR}

FILM

\section{Male Hysteria and the New Final Girl in 2018's Revenge}

Tim Posada

An "arthouse" film for one critic (Naahar) and "trashy exploitation" to another (Ide), the fortuitously titled Revenge (2018) became an unlikely anthem of the \#MeToo movement, according to media critics, praised for depicting "a badass woman" who defeats her aggressors in "ultraviolent" ways (Schager). But for Slate's Lena Wilson, the film's male gaze exploits the heroine's body and the use of violence merely shifts that brutality from male to female hands. These concerns are central to determining if the film provides insights relevant to \#MeToo or if it "[keeps] feminism at arms-length"(Wilson). The answer is both. While the film might remain problematic in its use of an equally problematic horror film subgenre, the rape-and-revenge film, part of the answer lies in how the gaze evolves, creating hysterical men facing a new kind of Final Girl.

\section{Hysterical Double Standards}

The rape-revenge film tends to follow a similar three-act structurethe rape, survival, revenge - and it is often chided for "eroticizing rape scenes" before "masquerading the revenge as female agency" (Virdi 27). This places the rape-revenge film agreeably in horror's longstanding tradition of torturing female bodies (Williams 5), contributing to a 
common trope: the hysterical woman. In Revenge, however, Jen (played by Matilda Lutz) does not become a hysteric, uncontrollably crying or irrationally running up stairs rather than out the front door. Instead she finds herself surrounded by hysterical men, fearing reprisal for their actions. The \#MeToo movement foregrounds these hysterical men who fear a cultural shift, as President Donald Trump, accused by twenty-two women of sexual misconduct, implied in October, 2018, when he said, "It's a very scary time for young men in America" (Wilkie).

Recent male hysteria masks itself as a defense against the alleged "hysteria" of \#MeToo with claims like "rape culture' has led to censorship and hysteria" (Kitchens) or "for those in the grips of hysteria, proof is the enemy" (Young). Responding to \#MeToo, Baltimore Sun columnist Michael Cromwell compared "sexual harassment hysteria" to McCarthyism, as did filmmaker and child rapist, Roman Polanski, who also labeled it "mass hysteria" (Pasternak). But male hysteria can be better understood through Judge Brett Kavanaugh's defense against rape allegations in front of a judiciary committee. National Review's Kyle Smith praised his speech as "history changing" and "emotional fireworks", while House minority leader Nancy Pelosi deemed Kavanaugh unhinged, "hysterical" (Segers). Comedian Michelle Wolf's response on Twitter more pointedly called attention to the double standard that favors men's emotional excess when she said, "Wow Kavanaugh, why so emotional? You on your period or something?". And as Jon Stewart noted in a segment on The Daily Show covering how female politicians are mocked for crying while male ones are lauded as brave, "[i]n politics, it's OK to be a pussy, as long as you've got a dick".

Double standards are hardly unique to American politics. As Pierre Bourdieu contends, social factors dictate taste, often violently, through classist, and implicitly sexist "[a]version to different life-styles" (56). This is on display in Revenge's user scores on websites IMDb and Rotten Tomatoes. While critics praised the film, users were less kind: 55 per cent on Rotten Tomatoes and 6.3/10 on IMDb. Media feedback is a notoriously complicated subject of study, but Wired's Matt Reynolds addresses the former, noting top-rated films are mostly male-led, revealing the user bias of the predominantly male participants of the site. Rotten Tomatoes user data is not public, but the website arguably shares the same or a similar demographic as IMDb. So conflict between the critical score of 93 per cent and the audience score of 55 per cent 
can be interpreted with this user bias in mind, not the inherent quality of the film.

User comments about Revenge's "suspension of disbelief" problems (i.e., Jen's ability to survive having been impaled by a tree or traverse the desert barefooted) or condemnations of political content ("\#MeToo" and "social justice warriors" directly invoked) must be compared to similar male films. For example, revenge films The Revenant (2015) and Inglorious Basterds (2009) feature similar challenges to suspension of disbelief, like Hugh Glass' (Leonardo DiCaprio) ability to survive the elements with protruding ribs following a bear attack, and even revisions to the actual histories they are each based on, like Hitler's assignation in Inglorious. Instead, both films, equivalently as violent as Revenge, were nominated for best picture and enjoy audience scores comparable to their high critical marks. For that matter, revenge films 13 Assassins (2010), John Wick (2014), and Mad Max: Fury Road (2015) all require suspensions of disbelief by pitting their heroic figures against hundreds of attackers. Based on available data, male audiences seem to forgive masculine films for sins against realism, while feminine ones are considered products of PC culture or merely inaccurate.

From politics to film, double standards are often disguised in other argumentative diagnoses, as was the case with the \#GamerGate harassment controversy in 2014. The online Gamergate community is often described by supporters as advocacy for "ethics in journalism", critiquing undeserved positive coverage of female reporters and "the burgeoning influence of so-called social-justice warriors in the gaming world", The Cut's Jesse Singal writes, detailing her history of negative encounters with Gamergaters. In yet another industry, women are held to a different standard, harassed with rape threats and condescending arguments, often wrapped in the language of logic and ethics. But the public outcry against \#GamerGate, which deemed the movement a form of "hysteria" (Gorton), share one detail in common with the (mostly liberal) responses to Bret Kavanaugh's public defense. No longer relying solely on "emotional" or "angry" to describe male behavior, the term "hysterical" has been loosed from a primarily female diagnosis in public discourse, at least to a degree. This took time since its more common use in nineteenth-century psychology as a woman's ailment. 


\section{Male Hysteria}

Neurologist Jean-Martin Charcot-who championed the hysteria diagnosis, noting symptoms in women like 'masturbation' and 'venereal excesses' (Didi-Huberman 72)—often displayed hysterical women during public lectures, their afflictions photographically chronicled. In his later research, however, he recorded sixty cases of male "hysterics" by the 1880s (Micale 365). He argued against common assumptions of the time, including practitioners' claim that a primary symptom of male hysteria was feminine behavior. Instead, these "hysterics" were "robust men presenting all of the attributes of the male sex" (Malice 380). In Revenge, Jen's weekend lover, Richard (Kevin Janssens), easily falls into this "robust" category as a caricature of masculinity: he hunts and sports tacky full-body racing attire. And when hysteria overtakes him, he acts in equally masculine ways, bribing Jen to stay silent about the rape, slapping her when she threatens to expose their affair to his wife, and rashly attempting to murder her by pushing her off a cliff.

Following his death, Charcot became known as "a charlatan who coached his hysterical female patients in their performances", resulting in the removal of male hysteria "from the record" once its champion was discredited (Gilman et al. 314). The diagnosis remained intact for women, even though Sigmund Freud, an admirer of Charcot's work, wrote in support of male hysteria. Alas, since his research focused mainly on women, he unintentionally aided male hysteria's erasure (Gilman et al. 314-15). That historical revision is easily identifiable in horror cinema, which favors Scream Queens and Final Girls more than clearly identifying the male hysterics of The Shining (1980), Videodrome (1983), From Beyond (1986), Event Horizon (1997), Slither (2006), Maniac (2012), and Sinister (2012). More recently, Hereditary (2018) serves as a unique example of male hysteria, employing its female counterpart as a red herring. Annie Graham's (Toni Collette) emotional journey remains in the forefront, while the slow mental deterioration of son Peter (Peter Wolff) is actually the objective of a satanist group making his body emotionally vulnerable for demon possession. Annie's hysteria creates distance between her and the rest of the family, especially a rational husband (Gabriel Byrne), whose stoicism only exacerbates the hysteria of wife and son. Contrasting the father's rationalism is Peter's hysteria, "effeminate" at points, as defined by Charcot's opposition (he 
continually screams for "mommy" and mirrors many of the hysterical responses of his mother throughout).

The conflict between feminine and masculine hysteria diagnoses is on display in Jen's attacker, Stan (Vincent Colombe). According to Charcot's findings, "women fell ill due to their vulnerable natures and inability to control their emotions, while men got sick from working, drinking, and fornicating too much", male hysteria manifesting in "rage, jealousy, and agitation" (Malice 406). When the rape occurs in Revenge, after a day of hunting and a night of drinking, Stan displays all three of Charcot's symptoms, but his subservience to Richard soon shows. Following Jen's rape, alpha male Richard returns to find Stan seated on a couch, guilty, waiting for Richard to fix the situation. As events unfold and the three men attempt to locate Jen, incorrectly presumed dead, Stan chooses to wait in a car, hoping she comes to him. After his attack, Stan reverts to a feminized male hysteria, characterized by Charcot's detractors as "timid and fearful" (Gilman et al. 289).

Stan's male hysteria transforms into a female hysteria familiar to horror connoisseurs, especially when Stan and Jen confront each other for the last time. After taking a bullet to the shoulder, Stan begins moaning in pain, hysterically, before he chases after Jen. During their pursuit, Jen shatters her flashlight's glass lens in Stan's path, leading to an elongated sequence in which he attempts to remove a large shard from his foot. Director Coralie Fargeat recalls film editors' pleas for a shorter cut of the sequence, but she wanted Stan's suffering extended to portray how he "becomes obsessed with taking the glass out" (Weinstein). Fargeat intentionally frames Stan's suffering as hysterical, while Jen's own pain occurs differently.

Before Brett Kavanaugh spoke "too emotionally at times", as he later described his behavior in an op-ed, his accuser Dr. Christine Blasey Ford calmly presented her story to that judiciary committee, never hysterical, providing expert commentary on a subject she also specializes in as well (Engber). Showing emotion, even when discussing trauma, remains poisoned by a patriarchal double standard. In Revenge, Jen would be justified to mourn, but she confronts the realities of her assaults in a more aggressive way, like other emerging Final Girls confronting the long arm of the male gaze. 


\section{The New Final Girl}

Horror cinema punishes women for their sexual desires. A skinnydipping hippy dies first in Jaws (1975). A high schooler's stomach is ripped open in A Nightmare on Elm Street (1984) when she spends the evening with her boyfriend. And Revenge's Jen is raped for dancing with a man she does not plan to copulate with. The foremost weapon against these women is the male gaze, which establishes "pleasure in looking" at female bodies as "passive" subjects of male fantasy "coded for strong visual and erotic impact" (Mulvey 19). A primary point here is the passive role of women as objects of desire. While Laura Mulvey coined "the male gaze" in 1975, one photo in Charcot's collection provides a unique connection to horror film tropes: fifteen-year-old patient Augustine, lying on a bed with flowing hair, a nightgown partially revealing a bare shoulder, legs crossed exposing more skin (Regnard). What should be an academic recording of hysteria is disguised eroticism. As mentioned earlier, modern critics suspect she was posed, aware of the camera's gaze upon her, and much like women in horror cinema she "evokes horrorfilm visions of vulnerable, beautiful young women sleeping or fainted on their beds" like Lucy (Sadie Frost) in Bram Stoker's Dracula (1992), donning evening wear while a vampire snacks on her (Smith 167-168).

Jen's overt sexuality could easily be diagnosable, according to Charcot and several decades of horror films that do just that. In the first act, the male gaze is intentionally employed, depicting Jen as a sexual prize complete with short skirt and red lollipop in mouth, alluding to "the fascinating, polarising image of the Lolita", Fargeat says (Fleming). These choices are not abnormal for Rhona K. Berenstein, who claims "sexuality is not mere performance but a sartorial display" (36). Each shot overdetermines Jen, from revealing outfits to cinematography that explores her body. Amidst this male gaze, however, Fargeat does include one notable scene of full male nudity to critique "societal attitudes" toward the female body, Fargeat says (Birds' Eye), revealing that the gaze never completely belonged to a heterosexual male point of view from the start.

Revenge resists depicting Jen as a virginal Final Girl, a term coined by Carol J. Clover in 1993 to describe the last female survivor of horror films. Clover's Final Girl, as exemplified by the victim-heroes of The Texas Chain Saw Massacre (1974), Halloween (1978), and A Nightmare on 
Elm Street (1984), are "boyish", "smart", and sexually reserved (40). In a previous decade, Jen's sexual promiscuity, complicity in an extramarital affair, and sartorial flaunting would mark her as an easy target for an on-screen death. Instead, "Jen's desire to 'be noticed' isn't framed as a sign of vapidity or moral weakness" (Dolinh). Her sexuality does not make her hysterical. No part of blame belongs to her, only her male attackers, who become hysterical when she refuses to comply and die as a passive subject should. And after Jen's assault, the male gaze inverts, no longer sexualizing her body for male pleasure.

This is hardly the only case of a shift in gaze. In a problematic example, Boys Don't Cry (1999) establishes a transgender gaze throughout most of the film. When Brandon's (Hilary Swank) secret is revealed to girlfriend Lana (Chloë Sevigny), however, the transgender gaze gives way to a lesbian one thanks to the director's "universal vision of humanism"; a change in demeanor occurs between both characters in the dialog and a final sex scene clearly coded as an intimate act between two women (Halberstam 298). French film Blue is the Warmest Color (2013) faces similar problems when depicting extensive lesbian sex scenes. A Posture magazine video features reactions to the scenes by lesbian spectators, who can easily tell the film is created by a heterosexual male director and depicts straight women simulating lesbian sex; one viewer even chides a scene for including "scissoring", a sex act common in straight male porn (Sleidi). Both films attempt to challenge Mulvey's claim that all "alternative cinema" can "only exist as a counterpoint" to the male gaze, eternally responding to, rather than developing entirely separate from, patriarchal cinema (16). Enchanted (2007) inverts the gaze by depicting a princess saving her man, now the damsel in distress, and Revenge's Jen is a female version of Rambo and Mad Max by Fargeat's own admission (Weinstein). Still, horror has a history of toying with the gaze, consciously or not.

Clover argues for an inverted gaze in most horror films come the third act, claiming that "fear and pain" draw "the male spectator into identification with the Final Girl" (152). Recently, the Final Girl has become more self-aware in meta horror films like The Cabin in the Woods (2012), Final Girl (2015) and The Final Girls (2015), while others like You're Next (2011) and The Witch (2016) subvert the trope, masking their proximity to it. For example, home-invasion film You're Next includes several hysterical women whose responses to increasing doom directly 
result in their deaths, while Final Girl Erin (Sharni Vinson)-another easy candidate for an early death, since she dates her professor-turns out to be resourceful not by necessity but because of her upbringing in a survivalist compound. She requires no new skills, only the right circumstances to put her training into practice. Even the rape-revenge subgenre receives occasional updates with films like Bound to Vengeance (2015), which begins with a rape victim's escape and capture of her rapist, only to discover she must now free his other victims caged around town. Revenge borrows from many of these revisionist horror films, like depicting a Final Girl who does not become a temptress to lure her enemies into a trap, as Jennifer (Camille Keaton) does in early raperevenge entry I Spit on Your Grave (1978). And unlike past Final Girls excessively coded as victims, Revenge identifies the men by their "fear and pain" at the mercy of an aggressive female gaze.

This is a unique choice in a film that features a rape and attempted murder. But the rape sequence, which avoids a gratuitous display, lasts only two minutes (I Spit on Your Grave's rape sequence lasts 45 minutes). Rape as a topic in fiction media remains controversial. In Hindi cinema, Jyotika Virdi claims its omission "bears the marks of a patriarchal discourse on honor and chastity", though showing it runs the risk of eroticizing trauma (Virdi 31). The American adaptation of The Girl with the Dragon Tattoo (2011) was chastised for depicting the graphic rape of Lisbeth Salander (Rooney Mara), but for Jeffrey A. Brown the scene is designed not to be erotic but horrific. "There is no hint of titillation, no suggestion that Salander wanted it, deserved it, or enjoyed it", Brown says. "There are no snappy comebacks or eleventh-hour rescue; there is nothing but violence and victimization" (Brown 56). Similarly, Virdi disagrees with Indian critics of one particular film, Insaaf Ka Tarazu (1980), which she argues does not "titillate" either (Virdi 33). So if Virdi and Brown find examples that resist eroticizing on-screen rape, then criticism is based more on showing the act at all. Conversely, HBO series Game of Thrones employs a cutaway in season 5 when Sansa Stark is raped, but the male showrunners' decision to focus instead on another male character forced to watch removes the female victim's agency by emphasizing a male character's trauma instead.

Revenge's use of the male gaze establishes what the film is willing to show, and when the attack begins the camera seems ready to bare all as Jen's attacker, Stan, begins to stick a hand down her underwear. Then 
another male character, Dimitri (Guillaume Bouchède), interrupts, but he is no savior-recalling the same outcome from Dragon Tattoo. Instead, he closes the door, turns on a TV, and goes swimming, his actions juxtaposing two brief medium shots of Jen thrust against a window and a third that focuses on her hand and the side of her traumatized face: a physical violation by one and a complicit violation by another. So rather than dwell on a graphic assault or make the scene about a man's pain, Revenge favors something between both, which emphasizes her trauma without eroticizing it. While the film resists exposing Jen's trauma here, no such restraint occurs when she performs cave-surgery on herself.

After Jen is pushed off a cliff and impaled by a tree branch, she must treat the resulting wound. She cauterizes it with the help of a beer can and hallucinogenic, which numbs her during the process, transitioning her from suffering victim to spectator in her own body alteration. This surreal sequence taps into the body horror subgenre, which features bodily transformation through mutation or mutilation. For Barbara Creed, films like Altered States (1980) and The Fly (1986) exhibit "male hysteria" that stems from an inability to "create life", which prompts these male hysterics to instead create "uncanny man-made wombs" that mutate their bodies in grotesque ways (Phallic Panic 43). Beyond science fiction, the Saw franchise (2004-) explores bodily transformation through torture; the "wombs" here are serial killer Jigsaw's unique mechanical contraptions that present victims with "decisions", Jigsaw (Tobin Bell) says in Saw II (2005), that coax survivors into becoming self-actualized subjects with a new appreciation for life.

Many popular entries from the 1980s and 1990s focused on male hubris, while newer entries in the 2010s breathe life into an array of topics from body modification in American Mary (2012) to anxieties about pregnancy in Honeymoon (2014) to slut shaming in Raw (2017). In most cases, the outcome is rarely positive, often ending with the heroine's death or (social) isolation. Jen's own transformation, however, is not designed to create the next hysterical, mutilated Scream Queen or tragic heroine. She feels no pain, which contrasts with body horror's anxiety over "infiltration of the Other" (Bukatman 237). She might be removing a foreign object from her body, but she is not becoming Other. Rather, she is returning to a pure self "grounded in nature and the elements", director Fargeat says (Birds' Eye). Hence, she awakens to find a phoenix 
branded on her stomach (the result of the beer can logo), resulting in a positive body modification, one inflicted upon her by a natural monster.

\section{A Natural Monster}

In Revenge's final moments, Jen walks outside after victoriously defeating all her attackers. As a helicopter approaches to take her away from the desert, she looks over her right shoulder directly into the camera. "Her existence would no longer depend on the male gaze", Fargeat says (Birds' Eye). But something else occurs. Unlike traditional depictions of the Final Girl, rape-revenge films are often characterized by graphic sequences of aggression, from Jeniffer's castration of one rapist in I Spit on Your Grave to Mary's off-the-book surgical experiments on her assailant in American Mary. By the end, the avenger sometimes transforms into a "violent monster" herself, Alexandra Heller-Nicholas notes (HellerNicholas 88). As Slate's Wilson says, avenging victims "become as cold and unfeeling as their attackers". Clover more broadly uses the term "female victim-hero" to describe female protagonists in horror films, saying these "heroes" also bear "some degree of monstrosity" (4). Creed examines this duality of humanity/monstrosity by discussing "bodies without souls", like a werewolf which "signifies a collapse of the boundaries between human and animal", embodying a violation of natural law ("Monstrous-Feminine" 70). Conversely, Jen is not a body without soul or a violation of natural law. Rather, her body modification is a return to natural law. Hysterical men, of all kinds, would clearly see such a return to nature as threatening; it calls into question gender expectations that belong to society, not nature. In short, Jen's return to a natural state of being is deemed monstrous Other by patriarchy.

Berenstein taps into this when she argues that horror cinema offers spectators a "form of performance" called "spectatorship-as-drag" (30). While the monstrous Other of most horror films is often coded as male, it can also be understood as something beyond a male/female dichotomy, "a temporary release from everyday identities" (Berenstein 8). In Dracula (1931), for example, the titular male-coded monster (Bela Lugosi) orders a vampire harem "to leave Renfield (Dwight Frye) alone so that he can have him to himself", which can be read as both heterosexual-the women thirsting for the man-and nonheterosexual-Dracula's desire for him (Berenstein 53). Spectatorship- 
as-drag allows heterosexual spectators to participate in this viewing practice, albeit temporarily, but other spectators might refuse to "relinquish" the "sometimes-illicit identifications and desires that get played out at the movies for those whose everyday identities run contrary to dominant culture" (Berenstein 58). The monstrous Other is a site of playful exploration amidst ideological constructs.

Taking Berenstein a step further, horror cinema, used in this way, ruptures not natural boundaries but socially formed ones that masquerade as natural. Jen is a monstrous Other not merely because she exacts vengeance but because she resides outside patriarchy's definition of normal. Her newfound identity stems from her treacherous walk through the desert, through nature, transforming her into a rare iteration of an "Edenic" figure. Women in tune with nature are often perceived as "docile, unintellectual and ruled by their physicality", a criticism even employed against films like Mad Max: Fury Road (Yates 354). But Michelle Yates challenges such a description of the film, instead arguing that it "transforms nature into a space of feminist possibility" by disrupting "a dominant Western environment narrative" (355). Jen, too, becomes empowered by nature, and her return to society, marked by that final gaze into the camera, serves as a promise to continually, aggressively confront the male gaze and the hysterical men who reinforce it most weekends at the box office, both as spectators and those boys-being-boys on screen. Jen does this first by embracing what is truly natural, found in the wilderness-not what patriarchy decides is natural-and then violently removing what is unnatural from her life (a rapist, an attempted murderer, a complicite voyeur). And she does this without screaming hysterically. To do so-at least for Fargeat, who seeks to ensure Jen "never [becomes] a victim again" (Birds' Eye)—would be derivative, another woman screaming for the camera.

Slate's Lena Wilson is likely correct that the film's use of "violence more than justice" is an insufficient message for \#MeToo. It certainly can be cathartic to watch Jen penetrate Richard's shotgun wound as he hysterically says to her, "you had to put up a fight. Women always have to put up a fucking fight". The deep roots of his sexism exposed, Revenge frames his current suffering and imminent death as justified. This is a far cry from I Spit on Your Grave, in which Jennifer tells one of her rapists, Stanley (Anthony Nichols), "Suck it, bitch", before killing him with a boat motor. But "revenge against men" is a problem for 
"feminism", Wilson says, "because it has nothing to do with men at all". Alas, Fargeat, a French director who did not know about \#MeToo or Time's Up when she began developing the film, never intended a literal experience: "women today need to be very 'loud' if they are going to have any chance of building an equal society and establishing crucial boundaries" (Birds' Eye). Her definition of loud involves a substantial amount of blood and even louder hysterical men.

Rather than embrace "bodily hysteria", described by Linda Williams as a notable currency of emotional women's films (4), Jen does not weep or scream throughout the film. Rather she ceases to speak following the rape and attempted murder. Practically, this is a problem for Wilson: "she uses brutality to dissociate from her trauma". She is right. To understand Jen's journey as a period rather than an ellips on victimhood is a challenge. "It becomes 'feminist' for women to solve their problems by beating the shit out of them", Wilson writes. Revenge, then, is an anthem of a movement in its early phase, not the goal. But Jen the Final Girl belongs to a broader shift away from female hysteria, away from masculine double standards that erase male hysteria. And Jen's final gaze is a call to arms directed at passive film spectators, some aware that their time might soon be up and others ready to challenge the male gaze's performative trappings.

\section{Works Cited}

Berenstein, Rhona J. Attack of the Leading Ladies: Gender, Sexuality, and Spectatorship in Classic Horror Cinema. Columbia University Press, 1996.

Bourdieu, Pierre. Distinction: A Social Critique of the Judgement of Taste, translated by Richard Nice. Harvard University Press, 1984.

Brown, Jeffrey A. "Torture, Rape, Action Heroes, and The Girl with the Dragon Tattoo." Heroines of Film and Television: Portrayals in Popular Culture, edited by Norma Jones, Maja Bajac-Carter, and Bob Batchelor, Rowand \& Littlefield, 2014, pp. 47-64.

Bukatman, Scott. Terminal Identity: The Virtual Subject in Postmodern Science Fiction. Duke University Press, 1993.

Clover, Carol J. Men, Women, and Chain Saws: Gender in the Modern Horror Film.

Princeton University Press, 1993. 
Creed, Barbara. "Horror and the Monstrous-Feminine: An Imaginary

Abjection." Horror, the Film Reader, edited by Mark Jancovich, Routledge, 2002, pp. 67-76.

- - Phallic Panic: Film, Horror and the Primal Uncanny. Melbourne University Press, 2005.

Cromwell, Michael. “\#MeToo Movement Goes Too Far.” The Baltimore Sun, December 19, 2017, www.baltimoresun.com/news/opinion/oped/bs-ed-op1220-metoo-toofar-20171219-story.html. Accessed August 13, 2018.

Didi-Huberman, Georges. Invention of Hysteria: Charcot and the Photographic Iconography of the Salpêtrière, translated by Alisa Hartz. MIT Press, 2003.

Dolinh, Aline. "Finding Feminist Catharsis in the Rape-Revenge Film." Film School Rejects, May 25, 2018, filmschoolrejects.com/finding-feministcatharsis-in-the-rape-revenge-film. Accessed July 2, 2018.

"Elizabeth Warren." The Daily Show, created by Madeleine Smithberg and Lizz Winstead, performance by Jon Stewart, season 19, episode 92, NEP Studio 52, 2014.

Engber, Daniel. "Ford's Dual Roles in Her Kavanaugh Testimony: Witness as a Victim, and Expert Witness in Psychology." Slate, September 27, 2018, slate.com/technology/2018/09/christine-blasey-ford-expert-witness-onpsychology.html. Accessed October 10, 2018.

"Exclusive Interview with Revenge Director, Coralie Fargeat." Birds' Eye View, May 12, 2018, www.birds-eye-view.co.uk/coralie-fargeat-interview. Accessed July 2, 2018.

Fleming, Amy. “'Revenge' Director Coralie Fargeat on Her Gory Riposte to the Male Gaze." Financial Times, May 9, 2018, www.ft.com/content/ e7a6fc26-52c1-11e8-84f4-43d65af59d43. Accessed July 2, 2018.

Gilman, Sander L., Helen King, Roy Porter, G.S. Rousseau, and Elaine Showalter. Hysteria Beyond Freud. University of California Press, 1993.

Gorton, Bruce. "Gamergate, Ethics and Hate.” TimesLIVE, September 22 2014, www.timeslive.co.za/ideas/2014-09-22-gamergate-ethics-and-hate. Accessed December 3, 2018.

Halberstam, Jack. "The Transgender Gaze in Boys Don't Cry." Screen, vol. 42, no. 3, 2001, pp. 294-298.

Heller-Nicholas, Alexandra. Rape-Revenge Films: A Critical Study. McFarland \& Company, Inc. Publishers, 2011.

Ide, Wendy. "Revenge Review - Cartoonish Exploitation Flick." The Guardian, May 13, 2018, www.theguardian.com/film/2018/may/13/revenge-reviewobserver-coralie-fargeat. Accessed July 21, 2018. 
Kavanaugh, Brett M. "I am an Independent, Impartial Judge." The Wall Street Journal, October 4, 2018, www.wsj.com/articles/i-am-an-independent-

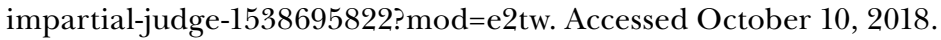

Kitchens, Caroline. “It's Time to End 'Rape Culture' Hysteria.” Time, March 20, 2014, time.com/30545/its-time-to-end-rape-culture-hysteria. Accessed June 18, 2018.

Micale, Mark S. "Charcot and the Idea of Hysteria in the Male: Gender, Mental Science, and Medical Diagnosis in Late Nineteenth Century France." Medical History, vol. 34, no. 4, 1990, pp. 363-411.

Mulvey, Laura. Visual and Other Pleasures. 2nd ed., Palgrave Macmillan, 1989.

Naahar, Rohan. "Revenge Movie Review: The Most Provocative Film of 2018 Invades Your Home, Abetted by Netflix.” Hindustan Times, June 7, 2018, www.hindustantimes.com/movie-reviews/revenge-movie-review-the-mostprovocative-film-of-2018-invades-your-home-abetted-by-netflix/storyDS1xH8RrLWeeaaa45MEwrO.html. Accessed August 14, 2018.

Pasternak, Karolina. "Lubię, jak jest pod górkę.” Newsweek Polska, NR20/2018, www.newsweek.pl/plus/kultura/roman-polanski-o-kinie-paryzu-i-magiilat-60-wywiad,artykuly,426817,1,z.html. Accessed August 13, 2018.

Regnard, Paul-Marie-Léon. "Attitudes Passionnelles Extase," 1878, The J. Paul Getty Museum, Paris, France (origin of photo), www.getty.edu/ art/collection/objects/145321/paul-marie-leon-regnard-attitudespassionnelles-extase-1878-french-1878. Accessed August 17, 2018.

Reynolds, Matt. "You Should Ignore Film Ratings on IMDb and Rotten Tomatoes." Wired, October 24, 2018, www.wired.co.uk/article/which-filmranking-site-should-i-trust-rotten-tomatoes-imdb-metacritic. Accessed December 1, 2018.

Schager, Nick. "'Revenge' is an Ultraviolent Rape-Revenge Saga for the \#MeToo Era." The Daily Beast, May 9, 2018, www.thedailybeast.com/ revenge-is-an-ultraviolent-rape-revenge-saga-for-the-metoo-era. Accessed July 20, 2018.

Segers, Grace. "Nancy Pelosi Calls Brett Kavanaugh 'Hysterical,' Says He is Unfit to Serve on the Supreme Court." CBS News, September 29, 2018, www.cbsnews.com/news/nancy-pelosi-calls-brett-kavanaugh-hysterical-sayshe-is-unfit-to-serve-on-the-supreme-court. Accessed October 10, 2018.

Sleidi, Yeni. "Lesbians React to Sex Scenes in 'Blue is the Warmest Color." YouTube, November 8, 2013, www.youtube.com/watch?v=rIjJ_VtU9PA. Accessed November 29, 2018.

Smith, Angela M. Hideous Progeny: Disability, Eugenics, and Classic Horror Cinema. Columbia University Press, 2011. 
Smith, Kyle. "Brett Kavanaugh's History-Changing Speech.” National Review, September 28, 2018, www.nationalreview.com/2018/09/brett-kavanaughshistory-changing-speech. Accessed October 10, 2018.

Virdi, Jyotika. "Reverence, Rape - and then Rape: Popular Hindi Cinema's 'Woman's Film.”' Screen, vol. 40, no. 1, 1999, pp. 17-37.

Weinstein, Max. "Desert Eagle: How Coralie Fargeat Shot Revenge in the Moroccan Desert, Preserved Her Creative Freedom, and More." MovieMaker Magazine, May 15, 2018, www.moviemaker.com/archives/ moviemaking/directing/desert-eagle-how-coralie-fargeat-shot-revenge-inthe-moroccan-desert-preserved-her-creative-freedom-and-more. Accessed August 13, 2018.

Wilkie, Christina. "Trump: It is 'a Very Scary Time for Young Men in America."” CNBC, October 2, 2018, www.cnbc.com/2018/10/02/trumpkavanaugh-allegations-usher-in-a-very-scary-time-for-young-men-inamerica.html. Accessed October 4, 2018.

Williams, Linda. "Film Bodies: Gender, Genre, and Excess." Film Quarterly, vol. 44, no. 4, 1991, pp. 2-13.

Wilson, Lena. "Revenge Tries to Elevate the Rape-Revenge Movie, But is the Genre Worth Saving?” Slate, May 11, 2018, slate.com/culture/2018/05/ revenge-and-the-case-against-rape-revenge-films.html. Accessed July 21, 2018.

Yates, Michelle. "Re-casting Nature as Feminist Space in Mad Max: Fury Road." Science Fiction Film and Television, vol. 10, no. 3, 2017, pp. 353-70.

Young, Cathy. "The Injustice of the 'Rape-Culture' Theory." Commentary, September 13, 2017, www.commentarymagazine.com/articles/campus-sexcrime-tribunals-losing-2. Accessed June 18, 2018. 


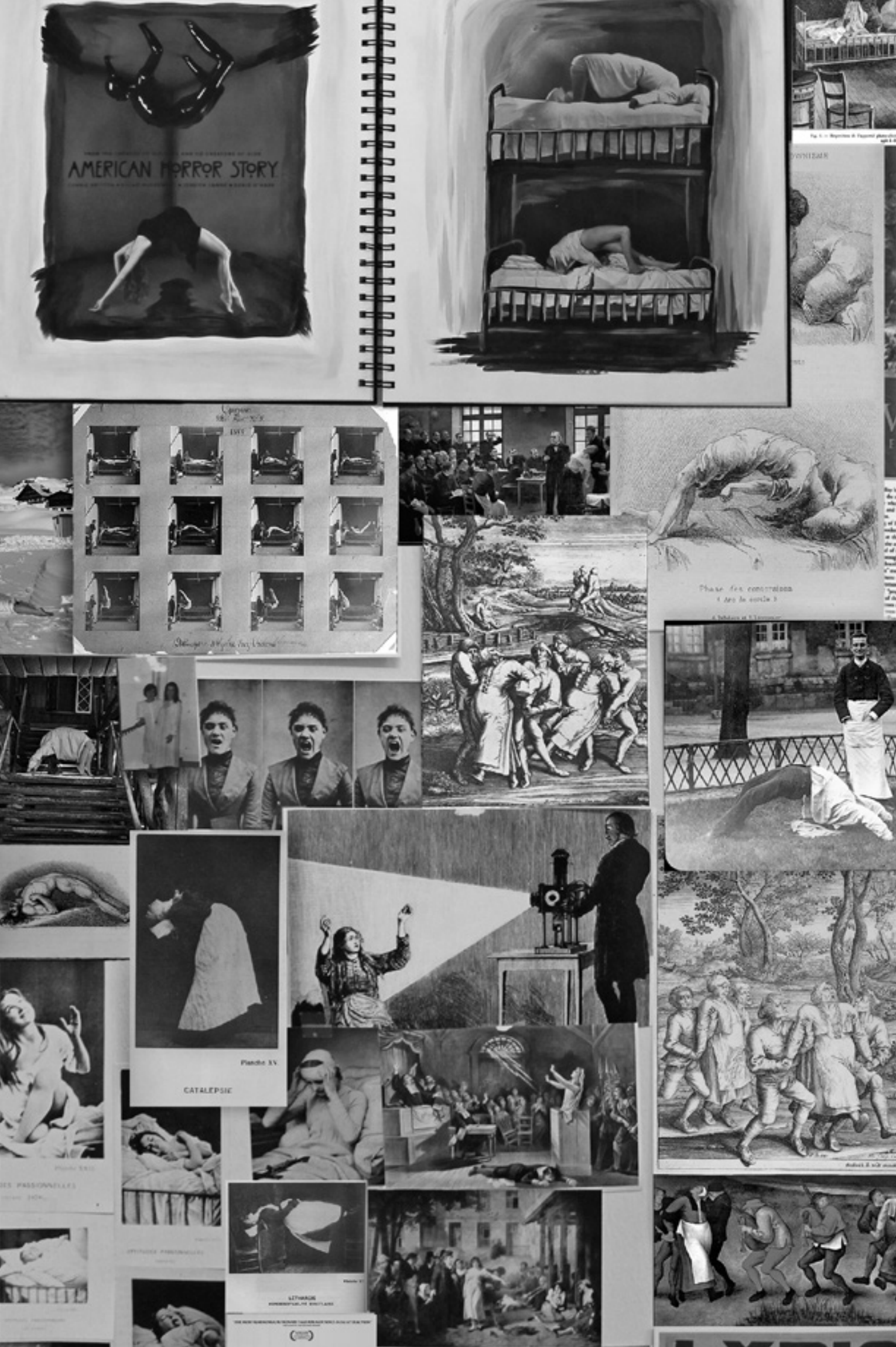

W .
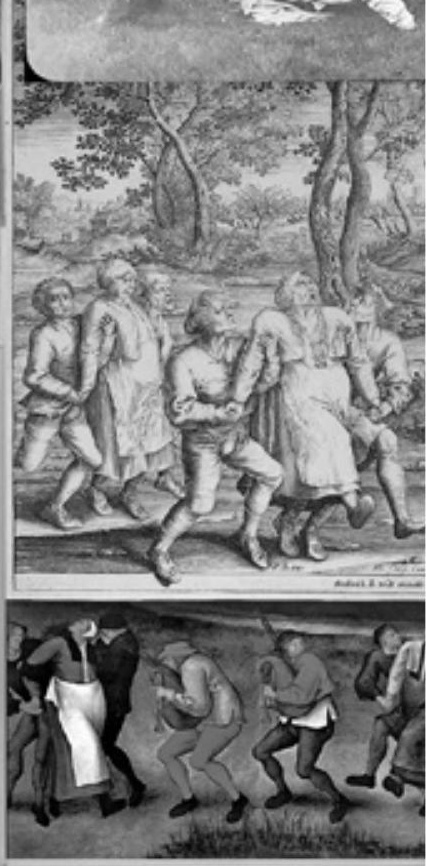



\title{
HYSTERICAL CURE Performing Disability in the Possession Film
}

\author{
Johanna Braun
}

Hysteria seems alive and well. Although the "death of hysteria" has been proclaimed on numerous occasions, we nevertheless seem to be living in hysterical times. Hysteria has a high currency in current public discussions and simultaneously finds its way into countless cultural manifestations-as we are able to witness in the colorful and diverse discussions in this collection.

In this investigation, I will take a closer look at a specific expression of the hysteric's performance in the present: the hysteric's politically charged and highly popular performance in mainstream US horror films and its discussion around pressing issues of disability and mental health. The aim of this investigation is to contextualize the figure of the hysteric - a historically well-studied object in arts and sciences-as a public performer whose hysterical "episodes" are clearly defined and understood in the realms of performance. We will look into a selection of the most successful US horror films of the past decade, ${ }^{1}$ which are summarized under the umbrella term Possession film (Clover), of which The Exorcist (Warner Bros., 1973) is generally seen as the highly popular originator. While The Exorcist was produced in the context of a series of other films of similar content, it was not until after 2000 that this subgenre became one of the most popular daughter genres of the US horror film. The box-office success of the restored and revised version of the original (2000) spawned two prequels (2004 and 2005). These 
reinterpretations and evolutions of the original story were closely followed by commercially successful, major studio productions of similar content that were eager to put the hysterical girl center stage and use this figure as a critical commentator on current pressing political discussions, especially touching on public health care debates, while also promoting stereotypical and stigmatizing images of mental and physical disabilities.

The references in the hysteric's current representations are striking: the Possession film echoes evidently the depiction of the hysteric from historical medical, artistic, and religious sources, specifically the imagery of Jean-Martin Charcot's medical studies of the mid-nineteenth century-with the hysteric dressed in white nightgowns, performing preferably in her bed and mimicking the "Grande Hystérie" with the excessive movement of the arc-en-circle: the iconic pose where the body is literally bending over backwards. Most of the selected films even feature the hysteric in this infamous position on their promotional posters.

This investigation follows the aim of uncovering how the current phenomenon continues the legacy of the hysteric - as popular performer who addresses pressing public debates-from historical material to the iconic horror film figure she is today.

And here lies already a significant detail: The hysteric in contemporary horror film is predominantly represented as a white middle-class girl. Therefore, when I use the term hysteric I refer to the female hysteric. ${ }^{2}$ Another circumstance is certainly that while women, children, and people with disabilities were excluded from large-scale government decisions, and even to this day still belong to marginalized groups spanning diverse categories that differ in terms of class, race, and gender, the presumed mentally ill girl is a convenient bundling of these interest groups.

The dominant representation of the hysteric as a white middle-class girl can be seen as a reflection of the historical material these movies stereotypically reference, while it also reveals the still marginalized experiences and representations of a more diverse demographic. But what also needs to be addressed is that, through the hysterical/possessed white middle-class girl, a wide range of discussions around race, class, and gender are voiced, and take possession of and are negotiated through the hysteric's body in those narratives. ${ }^{3}$ 
My assumption notwithstanding that physical and mental symptoms can also manifest themselves in a similar fashion when detached from social and cultural influences, the hysteric-as she is represented in the Possession film-is also influenced by political, cultural, societal, and historical construction processes (Micale/Porter 26). Therefore, I am not investigating the personal experiences of hysterics, but the historical, cultural, and political frameworks that often lead to such forms of representation.

Most importantly, the hysteric in these current narratives strikingly references established representations of the hysteric as (public) performer that extend well beyond the influential European studies of the nineteenth century. Thus, for example, although the medical term hysteria was struck from the Diagnostic and Statistical Manual of Mental Disorders at the end of the twentieth century, it simultaneously reappeared as Histrionic Personality Disorder (Latin: histrio, actor/actress). This rebranding just further underlines my point: the hysteric is thereby diagnosed as performer. (For the transformation of the term in a medical context please see: Skull 2009, Devereux 2014)

Therefore, while the hysteric's visual repertoire points to the fact that something of pressing urgency is being communicated, it is especially the hysteric's ambivalent performance that is relevant in its contemporary context. The hysteric challenges, blurs, and transgresses boundaries of race, class, gender, sexuality, religious belief, and time periods with ease-all the while performing excessively the repertoire of mental and physical impairment. While The Exorcist was the center of attention of influential feminist American horror film scholarship (Creed, Clover) and was embedded in the public debates of its time, the current phenomenon falls on a blind spot in relation to its evidential discussion of pressing contemporary political discourses. Therefore, the contemporary hysteric's excessive performance in US mainstream horror film provides interesting insights into current public discourses of healthcare politics-especially with regard to people with disabilities and mental illnesses-while additionally extending to women's rights, racial politics, and migration policies.

To understand these current debates we have to bend over backwards, stretch through the hysteric's complex and at times contradictory "hystories" (Showalter 1997), and look at the historical connection of hysteria, performance, and politics in order then, hopefully, to be able to contextualize the ways this "Kunstfigur" has again attained such currency in our present day. 


\section{Mapping the Hysteric Playing Field}

Before we can move forward I need to explain what I mean when I use such broad terms as Hysteria and Performance, which are central to a variety of academic fields and whose definitions are ambiguous and remain contested. I choose the term hysteria deliberately, because it encompasses religious, medical, and political concepts through its extensive histories (in fact and fiction), and the forms of its representation were conceived in terms of performance art. This figure is not just mad, possessed, or simulating excessively one of the former: it references a range of representations that are historically specific to the hysteric. I use the term performance broadly and inclusively, to describe the hysteric as performing (doing) an action in front of an audience.

My investigation is furthermore located in the relatively new field of performance (history) studies, and unites the hysteric as mediator between historical practices that were aware of their own performativity with the current representations in US culture that are performing this historical awareness and self-reflection. These performances can again be either in the framework of religious practices, medical studies, or theater and film productions, or in the form of political debates and protest culture as well, or they can be a combination of all of them. Either way, they are culturally informed and in turn produce culture. Influential New Hystorian Elaine Showalter termed those cultural narratives Hystories $(1997,5)$.

With the high impact these films have, they are highly successful in publicizing and circulating views of hysteria, and Elaine Showalter already outlined how such representations are influenced by medical practices and then, in return, influence the latter (100). However, the focus of this analysis is more concerned with how these representations are embedded in the evidential discussion of pressing contemporary political discourses, especially around disability rights. In pursuing this focus, this investigation follows the mission of the New Hystorians: "All of us realize that we have been coaxing out the representations of hysteria, rhetorically searching for its metaphors and metonymies, visually following its iconographic relations and imagery-all this out of a belief in the significance of the cultural representations of illness within society" (Hysteria Beyond Freud xi-xii).

This is especially evident in the portrayal of the ritual of the actual exorcism, which represents the cure. While historical instances, into which we will look in a moment, mostly played on the notion that the 
possession has to be overcome through ritual and performance, it is interesting to witness the fact that current portrayals show the hysteric as "resistant to cure", and thereby place the hysteric within the framework of identity politics in disability studies that celebrate and protect the protagonist's disabilities, instead of framing them as a state to be overcome. Therefore, these representations are very much informed by current scholarship and discussion of disability studies that refuse to re-subscribe to a cure narrative.

My research, as a consequence of these tendencies, takes as its basis a series of studies that examine the cultural relevance of the representation of the hysteric. Although, as mentioned before, the diagnosis of hysteria started to vanish from-or let's rather say, began to disguise in new forms - a medical context by the end of the twentieth century, a wealth of historical studies about hysteria simultaneously appeared as a cultural phenomenon (Veith, Micale, Shorter, Showalter, Skull). Mark S. Micale gave the first comprehensive overview of the research landscape in Approaching Hysteria (1995), introducing the term New Hysteria Studies. Elaine Showalter later coined in response the term New Hysterians (1997, 7) and I see this investigation as continuation and homage to their influential work.

My project is in part based on the cultural studies that deal with the representation of hysteria in its medical context, especially in the context of visualizations of "madness", in visual media in general (Gilman, Haslam, Philo, Blackman/Walkerdine, Pickering, Didi-Huberman, Harper, Cross, Serlin, Hustvedt, Scott/Scarth/Chung, Timpano), in theater (Kaplan/Rudolph, Mukherjee, Wald, Reiss, Harpin/Foster, Marshall), and in film in particular (Fleming/Manvell, Gabbard/ Gabbard).

As the hysteric is clearly embedded in medical discussions throughout its history spanning centuries-especially public discussions on mental health and physical impairment-it is meaningful to tie the field of disability studies into this discussion.

Disability studies have emerged as an interdisciplinary endeavor of the social sciences, humanities, and medicine, alongside performance studies. The field can be broadly categorized into two main research scopes: disability as a metaphor in cultural productions, and artists (from all kinds of artistic backgrounds) who deal first-hand with disability in their practice. Both disability and performance studies, overlapping in their interdisciplinary approach and their originating 
disciplines, have also increasingly embraced their shared research interests. These merging developments of the fields therefore influence this investigation. (for performance studies and disability studies please see: Kuppers, Sandahl/Auslander, Henderson/Ostrander.) While I acknowledge and celebrate scholarship and artistic practices that bring disability activists, artists, and scholars to the forefront, this paper is dedicated to the metaphor of disability and the political, social, and legal implementations embedded in the representation of disability within the hysteric's performance in the Possession film.

And here we are already at the intersection where the horror genre comes into play.

Horror film scholarship and performance studies have an oftenoverlooked, nevertheless highly interesting connection. In particular, Linda Williams' concept of horror as "body genre", on account of the strong physical response elicited by it (1991), Rhona Berenstein's concept of gender performativity to "offer a theory of classic horror spectatorship as a form of performance" (30; "spectatorship-as-drag", drawing on Clover Carol Clover and Judith Butler) and Matt Hills' notion of "thinking about theories of horror as performative" (Hills 205; drawing on Austin's speech act theories) serve here as guiding lights to establish a link between (new) hysteria studies, (horror) film studies, and performance studies. Furthermore, horror and disability studies have been increasingly investigating their shared research interest, especially as the horror genre has been historically and from its core tropes very much invested in distributing images of mental and physical disabilities (Wahl, Zimmerman, Robinson, Butler/Palesh, Wedding/Boyd/Niemiec).

So, as we can see here, the hysteric bundles a diverse group of fields, and it comes therefore as almost no surprise that hysteria, on one hand, inspires diverse cultural productions and, on the other, attracts such a productive scholarship legacy to this day. This only underlines the assumptions of most hysteria studies scholars who have emphasized the non-linear, complex, and at times contradictory history and manifestation of hysteria-as is also visible in several contributions in this collection.

\section{Three Key Stages for the Hysteric's Performance}

So let's stretch a little further and look at three key moments where the hysteric is performing on the political center stage. It is important 
to keep in mind that this is only a selection of the hysteric's historical political performances, but nevertheless, as we will see in a moment, they are significant recurring themes in its contemporary manifestations.

\section{Medical Theater}

Hysteria revealed its connection to the performing arts at the very moment of its diagnosis. The notorious characteristic of hysteria, as a mimetic disorder, to simulate other disease symptoms ultimately led to the rebranding of hysteria as Histrionic Personality Disorder. Histrionic derives from the Latin histrio, and thus diagnoses the hysteric as actress. Feminist, psychoanalytically informed studies have already described the hysteric in the medical context as performer (e.g. von Braun 31, Bronfen). However, this portrayal is dominated by a certain epoch: the Salpêtrière hospital in Paris in the second half of the nineteenth century. The fact that hysterical patients at the Salpêtrière were treated as actresses, that they "performed" in scientific amphitheaters in front of a (paying) public audience, and that "successful acts" went on tour to other hospitals and amphitheaters testifies to the close relationship between hysteria and performance arts. Two often-cited studies have dedicated themselves to the Theater of Hysteria in the Salpêtrière: Georges Didi-Huberman's Invention of Hysteria. Charcot and the Photographic Iconography of the Salpêtrière (2003) and Asti Hustvedt's Medical Muses. Hysteria in Nineteenth-century Paris (2011). I want to add Jonathan W. Marshall's detailed analysis in Performing Neurology. The Dramaturgy of Dr Jean-Martin Charcot (2016) to this discussion.

Although these insightful studies focus on this specific setting, they clearly show that the representation of the hysteric at the Salpêtrière was inspired by a broad historical performance repertoire. Thus, Didi-Huberman writes: "hysteria in the clinic became the spectacle, the invention of hysteria. Indeed, hysteria was covertly identified with something like an art, close to theatre or painting" (xi). Asti Hustvedt describes Hysteria's Theater in a short chapter, and confirms the interaction of art and science: "The diagnosis of hysteria identified it as a 'theatrical' illness, and illness of surface and illusion, as a form of fiction. This diagnosis produced in turn further layers of fiction and theater" (90). This testifies to the fact that the representation of the hysteric at the Salpêtrière was informed by historical depictions and, in turn, produced new templates of hysteric performances.

It is well known that Jean-Martin Charcot, the famous director of the Salpêtrière, was keen on art history and co-published the illustrated 
books Les Démoniaques dans l'art (1887) and Les Difformes et les malades dans l'art (1889) with Paul Richer. In the former, the two authors follow the historical connection between the hysteric and the possessed through art history, and Charcot himself concludes in the introduction that hysterics (especially the ecstatics) can be compared with demoniacs in many ways (1887 xxii). Laure Murat illustrated in The Man Who Thought He Was Napoleon. Towards a Political History of Madness (2014) that the relation between psychotherapy and theater was already well established a century before Charcot was the director of the Salpêtrière (consult especially chapter two).

The studies of Charcot and his colleagues clearly relate to public exorcisms, in which hysterics had to perform before a public audience. In spite of this historical awareness of the medical context at the Salpêtrière, the close relationship between hysteria and performance goes unnoticed in the studies of Hustvedt and Didi-Huberman. The Salpêtrière is described as a high-profile tourist attraction (Gilman 1982: 194; Showalter 1997: 32; on performance and pathology in the nineteenth century see Kapsalis) and Jonathan W. Marshall's analysis goes into great detail to reveal this pressing intersection of theater and performance practices in the Salpêtrière's amphitheaters. Nevertheless, the focus in these studies is the Paris of the outgoing nineteenth century; the transmissions of this discourse to the present time remain unaffected. This investigation aims to build on those discussions in relation to their current manifestations.

\section{Theater of Possession}

The imagination of mentally ill people, particularly of hysterical girls and women, as possessed by the devil is widely dispersed in European history. In Western societies, demonology as an explanation for psychopathological phenomena and thus the stigmatization of mental disorders was well established in the Middle Ages in science and art and prevailed up to the eighteenth century, be it in the form of the actual imagination of supernatural phenomena or simply as a literary motif. It is important to note that hysteria and melancholia were the main explanatory models for demoniacs. This European phenomenon has already been extensively investigated in historical studies (de Certeau, Walker, Caciola, Kallendorf, Almond, Ferber, van Dijkhuizen, Levack, Uszkalo, Weigert). It is interesting to note, however, that in these studies on exorcism it is emphasized again and again that these rituals resemble theatrical performances, that the hysterics used a "script", and that they 
were staged on public stages in the marketplace as moral entertainment and embedded in political discourses. The phrase "to perform an exorcism" further underlines my point that exorcism and performance are closely related.

Michel Foucault already wrote about the Theater of Possession (Abnormal Lectures: 205). The historian Michel de Certeau dedicated a chapter to the Theater of the Possessed and described the possessed as actresses (85ff.). See also Jan Frans van Dijkhuizen's Devil Theater. Demonic Possession and Exorcism in English Renaissance Drama 1558-1642 (2007). Brian Levack also has a chapter on The Performance of the Possessed (2013, 139-168), illustrating how the possessed followed scripts and other written templates. Hilaire Kallendorf has devoted a book-length study to these text documents in England (2003). Sarah Ferber confirms that the events were theatrical demonstrations in front of thousands of people (2004: 36). All these studies focus on European case studies such as Marthe Brossier (1598), Nicole Obry (1566), and Jeanne Féry (15841585) in France and Anne Gunter (1604) in England. It is significant, however, that this is not only a European phenomenon, since already in the founding years of the United States hysterics emerge as possessed witnesses in politically charged events, as in the case of Elizabeth Knapp in October 1671, or the so-called Salem witch trials in New England (1692-93). William W. Coventry's Demonic Possession on Trial. Case Studies in Early Modern England and Colonial America, 1593-1692 (2003) depicts these transferences. Thus, even though there is extensive reading on the phenomenon of the hysteric as possessed in a European context, and even on the relation between the staging of public exorcisms and the performing arts, the transmissions of these discourses to the United States in general and the current US pop culture are pressing on a blind spot.

\section{Theater of the Occult}

Within the framework of the extremely popular spiritualist séances in Europe and America in the mid-nineteenth century, the fertile interaction of science, performance art, and the occult is all too visible around the depiction of the hysteric's performance. Charcot himself wrote a paper on "Spiritualism and Hysteria" (1877-89). Charcot and Freud used hypnosis in their treatment of hysteria and were greatly inspired by so-called "trance performers". There are several studies which depict the close relationship between hysteria and spiritualism and their involvement in politics (see Luckhurst 96ff., Porter/Nicholson/ 
Bennett 5, Finn, McGarry 126, Grimes 91ff.). Furthermore, my project is especially informed by studies on the structure and performance of the séance as a form of theater (see Lehman, Hammer, Kontou/Willburn, Lingan, Bennett: chapter: Sacred Theaters 83ff). Alex Owen was able to establish that a series of spiritual mediums in England and the US in the nineteenth century, such as Victoria Woodhull, had previous experience with acting training before they performed séances (54-55).

However, the spiritualist performances were not bound just to theater arts. Spiritualists consciously took advantage of the latest technological achievements and integrated them into their innovative politically charged performances. (On the implication of the feminist and spiritualist movement see Basham, Wessinger, Braude, McGarry.) Matthew Solomon shows how spiritualism and film projection were closely interrelated: using the records of the History of the Kinetograph, Kinetoscope and Kineto-Phonograph-published by W.K.L Dickson, the inventor of the Kinetoscopes, and his sister Antonia Dickson-the first film screenings strongly resembled séances (40-41). Thomas Edison, according to Dickson and Dickson, screened the projection to the auditorium from behind a projection screen, separating the rooms with a black curtain. This approach is strongly reminiscent of séance reports under test conditions, and here the suspicion arises that the spiritualist mediums used the new technology of image projection, as they did before with magic lanterns and similar illusion apparatuses, before the images were used in public film screenings. (See also Barber 78, Braun 2017 77ff.) Professional mediums not only used slide projectors in their performances, but later also staged projections of moving pictures effectively. (For the close interaction of spiritual and technological medium see Lockhurst 3.) These practices occurred simultaneously with the staging of the hysteric in Charcot's psychiatric and later in Freud's psychoanalytical studies and were influenced by, and in turn had an influence on, those studies. To this day, the current representation of the hysteric in US mainstream horror film references extensively this material of the hysteric as a technologically aware and medial body of communication. While the spiritualist medium has been analyzed in its connection to the performing arts and new technologies, the transferences of these discourses onto the present day, especially the obvious references to these practices in the current phenomenon of the hysteric in the US mainstream horror film, are noticeably left out. 


\section{The Hysteric in The Exorcist as a bundling of these discussions}

So before we can look into the contemporary manifestations of the hysteric's performance in the Possession film, we need to look at the Possessions film's origin and the debates that were, on the one hand, influences on it and, in turn, had a great impact on these ongoing discussions.

Generally, The Exorcist (1973), heralding the so-called mainstream horror film in the 1970s (King 284, Waller 5, Derry 203), is seen as the core of the Possession film. The Exorcist stands out because it resonated with audiences enough to give rise to decades' worth of cinematic imitators who faithfully copied the basic premise of the film, to the extent that a new and highly prolific sub-genre formed.

Also, The Exorcist had a similar effect to Frankenstein (1931), since the hysterical girl became the iconic trope in horror film that extends to film incarnations not having the "supporting role" of an actual exorcist. Therefore, although The Exorcist has inspired many different cinematic tropes, the core of the subgenre is firmly set on the spectacle of the hysterical girl's performance.

Although mostly overlooked, The Exorcist is evidently firmly embedded in discussions surrounding disabilities and (horror) film. Interestingly, the scholarship on disability studies and horror film studies is still surprisingly slim, although stereotypes of physical and mental disabilities are the core tropes of the most influential horror movies, which range from The Hands of Orlac (1924), The Phantom of the Opera (1925), the "Mad Dr." and his disabled patient/assistant/creation in Frankenstein (1931), Freaks (1932), Whatever Happened to Baby Jane? (1962), or the physically and mentally impaired serial killer in the Slasher films (most prominently, the Halloween, Nightmare on Elm Street, Friday the $13^{\text {th }}$, and the Texas Chainsaw Massacre series), to name only a few.

The film history of the representation of psychiatric disabilities, especially with a focus on "possession", can be traced back to the early twentieth century, with such influential examples as The Cabinet of Dr. Caligari (1919) and Dr. Jekyll and Mr. Hyde (1931). Nevertheless, it was especially after World War II that the visibility of mental illness dramatically increased on screen (Schneider). The Exorcist is very much informed by those discussions and was instrumental in creating and promoting stereotypical images of disability. 
In one of the fist substantive looks at feature films, Robert Bogdan, Douglas Biklen, Arthur Shapiro, and David Spelkoman's “The Disabled. Media's Monster" (1982), examined the symbolism of disabilities in horror films, with particular emphasis on the stereotype of the person with disabilities as dangerous. They emphasized that such standards as scarred, deformed, and physically and mentally handicapped monsters presumably led to a fear of people with disabilities. Disability historian Paul K. Longmore examined in his landmark piece "Screening Stereotypes. Images of Disabled People in Television and Motion Pictures" (1985) numerous negative themes and images across a wide range of films (and especially horror films), as did disability scholar Martin Norden in his book The Cinema of Isolation. A History of Physical Disability in the Movies (1994) and Michael Fleming and Roger Manwell in Images of Madness. The Portrayal of Insanity in the Feature Film (1985). More recently, Angela Smith's oftenquoted Hideous Progeny. Disability, Eugenics, and Classic Horror Cinema (2011) analyzes in detail how classic horror cinema and disability studies intersect in particular, and Travis Sutton's “Avenging the Body: Disability in the Horror Film" (2014) examines how these discussions are especially relevant in the horror film in general.

However, the story here is much more complex. While one can definitely argue that the portrayal of the brutalized, vandalized, and victimized body of the young girl Regan in The Exorcist, whose physical and psychological contortions seem to be a manifestation of "the devil inside" and, therefore, very much inspired by the discussions of mental illness and demon possession from the Middle Ages, it is also interesting to see that the film addresses pressing questions of cure and healthcare in front of the political stage it was filmed against. More specifically, The Exorcist is embedded in public debates against the background of antipsychiatry and the imported European critique of psychiatryespecially influenced by French thinkers such as Michel Foucault, Jacques Lacan, Gilles Deleuze, and Félix Guattari, among others-as well as the resulting Psychiatry Reform, the Student Revolt, and the Civil Rights Movement of the 1960s and 1970s in the United States. Therefore, The Exorcist is clearly embedded in discussions around deinstitutionalization, which was also prominently featured in such films as The Snake Pit (1948) and One Flew Over the Cuckoo's Nest (1975), and operates in two ways: it represents the stigmatizing perceptions of people with disabilities and criticizes their medical and religious treatments. 
The "deinstitutionalization" movement describes the development where people with psychological disabilities were gradually released from institutional care in asylums to long-term community care networks in more private settings. John F. Kennedy introduced the term "deinstitutionalization" in the Community Mental Health Centers Acts (CMHC) in the early 1960s, which was a response at a time when several instances were exposed for their overcrowded, insanitary, and abusive care in US asylums, which led to a public outcry and ultimately to John F. Kennedy's unveiling of a new policy regarding national mental health care in February 1963.

The Community Mental Health Centers Acts very much built on the National Mental Health Act of 1946, which established and provided funds for a National Institute of Mental Health (NIMH), signed into law on July 3, 1946. The National Mental Health Act was first created in response to the increasing number of veterans battling with mentalillness, but was later broadened when studies revealed that the US population in general had an increased risk of undiagnosed and untreated mental health issues, a move which led to several new strategies in diagnosing and treating people facing mental health issues and emphasized proper medical and therapeutic treatment over institutionalization. This came also with the Community Mental Health Centers Act, which allocated federal funding towards the release of mentally ill persons from asylums into nationwide community care networks.

Anthony Carlton Cooke has shown in Moral Panics, Mental Illness Stigma, and the Deinstitutionalization Movement in American Popular Culture (2017) how the deinstitutionalization movement led to several stigmatizing tropes in horror, crime, and thriller film genres which have a lasting impact on public notions surrounding mentally ill patients released and "roaming free" amongst society. The fear of the "mentally ill patient" who escapes the asylum or somehow escapes institutionalization can be found universally in US horror films, from Halloween's (1978-) Michael Myers to the "seeing" insane in Birdbox (2018).

The Exorcist is very much embedded in these discussions of its time, as we can see how a single mother is trying her very best to care for her daughter in the private setting of her home while bringing in medical and in the end religious practitioners-as the last resort-to cure her daughter of the hysteric psychological and physical outbreaks that she performs so vividly in her bedroom. While we learn later, through countless re-tellings of the story, that the supposedly happy end of The Exorcist's cure narrative does not last, the original nevertheless ends 
with the curing of the hysterical girl. This is something that changes drastically in the current manifestations.

\section{The New Hysteric and the Resistance to Cure}

While The Exorcist was produced in the context of a series of other films of similar content, it was not until after 2000 that this subgenre became one of the most popular daughter genres of the US horror film. The box-office success of the restored and revised version of the originalwith the promising title The Exorcist: The Version You Have Never Seen (Warner Bros., 2000)—spawned two prequels: Exorcist: The Beginning (Warner Bros., 2004) and Dominion: Prequel to the Exorcist (Warner Bros., 2005). These reinterpretations and evolutions of the original story were closely followed by commercially successful, major studio productions of similar content.

A selection of the most successful US horror films of the past decade, such as An American Haunting (Lionsgate, 2005), The Exorcism of Emily Rose (Sony, 2005), the Paranormal Activity series (Paramount, since 2007), The Last Exorcism I and II (Lionsgate, 2011/2013), The Devil Inside (Paramount, 2012), The Possession (Lionsgate, 2012), The Conjuring series, which evolved into the "Conjuring universe" with several spin-off series (Warner Bros., since 2013), Deliver Us From Evil (Sony, 2014), The Quiet Ones (Lionsgate, 2014), Jessabelle (Liongate, 2014), Insidious series (Sony, since 2015), Ouija I and II: Origin of Evil (Universal, 2014/2016), The Possession of Hannah Grace (Sony, 2018), to name only a few, are prime examples of the hysteric's resurrection as a vibrant horror film icon that negotiates pressing public discussions in recent years.

Consequently, my investigations tie in with a small series of film studies that examine the young hysteric girl Regan from The Exorcist in particular (Carroll, Clover, Creed, Schreck, Lebeau, Derry, RommelRiuz, Renner, Kord) and the current phenomenon of Possession film in general (Balmain, Wetmore, Miller, Scahill). What has thus far been missing in (horror) film studies, however, is a comprehensive analysis of the current phenomenon and an extensive problematization of these productions in their mediation and representation of hysteria. ${ }^{4}$

Furthermore, along the way, this investigation follows a strain of scholarship that makes connections visible between various cycles of horror films and their historical contexts regarding specific historical events in relation to gender, sexual orientation, race, class, and more 
recently disability (e.g. Kracauer, Ross, Derry, Grant/Sharrett, Twitchell, Jancovich, Benshoff, Lowenstein, Blake, Smith).

Due to their production and distribution period, the aforementioned films belong to the so-called post-9/11 American horror film. It is interesting that, in post-9/11 horror film criticism, which mainly associates the emergence of various mainstream horror films with the political and cultural discourses of their time, the resurrection of classic (male) horror film figures such as the vampire and zombie, as well as the wave of big budget horror remakes of the Slasher film and the emergence of the so-called "Torture Porn" film, are well discussed (e.g. Birkenstein/ Froula/Randell, Briefel/Miller, Wetmore, Aston/Walliss, Kerner, Westwell, McCollum), whereas the widespread resurrection of the iconic figure of the hysteric/possessed girl in mainstream American horror film is in contrast under-analyzed. Therefore, this investigation is dedicated to bridging this gap in research concerning the representation of women in contemporary (American) horror film.

All these aforementioned movies of the Possession film reference in evident ways the historically informed performance repertoire of the hysteric, with the girl starting to communicate with invisible entities that are perceived by their caretakers either as "invisible friends" or as voices in their heads. The at first playful attempt at communicating with the dead through Ouija boards or séances leads to the girl's direct communication with an outside presence that tries to communicate something of pressing urgency to the hysteric's surroundings through her body. The cinematic climax is often the hysteric in her iconic pose of the arc-en-circle that she impressively performs, in her white nightgown, in her bed, while her caretakers bewilderedly listen to what this excessive body is revealing. While it is often framed in the beginning that the hysteric has a mental disability, which later manifests itself in physical impairment and then turns out to have a supernatural origin, it is nevertheless the cure narrative that prevails throughout these films. Without wanting to spoil any viewing experiences, I need to disclose that it is interesting to witness that, in current instances, the hysteric turns out not only to be a vessel for an "outside" presence, but she is somehow in collaboration with the possessing entity, as in Jessabelle (2014), Ouija: Origin of Evil (2016), or highlighting the contagious nature of hysteria, as in the Insidious series (2015-) and The Conjuring series (2013-), and in spin-offs of the Annabelle series (2014-) or The Nun (2018) and, most recently, The Curse of La Llorona (2019). 
The Curse of La Llorona (2019) highlights the "wandering" nature of hysteria through a "migrating" curse from Mexico to Los Angeles, and its contagious essence as it is afflicting multi-generational family bonds and travels through different time periods. The Conjuring Universe in general highlights this concept of "wandering" hysteria in all of its productions, as each "chapter" is focused on a different time period and location. Conjuring I centers on a family in 1971 in Rhode Island, Conjuring II is set in London in the late 1970s, Annabelle in 1967, and Annabelle: Creation in the late 1940s and 1950s in California, The Nun in 1952 in a monastery in Romania, and The Curse of La Llorona is set between 1673 Mexico and Los Angeles in the early 1970s. The Nun also makes countless references to the historical well-covered possessions at Loudon, highlighting the historical awareness of those productions. The Annabelle series features the demonic puppet that transfers hysteria epidemically to its surroundings throughout different time periods, therefore referencing imaginations of the contagious inanimate body to the human body (for more on hysteria, corporality, and puppets, please see Timpano).

It is also interesting to witness that only in the films that feature a girl or woman as the main hysterical afflicted character is the hysteric showing the stereotypical images of hysteria, crawling, speaking in tongues, and most prominently performing the "Grande Hystérie" with the excessive movement of the arc-en-circle. In films where the main hysterical character is a boy or man, we can still see direct references to broader concepts of hysteria, although the "iconic" performance repertoire of the hysteric is missing, as we can see, for example, in the Insidious series (2015-). In the first two films the narrative focuses on a father and his son. While there are evident references to disability and health care debates and questions of the hereditary nature of mental illness, and that it is the father who is clearly getting more "hysterical" throughout the narrative, it is especially Insidious: Chapter 3 (2015) and Insidious: The Last Key (2018) that center on the female hysteric who exhibits all the iconic gestures of hysteria.

Although, often, the origins of the possession in all those instances are still supernatural, and therefore very much drawing on historical and stigmatizing views on mental illness and disability as "curse", the happy end is not celebrated with a cure. This new take on the hysteric very much facilitates the current trend for prequel and sequel iterations, and can therefore be seen as a choice for production and economic reasons, as well as the trend of the unreliable narrator as a 
film device in general; however, it also shows a new self-awareness of the self-reflective media figure of the hysteric. It is especially interesting to witness that perspectives on the "anti-psychiatry" movement, with insanity presented as a means to exist in a "mad world", as a cinematic trope, are experiencing a revival in the current manifestations of the Possession film. These tendencies evidently reflect current discussions around disability rights and activism and broader public discussions about hysteria and our current political climate.

The so-called disability rights movement, with the establishment of the Society of Disability Studies in 1982, has been a powerful force in the past decades, addressing public attitudes toward people with disabilities and advocating for federal legislation, beginning with Sections 501-4 of the Vocational Rehabilitation Act of 1973 and culminating in the landmark legislation of the American with Disabilities Act (ADA) of 1990, which is the most comprehensive and foundational civil rights law prohibiting discrimination on the basis of disability. These landmark legislations were only achieved by the relentless and continuous work of countless disability activists, scholars, and artists (see also Linton, Shapiro, Fleischer/Zames, Sandahl/Auslander, among others).

More recently, the signing into law by President Obama of the Mental Health Reform Act in December 2016-in tandem with the Helping Families in Mental Health Crisis Act of 2015-which is a component of the 21st Century Cures Act, is considered one of the most significant bills targeting mental health reform since 1963. On the other hand, since 2017 there have been many proposed changes to US healthcare, including several efforts to repeal and replace the Affordable Care Act (ACA), which also led to funding cuts in the health sector in general and to reduced access to treatment by people with physical and mental health disabilities in particular.

The decision to portray the hysteric as resistant to any kind of cure in these current narratives is evidently informed by these public discourses as well as by discussions circulating in the fairly new scholarship on disability in film and disability justice, as well as by the emerging field of Crip theory and popular writings, such as Alison Kafer's Feminist, Queer, Crip (2013) in particular, which criticize the often expressed notion of disability as something to overcome and thereby heavily critique the so-called cure narrative (see also McRuer 2006 and 2018, Hall). The field is defined by the turn of disability studies from a medical model, which framed disability as pathological and an individual problem 
that needed to be cured or rehabilitated, to the notion of disability as socially constructed.

Unfortunately, however, the progression of disability rights has been anything but straightforward since then. The Possession film therefore also addresses problematic tendencies, for instance the passing of legislations such as Kendra's Law, a New York state law that has been effective since 1999 and authorizes forced outpatient treatment for people with severe mental illnesses, and which reinforces the link existing in public imaginations between mental illness and violence. In several of the selected films the hysteric is treated under brutal and violent circumstances in private settings, often framed as tortured, vandalized, and forcibly restrained in locked-up hidden bedrooms, attics, and basements. The hysterical girl, who is not medically treated but in a religious context mis-treated, is experiencing a comeback as a consequence. The Exorcism of Emily Rose (2005) is based on Felicitas D. Goodman's influential study The Exorcism of Anneliese Michel (1981), which told the story of a girl who was suffering from epilepsy and was subjected by her parents to an exorcism instead of medically supervised treatment, a decision that led to the girl's death. Anneliese Michel's sensationalized story was then also revisited in Requiem (2006), Anneliese: The Exorcist Tapes (2011), and The Devil Inside (2012). The Taking of Deborah Logan (2014) in a similar fashion links demonic possession with Alzheimer's. The film ends_caution: spoiler alert-with the girl Cara, a cancer patient abducted by the hysteric title role Deborah Logan, with the report that the girl has survived cancer but has been possessed instead. The medical cure narrative is overturned by a supernatural resistance to cure.

What becomes evident in these films is that the Possession film gives interesting insights into the complex relations of how disability is portrayed and negotiated for a contemporary mass audience. The Possession film heavily draws on historically well-established notions around staging and performing hysteria to discuss pressing topics of its time, especially around disability and healthcare. And just as the history of the hysteric is not linear and straightforward, the Possession film as well falls into the trap of representing and promoting stigmatizing perceptions of people with disabilities, while also severely criticizing the treatment methods used. Furthermore, these films can be very much seen to discuss the old premise: you have to be mad in a mad mad world, and therefore can be seen as an intriguing reflection of the hysterical times that we are currently living in. 


\section{Notes}

1 The selection for the core filmography is based on fifteen horror films that belong to the so-called Possession film subgenre, that were distributed in the early twenty-first century by major American film studios (that promote these films nationwide-and even internationally), that were commercial successes and are rated in the top 100 "most popular" horror films since 1980 (based on ratings by box-office reporting service Box Office Mojo; as well as Rotten Tomatoes and IMDb) and that reference the female hysteric of European studies from the late nineteenth century in obvious, stereotypical, ways.

2 It is striking that although Thomas Sydenham studied hysteria in men in the late seventeenth century and Charcot and Freud later did so in the late nineteenth century, it is especially girls and young women who are the center of attention in European and American hysteria studies. This is also the case of the fairly new medical term Histrionic Personality Disorder. $H P D$ was intended to have a gender-neutral connotation; nevertheless it is mostly diagnosed in women. (Confer: Kaplan 1983; Ford/Widiger 1989; Hamilton/Rothbart/Dawes 1996). Although, there are currently several instances where the hysteric is male (as analyzed in several chapters in this volume), it is evident that the Possession film draws heavily on the female hysteric's experience.

3 While the focus of this investigation is to look into the ways the hysteric performs disability, it is the outline of my postdoctoral research project, "The Hysteric as Conceptual Operator", to investigate how the hysteric in those narratives communicates and negotiates pressing issues around race, class, gender, and migration, through the entities that take possession of the hysteric. But those topics deserve a detailed analysis of their own.

4 Influential scholarship in American horror film, which emerged in the late 1970s, drew primarily from (Freudian) psychoanalytic film theories, and also the study of women in horror has been firmly shaped by the dominance of psychoanalytic theories, which is due to the influence of psychoanalysis in the 1970s in the development of feminist film theory, in film theory in general, and in (American) horror film theory in particular. Influenced by those developments and in turn influential on the development of (feminist horror) film theory were Linda Williams (1983), Carol Clover (1993), and Barbara Creed (1993), who have been to this day the main reference points regarding women in horror film scholarship. Although Creed discussed hysteria briefly (56-7) and The Exorcist and the possession film at length as well, she left out the correlation between the two. Clover also analyzed The 
Exorcist among other films in Chapter Two and mentioned a "narrative of female hysteria" (70ff.), but does not elaborate further on the connection. While the scholarship on women in horror produced a variety of influential and interesting studies around the 1990s, the research has since been significantly marginal.

\section{Works Cited}

Almond, Phillip C. Demonic Possession and Exorcism in Early Modern England: Contemporary Texts and their Cultural Contexts. Cambridge University Press, 2004.

Aston, James, and John Walliss, editors. To See the Saw Movies: Essays on Torture Porn and Post-9/11 Horror. McFarland, 2013.

Auslander, Philip, and Carrie Sandahl, editors. Bodies in Commotion: Disability and Performance. University of Michigan Press, 2005.

Balmain, Colette. "The Enemy Within: The Child as Terrorist in the Contemporary American Horror Film.” Monsters and the Monstrous, edited by Niall Scott. Rodopi, 2007, pp. 133-148.

Barber, X. Theodore. "Phantasmagorical Wonders." Film History, vol. 3, no. 2, 1989, pp. 73-86.

Basham, Diana. The Trial of Woman: Feminism and the Occult Sciences in Victorian Literature and Society. London: Macmillan, 1992.

Bennett, Bridget. Transatlantic Spiritualism and Nineteenth-Century American Literature. Palgrave McMillan, 2007.

Benshoff, Harry M. Monsters in the Closet: Homosexuality and the Horror Film. Manchester University Press, 1997.

Berenstein, Rhona J. Attack of the Leading Ladies: Gender, Sexuality and Spectatorship in Classic Horror Cinema. Columbia University Press, 1996.

Birkenstein, Jeff, Anna Froula and Karen Randell. Reframing 9/11: Film, Popular Culture and the "War On Terror". Continuum, 2010.

Blackman, Lisa, and Valerie Walkerdine. Mass Hysteria. Critical Psychology and Media Studies. Palgrave, 2001.

Blake, Linnie. The Wounds of Nations: Horror Cinema, Historical Trauma and National Identity. Manchester University Press, 2008.

Bogdan, Robert, Douglas Biklen, Arthur Shapiro, and David Spelkoman. "The Disabled: Media’s Monster.” Social Policy, vol. 13, no. 2, Fall 1982, pp. 32-35.

Braude, Ann. Radical Spirits: Spiritualism and Women's Rights in NineteenthCentury America. Beacon, 1989.

Braun, Christina von. Nicht ich: Logik, Lüge, Libido. Verlag Neue Kritik, 1985. 
Braun, Johanna. All-American-Gothic Girl: Das Gerechtigkeit einfordernde Mädchen in US-amerikanischen Erzählungen. Passagen Verlag, 2017.

Braun, Johanna, editor. There is a Method to this Madness: Hysteria and the Arts. Palgrave Macmillan, 2020.

Briefel, Bronfen, Elisabeth. The Knotted Subject: Hysteria and its Discontents. Princeton University Press, 1998.

- - "The Language of Hysteria: A Misappropriation of the Master Narratives.” Women: A Cultural Review, vol. 11, no. 1-2, 2000, pp. 8-18.

Butler, Lisa D., and Oxana Palesh. "Spellbound: Dissociation in the Movies." Journal of Trauma and Dissosiation, vol. 5, no. 2, 2004, pp. 61-87.

Caciola, Nancy. Discerning Spirits: Divine and Demonic Possession in the Middle Ages. Cornell University Press, 2003.

Carlton Cooke, Anthony. Moral Panics, Mental Illness Stigma, and the Deinstitutionalization Movement in American Popular Culture. Palgrave Macmillan, 2017.

Certeau, Michel de. La Possession at Loudun (Gallimard/Julliard,1970), translated as The Possession at Loudun, by Michael B. Smith. University of Chicago Press, 1996.

Charcot, Jean-Martin. CEuvres complètes, edited by Désiré-Magloire Bourneville et al. Progrès Médical, 1888-1894, 13 vols.

- - . "Spiritualism and Hysteria". Clinical Lectures on Disease of the Nervous System, translated by Thomas Saville, 3.Vols. New Sydenham Society, 1877-1989. vol. 3, pp. 205-206.

- - . and Paul Richer. Les Démoniaques dans l'art. Paris: Adrien Delahaye and Emile Lecrosner, 1887.

- - and Paul Richer. Les Difformes et les malades dans l'art. Paris: Lecrosnier et Babé, 1889.

Clover, Carol. Men, Women Ẽ Chainsaws: Gender in the Modern Horror Film. Princeton University Press, 1993.

Coventry, William W. Demonic Possession on Trial: Case Studies in Early Modern England and Colonial America, 1593-1692. Writers Club Press, 2003.

Creed, Barbara. The Monstrous-Feminine: Film, Feminism, Psychoanalysis. Routledge, 1993.

Cross, Simon. Mediating Madness: Mental Distress and Cultural Representation. Palgrave Macmillan, 2010.

Derry, Charles. Dark Dreams 2.0. A Psychological History of the Modern Horror Film from the 1950s to the 21st Century. McFarland, 2009.

Devereux, Cecily. "Hysteria, Feminism, and Gender Revisited: The Case of the Second Wave." English Studies in Canada, vol. 40, no. 1, March 2014, pp. $19-45$. 
Didi-Huberman, Georges. Invention of Hysteria: Charcot and the Photographic Iconography of the Salpêtrière (1982), translated by Alisa Hartz. MIT Press, 2003.

Dijkhuizen, Jan Frans van. Devil Theater: Demonic Possession and Exorcism in English Renaissance Drama 1558-1642. D.S. Brewer, 2007.

Ferber, Sarah. Demonic Possession E Exorcism in Early Modern France. Routledge, 2004.

Finn, Michael R. Hysteria, Hypnotism, the Spirits and Pornography. University of Delaware Press, 2009.

Fleischer, Doris Zames, and Frieda Zames. The Disability Rights Movement: From Charity to Confrontation. Temple University Press, 2001.

Fleming, Michael, and Roger Manvell. Images of Madness: The Portrayal of Insanity in the Feature Film. Associated University Presses, 1985.

Foucault, Michel. “26. February 1975.” Abnormal Lectures. Verso, 2003, pp. 201-230.

Gabbard, Krin, and Glen O. Gabbard. Psychiatry and the Cinema. University of Chicago Press, 1987.

Gilman, Sander L. Difference and Pathology: Stereotypes of Sexuality, Race, and Madness. Cornell University Press, 1985.

_- . Seeing the Insane. Wiley, 1982.

- - Disease and Representation: Images of Illness from Madness to Aids. Cornell University Press, 1988.

——. "The Image of the Hysteric." Hysteria Beyond Freud, edited by Sander

L. Gilman, Helen King, Roy Porter, G. S. Rousseau, and Elaine

Showalter. Berkeley: University of California Press, 1993, pp. 345-452.

- - Helen King, Roy Porter, G.S. Rousseau, and Elaine Showalter, editors. Hysteria Beyond Freud. University of California Press, 1993.

Goodman, Felicitas D. The Exorcism of Anneliese Michel. Doubleday, 1981.

Grant, Barry Keith, and Christopher Sharrett, editors. Planks of Reason: Essays on the Horror Film. Scarecrow Press, 1984, rev. ed. 2004.

Grimes, Hilary. The Late Victorian Gothic: Mental Science, the Uncanny and Scenes of Writing. Ashgate, 2011.

Hall, Kim, editor. Feminist Disability Studies. Indiana University Press, 2011.

Hammer, Anita. Between Play and Prayer: The Variety of Theatricals in Spiritual Performance. Rodopi, 2010.

Harper, Stephen. Madness, Power and the Media: Class, Gender and Race in Popular Representations of Mental Distress. Palgrave Macmillan, 2009.

Harpin, Anna, and Juliet Foster, editors. Performance, Madness and Psychiatry: Isolated Acts. Palgrave Macmillan, 2014. 
Haslam, John. Illustrations of Madness. Routledge (Facsimile of 1810 edition edited by Roy Porter).

Henderson, Bruce, and Noam Ostrander, editors. Understanding Disability Studies and Performance Studies. Routledge, 2010.

Hills, Matt. "Doing Things with Theory: From Freud's Worst Nightmare to (Disciplinary) Dreams of Horror's Cultural Value.” Psychoanalysis and the Horror Film: Freud's Worst Nightmares, edited by Steven J. Schneider. Cambridge University Press 2004, pp. 205-222.

Hustevedt, Asti. Medical Muses: Hysteria in Nineteenth-century Paris. W.W. Norton, 2011.

Jancovich, Mark. Horror. Batsford, 1992.

Kafer, Alison. Feminist, Queer, Crip. Indiana University Press, 2013.

Kallendorf, Hilaire. Exorcism and Its Texts: Subjectivity in Early Modern Literature of England and Spain. University of Toronto Press, 2003.

Kaplan, Ellen, and Sarah J. Rudolph. Images of Mental Illness Through Text and Performance. Edwin Mellen Press, 2005.

Kapsalis, Terri. Public Privates: Performing Gynecology from both Ends of the Speculum. Duke University Press, 1997.

Kerner, Aaron M. Torture Porn in the Wake of 9/11: Horror, Exploitation, and the Cinema of Sensation. Rutgers University Press, 2015.

King, Stephen. Danse Macabre. Everest House, 1981.

Kontou, Tatiana, and Sarah Willburn, editors. The Ashgate Research Companion to Nineteenth-Century Spiritualism and the Occult. Ashgate, 2012.

Kord, T.S. Little Horrors: How Cinema's Evil Children Play on Our Guilt. McFarland, 2016.

Kracauer, Siegfried. From Caligari to Hitler: A Psychological History of the German Film. Princeton University Press, 1947.

Kuppers, Petra. Disability and Contemporary Performance: Bodies on Edge. Routledge, 2003.

——. "Bodies, Hysteria, Pain: Staging the Invisible." Bodies in Commotion: Disability and Performance, edited by Philip Auslander and Carrie Sandahl. University of Michigan Press, 2005, pp. 147-162.

Lebeau, Vicky. Childhood and Cinema. Reaktion Books, 2008.

Lehman, Amy. Victorian Women and the Theatre of Trance: Mediums, Spiritualists and Mesmerists in Performance. McFarland, 2009.

Levack, Brian. The Devil Within: Possession and Exorcism in the Christian West. Yale University Press, 2013.

Lingan, Edmund B. The Theatre of the Occult Revival: Alternative Spiritual Performance from 1875 to the Present. Palgrave Macmillan, 2014. 
Linton, Simi. Claiming Disability: Knowledge and Identity. New York University Press, 1998.

Longmore, Paul K. "Screening Stereotypes: Images of Disabled People in Television and Motion Pictures." Social Policy, vol. 16, summer 1985, pp. 31-37.

Lowenstein, Adam. Shocking Representations: Historical Trauma, National Cinema and the Modern Horror Film. Columbia University Press, 2005.

Luckhurst, Roger. The Invention of Telepathy, 1870-1901. Oxford University Press, 2002.

Marshall, Jonathan W. Performing Neurology: The Dramaturgy of Dr Jean-Martin Charcot. Palgrave-Macmillan, 2016.

McCollum, Victoria. Post-9/11 Heartland Horror: Rural Horror Films in an Era of Urban Terrorism. Routledge, 2016.

McGarry, Molly. Ghosts of Futures Past: Spiritualism and the Cultural Politics of Nineteenth America. University of California Press, 2008.

McRuer, Robert. Crip Theory: Cultural Signs of Queerness and Disability. NYU Press, 2006.

- - Crip Times: Disability, Globalization, and Resistance. New York University Press in 2018.

Micale, Mark S. Approaching Hysteria: Disease and Its Interpretations. Princeton University Press, 1995.

—— and Roy Porter, editors. Discovering the History of Psychiatry. Oxford University Press, 1994.

Miller, April. "Real-to-Reel Recessionary Horrors in Drag me to Hell and Contagion." The Great Recession in Fiction, Film, and Television. Twenty-FirstCentury, edited by Kirk Boyle und Daniel Mrozowski. Lexington Books, 2013, pp. 29-49.

Mukherjee, Ankhi. Aesthetic Hysteria: The Great Neurosis in Victorian Melodrama and Contemporary Fiction. Routledge, 2007.

Murat, Laure. The Man Who Thought He Was Napoleon: Toward a Political History of Madness, translated by Deke Dusinberre. University of Chicago Press, 2014.

Norden, Martin. The Cinema of Isolation: A History of Physical Disability in the Movies. Rutgers University Press, 1994.

Owen, Alex. The Darkened Room: Women, Power and Spiritualism in Late Victorian England. University of Pennsylvania Press, 1990.

Philo, Greg, editor. Media and Mental Distress. Longman, 1996.

Pickering, Michael. Stereotyping: The Politics of Representation. Palgrave Macmillan, 2001. 
Porter, Roy, Helen Nicholson, and Bridget Bennett, editors. Women, Madness, and Spiritualism, 2 volumes. Routledge, 2003.

Reiss, Benjamin. Theaters of Madness. University of Chicago Press, 2008.

Renner, Karen J. The "Evil Child" in Literature, Film and Popular Culture. Routledge, 2013.

Robinson, David J. Reel Psychiatry. Movie Portrayals of Psychiatric Conditions. Rapid Psychler Press, 2003.

Rommel-riuz, W. Bryan. "Exorcising the Demons Within. Gender, Race, and the Problem of Evil in American History and Cinema." American History Goes to the Movies: Hollywood and the American Experience, Rommel-Riuz. Routledge, 2011, pp. 10-46.

Scahill, Andrew. The Revolting Child in Horror Cinema. Palgrave Macmillan, 2015.

Schneider, I. "Images of the Mind: Psychiatry in Commercial Film." American Journal of Psychiatry, vol. 134, 1977, pp. 613-620.

Schreck, Nikolas. The Satanic Screen: An Illustrated Guide to the Devil in Cinema. Creation Books, 2001.

Schutzman, Mady. The Real Thing: Performance, Hysteria, and Advertising. Wesleyan University Press, 1999.

Scott, Francesca, Kate Scarth, and Ji Won Chung, editors. Picturing Women's Health. Routledge, 2016.

Serlin, David, editor. Imagining Illness: Public Health and Visual Culture.

University of Minnesota Press, 2010.

Shapiro, Joseph P. No Pity: People with Disabilities Forging a New Civil Rights Movement. Three Rivers Press, 1994.

Shorter, Edward. A History of Psychiatry: From the Era of the Asylum to the Age of Prozac. John Wiley and Sons, 1997.

Showalter, Elaine. Hystories: Hysterical Epidemics and Modern Culture. Columbia University Press, 1997.

——. “On Hysterical Narrative.” Narrative, vol. 1, no. 1, 1993, pp. 24-35.

Skull, Andrew. Hysteria: The Disturbing History. Oxford University Press, 2009.

Smith, Angela. Hideous Progeny: Disability, Eugenics, and Classic Horror Cinema. Columbia University Press, 2011.

Solomon, Matthew. "Magic, Spiritualism, and Cinema, 1895." Cinema E Cie, vol. 3, 2003, pp. 39-45.

Sutton, Travis. "Avenging the Body: Disability in the Horror Film." A Companion to the Horror Film, edited by Harry M. Benshoff. John Wiley \& Sons, 2014, pp. 73-89.

Timpano, Nathan J. Constructing the Viennese Modern Body: Art, Hysteria, and the Puppet. Routledge, 2017. 
Twitchell, James. Dreadful Pleasures: An Anatomy of Modern Horror. Oxford University Press, 1985.

Uszkalo, Kirsten C. Bewitched and Bedeviled: A Cognitive Approach to Embodiment in Early English Possession. Palgrave Macmillan, 2015.

Veith, Ilza. Hysteria: The History of a Disease. University of Chicago Press, 1965.

Wahl, Otto F. Media Madness: Public Images of Mental Ilness. Rutgers University Press, 1995.

Wald, Christina. Hysteria, Trauma and Melancholia: Performative Maladies in Contemporary Anglophone Drama. Palgrave Macmillan, 2007.

Walker, Daniel P. Unclean Spirits: Possession and Exorcism in France and England in the Late Sixteenth and Early Seventeenth Centuries. Scolar Press, 1981.

Waller, Gregory A, editor. American Horrors: Essays on the Modern American Horror Film. University of Illinois Press, 1987.

Wedding, Danny, Mary Ann Boyd, and Ryan M. Niemiec. Movies and Mental Illness: Using Films to Understand Psychopathology, ${ }^{\text {rd }}$. rev. ed. Hogrefe Publishing, 2010.

Weigert, Laura. French Visual Culture and the Making of Medieval Theater. Cambridge University Press, 2015.

Wessinger, Catherine, editor. Women's Leadership in Marginal Religions. University of Illinois Press, 1993.

Westwell, Guy. Parallel Lines: Post-9/11 American Cinema. Wallflower Press, 2014.

Wetmore, Kevin J. Post-9/11 Horror in American Cinema. Continuum, 2012.

Williams, Linda. "Film Bodies: Gender, Genre, and Excess." Film Quarterly, vol. 44, no. 4, 1991, pp. 2-13.

Zimmerman, Jaqueline Noll. People Like Ourselves: Portrayals of Mental Illness in the Movies. Scarecrow Press, 2003. 


\section{BIBLIOGRAPHY}

Albert, Daniel A., et al. Reasoning in Medicine: An Introduction to Clinical Inference. Johns Hopkins University Press, 1988.

Albright, Ann. "Space and Subjectivity." Dance Chronicle, vol. 32, no. 2, 2009, pp. 312-17.

Allen, Polly Wynn. Building Domestic Liberty: Charlotte Perkins Gilman's Architectural Feminism. University of Massachusetts Press, 1988.

Almond, Philip C. Demonic Possession and Exorcism in Early Modern England. Cambridge University Press, 2004.

Alvarado, Carlos S. "Nineteenth-Century Hysteria and Hypnosis: A Historical Note on Anderson, Laurie. USA Live. Audio recording. Warner, 1984.

Appignanesi, Lisa. Mad, Bad and Sad: A History of Women the Mind Doctors from 1800 to the Present. Virago, 2008.

Aragon, Louis, \& André Breton. "Le cinquantenaire de l'hystèrie." Révolution surréaliste, no. 11, 1928, pp. 20-22

Association of Hysteric Curators. www.facebook.com/hystericcurators/?hc ref=ARQA5RYRaLNgewL_X-WISOQrjZIuzUE22HiDw6r5bSMseMJjxCBwcvreHpXU_iKPxM\&_tn__=kC-R. 28 January 2019.

Auerbach, Jonathan. "Chasing Film Narrative: Repetition, Recursion, and the Body in Early Cinema.” Critical Inquiry, vol. 26, no. 4, 2000, pp. 798-820. Austin, John Langshaw. How To Do Things with Words. vol. 88. Oxford University Press, 1975.

Baer, Ulrich. Spectral Evidence: The Photography of Trauma. MIT Press, 2002. 
Balmain, Colette. "The Enemy Within. The Child as Terrorist in the Contemporary American Horror Film”. Monsters and the Monstrous, edited by Niall Scott. Rodopi, 2007, pp. 133-148.

Baird, Bruce. Hijikata Tatsumi E゚ Butoh. Palgrave, 2012.

Bal, Mike. Travelling Concepts in the Humanities. A Rough Guide. University of Toronto Press, 2002.

Bannister, H. M. and Ludwig Hektoen, "Race and Insanity." American Journal of Insanity, vol. 44, 1888, pp. 456-70.

Barrett, Laura. “'Here But Also There': Subjectivity and Postmodern Space in Mao II”. Modern Fiction Studies, vol. 45, no.3, 1999.

Beadles, Cecil F. "The Insane Jew." Journal of Mental Science, vol. 46, 1900, p. 736.

Beizer, Janet. Ventriloquized Bodies: Narratives of Hysteria in NineteenthCentury France. Cornell University Press, 1994.

Bennett, Bridget. Transatlantic Spiritualism and Nineteenth-Century American Literature. Palgrave McMillan, 2007.

Berenstein, Rhona J. Attack of the Leading Ladies: Gender, Sexuality, and Spectatorship in Classic Horror Cinema. Columbia University Press, 1996.

Bernheimer, Charles and Claire Kahane, editors. In Dora's Case: Freud Hysteria - Feminism, second and revised edition. Columbia University Press, 1990 (1985).

Billings, John S. Vital Statistics of the Jews in the United States. Census Bulletin, No. 19, 30. Dec. 1890, pp. 23.

Binet, Alfred. "The Paradox of Diderot.” Popular Science Monthly, vol. 51, Aug. 1897, pp. 539-44.

Blackman, Lisa and Walkerdine, Valerie. Mass Hysteria. Critical Psychology and Media Studies. Palgrave, 2001.

Blackshaw, Gemma and Leslie Topp. Madness and Modernity: Mental Illness and the Visual Arts in Vienna 1900. Lund Humphries, 2009.

Blagov, Pavel S., Katherine A. Fowler, and Scott O. Lilienfeld. "Histrionic Personality Disorder.” Personality Disorders: Toward the DSM-V, edited by William O’Donohue, Katherine A. Fowler, Scott O. Lilienfeld. Sage, 2007, pp. 203-32.

Blanche Wittmann." Australian Journal of Clinical and Experimental Hypnosis, vol. 37, no. 1, 2009, pp. 21-36.

Blum, Harold. "Setting Freud and Hysteria in Historical Context." The Psychoanalytic Century: Freud's Legacy for the Future, edited by David. E. Scharff. Other Press, 2001, pp. 159-163.

Braude, Ann. Radical Spirits. Spiritualism and Women's Rights in NineteenthCentury America. Beacon, 1989. 
Bogdan, Robert, Douglas Biklen, Arthur Shapiro, and David Spelkoman.

“The Disabled: Media's Monster." Social Policy, vol. 13, no. 2, Fall 1982, pp. 32-35.Böhler, Arno, Christian Herzog, Alice Pechriggl (Eds). Korporale Performanz. Transcript, 2013.

Bollas, Christopher. Hysteria. Routledge, 2000.

Borossa, Julia. Ideas in Psychoanalysis: Hysteria. Icon Books, 2000.

Bourdieu, Pierre. Distinction: A Social Critique of the Judgement of Taste, translated by Richard Nice. Harvard University Press, 1984.

Bourneville, Désiré-Magloire and Paul Régnard. Iconographie Photographique de la Salpêtrière. Aux Bureaux Progrès médical, 1877-1880, 3 vols.

Braun, Christina von. Nicht ich: Logik, Lüge, Libido. Verlag Neue Kritik, 1985.

Braun, Johanna. All-American-Gothic Girl: Das Gerechtigkeit einfordernde Mädchen in US-amerikanischen Erzählungen. Passagen Verlag, 2017.

Breton, André. Nadja. Translated by Richard Howard. Grove, 1977.

Brooks, Peter. Body Work: Objects of Desire in Modern Narrative. Harvard University Press, 1993.

Bronfen, Elisabeth. The Knotted Subject: Hysteria and its Discontents. Princeton University Press, 1998.

——. "Die Verführung der Hysterie." Trauma: Zwischen Psychoanalyse und kulturellem Bedeutungsmuster, edited by Elisabeth Bronfen, Birgit R. Erdle, and Sigrid Weigel. Böhlau, 1999.

——. "Noir Hysteria: Figures of Masculinity in Crisis in Contemporary Cinema." Figurationen, vol 3, no 1, pp. 65-80.

Bronfen, Elisabeth. The Knotted Subject. Princeton University Press, 1998.

Boss, Jeffrey M.N. "The Seventeenth-Century Transformation of the Hysteria Affection and Sydenham's Baconian Medicine”, Psychological Medicine, vol. 9, 1979, pp. 221-34.

Benedikt, Moriz. Die Seelenkunde des Menschen als reine Erfahrungswissenschaft.

Leipzig: O. R. Reisland, 1895.

- - "The Insane Jew. An Open Letter to Dr. C. F. Beadles." The Journal of Mental Science, vol. 47, 1901, pp. 503-9.

——. "Der geisteskranke Jude." Nord und Süd, vol. 167, 1918, pp. 266-70.

Berenstein, Rhona J. Attack of the Leading Ladies: Gender, Sexuality and

Spectatorship in Classic Horror Cinema. Columbia University Press, 1996.

Briggs, Laura. "The Race of Hysteria: 'Overcivilization' and the 'Savage'

Woman in Late Nineteenth-Century Obstetrics and Gynecology." American Quarterly, vol. 52, no. 2, 2000, pp. 246-73.

Brown, Jeffrey A. "Torture, Rape, Action Heroes, and The Girl with the Dragon

Tattoo." Heroines of Film and Television: Portrayals in Popular Culture, edited by 
Norma Jones, Maja Bajac-Carter, and Bob Batchelor, Rowand \& Littlefield, 2014, pp. 47-64.

Bukatman, Scott. Terminal Identity: The Virtual Subject in Postmodern Science Fiction. Duke University Press, 1993.

Burschenschaft Hysteria. www.facebook.com/BurschenschaftHysteria/. 28 January 2019.

Burschenschaft Hysteria: Hymne. youtube, 16 March, 2018, www.youtube.com/ watch?v=spBIXjVgTCQ. Accessed 28 January 2019.

Busfield, Joan. Men, Women and Madness: Understanding Gender and Mental Disorder. Macmillan, 1996.

Butler, Judith. “Gender Relations.” Undoing Gender. Routledge 2004, pp. 40-56.

Caillois, Roger. “Mimétisme et psychasthénie légendaire.” Minotaure. no. 7, 1935, pp. 5-10.

Caldwell, Ellen C. "The History of 'Your Body is A Battleground"” jstordaily, July 15, 2016, daily.jstor.org/the-history-your-body-is-a-battleground/. Accessed 28 January 2019.

Campbell, Patrick and Adrian Kear, editors. Psychoanalysis and Performance. Routledge, 2001.

Carlton Cooke, Anthony. Moral Panics, Mental Illness Stigma, and the Deinstitutionalization Movement in American Popular Culture. Palgrave Macmillan, 2017.

Carroll, Noel. The Philosophy of Horror: Or, Paradoxes of the Heart. Routledge, 1990.

Cartwright, Lisa. Screening the Body: Tracing Medicine's Visual Culture. University of Minnesota Press, 1995.

Caruth, Cathy. "Unclaimed Experience: Trauma \& the Possibility of History." Yale French Studies, no. 79, 1991, pp. 181-92.

Cascardi, Michele and Cathy Brown. "Concept Creep or Meaningful Expansion? Response to Haslam.” Psychological Inquiry, vol. 27, 2016, pp. 24-28.

Certeau, Michel de. The Possession at Loudon, translated by Michael Smith. Chicago UP, 2000.

Chait, Jonathan. "Conservative Economists Turning Back to Debt Hysteria." New York - Intelligencer, 29 March. 2019, nymag.com/intelligencer/2018/03/ conservative-economists-turning-back-to-debt-hysteria.html. 28 January 2019.

Charcot, Jean-Martin. CEuvres complètes, edited by Désiré-Magloire Bourneville et al. Progrès Médical, 1888-1894, 13 vols. 
-_. "Spiritualism and Hysteria". Clinical Lectures on Disease of the Nervous System, translated by Thomas Saville, 3.Vols. New Sydenham Society, 1877-1989. Vol. 3, pp. 205-206.

- - and Paul Richer. Les Démoniaques dans l'art. Paris: Adrien Delahaye and Emile Lecrosner, 1887.

- - Paul Richer. Les Difformes et les malades dans l'art. Paris: Lecrosnier et Babé, 1889.

- - Lectures on the Disease of the Nervous System delivered at La Salpêrière, translated by George Sigerson. London: New Sydenham Society, 1877.

Cheng, Anne Anlin. The Melancholy of Race: Psychoanalysis, Assimilation, and Hidden Grief. Oxford University Press, 2000.

Chesler, Phyllis. Women and Madness. Palgrave Macmillan, 1972/2005.

Chevalier, Yves. "Freud et l'antisemitisme - jalousie." Amitié judéo-chretienne de France, vol. 37, 1985, pp. 45-50.

Cixous, Hélène. "Portrait of Dora." translated by Ann Liddle. Selected Plays of Hélène Cixous, edited by Eric Prenowitz. Routledge, 2004: 35-59.

- - "Laugh of the Medusa." translated by Keith Cohen and Paula Cohen. Signs, vol. 1, no. 4, 1976, pp. 875-93.

- - and Catherine Clément. The Newly Born Woman (1975), translated by Betsy Wing. University of Minnesota Press, 1986.

Clarke, J. Mitchell. "Hysteria and Neurasthenia." Brain, vol. 17, 1894, pp. 118-78.

Clare, Eli. Brilliant Imperfection: Grappling with Cure. Duke University Press, 2017.

Clover, Carol J. Men, Women, and Chain Saws: Gender in the Modern Horror Film. Princeton University Press, 1993.

Cohn, Norman. The Pursuit of the Millennium: Revolutionary Millenarians and Mystical Anarchists of the Middle Ages. Secker and Warburg, 1957.

Cohut, Maria. “Mass Hysteria: An Epidemic of the Mind?” Medical News Today, 27 July 2018, www.medicalnewstoday.com/articles/322607.php. Accessed 28 January 2019.

Coventry, William W. Demonic Possession on Trial: Case Studies in Early Modern England and Colonial America, 1593-1692. Writers Club Press, 2003.

Creed, Barbara. The Monstrous-Feminine: Film, Feminism, Psychoanalysis.

Routledge, 1993.

- - "Horror and the Monstrous-Feminine: An Imaginary Abjection." Horror, the Film Reader, edited by Mark Jancovich, Routledge, 2002, pp. 67-76.

- - Phallic Panic: Film, Horror and the Primal Uncanny. Melbourne University Press, 2005. 
Cromwell, Michael. “\#MeToo Movement Goes Too Far.” The Baltimore Sun, 19 Dec. 2017, www.baltimoresun.com/news/opinion/oped/bs-ed-op-1220metoo-toofar-20171219-story.html. Accessed 13 Aug. 2018.

Cross, Simon. Mediating Madness: Mental Distress and Cultural Representation. Palgrave Macmillan, 2010.

David-Ménard, Monique. Hysteria from Freud to Lacan: Body and Language in Psychoanalysis, translated by Catherine Porter. Cornell University Press, 1989.

Davis, Cynthia. J. Bodily and Narrative Forms: The Influence of Medicine on American Literature, 1845-1915. Stanford University Press, 2000.

Dean, Jodi. Crowds and Party. Verso, 2018.

DeLillo, Don. Mao II. Penguin Books, 1991.

Derrida, Jacques. Archive Fever: A Freudian Impression, translated by Eric Prenowitz. The University of Chicago Press, 1996.

Des Niau (pseudonym of Nicolas Aubin). The History of the Devils of Loudun. Translated by Edmund Goldsmid. Private printing, Edinburgh, 1887.

Devereux, Cecily. "Hysteria, Feminism, and Gender Revisited: The Case of the Second Wave”, English Studies in Canada, vol. 40, no. 1, March 2014, pp. $19-45$.

Didi-Huberman, Georges. Invention of Hysteria: Charcot and the Photographic Iconography of the Salpêtrière (1982), translated by Alisa Hartz. MIT Press, 2003.

Didi-Huberman, Georges. Atlas. Exh. cat. Museo National Centro de Arte, 2010.

- - Confronting Images, translated by John Goodman. Pennsylvania State UP, 2005.

- - The Invention of Hysteria, translated by Alisa Hartz. MIT, 2003.

Diamond, Elin. "Realism and Hysteria: Toward a Feminist Mimesis." Discourse, vol. 13, no. 1, 1990-91, pp. 59-92.

——. "Introduction." Performance and Cultural Politics, edited by Elin Diamond. Routledge, pp. 1-12.

—_. Unmaking Mimesis: Essays on Feminism and Theater. Routledge, 1997.

Dijkhuizen, Jan Frans van. Devil Theater: Demonic Possession and Exorcism in English Renaissance Drama 1558-1642. D.S. Brewer, 2007.

Dixon, C. Madeleine. “Mary Wigman.” Theatre Arts Monthly, vol. 15, no. 1, 1931, pp. 36-42.

Dolinh, Aline. "Finding Feminist Catharsis in the Rape-Revenge Film." Film School Rejects, 25 May 2018, filmschoolrejects.com/finding-feministcatharsis-in-the-rape-revenge-film. Accessed 2 July 2018. 
Döring, Tobias. "The Real Inspector Freud: Kim Morrissey, Terry Johnson, and the Drama of Hysteria." Drama and Reality: Contemporary Drama in English, 4 volumes, edited by Bernhard Reitz. Wissenschaftlicher Verlag Trier, 1996, pp. 29-46.

- —. "Performing Psychoanalysis: The Knots of Freudian Drama and the London Stage." Psychoanalytic-ism: Uses of Psychoanalysis in Novels, Poems, Plays and Films, edited by Ingrid Hotz-Davies and Anton Kirchhofer. Wissenschaftlicher Verlag Trier, 2000, pp. 155-176.

Drumont, Eduoard. La France juive: Essai d'histoire contemporaine, 2 vols. Paris: C. Marpon et E. Flammarion, 1886.

Duchenne de Boulogne, Guillaume. The Mechanism of Human Facial Expression, translated by Andrew Cuthbertson. Cambridge UP, 1990.

Du Preez, Amanda. "Putting on Appearances: Mimetic representations of hysteria." De arte, vol. 69, 2004, pp. 47-61.

——. "Positioning the Body: Hysteria Meets Technology." Gendered Bodies and New Technologies: Rethinking Embodiment in a Cyber-era, by Amanda du Preez. Cabmbridge Scholar Publishing, 2009, pp. 1-34.

Evans, Martha Noel. Fits and Starts: A Genealogy of Hysteria In Modern France. Cornell University Press, 1991.

Editors. "Dissociative Psychopathology, Non-Epileptic Seizures, \& Neurology." Journal of Neurology, Neurosurgery $\mathcal{E}$ Psychiatry, vol. 69, 2000, pp. 285-91.

Eisner, Lotte. The Haunted Screen, translated by Roger Greaves. California UP, 1965.

Elswit, Kate. "Berlin...Your Dance Partner Is Death.” TDR: The Drama Review, vol. 53, no. 1, 2009, pp. 72-92.

Elswit, Kate, et al. "What We Know." Routledge Companion to Butoh Performance, edited by Bruce Baird and Rosemary Candelario. Routledge, 2019, pp. 126-136.

Ellsworth, Angela. Her/She Senses, aellsworth, since 1992, www.aellsworth.com/ hershesenses/. Accessed 28 January 2019.

Engber, Daniel. "Ford's Dual Roles in Her Kavanaugh Testimony: Witness as a Victim, and Expert Witness in Psychology.” Slate, 27 Sept. 2018, slate.com/ technology/2018/09/christine-blasey-ford-expert-witness-on-psychology. html. Accessed 10 Oct. 2018.

Ernst, Waltraud and Thomas Mueller, editors. Transnational Psychiatries: Social and Cultural Histories of Psychiatry in Comparative Perspective c. 1800-2000. Cambridge, 2010.

Evans, Martha Noel. Fits and Starts: A Genealogy of Hysteria in Modern France. Cornell University Press, 1991. 
Eye Art Collective. "FAC. Feminist Art Collective.” eye-art-collective, factoronto. org/schedule/film-night/eye-art-collective/. Accessed 28 January 2019.

Eye Art Collective. Hysteria FemCon 2015, autistici, December 2014, (www. autistici.org/archive/20180802201244/www.eyeartcollective.com/ hysteria/. Accessed 28 January 2019.

Falret, Jules. Études clinique sur les malades mentales et nerveuses. Baillière, 1890. Felman, Shoshana and Dori Laub, Testimony: Crises of Witnessing in Literature, Psychoanalysis, and History, Routledge, 1992.

Ferber, Sarah. Demonic Possession and Exorcism in Early Modern France. Routledge, 2004.

Fetteringhil Zwicker, Lisa. "The Burschenschaft and German Political Culture." Central European History, Vol. 42, No. 3, September 2009, pp. 389-428, www.jstor.org/stable/40600783. Accessed 28 January 2019.

Finlay, Heather. "Queer Dora: Hysteria, Sexual Politics, and Lacan's Intervention on Transference." GLQ A Journal of Lesbian and Gay Studies, vol. 1, no. 3, 1994, pp. 323-347, doi.org/10.1215/10642684-1-3-323. Accessed 28 January 2019.

Finn, Michael R. Hysteria, Hypnotism, the Spirits and Pornography. University of Delaware Press, 2009.

Finzi, Daniela and Hermann Westerink. Dora, Hysteria, and Gender. Reconsidering Freud's Case Study. Leuven University Press, 2018.

Fishberg, Maurice. The Jews: A Study of Race and Environment, New York: Walter Scott, 1911.

-—. "Nervous Diseases." The Jewish Encyclopedia, 12 volumes. New York: Funk and Wagnalls, 1904, 9: 225-27.

Fleming, Michael and Roger Manvell. Images of Madness: The Portrayal of Insanity in the Feature Film. Associated University Presses, 1985.

Folley, Aris. "Florida GOP candidate: I was abducted by aliens but that doesn't define me." The Hill, 24 Aug. 2018.

Ford M., Widiger TA. "Sex bias in the diagnosis of histrionic and antisocial personality disorders". Journal of Consulting and Clinical Psychology, 1989; 57:301-305.

Foucault, Michel. Madness and Civilization. A History of Insanity in the Age of Reason. Random House, 1965.

- - History of Madness. Translated by J. Khalfa and J. Murphy. Routledge, 2009.

——. “26. February 1975.” Abnormal Lectures. Verso, 2003, pp. 201-230.

Freud, Sigmund and Joseph Breuer. Studies in Hysteria. 1895, translated by Nicola Luckhurst. Penguin, 2004. 
Freud, Sigmund. Studies on Hysteria. Standard Edition. Vol. 2 Hogarth Press, 1955.

Freud, Sigmund. Standard Edition of the Complete Psychological Works of Sigmund

Freud, edited and translated by J. Strachey, A. Freud, A. Strachey, and A.

Tyson, 24 vols. London: Hogarth, 1955-1974.

Freud, Sigmund. A Case of Hysteria (Dora), translated by Anthea Bell. Oxford University Press, 2013.

- - Studienausgabe, Band VI: Hysterie und Angst. Fischer, 1975.

Frühstück, Sabine. "Male Anxieties: Nerve Force, Nation, \& the Power of

Sexual Knowledge.” Journal of the Royal Asiatic Society, vol. 15, no. 1, 2005, pp. 71-88.

Furse, Anna. Augustine (Big Hysteria): Writing the Body. Harwood Academics Publisher, 1997.

- - "A Spectacle of Suffering", The Visual-Narrative Matrix: Interdisciplinary Collisions and Collusions, edited by Graham Coulter-Smith. Fine Art Research Center, 2000, pp. 73-77.

Gabbard, Krin and Glen O. Gabbard. Psychiatry and the Cinema. University of Chicago Press, 1987.

Gallop, Jane. "Keys to Dora”. Feminism and Psychoanalysis: The Daughter's Seduction. Macmillan, 1982.

Gilbert, Sandra and Susan Gubar. The Madwoman in the Attic: The Writer and the Nineteenth Century Literary Imagination. Yale University Press, 1979.

Gilman, Sander L. Difference and Pathology: Stereotypes of Sexuality, Race, and Madness. Cornell University Press, 1985.

- - Seeing the Insane. Wiley, 1982.

- - Disease and Representation: Images of Illness from Madness to Aids. Cornell University Press, 1988.

——. The Jew's Body. Routledge, 1991.

- - "The Image of the Hysteric", Hysteria Beyond Freud. edited by Sander

L. Gilman, Helen King, Roy Porter, G. S. Rousseau, and Elaine Showalter.

Berkeley: University of California Press, 1993, pp. 345-452.

- - editor. The Face of Madness: Hugh W. Diamond and the Origin of Psychiatric Photography. New York: Brunner/Mazel, 1976.

Gilman, Sander L., Helen King, Roy Porter, G.S. Rousseau, and Elaine Showalter. Hysteria Beyond Freud. University of California Press, 1993.

Gilman, Charlotte Perkins. "Why I Wrote the 'Yellow Wallpaper'?” Forerunner, vol. 4, Oct. 1913, p. 271.

- - The Yellow Wallpaper. Old Westbury, The Feminist Press, 1973.

- - The Living of Charlotte Perkins Gilman: An Autobiography. Harper and Row, 1963. 
Goldstein, Jan. Console and Classify: the French Psychiatric Profession in the Nineteenth Century, Cambridge University Press, 1987.

_- . "The Wandering Jew and the Problem of Psychiatric Anti-semitism in Fin-de-Siècle France.” Journal of Contemporary History, vol. 20, 1985, pp. 521-52.

Gilroy, Paul. Postcolonial Melancholia. Columbia University Press, 2004.

Goldstein, Jan. "The Uses of Male Hysteria: Medical and Literary Discourse in Nineteenth-Century France.” Representations, vol. 34, 1991, pp. 134-65.

Gordon, Rae. Why the French Love Jerry Lewis. Stanford University Press, 2002.

Grose, Anouchka, editor. Hysteria Today. Karnac, 2016.

Gush, Rose-Anne. "Fraternising in Austria." Art Monthly 410, October 2017, pp. 41-42.

Harper, Stephen. "Media, Madness and Misrepresentation: Critical Reflections on Anti-Stigma Discourse.” European Journal of Communication, vol. 20, no. 4, pp. 460-483.

- - Madness, Power and the Media: Class, Gender and Race in Popular Representations of Mental Distress. Palgrave Macmillan, 2009.

Howard, Ellie. "Interview with feminist Artist Agata Cardoso," covenberlin, 7 September 2015, http://www.covenberlin.com/interview-with-feministartist-agata-cardoso/. Accessed 28 January 2019.

Halberstam, Jack. "The Transgender Gaze in Boys Don't Cry." Screen, vol. 42, no. 3, 2001, pp. 294-298.

Hales, Barbara. "Mediating Worlds: The Occult as Projection of the New Woman in Weimar Culture." German Quarterly, vol. 83, no. 3, 2010, pp. 317-32.

Harpin, Anna; and Juliet Foster. Performance, Madness and Psychiatry: Isolated Acts. Palgrave Macmillan, 2014.

Harding, Christopher, et al. Religion $\mathcal{E}$ Psychotherapy in Modern Japan. Routledge, 2014.

Haslam, Nick. “Concept Creep: Psychology's Expanding Concepts of Harm and Pathology." Psychological Inquiry, vol. 27, 2016, pp. 1-17.

Haslam, John. Illustrations of Madness. Routledge (Facsimile of 1810 edition edited by Roy Porter).

Hertz, Neil. "Dora's Secrets, Freud's Techniques." The End of the Line: Essays on Psychoanalysis and the Sublime. New York: Columbia University Press, 1985, pp. 122-143.

Hijikata, Tatsumi. "Various essays." TDR: The Drama Review, vol. 44, no. 1, pp. 36-81.

Hills, Matt. "Doing Things with Theory: From Freud's Worst Nightmare to (Disciplinary) Dreams of Horror's Cultural Value.” Psychoanalysis and 
the Horror Film: Freud's Worst Nightmares, edited by Steven J. Schneider. Cambridge University Press 2004, pp. 205-222.

Holborn, Mark, et al. Butoh: Dance of the Dark Soul. Aperture, 1987.

Heller-Nicholas, Alexandra. Rape-Revenge Films: A Critical Study. McFarland, 2011.

Herndl, Diane Price. Invalid Women: Figuring Feminine Illness in American Fiction and Culture, 1840-1940. University of North Carolina Press, 1993.

- - . "The Writing Cure: Charlotte Perkins Gilman, Anna O., and 'Hysterical' Writing." NWSA Journal, vol. 1, no.1, 1988, pp. 52-74.

Hide, Louise. Gender and Class in English Asylums, 1890-1914. Palgrave Macmillan, 2014.

Hoppe, Hugo. Krankheiten und Sterblichkeit bei Juden und Nichtjuden. Berlin: S. Calvary \& Co., 1903.

Hunter, Dianne, editor. The Makings of Dr Charcot's Hysteria Shows: Research Through Performance. Edwin Mellen Press, 1998.

- —. "Hysteria, Psychoanalysis, and Feminism: The Case of Anna O." (1983). Writing on the Body: Female Embodiment and Feminist Theory, edited by Katie Conboy, Nadia Medina, and Sarah Stanbury. Columbia University Press, 1997, pp. 257-76.

Hustvedt, Asti. Medical Muses: Hysteria in Nineteenth-century Paris. W.W. Norton, 2011.

Hyde, Frank G. "Notes on the Hebrew Insane." American Journal of Insanity, vol. 58, 1901-1902, p. 470.

Hysteria. hysterical feminisms, www.hystericalfeminisms.com/about-intro/. Accessed 30 September 2018.

Hysteria. Hysteria Manifesto. (linkedin), www.linkedin.com/company/hysteriaperiodical. Accessed 28 January 2019.

Hysteria@hysterical feminisms. hysterical feminisms.www.facebook.com/ hystericalfeminisms/. Accessed 28 January 2019.

www.vice.com/en_us/article/avykxe/interview-with-two-members-of-thefeminist-collective-hysteria. Accessed 28 January 2019.

These Hysterical Women, www.facebook.com/hystericcurators/photos/a.347 $864798728269 / 979934885521254 /$ ?type=3\&theater. Accessed 28 January 2019.

These Hysterical Women, www.radcliffe.harvard.edu/schlesinger-library/ item/advertisement-titled-these-hysterical-women. Accessed 28 January 2019.

Irigary, Luce. This Sex Which Is Not One. Translated by Catherine Porter and Carolyn Burke. Cornell University Press, 1985. 
- - Speculum of the Other Woman, (1974) translated by Gillian C. Gill. Cornell University Press, 1985.

Jacobs, David M. The Threat: The Secret Alien Agenda. Simon \& Schuster, 1998. Jameson, Frederic. Postmodernism, or, The Cultural Logic of Late Capitalism. Duke University Press, 1991.

Kafer, Alison. Feminist, Queer, Crip. Indiana University Press, 2013.

Kallendorf, Hilaire. Exorcism and Its Texts: Subjectivity in Early Modern Literature of England and Spain. University of Toronto Press, 2003.

Kaplan, Ellen and Sarah J. Rudolph. Images of Mental Illness Through Text and Performance. Edwin Mellen Press, 2005.

Kaplan, Marcie. “A Woman's View of DSM-III.” American Psychologist, vol. 38, 1983, pp. 786-92.

Kapsalis, Terri. Public Privates: Performing Gynecology from both Ends of the Speculum. Duke University Press, 1997.

Kasmer, Lisa. "Charlotte Perkins Gilman's 'The Yellow Wallpaper': A Symptomatic Reading." Literature and Psychology, vol. 36, no. 3, 1990, pp. 1-15.

Kelly, Mary. "That Obscure Subject of Desire: An Interview with Mary Kelly by Hal Foster." Imaging Desire, Mary Kelly. MIT Press, 1996, 1998, pp. 165-79.

Kennard, Jean E. "Convention Coverage or How to Read Your Own Life.” The Captive Imagination: A Casebook on "The Yellow Wallpaper", edited by Golden. The Feminist Press, 1992, pp. 168.

Kiell, Norman editor. Freud without Hindsight: Reviews of His Works (1893-1939). International Universities Press, 1988.

Kim, Suk-Young. DMZ Crossing: Performing Emotional Citizenship along the Korean Border. Columbia University Press, 2014.

King, Helen. "Hippocratic Hysteria: the Womb and Its Destinations." Hysteria Beyond Freud, edited by Sander L. Gilman, Helen King, Roy Porter, G. S. Rousseau, and Elaine Showalter. University of California Press, 1993, pp. 14-25.

Kirby, Vicki.. Routledge, 1997.

Kitchens, Caroline. "It's Time to End 'Rape Culture' Hysteria.” Time, 20 March 2014, time.com/30545/its-time-to-end-rape-culture-hysteria. Accessed 18 June 2018.

Knight, Denise D. “'All the Facts of the Case': Gilman's Lost Letter to Dr. S. Weir Mitchell.” American Literary Realism, vol. 37. no. 3, 2005, pp. 259-77.

Kolodny, Annette. "A Map for Rereading: Or Gender and the Interpretation of Literary Texts.” New Literary History, vol. 11, 1980, pp. 451-67.

Kontou, Tatiana and Sarah Willburn, editors. The Ashgate Research Companion to Nineteenth-Century Spiritualism and the Occult. Ashgate, 2012. 
Köttig, Michaela, Renate Bitzan, and Andrea Petö, editors. Gender and Far Right Politics in

Europe, Palgrave Macmillan, 2017.

Kracauer, Siegfried. From Caligari to Hitler: A Psychological History of the German Film. Princeton University Press, 1947.

Krasny, Elke. "Curatorial Materialism. A Feminist Perspective on Independent and Co-Dependent Curating." OnCurating issue 29, May 2016, pp. 96-106, http://www.on-curating.org/issue-29-reader/curatorial-materialism-afeminist-perspective-on-independent-and-co-dependent-curating.html. Accessed 28 January 2019.

Kristeva, Julia. Revolution in Poetic Language. Columbia University Press, 1984.

Kristof, Nicholas. "Hysteria about Refugees, but Blindness on Guns." The New York Times, 5 December 2015, www.nytimes.com/2015/12/06/opinion/ sunday/hysteria-about-refugees-but-blindness-on-guns.html. Accessed 28 January 2019.

Kromm, Jane. The Art of Frenzy: Public Madness in the Visual Culture of Europe, 1500-1850. Continuum, 2002.

Kukla, Rebecca. Mass Hysteria: Medicine, Culture, and Mothers'Bodies. Rowman, 2005.

Kuppers, Petra. Disability and Contemporary Performance: Bodies on Edge. Routledge, 2003.

——. "Bodies, Hysteria, Pain: Staging the Invisible." Bodies in Commotion: Disability and Performance, edited by Philip Auslander and Carrie Sandahl. University of Michigan Press, 2005, pp. 147-162.

Lacan, Jacques. Die Bedeutung des Phallus The Meaning (or Signification) of the Phallus), Lecture at the Mack Planck Society in Munich, 9 May 1958, lacanianworks, www.lacanianworks.net/?p=11851. Accessed 28 January, 2019.

Lacan, Jacques. "Intervention on Transference." Jacques Lacan and the École Freudienne: Feminine Sexuality, edited by Juliet Mitchell and Jacqueline Rose. Macmillan, 1982.

LaCoss, Don. "Hysterical Freedom: Surrealist Dance \& Hélène Vanel's Faulty Functions." Women E Performance, vol. 15, no. 2, 2005, pp. 37-61.

Lane, Ann J. To Herland and Beyond: The Life and Work of Charlotte Perkins Gilman. Pantheon Books, 1990.

Le Bon, Gustave. The Crowd: A Study of the Popular Mind. Batoche Books, 2001. Lemming, Becky. "Nothing is Okay. An Interview with the Minds behind the feminist journal 'HYSTERIA.”” Vice, 27. August 2015.

Ledley, Robert S. and Lee B. Lusted. "Reasoned Foundations of Medical Diagnosis.” Science, vol. 130, 1959, pp. 9-21. 
Lehman, Amy. Victorian Women and the Theatre of Trance: Mediums, Spiritualists and Mesmerists in Performance. McFarland, 2009.

Lerner, Paul. Hysterical Men: War, Psychiatry, and the Politics of Trauma in Germany, 1890-1930. Cornell University Press, 2003.

Levack, Brian. The Devil Within: Possession and Exorcism in the Christian West. Yale University Press, 2013.

Lingan, Edmund B. The Theatre of the Occult Revival: Alternative Spiritual Performance from 1875 to the Present. Palgrave Macmillan, 2014.

Longmore, Paul K. "Screening Stereotypes: Images of Disabled People in Television and Motion Pictures." Social Policy, vol. 16, summer 1985, pp. 31-37.

Lomas, David. “'Modest recording instruments': Science, Surrealism \& Visuality." Art History, vol. 27, no. 4, 2004, pp. 627-50.

Luckhurst, Roger. The Invention of Telepathy, 1870-1901. Oxford University Press, 2002.

Lyons, Gene. "How to end border wall hysteria. Get real." Chicago Sun Times, 1 January 2019, chicago.suntimes.com/columnists/wall-border-securitydonald-trump-nancy-pelosi-gene-lyons-federal-shutdown/. Accessed 28 January 2019.

Lyotard, Jean-François. The Postmodern Condition: A Report on Knowledge. The University of Minnesota Press, 1984.

Mackie, Vera. "New Women, Modern Girls \& the Shifting Semiotics of Gender.” Intersections, no. 32, July 2013. http://intersections.anu.edu.au/ issue32/mackie_review_article.htm

Manning, Susan. "Feminism, Utopianism, \& the Incompleted Dialogue of Modernism.” Ausdruckstanz, edited by Gunhild Oberzaucher-Schüller et al. Friedrich Noetzel Verlag, 1992, pp. 105-15.

Marder, Elissa. The Mother in the Age of Mechanical Reproduction: Psychoanalysis, Photography, Deconstruction. Fordham University Press, 2012.

Marshall, Jonathan W. "The Archaeology of the Abstract Body: Parascientific Discourse \& the Legacy of Dr J.-M. Charcot, 1876-1969.” French History Ẽ Civilization: Papers From the George Rudé Seminar, vol. 3, 2009, pp. 92-111, reproduced on http://www.h-france.net/rude/rudevolumeiii/ MarshallVol3.pdf . "Dancing the Elemental Body: Jonathan Marshall Talks With Min Tanaka \& Yumi Umiumare About the History of Butoh \& Body Weather Today." Performance Paradigm, vol. 2, 2006, pp. 54-73, reproduced on http://www.performanceparadigm.net/wp-content/ uploads/2007/06/6marshall.pdf 
——. "Kleist's Übermarionetten \& Schrenck-Notzing's Traumtänzerin: Nervous Mechanics \& Hypnotic Performance Under Modernism." Heinrich von Kleist $\mathcal{E}$ Modernity, edited by Bernd Fischer \& Tim Mehigan. Camden, 2011, pp. 261-81.

- - Performing Neurology: The Dramaturgy of Dr Jean-Martin Charcot. Palgrave Macmillan, 2016.

- - . "The Priestesses of Apollo \& the Heirs of Aesculapius: Medical ArtHistorical Approaches to Ancient Choreography After Charcot." Forum for Modern Language Studies, vol. 43, no. 4, 2007, pp. 410-26.

- - "The Theatre of the Athletic Nude: The Teaching and Study of Anatomy at the École des Beaux-Arts, Paris, 1873-1940.” Being There: AfterProceedings of the 2006 Conference of the Australasian Association for Drama, Theatre E्F Performance Studies, June 2008, http://ses.library.usyd.edu.au/ bitstream/2123/2511/1/ADSA2006_Marshall.pdf

——. "“The World of the Neurological Pavilion': Hauntology \& European Modernism 'mal tourné.” TDR: The Drama Review, vol. 57, no. 4, 2013, pp. 60-85.

Marshall, Jonathan W. and Jean Baudrillard. "Theatre of Revulsion.” TDR: The Drama Review, vol. 57, no. 4, 2013, pp. 52-59.

Marshman, Michelle. "Exorcism as Empowerment." Journal of Religious History, vol. 23, no. 3, 1999, pp. 265-81.

Masson, Jeffrey Moussaieff, editor. The Complete Letters of Sigmund Freud to Wilhelm Fliess, 1887-1904, Harvard University Press, 1985.

Matlock, Jann. Scenes of Seduction: Prostitution, Hysteria, and Reading Difference in Nineteenth-Century France. Columbia University Press, 1994.

McCarren, Felicia. "The 'Symptomatic Act' circa 1900: Hysteria, Hypnosis, Electricity, Dance.” Critical Inquiry, vol. 21, no. 4, 1995, pp. 748-774.

McLary, Laura. "Restaging Hysteria: Mary Wigman as Writer \& Dancer." Studies in 20th Century Literature, vol. 27, no. 2, 2003, pp. 1-19.

McRuer, Robert. Crip Theory: Cultural Signs of Queerness and Disability. NYU Press, 2006.

- - Crip Times: Disability, Globalization, and Resistance. New York University Press in 2018.

Meige, Henry. Étude sur certains néuropathes voyageurs: Le juif-errant à la Salpêtrière. Paris: L. Battaille et cie., 1893.

Metzger, Sean. Chinese Looks: Fashion, Performance, Race. Indiana University Press, 2014.

Micale, Mark S. Hysterical Men: The Hidden History of Male Nervous Illness. Harvard University Press, 2008. 
editor. The Mind of Modernism: Medicine, Psychology, and the Cultural Arts in Europe and America, 1880-1940. Stanford University Press, 2004.

- - Approaching Hysteria: Disease and Its Interpretations. Princeton University Press, 1995.

——. "Hysteria Male/Hysteria Female: Reflections on Comparative Gender Construction in Nineteenth-Century France and Britain”, Science and Sensibility: Gender and Scientific Enquiry, 1780-1945, edited by Marina Benjamin. Basil Blackwell, 1991, pp. 200-39.

- - "Charcot and the Idea of Hysteria in the Male: Gender, Mental Science, and Medical Diagnosis in Late Nineteenth Century France.” Medical History, vol. 34, no. 4, 1990, pp. 363-411.

- - " "Hysteria and its Historiography: A Review of Past and Present Writings (I)". History of Science, vol. 27, no. 3, 1989, pp. 223-261.

- - "Hysteria and its Historiography: A Review of Past and Present Writings (II).” In: History of Science, vol. 27, no. 4, 1989, pp. 319-51.

Micale, Mark S. and Roy Porter, editors. Discovering the History of Psychiatry. Oxford University Press, 1994.

Michaud, Philippe-Alain. Aby Warburg $\mathcal{E}^{2}$ the Image in Motion, translated by Sophie Hawkes. Foreword Georges Didi-Huberman. Zone, 2004.

Mitchell, Juliet. Mad Men and Medusas: Reclaiming Hysteria. Basic Books, 2000.

- - Psychoanalysis and Feminism. Pantheon, 1974.

Mitchell, Silas Weir. Wear and Tear or, Hints for the Overworked. 5th ed. Philadelphia: Lippincott, 1871.

Moi, Toril. "From Femininity to Finitude: Freud, Lacan, and Feminism, Again.” Signs, vol. 29, no. 3, 2004, pp. 841-78.

Moore, Suzanne. "How a toy helicopter revealed Brexit Britain's mass delusion." The Guardian, 7 January 2019, www.theguardian.com/ commentisfree/2019/jan/07/drones-brexit-hysteria-anxiety. Accessed 28 January 2019.

Morantz, Regina. “The Lady and Her Physician.” Clio's Consciousness Raised: New Perspectives on the History of Women, edited by Lois W. Banner and Mary S. Hartman. Octagon Books, 1976.

Morgan, Eleanor. Hysterical: Why We Need to Talk about Women, Hormones, and Mental Health. Seal Press, 2019. (forthcoming as of time of writing)

Morgan, Wesley G. "Freud's Lithograph of Charcot: A Historical Note." Bulletin of the History of Medicine, vol. 63, 1989, pp. 268-72.

Mulvey, Laura. Visual and Other Pleasures. 2nd ed., Palgrave Macmillan, 1989.

Mudde, Cas. "The Populist Zeitgeist.” Government and Opposition, vol 39, issue 4, Autumn 2004, pp. 534-63. 
Mukherjee, Ankhi. Aesthetic Hysteria: The Great Neurosis in Victorian Melodrama and Contemporary Fiction. Routledge, 2007.

Murat, Laure. The Man Who Thought He Was Napoleon: Toward a Political History of Madness, translated by Deke Dusinberre. University of Chicago Press, 2014.

Möbius, P. J. Über den physiologischen Schwachsinn des Weibes, Halle: Marhold, 1901.

Norden, Martin. The Cinema of Isolation: A History of Physical Disability in the Movies. Rutgers University Press, 1994.

Olcott, Henry. Old Diary Leaves 1883-7. Cambridge University Press, 2011.

Owen, Alex. The Darkened Room: Women, Power and Spiritualism in Late Victorian England. University of Pennsylvania Press, 1990.

Palau, Pierre and Olaf (pseudonym of Joseph Babinski). Les Détraquées. No publisher listed, c.1958.

Penry, Kiffin, et al. "Automatisms Associated With the Absence of petit mal Epilepsy." Archives of Neurology, vol. 21, no. 2, 1969, pp. 142-49.

Philo, Greg, editor. Media and Mental Distress. Longman, 1996.

Pickering, Michael. Stereotyping: The Politics of Representation. Palgrave Macmillan, 2001.

Pletka, Danielle. “The Anti-Trump Hysteria Isn't Helping.” The Atlantic, 17 July 2018, www.theatlantic.com/ideas/archive/2018/07/the-anti-trumphysteria-isnt-helping/565373/. Accessed 28 January 2019.

Poirier, Suzanne. "The Weir Mitchell Rest Cure: Doctor and Patients." Women's Studies, vol. 10, 1983, pp. 15-40.

Pomonis, Mary Anna. "The Association of Hysteric Curators: Ladies of the Largest Hearts.” radical actions, 1 March, 2016, www.radicalactions.com/ association-of-hysteric-curators. Accessed 28 January, 2019.

Porter, Roy. "The Body and the Mind, the Doctor and the Patient: Negotiating Hysteria." Hysteria Beyond Freud, edited by Sander L Gilman, Helen King, Roy Porter, G.S. Rousseau, and Elaine Showalter. Berkeley and London, University of California Press, 1993, pp. 225-285.

- - A Social History of Madness: Stories of the Insane. Weidenfeld and Nicolson, 1987.

Porter, Roy; Helen Nicholson; and Bridget Bennett, editors. Women, Madness, and Spiritualism, 3 volumes. Routledge, 2003.

Raj, Kailash. Mahavidya Chinnamasta, amazon, www.amazon.in/Exotic-IndiaMahavidya-Chinnamasta-Watercolor/dp/B01JZO9IDQ. Accessed 28 January, 2019.

Rancilio, Cesare, editor. "Buto," special issue of Scènes: Revue de l'Espace Kiron, vol. 1, Espace Kiron, Paris, 1985. 
Raymond, Fulgence. L'Étude des Maladies du Système Nerveux en Russie, Paris: O. Doin, 1889.

Regnard, Paul-Marie-Léon. "Attitudes Passionnelles Extase," 1878, The J. Paul Getty Museum, Paris, France (origin of photo), www.getty.edu/ art/collection/objects/145321/paul-marie-leon-regnard-attitudespassionnelles-extase-1878-french-1878. Accessed 17 Aug. 2018.

Reik, Theodor. Jewish Wit. Gamut Press, 1962.

Reiss, Benjamin. Theaters of Madness. University of Chicago Press, 2008.

Reiss, Steven. Touching Base: Professional Baseball and American Culture in the Progressive Era. University of Illinois Press, 1999.

Richer, Paul. Études cliniques sur la grande hystérie ou l'hystéro-épilepsie. Delahaye et Lecroisnier, 1885.

Richter, Dorothee. "Artists and Curators as Authors - Competitors, Collaborators, or Teamworkers.” OnCurating issue 19, June 2013, pp. 43-57, http://www.on-curating.org/issue-19-reader/artists-and-curatorsas-authors-competitors-collaborators-or-team-workers.html. Accessed 28 January, 2019.

Riddley, Matt. "Ignore the global warming hysteria: hurricanes are not getting worse.” The Spectator, 20 October 2018, www.spectator.co.uk/2018/10/ matt-ridleys-diary-ignore-the-global-warming-hysteria-hurricanes-are-notgetting-worse/. Accessed 28 January 2019.

Ripa, Yannick. Women and Madness: The Incarceration of Women in NineteenthCentury France. Polity, 1990.

Roach, Joseph. Cities of the Dead. Columbia UP, 1996.

Roelcke, Volker, Paul Weindling; and Louise Westwood. International Relations in Psychiatry: Britain, Germany, and the United States to World War II. University of Rochester Press, 2010.

Roose, Kevin. “False Flag' Theory on Pipe Bombs Zooms From Right Wing Fringe to Mainstream." New York Times, 25 Oct. 2018.

Rose, Jaqueline. “Introduction II.” Feminine Sexuality. Jacques Lacan and the école freudienne, edited by Juliet Mitchell and Jaqueline Rose, translated by Jacqueline Rose, Macmillan Press, 1982, pp. 27-58.

Sas, Miryam. "Hands, Lines, Acts: Butoh \& Surrealism." Qui parle, vol. 13, no. 2, 2003, pp. 19-51.

Satow, Roberta. "Where has all the Hysteria Gone?" Psychoanalytic Review, vol. 66, pp. 463-77.

Savage, Michael. Stop Mass Hysteria: America's Insanity from the Salem Witch Trials to the Trump Witch Hunt. Center Street, 2018. 
Schneider, Manfred. "Hysterie als Gesamtkunstwerk." Ornament und Askese: Im Zeitgeist des Wien der Jahrhundertwende, edited by Alfred Pfabigan. Brandstätter, 1985, pp. 212-29.

Schnitzler, Arthur. Medizinische Schriften, edited by Horst Thomé. Paul Zsolnay, 1988.

Schuster, David G. Neurasthenic Nation: America's Search for Health, Happiness, and Comfort, 1869-1920. Rutgers University Press, 2011.

Scott, Joan. "Gender: A Useful Category of Historical Analysis." American Historical Review, vol. 91, no. 5, 1986, pp. 1053-75.

-_. "Unanswered Questions." American Historical Review, vol. 113, no. 5, 2008, pp. 1422-1429.

Scott, Francesca, Kate Scarth, and Ji Won Chung, editors. Picturing Women's Health. Routledge, 2016.

Segers, Grace. "Nancy Pelosi Calls Brett Kavanaugh 'Hysterical,' Says He is Unfit to Serve on the Supreme Court." CBS News, 29 Sept. 2018, www. cbsnews.com/news/nancy-pelosi-calls-brett-kavanaugh-hysterical-says-heis-unfit-to-serve-on-the-supreme-court. Accessed 10 Oct. 2018.

Séglas, Jules. Leçons clinique sur les maladies mentales et nerveuses. Asselin et Houzeau, 1895.

Serlin, David, editor. Imagining Illness: Public Health and Visual Culture.

University of Minnesota Press, 2010.

Sigerist, H.E. A History of Medicine. Oxford University Press, 1951.

Shorter, Edward. A History of Psychiatry: From the Era of the Asylum to the Age of

Prozac. John Wiley and Sons, 1997.

Showalter, Elaine. Hystories: Hysterical Epidemics and Modern Culture. Columbia University Press, 1997.

- - "To Recommend a Cure: Beyond Social Realism and In-Yer-Face

Theater." Extending the Code: New Forms of Dramatic and Theatrical Expression, edited by Hans-Ulrich Mohr and Kerstin Mächler. Wissenschaftlicher Verlag Trier, 2004, pp. 45-60.

- - "Hysteria, Feminism, and Gender." Hysteria Beyond Freud, edited by Sander L. Gilman, Helen King, Roy Porter, G.S. Rousseau, and Elaine Showalter. University of California Press, 1993, pp. 287-335.

_- The Female Malady. Pantheon, 1985.

-_. "Victorian Women and Insanity." Victorian Studies, vol. 23, 1979-80,

pp.157-81. reprinted in Madhouses, Mad-Doctors, and Madmen, pp. 313-36.

Skull, Andrew. Madness in Civilization. Princeton University Press, 2015.

-—. Hysteria: The Disturbing History. Oxford University Press, 2009.

- - editor. Madhouses, Mad-Doctors, and Madmen: The Social History of

Psychiatry in the Victorian Era. Athlone, 1981. 
Slaymaker, Doug. "When Sartre Was an Erotic Writer: Body, Nation \& Existentialism in Japan.” Japan Forum, vol. 14, no. 1, 2002, pp. 77-101.

Sluhovsky, Moshe. "The Devil in the Convent." American Historical Review, vol. 107, no. 5, 2002, pp. 1379--411.

Smith, Angela M. Hideous Progeny: Disability, Eugenics, and Classic Horror Cinema. Columbia University Press, 2011.

Smith, Kyle. "Brett Kavanaugh's History-Changing Speech.” National Review, 28 Sept. 2018, www.nationalreview.com/2018/09/brett-kavanaughs-historychanging-speech. Accessed 10 Oct. 2018.

Smith-Rosenberg, Carroll. "The Hysterical Woman: Sex Roles and Role Conflict in 19th Century America.” Social Research, vol. 39, 1979, pp. 652678; reprinted in C. Smith-Rosenberg. Disorderly Conduct: Visions of Gender in Victorian America. Oxford University Press, 1985, pp. 197-216.

Sontag, Susan. Illness and Metaphor and Aids and its Metaphors. Doubleday, 1978/1989.

Spektor, Matias. "It's Not Just the Right That's Voting for Bolsonaro. It's Everyone.” Foreign Policy, 26 October, 2108, foreignpolicy.com/2018/10/26/ its-not-just-the-right-thats-voting-for-bolsonaro-its-everyone-far-rightbrazil-corruption-center-left-anger-pt-black-gay-racism-homophobia/. Accessed 28 January 2019.

Strauss, Hermann. "Erkrankungen durch Alkohol und Syphilis bei den Juden.” Zeitschrift für Demographie und Statistik der Juden. vol. 4 N.F., 1927, pp. 33-39.

Sulloway, Frank. Freud: Biologist of the Mind. Basic, 1979.

Sutton, Travis. "Avenging the Body: Disability in the Horror Film." A Companion to the Horror Film, edited by Harry M. Benshoff. John Wiley \& Sons, 2014, pp. 73-89.

Suzuki, Akhito. "Lunacy and Labouring Men: Narratives of Male Vulnerability in Mid-Victorian London.” Medicine, Madness and Social History: Essays in Honour of Roy Porter, edited by Roberta Bivins and John V. Pickstone. Palgrave Macmillan 2007, pp. 118-128.

Tasca, Cecilia, Mauro Giovanni Carta, and Bianca Fadda. "Women and Hysteria in the History of Mental Health." Clinical Practice $\mathcal{E}$ Epidemology in Menthal Health, vol 8, 2012. 2012; 8, pp. 110-119, doi: 10.2174/1745017901208010110

Theriot, Nancy M. "Women's Voices in Nineteenth-Century Medical Discourse: A Step toward Deconstructing Science.” Signs: Journal of Women in Culture and Society, vol. 19, 1993, pp. 1-31.

Theweleit, Klaus. Male Fantasies. Polity, 1987. 
Thrailkill, Jane F. "Doctoring 'The Yellow Wallpaper.” English Literary History, vol. 69, no. 2, 2002, pp. 525-66.

Timpano, Nathan J. Constructing the Viennese Modern Body: Art, Hysteria, and the Puppet. Routledge, 2017.

Tomes, Nancy. "Feminist Histories of Psychiatry." Discovering the History of Psychiatry, edited by Mark S. Micale and Roy Porter. Oxford University Press, 1994, pp. 348-83.

Townsend, Joanna. "Elizabeth Robins: Hysteria, Politics, and Performance." Women, Theater and Performance: New Histories, New Historiographies, edited by Maggie B. Gale and Viv Gardner. Manchester University Press, 2000, pp. $102-120$.

Trillat, Etienne. Histoire de l'hystérie. Seghers, 1986.

Truter, Orlando. The Originating Impulses of Ankoku Butoh. MA thesis. Rhodes University, 2007.

Veith, Ilza. Hysteria: The History of a Disease. University of Chicago Press, 1965.

Veyrac, S. "Une heure chez Sarah Bernhardt." Chronique médicale, vol. 4, no. 19, 1 Oct. 1897, pp. 609-606.

Vigouroux, Auguste and Paul Juquelier. La contagion mentale. Octave Doin, 1905.

Virdi, Jyotika. "Reverence, Rape - and then Rape: Popular Hindi Cinema's 'Woman's Film.'” Screen, vol. 40, no. 1, 1999, pp. 17-37.

Wahl, Otto F. Media Madness: Public Images of Mental Ilness. Rutgers University Press, 1995.

Wajeman, Gérard. “The Hysteric's Discourse.” Symptom: Online Journal for Lacan.com, vol. 4, 30.012004 (1982).

Wald, Christina. Hysteria, Trauma and Melancholia: Performative Maladies in Contemporary Anglophone Drama. Palgrave Macmillan, 2007.

Walker, Daniel P. Unclean Spirits: Possession and Exorcism in France and England in the Late Sixteenth and Early Seventeenth Centuries. Scolar Press, 1981.

Walsh, Matt. "\#Metoo is Mass Hysteria - It Needs to End." World Net Daily WND, vol. 29, September 2018, www.wnd.com/2018/09/metoo-is-masshysteria-it-needs-to-end/. Accessed 28 January, 2019.

Webster, Jamison. Conversion Disorder: Listening to the Body in Psychoanalysis. Columbia University Press, 2018.

Weidinger, Bernhard. "Student corporations in the 19th and 20th century." 6 January, 2018. https://geschichte.univie.ac.at/en/articles/studentcorporations-19th-and-20th-century. Accessed 28 January, 2019.

Wessely, Simon and Valery Krasnov, editors. Psychological Responses to the New Terrorism: A NATO-Russia dialogue. IOS Press, 2005. 
Westerink, Herman. "Demonic Possession and the Historical Construction of Melancholy and Hysteria." History of Psychiatry, vol. 25, no. 3, 2014, pp. 335-49.

Weygandt, Wilhelm. Atlas und Grundriss der Psychiatrie, München: J. F. Lehmann, 1902.

Wiener Psychoanalytische Vereinigung. Protokolle der Wiener Psychoanalytischen Vereinigung, edited by Herman Nunberg and Ernst Federn. 4 vols. Fischer, 1976-91; translation from Minutes of the Vienna Psychoanalytic Society, translated by M. Nunberg, 4 vols. International Universities Press, 1962-75.

Wigman, Mary. The Language of Dance, translated by Walter Sorell. Weslyan University Press, 1966.

——. The Mary Wigman Book, translated by Walter Sorell. Weslyan UP, 1975.

Williams, Allison. "Let's get real about the Erdogan hysteria." Handelsblatt Today, 1 January 2018, www.handelsblatt.com/today/opinion/balancingact-lets-get-real-about-the-erdogan-hysteria/23583496.html?ticket=ST838652-NZarQtRtIJ6K1hZkaN4F-ap4. Accessed 28 January 2019.

Williams, Raymond. Keywords. A Vocabulary of Culture and Society. New York: Oxford University Press, 1976.

Wilkie, Christina. "Trump: It is 'a Very Scary Time for Young Men in America.” CNBC, 2 Oct. 2018, www.cnbc.com/2018/10/02/trumpkavanaugh-allegations-usher-in-a-very-scary-time-for-young-men-inamerica.html. Accessed 4 Oct. 2018.

Williams, Katherine E. "Hysteria in Seventeenth-Century Case Records and Unpublished Manuscripts", History of Psychiatry, vol. 1, 1990, pp. 383-401. Williams, Linda. "Film Bodies: Gender, Genre, and Excess." Film Quarterly, vol. 44, no. 4, 1991, pp. 2-13.

Wood, Ann Douglas. “The Fashionable Diseases': Women's Complaints and Their Treatment in Nineteenth-Century America." The Journal of Interdisciplinary History, vol. 4, no. 1, 1973, pp. 25-52.

Wood, James. "Human, All Too Inhuman: On the Formation of a New Genre: Hysterical

Realism.” The New Republic, 23 July 2000 newrepublic.com/article/61361/ human-inhuman Accessed 10 Jan. 2019.

Yarom, Nitza. The Matrix of Hysteria: Psychoanalysis of the Struggle Between the Sexes as Enacted in the Body. Routledge, 2005.

Yates, Michelle. "Re-casting Nature as Feminist Space in Mad Max: Fury Road." Science Fiction Film and Television, vol. 10, no. 3, 2017, pp. 353-70.

Young, Cathy. "The Injustice of the 'Rape-Culture' Theory." Commentary, 13 Sept. 2017, www.commentarymagazine.com/articles/campus-sex-crimetribunals-losing-2. Accessed 18 June 2018. 
Y.S.K, Perana. "'Hysteria': Of Feminism, Gender Equality And The Collective Outrage Against Patriarchy." youthkiawaaz, no date, www.youthkiawaaz. com/2014/11/hysteria-by-eye/. Accessed 28 January, 2019. 



\section{NOTES ON THE CONTRIBUTORS}

Johanna Braun is a scholar, artist, curator and Erwin Schrödinger PostDoc Fellow. Braun's interdisciplinary work was awarded with grants by the Federal Chancellery of Austria (2014, 2015, 2017, 2019), an Emanuel-and-Sofie-Fohn Foundation scholarship (2015), and a research scholarship of the City of Vienna (2016). In 2018 she received an Erwin Schrödinger Fellowship from the Austrian Science Fund (FWF) for her postdoctoral project The Hysteric as Conceptual Operator [J 4164-G24], conducted at the University of California, Los Angeles, Stanford University and the University of Vienna. Braun published her monograph All-American-Gothic Girl: The justice seeking girl in US narratives (Passagen Verlag, 2017) and edited the artistic-philosophical anthology Beschwörungsrituale (Turia+Kant, 2016), in conjunction to numerous contributions to anthologies, art catalogues, and journals. Her academic and artistic research focuses on (new) hysteria studies, (media) philosophy, performance studies, genre film and intermediality.

Vivian Delchamps is an English PhD candidate at the University of California, Los Angeles, where she is also pursuing a certificate in gender studies. She studies and teaches 19th-century American literature and is interested in disability studies, bioethics, dance, and the medical/ health humanities. Her dissertation, "Diagnosis and 19th-Century American Literature," surveys authors including Silas Weir Mitchell, 
Emily Dickinson, Charlotte Perkins Gilman, Walt Whitman, and Frances E. W. Harper to analyze literary interpretations of medical diagnosis's complexities and contradictions. Her research has been partially supported by a 2019-2020 English Department Dissertation Year Fellowship, 2018 Emily Dickinson International Society Graduate Student Fellowship, a 2017 Andrew W. Mellon EPIC Fellowship in Teaching Excellence, and a 2017 UCLA Graduate Summer Research Mentorship. Delchamps is also the Disability Studies Advisor for the Disability Law Journal at UCLA and the founder, instructor, and vice president of the Dancesport Club at UCLA.

Cecily Devereux is a Professor of English and Film Studies at the University of Alberta, in Edmonton, Alberta. Her research focuses on questions of femininity in the imperial context across a range of categories, including the representation and circulation of the maternal body, ideologies of imperial motherhood, eugenics and eugenic feminism, hysteria (ESC 40.1 2014), and the travel, mobility, and traffic of female bodies in the nineteenth century and into the twentieth. She is the author of Growing a Race: Nellie L. McClung and the Fiction of Eugenic Feminism, (McGill-Queen's UP, 2005) and has co-edited volumes on women writing in the British Empire for Routledge (2009) and Pickering and Chatto (2006). She has just completed a study of early twentieth-century Salome dancers, erotic dance, and the politics of "reproductive fetishism."

Sander L. Gilman is a distinguished professor of the Liberal Arts and Sciences as well as Professor of Psychiatry at Emory University. A cultural and literary historian, he is the author or editor of well over ninety books. He is the author of the basic study of the visual stereotyping of the mentally ill, Seeing the Insane (John Wiley and Sons, 1982; reprinted: 1996 and 2014) as well as the standard study of Jewish Self-Hatred (Johns Hopkins University Press, 1986, which is still in print). For twenty-five years he was a member of the humanities and medical faculties at Cornell University where he held the Goldwin Smith Professorship of Humane Studies. For six years he held the Henry R. Luce Distinguished Service Professorship of the Liberal Arts in Human Biology at the University of Chicago. For four years he was a distinguished professor of the Liberal Arts and Medicine at the University of Illinois at Chicago where he created the 'Humanities Laboratory'. He served as the Visiting Historical Scholar at the National Library of Medicine, Bethesda, MD (1990- 
1991); as a fellow of the Center for Advanced Study in the Behavioral Sciences, Stanford, CA (1996-1997); as a Berlin prize fellow at the American Academy in Berlin (2000-2001); as the Weidenfeld Visiting Professor of European Comparative Literature at Oxford University (2004-2005); as Professor at the Institute in the Humanities, Birkbeck College (2007-2012); as a Visiting Research Professor at The University of Hong Kong (2010-2013); and recently as the Alliance Professor of History at the Ludwig Maximilian University, Munich (2017-2018). He has been a visiting professor at numerous universities in North America, South Africa, The United Kingdom, Germany, Israel, China, and New Zealand. He was president of the Modern Language Association in 1995. He has been awarded a Doctor of Laws (honoris causa) at the University of Toronto in 1997, elected an honorary professor of the Free University in Berlin (2000), an honorary member of the American Psychoanalytic Association (2007), and made a Fellow of the American Academy of Arts and Sciences (2016).

Elke Krasny is a curator, cultural theorist, urban researcher, and writer and Professor for Art and Education at the Academy of Fine Arts Vienna. Her feminist scholarship and her curatorial work focus on critical practices in architecture, urbanism, and contemporary art addressing the interconnectedness of ecology, economy, labor, and memory. In her conceptually driven and research-based curatorial practice she works along the intersections of art, architecture, education, feminism, landscape, spatial politics, and urbanism. She aims to contribute to innovation and debate in these fields through forging experimental post-disciplinary alliances between research, teaching, curating, and writing. Krasny is the author and editor of numerous essays and books including Critical Care: Architecture and Urbanism for a Broken Planet with Angelika Fitz (MIT Press, 2019), In Reserve: The Household! with Regina Bittner (Spector Books, 2016), and Curating in Feminist Thought (OnCurating 29, 2016) with Lara Perry and Dorothee Richter.

Jonathan W. Marshall is an interdisciplinary scholar with a background in history and Senior Lecturer at the West Australian Academy of Performing Arts, Edith Cowan University, Perth, where he teaches and supervises artist-researchers and other students. Marshall has published extensively on butoh, as well as on the relationship of Kleist's work to the history of medicine, the relationship of contemporary photography to theatre and global capitalism; the history of medicine as it relates to 
theatre and art and other topics. In 2016, he published his monograph Performing Neurology: The Dramaturgy of Dr Jean-Martin Charcot; which focuses on late 19th century French neurology and performance at Palgrave Macmillan.

Sean Metzger is Professor in the UCLA School of Theatre, Film, and Television and the President of Performance Studies international (2016-2020). Prior to his position at UCLA, Metzger has taught for eight years at Duke University, where he held appointments in the English, Theater Studies, and Asian \& Middle Eastern Studies departments. In 2014, he taught for the UC Education Abroad Program in Shanghai and, in 2008, he was awarded the inaugural Fulbright Research Chair in North American Society and Culture at Concordia University, Montreal. Metzger works on performance and visual culture (art, fashion, film, theater) and has published extensively on the intersection of Asian American, Caribbean, Chinese, film, performance and sexuality studies. The author of Chinese Looks: Fashion, Performance Race (Indiana University Press, 2014) and The Chinese Atlantic: Seascapes and the Theatricality of Globalization (Indiana University Press, 2020), he is also the co-editor of Theatre Journal. He has coedited an additional five collections of essays and a volume of plays.

Tim Posada is the chair of journalism and new media at Saddleback College. He holds a Ph.D. in cultural studies from Claremont Graduate University, where he wrote his dissertation on the emerging language of superhero media. He also serves as film columnist for the Beverly Press. His writings have appeared in The Journal of Popular Culture, Palgrave Communications, and volumes on film theory, digital media, comics studies, and race and gender in speculative fiction. He is currently working on a book for Lexington Books/Fortress Academic on depictions of the body, soul, and spirit in popular culture.

Elaine Showalter, Emeritus Professor of English at Princeton University, is an American literary critic and teacher, and founder of gynocritics, a school of feminist criticism concerned with "woman as writer...with the history, themes, genres, and structures of literature by women." Elaine Showalter, combines scholarly expertise in English and American literature with a passion for a wide range of cultural subjects. Showalter has published influential books on the intersection of feminist theory, medical history/history of psychiatry and hysteria studies, such as: The 
Female Malady: Women, Madness, and English Culture, 1830-1980 (1985); Sexual Anarchy: Gender and Culture at the Fin de Siècle (1990); Hystories: Historical Epidemics and Modern Culture (1997), Showalter edited several volumes, including The New Feminist Criticism (1985) and Daughters of Decadence: Women Writers of the Fin de Siècle (1993).

Dominik Zechner studied media studies and philosophy in Vienna and received his Ph.D. in German literature from New York University, where he was the recipient of a Mellon Dissertation Fellowship. His dissertation explores the problem of finitude in the work of Franz Kafka. He has edited a special issue of Modern Language Notes on the topic of literary prizes and acceptance speeches, and has published essays on Jacques Derrida, Franz Kafka, Thomas Bernhard, and Friedrich Kittler. During the 2019-20 academic year, he was the Artemis A.W. and Martha Joukowsky Postdoctoral Fellow at Brown University's Pembroke Center for Teaching and Research on Women, before starting his appointment as Assistant Professor of German at Rutgers University. 


